\title{
Students' learning experiences with the Web 2.0 tool MyPortfolio: a case study of one high school classroom
}

By

\section{Rochelle Alison Duke}

\author{
A thesis submitted to the Victoria University of \\ Wellington in partial fulfilment of the requirements for \\ the degree of Master of Education
}

Victoria University of Wellington

2010 


\section{Abstract}

Portfolio learning has been utilised in education for many years and a natural development in today's digital environment has been the move from paper to electronic portfolios (e-portfolios).

The development of e-portfolios in New Zealand has also been driven by two forces- the emerging view that e-portfolios can be an effective way to support constructivist approaches to learning and help develop students into 'lifelong learners'; and the beliefs about today's digital environment and the way in which students should and do operate within this.

In many ways, e-portfolio research is a relatively young field of study and much of the research that has been conducted has occurred in the tertiary environment and related to the perceptions of the instructor or technologist. In an attempt to add depth to current e-portfolio research, this study made use of a mixed-methods, descriptive case study approach in order to focus on the perceptions of a group of high school students and the way in which they experienced using the e-portfolio application MyPortfolio for the first time.

Key findings of this study focus on the way in which students experienced using MyPortfolio and the fact that although it is often claimed that e-portfolio tools can be effective in helping developing reflective thinking in students, overall, the students in this study predominately saw MyPortfolio as a tool to organise and process knowledge rather than something that could help them to engage in 'deep learning'.

The experiences and perceptions of the students in this study also challenged ideas about how much students want to use ICT within the school environment and this study suggests that increased use of ICT can lead to students missing the social interaction that usually occurs within the classroom. In a similar vein, the students in this study also challenged the idea of the 'digital native' and their experiences suggest that, as with any area of learning, students' skills with using ICT varied greatly.

The way that the students in this study made use of MyPortfolio also demonstrates the fact that although e-portfolio tools such as MyPortfolio offer 
students the opportunity to engage in reflective learning, they do not necessarily undertake this naturally.

Finally, the findings of this study highlight the role of the teacher in supporting effective use of ICT for learning. 


\section{Acknowledgements}

This thesis has been a number of years in the gestation and I have many people to thank for its completion. Firstly, I extremely grateful to my school, the Ministry of Education and the PPTA for the provision of the study scholarship that allowed me the space and time to work on this thesis. The study grants are an amazing opportunity and I feel so lucky to have been granted one. Thanks also to the Federation of Graduate Women- Victoria Branch for the scholarship which allowed me to buy a laptop- I would have been lost without it.

Thanks also to my school for allowing me into the school in order to conduct the necessary data collection. I cannot speak more highly of the teacher and students involved in this study. The teacher was consistently flexible, professional, and helpful and I am so appreciative of the way in which she accommodated me. The students in this study were a joy to work with and I appreciated the way in which they engaged in the tasks set and shared their thoughts and ideas with me. I am particularly grateful to the six case study students- Nancy, Robina, Hannah, Ashleigh, Mary and YoYo- whose willing engagement allowed me extra insight into the student perspective.

Several fortuitous meetings steered me into researching e-portfolios and I would particularly like to give thanks to Jill Wilson from CWA NewMedia for generously agreeing to meet with me. Her ideas and enthusiasm pointed me in the direction of Penny Leach at Catalyst who was generous enough to meet with me to throw around a whole range of ideas about ICT and learning. Her engagement in this area is inspiring. Penny's ideas then led me to meet with Richard Wyles of Flexible Learning, and this meeting introduced me to MyPortfolio and the possibilities it offered. Finally, I met with Andy Kirks, also from Flexible Learning, who managed the school use of MyPortfolio. Andy's enthusiasm for ICT in education and knowledge in the area encouraged me to make use of MyPortfolio and I am grateful for his on-going support throughout the course of the study.

I would also like to acknowledge the Ministry of Education for funding the trial of MyPortfolio that allowed this research to occur. 
I would also like to acknowledge two key researchers in the area of eportfolio research- Dr Helen Barrett and Dr Elizabeth Hartnell-Young. I was fortunate to be able to communicate with both women and these communications helped develop my thinking about this topic. I would also like to thank $\mathrm{Dr}$ Hartnell-Young for allowing me to utilise her research instruments for my data collection.

I would like to say thank you to my supervisor, Barbara Craig, whose extensive knowledge of ICT in schools helped me to bring together the various aspects of my research. You have challenged me and encouraged me to think harder about this topic and I am grateful for her help and feedback throughout this task. It has not always been an easy time but I appreciate the way in which your thorough feedback has enabled me to finish this thesis.

To all the other post-graduate students at 31 Campbell- I know I wasn't there very often but I enjoyed chatting to you and hearing about your work. Good luck to you all!!!

To all my friends and family who have asked me how it's going (for better or worse!), drunk coffee with me, encouraged me, cheered me and sympathised with me and taken it graciously when I abruptly changed the topic- your kindness has meant a lot.

A particularly big thanks to Mum who came to visit several times in order to give me free time to work. I have really appreciated you support and encouragement.

This thesis has not been the only thing gestating over the last two years and I must acknowledge my beautiful daughter Caitlin. It has certainly not been easy to fit the thesis around you but I cannot imagine a lovelier daughter to take this journey with. Big kisses, little one.

And finally, to my amazing husband, Marty. This journey has certainly given an insight into your long road and I admire you even more than ever now. You have been my rock throughout this thesis and I am so amazingly grateful for your unswerving encouragement and conviction that I could do this. I cannot imagine how I would have finished this without you. Thanks. 


\section{Table of Contents}

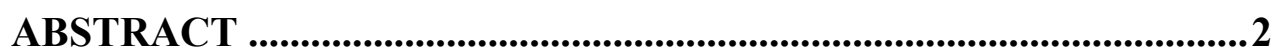

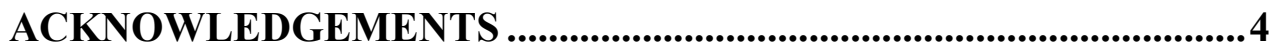

TABLE OF CONTENTS ...........................................................................6

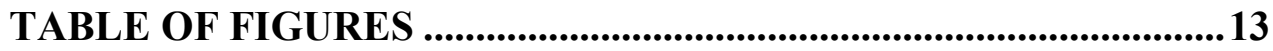

1 INTRODUCTION

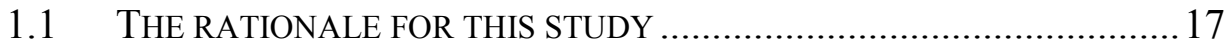

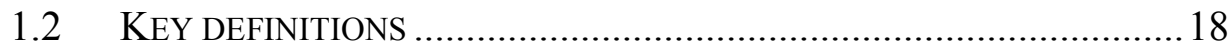

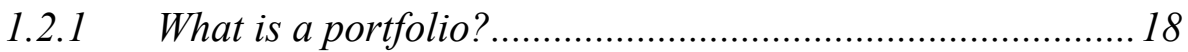

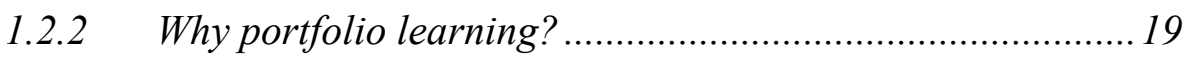

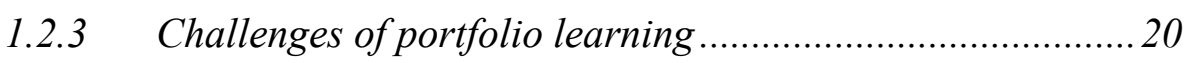

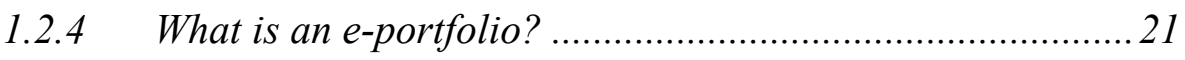

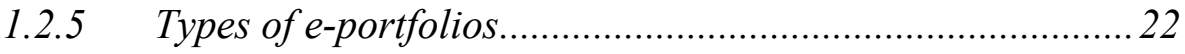

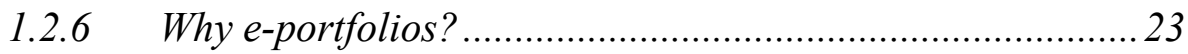

1.2.7 E-portfolios: Creating life-long learners ............................26

1.2.8 Challenges of e-portfolio learning .........................................2 26

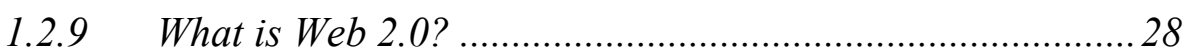

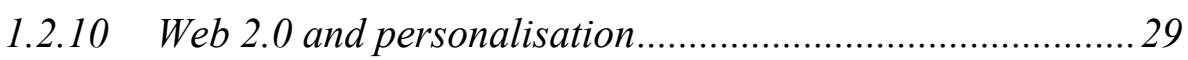

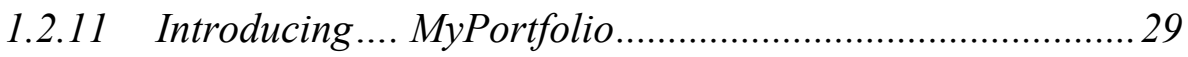

1.2.12 ICT in a blended learning environment ............................. 31

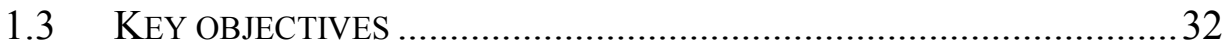

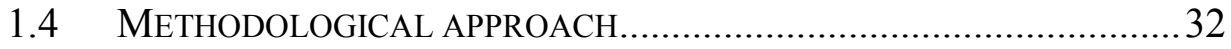

1.5 SUMMARY OF THE CHAPTERS IN THIS THESIS................................. 33

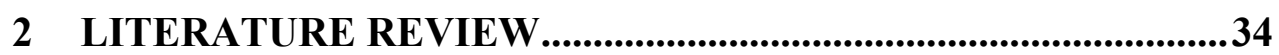

2.1 THE THEORETICAL FRAMEWORK ……............................................ 34

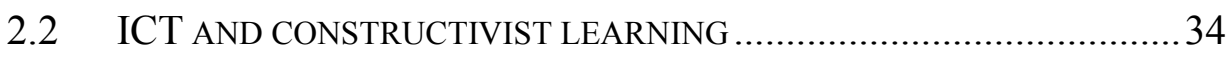

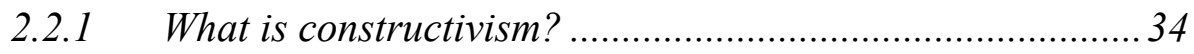

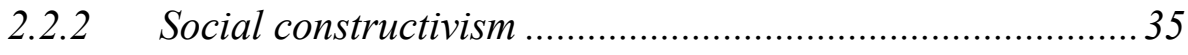

2.2.3 The role of the teacher in constructivist learning using ICT36 
2.3 DraWING IT ALL TOGETHER- CONSTRUCTIVIST LEARNING, ICT AND

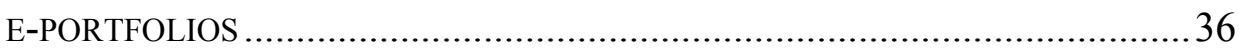

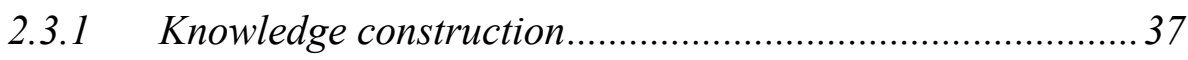

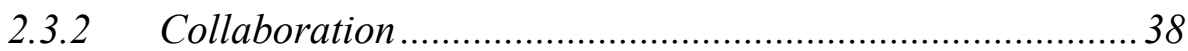

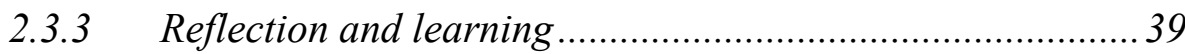

2.3.4 ICT and learning- a contested area ................................... 39

2.3.5 Engaged learning- the motivational aspects of ICT ............ 40

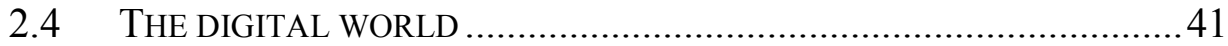

2.4.1 The 'Net Generation' and 'Digital Natives' debate............. 41

2.5 ICT POLICY IN NEW ZEALAND SCHOOLS ...................................... 44

2.5.1 E-portfolios and ICT Policy in New Zealand...................... 45

2.5.2 E-portfolios and the New Zealand Curriculum................... 46

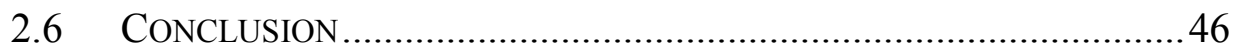

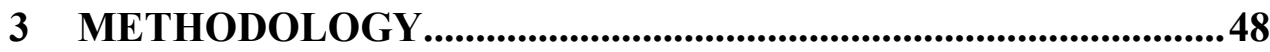

3.1 RESEARCH OBJECTIVES AND QUESTIONS ....................................48

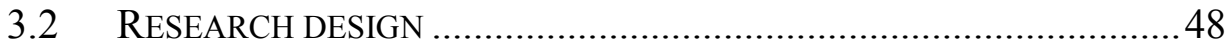

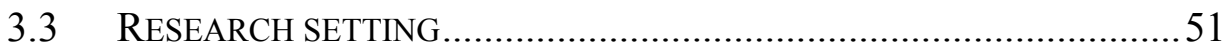

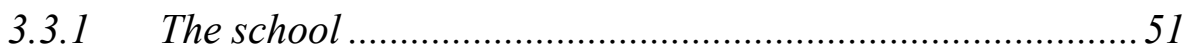

3.3.2 The setting for the data collection.......................................52

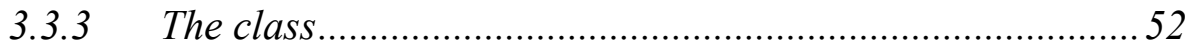

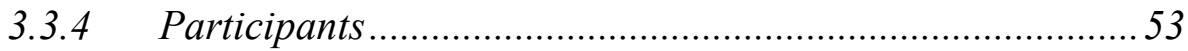

3.3.5 My role: the participant-observer .......................................54

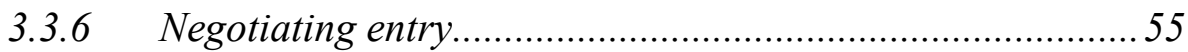

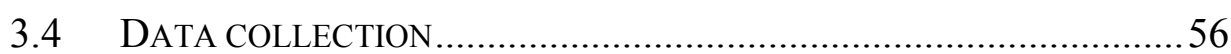

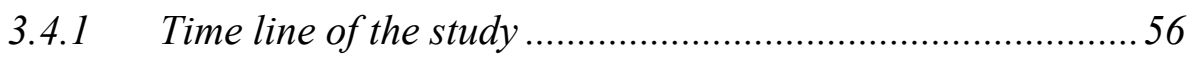

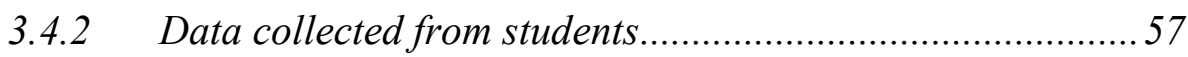

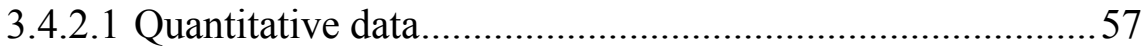

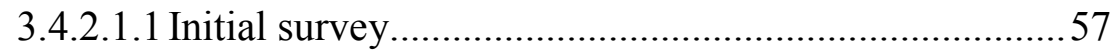

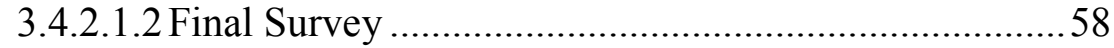

3.4.2.1.3 Selection of the case study students ............................58

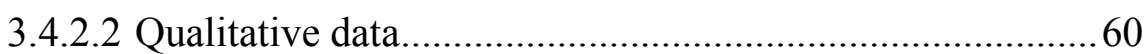

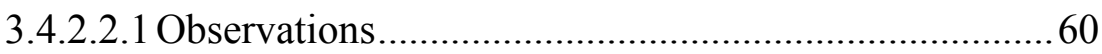

3.4.2.2.2 Case study students' daily logs ................................. 61 
3.4.2.2.3 Students' MyPortfolio work 61

3.4.2.2.4 Final interviews with case study students 62

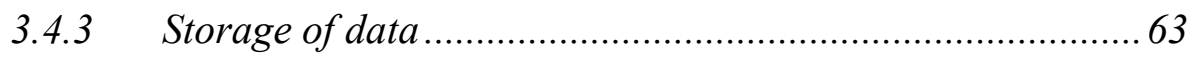

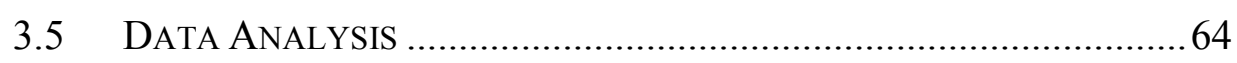

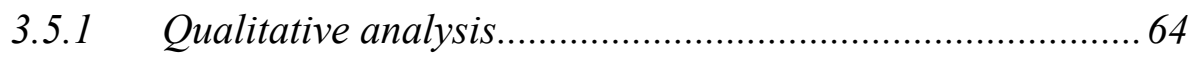

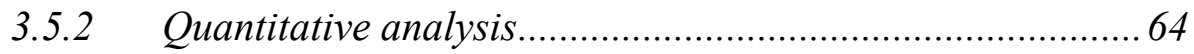

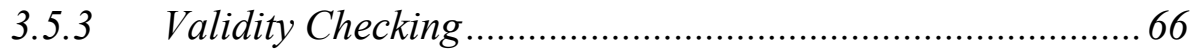

3.6 REFLEXIVITY AND POWER: CONSIDERATIONS OF MY ROLE AS

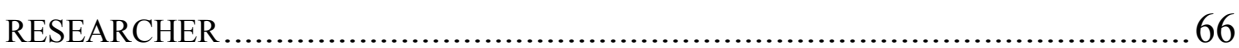

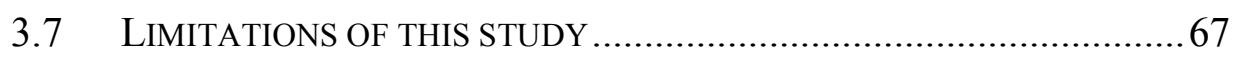

3.8 OTHER ETHICAL CONSIDERATIONS ..............................................6 67

4 HOW DID THE STUDENTS MAKE USE OF MYPORTFOLIO?

69

4.1.1 Introduction to the students' use of MyPortfolio ................. 70

4.1.2 The structure of MyPortfolio................................................ 70

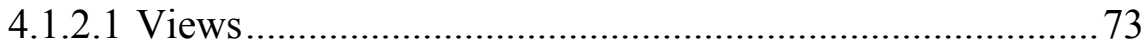

4.1.2.1.1 How students used the views ..................................... 74

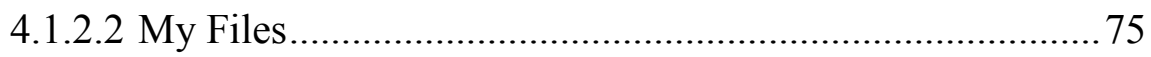

4.1.2.2.1 How the students used 'my files'................................. 76

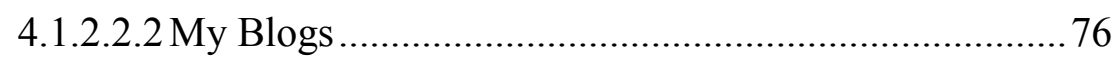

4.1.2.2.3 How did the students make use of the blogs? ..............77

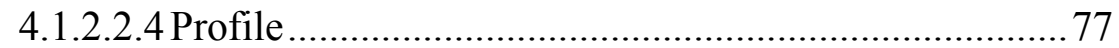

4.1.3 How students used the profiles............................................ 77

4.1.3.1 Other aspects of MyPortfolio not utilised in this study ......80

4.2 THEMES THAT EMERGED FROM THE STUDENT USE OF MYPORTFOLIO 80

4.2.1 'Too hard'- struggles with new technology ........................80

4.2.2 Struggles with learning to navigate ..................................... 81

4.2.3 Uploading and downloading files ..................................... 82

4.2.4 The effect of struggles with technology ............................... 83

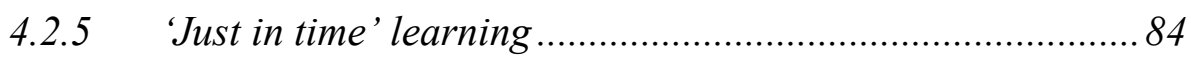

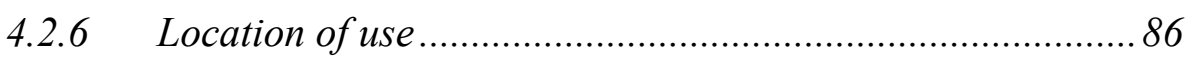

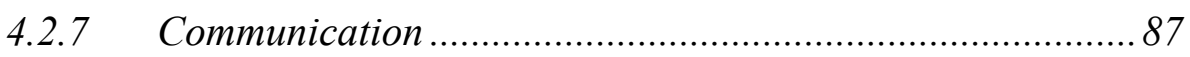




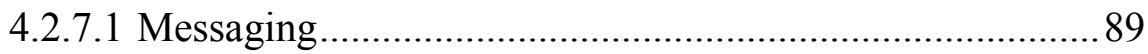

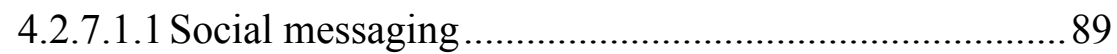

4.2.7.1.2 Task-related messaging ................................................. 90

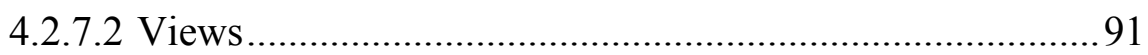

4.2.7.3 Communicating with the teacher..........................................92

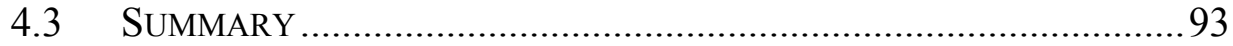

5 THE STUDENTS' PERCEPTIONS OF MYPORTFOLIO..............94

5.1 WHAT WERE THE STUDENTS' PERCEPTIONS? ...................................95

5.1.1 A 'fun' way to learn- The influence of technology...............95

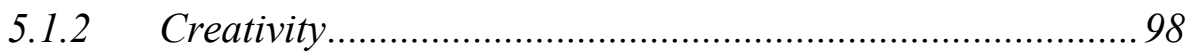

5.1.3 Organisational aspects of MyPortfolio..................................98

5.1.3.1 Organisation - resources ...................................................98

5.1.3.2 Access .......................................................................... 99

5.1.3.3 Time Management............................................................... 100

5.1.3.3.1 Procrastination............................................................... 100

5.1.4 Sense of community ....................................................... 101

6 HOW DOES MYPORTFOLIO SUPPORT CONSTRUCTIVIST APPROACHES TO LEARNING? .....................................................................104

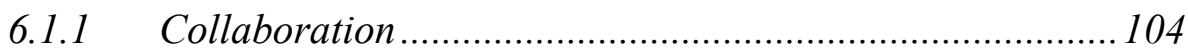

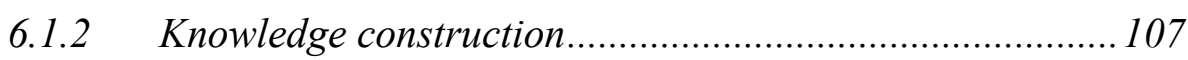

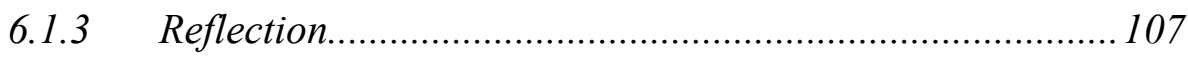

6.1.3.1 Connection to learning .......................................................109

6.1.3.2 Connections to self as learner............................................109

6.1.3.3 Evaluation of the quality of work ......................................110

6.1.3.4 Overall levels of reflection................................................111

6.1.4 Summary .....................................................................

7 THE CASE STUDY STUDENTS- AN IN-DEPTH LOOK AT HOW SIX STUDENTS USED AND PERCEIVED MYPORTFOLIO .........113

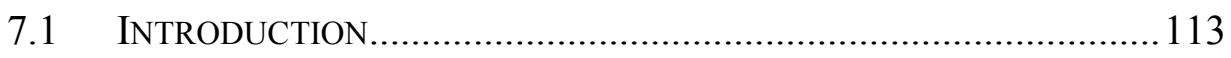

7.2 INTRODUCTION TO THE CASE STUDY STUDENTS …………............113

7.3 SELECTION OF THE CASE STUDY STUDENTS .....................................114

7.3.1 Time spent using computers .............................................. 114 


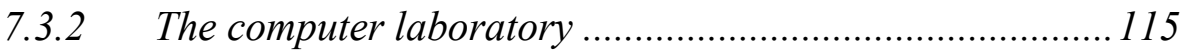

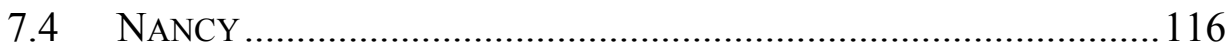

7.4.1 Initial use ..................................................................... 116

7.4.1.1 Navigating MyPortfolio................................................... 118

7.4.2 Nancy's use of MyPortfolio............................................... 119

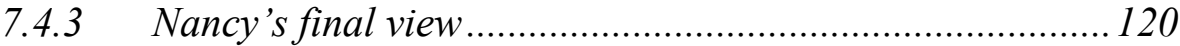

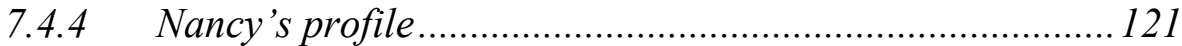

7.4.5 Nancy's perspective of MyPortfolio.................................... 125

7.4.5.1 Planning and organisation ............................................ 125

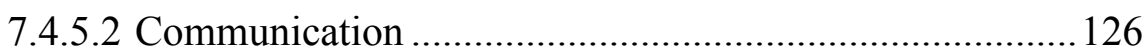

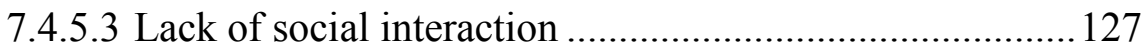

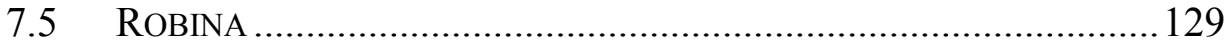

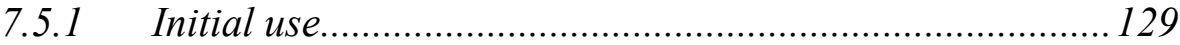

7.5.2 Robina's use of MyPortfolio ............................................ 133

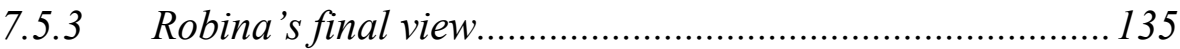

7.5.4 Robina's profile ................................................................ 136

7.5.5 Robina's perspective of MyPortfolio ................................... 137

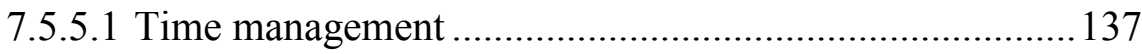

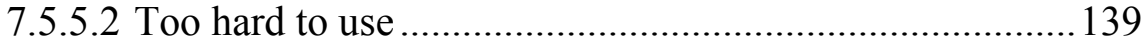

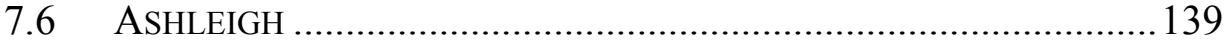

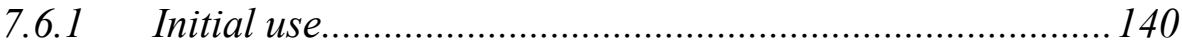

7.6.2 Ashleigh's use of MyPortfolio............................................. 141

7.6.3 Ashleigh's final view .......................................................... 141

7.6.4 Ashleigh's profile ............................................................. 143

7.6.5 Ashleigh's perspective of MyPortfolio............................. 144

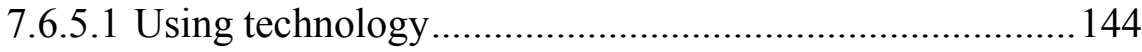

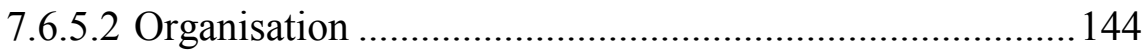

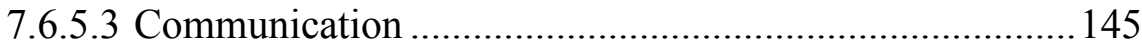

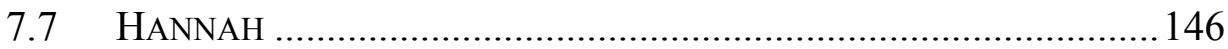

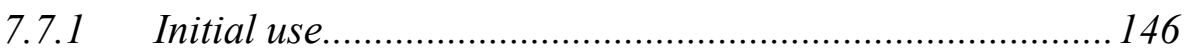

7.7.2 Hannah's use of MyPortfolio .............................................. 147

7.7.3 Hannah's final view ...................................................... 148

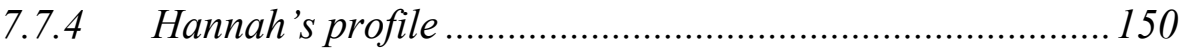

7.7.5 Hannah's perspective of MyPortfolio ................................. 151 
7.7.5.1 Collaboration

7.7.5.2 Too hard to use 151

7.8 YoYo 153

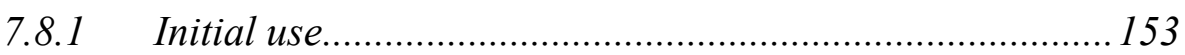

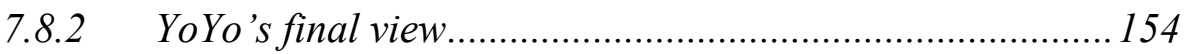

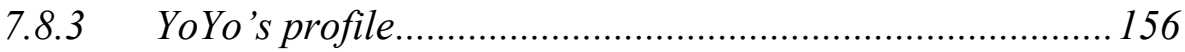

7.8.4 YoYo's perspective of MyPortfolio...................................... 158

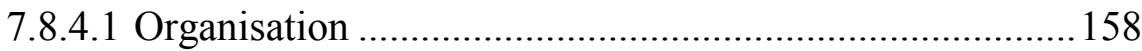

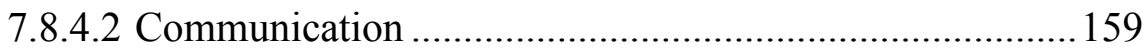

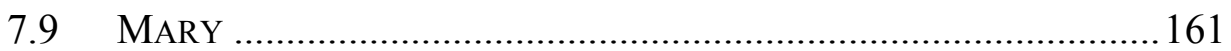

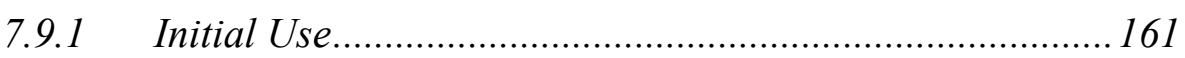

7.9.2 Mary's use of MyPortfolio ............................................... 161

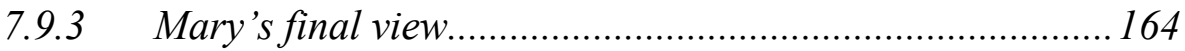

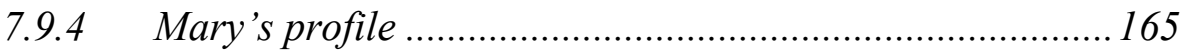

7.9.5 Mary's perception of MyPortfolio ........................................ 166

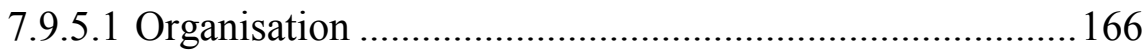

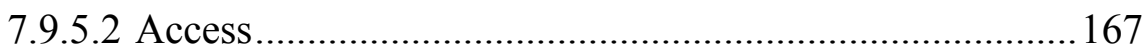

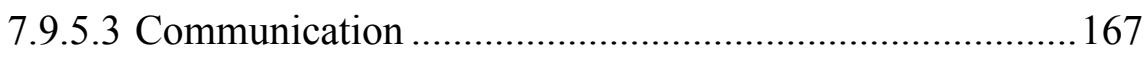

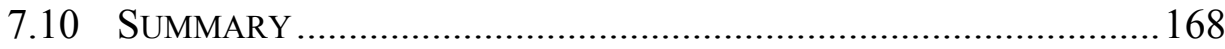

8 CONCLUSIONS AND IMPLICATIONS .................................169

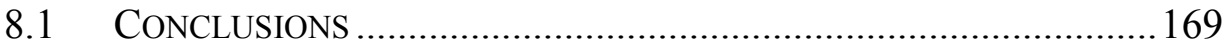

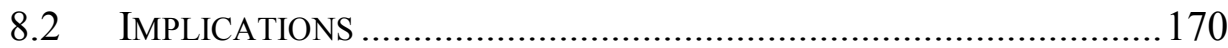

8.2.1 A tool to process knowledge.............................................. 170

8.2.2 On-line or face-to-face- how blended should the learning be?

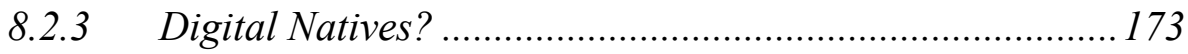

8.2.4 Supporting constructivist approaches to learning .............176

8.2.5 The role of the teacher .................................................... 178

8.2.6 Conclusion ................................................................... 180

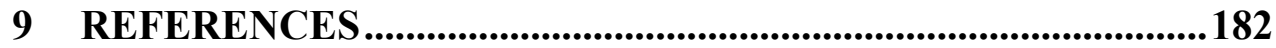

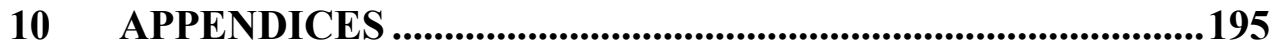

APPENDIX 1: ADDITIONAL DATA FROM THE FINAL SURVEY ....................195 


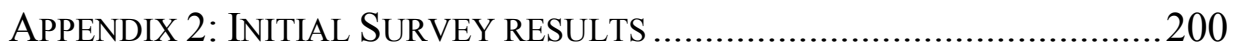

APPENDIX 3: CASE STUDY STUDENTS' INITIAL SURVEY DATA ...............201

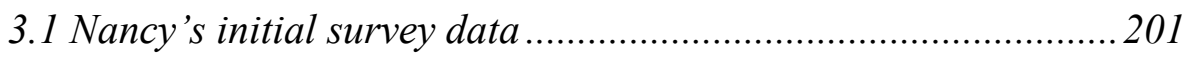

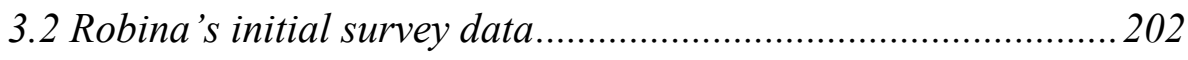

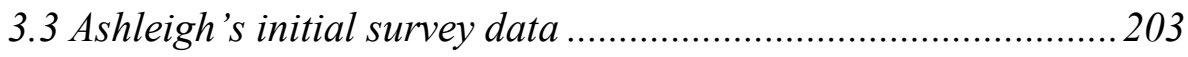

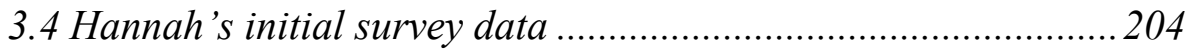

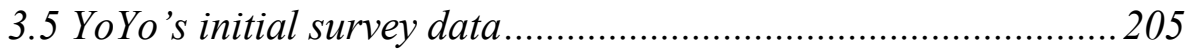

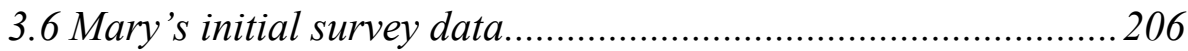

APPENDIX 4: INITIAL SURVEY QUESTIONS...........................................207

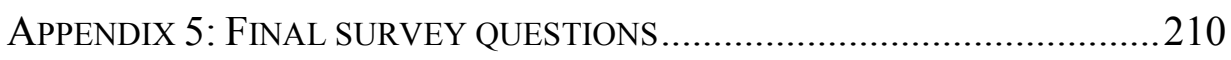

APPENDIX 6: LEARNER INTERVIEW SCHEDULE......................................213

APPENDIX 7: STUDENT OBSERVATIONS SHEET …..................................214

APPENDIX 8: CASE STUDY STUDENTS’ DAILY LOG …............................215

APPENDIX 9: ADDITIONAL FUNCTIONS WITHIN MYPORTFOLIO...............216

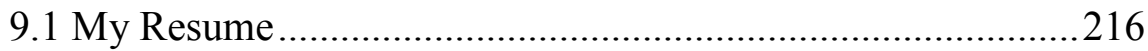

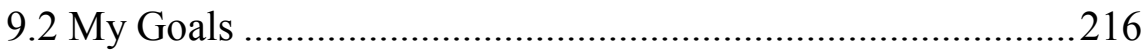

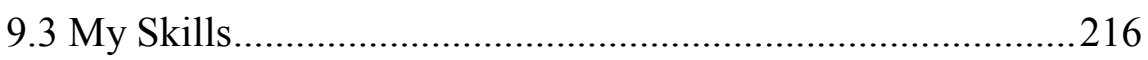

APPENDIX 10: INFORMATION LETTERS AND CONSENT FORMS ................217 


\section{Table of Figures}

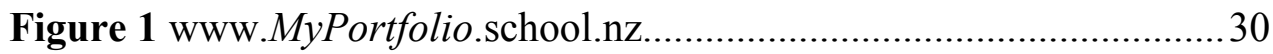

Figure 2 Summary of data sources ..................................................5

Figure 3 Summary of case study students' initial attitudes ....................60

Figure 4 The student view of MyPortfolio- home page.............................71

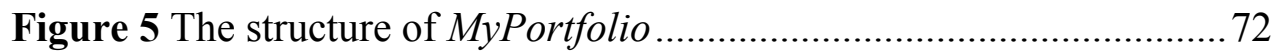

Figure 6 'Drag and drop' options for setting up a view 3/11/09 ..............73

Figure 7 A completed final view (15/11/08) with key features of the

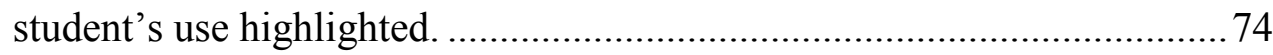

Figure 8 An example of a view (28/11/08) in which the student made few

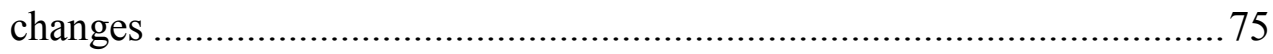

Figure 9 An example of a 'My Files' section of MyPortfolio ....................76

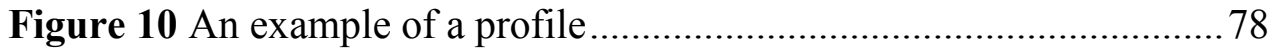

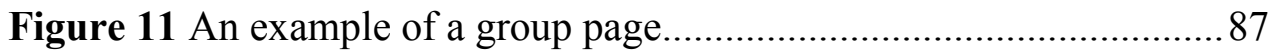

Figure 12 Notifications page- showing messages received .....................88

Figure 13 An example of the class view- the teacher was able to post updates and resources on the view for the students to check in their own

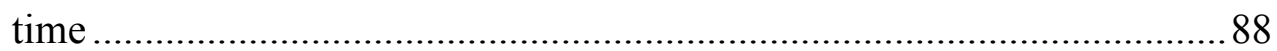

Figure 14 An example of a notifications screen .................................... 89

Figure 15 An example of a message from one student to another.............91

Figure 16 An example of feedback from the teacher to a student on a view $(21 / 10 / 08)$

Figure 17 Messages from students XXX and YYY informing the teacher

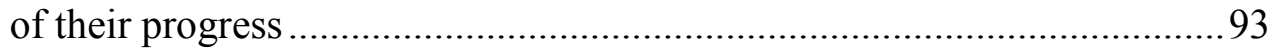

Figure 18 Additional view created by a survey group student ...............97

Figure 19 An example of a comment in a student's final evaluation $(11 / 11 / 08)$ 
Figure 20 An example of the comments in a survey group student's daily reflective $\log$

Figure 21 An example of a survey student's final evaluation

Figure 22 A student's final evaluation- reflection on the quality of work

Figure 23 Attitudes towards computer use

Figure 24 Layout of the computer laboratory at the school and the case study students locations through out the course of the study

Figure 25 A message to the teacher from Nancy- updating the teacher on Nancy's progress (After Lesson 2)

Figure 26 Nancy's 'My files' section (15/11/08) showing the artefacts Nancy had uploaded by the end of the study

Figure 27 Nancy's final view (25/11/08) showing the artefacts that Nancy added throughout the course of the study

Figure 28 Detail from Nancy's final view (25/11/08) showing her use of the file download tool

Figure 29 Nancy's profile at the beginning of the study (Lesson 2) .......122 Figure 30 Nancy's profile at the end of the study (7/11/08) with detail showing the development in her profile.

Figure 31 A message from Nancy to the teacher (28/10/08) showing one of the ways in which Nancy communicated with the teacher. 126

Figure 32 Robina's view at the beginning of the study $(17 / 10 / 08)$ 131

Figure 33 Robina's view at the end of the second week of the study $(28 / 11 / 08)$

Figure 34 Robina's 'My Files' (28/11/08)- showing the different files that Robina uploaded throughout the study.... 132

Figure 35 A message from Robina to teacher (16/10/08) showing Robina's contact with the teacher after school 134 
Figure 36 Robina's final view (28/11/08) with detail showing the development of her view throughout the course of the study

Figure 37 Detail from Robina's final view (28/11/08) showing the way her skill in using MyPortfolio developed

Figure 38 Robina's profile (28/10/08) showing the lack of development in her profile throughout the study

Figure 39 An example of a message that the teacher sent Robina $(16 / 10 / 08)$ 138

Figure 40 Ashleigh's final view (17/10/08) with detail showing the way she made use of MyPortfolio

Figure 41 Ashleigh's profile in MyPortfolio at the beginning of the study

Figure 42 Ashleigh's profile in MyPortfolio at the end of the study

Figure 43 Social messages sent from Ashleigh to other students.....

Figure 44 Hannah's final view (15/11/08) showing the way in which she made use of MyPortfolio 149

Figure 45 Hannah's profile at the beginning of the study $(18 / 11 / 08) \ldots . .150$

Figure 46 Hannah's profile (1/9/09) showing the changes in text that Hannah made after the study had concluded 150

Figure 47 A message sent by Hannah to another group member (22/10/08)

Figure 48 YoYo's final view (18/11/08) showing the way in which YoYo made use of MyPortfolio

Figure 49 Detail from YoYo's view (18/11/08) showing the way in which YoYo personalised her view. 155

Figure 50 YoYo's profile (17/10/08) showing the way in which her profile reflected her interests 156 
Figure 51 YoYo's profile mid way through the study (29/10/08) showing the changes she had made.

Figure 52 YoYo's profile at the end of the study (7/11/08) showing further changes that reflected YoYo's interests

Figure 53 Messages from YoYo to other students showing the way in which she used MyPortfolio to complete the work set.

Figure 54 Mary's final view (15/11/08) showing the way in which she made use of MyPortfolio

Figure 55 Mary's profile (24/11/08)- Mary did not make any changes throughout the study after the initial lesson.

Figure 56 Mary's second view (26/11/08) showing the way in which Mary created a second view that was not related to the class work 166

Figure 57 A message from Mary to another member of her group showing the way in which Mary's group collaborated in order to complete the tasks set.. 168

Figure 58 Gifford's (1996) mediated learning model 179 


\section{Introduction}

\subsection{The rationale for this study}

The use of portfolios within an educational context is by no means a new phenomenon and has come in and out of fashion many times over the years. While traditionally portfolios have been produced in hard copy, with the increased availability of technology within schools, electronic portfolios (eportfolios) have begun to grow in popularity (Greenberg, 2004; Jafari \& Greenberg, 2003) and are now used in many different contexts throughout the education system, from early childhood through into tertiary level.

As with the increased emphasis on the use of information and communications technologies (ICT) tools in general, the use of e-portfolios has been particularly driven by two forces operating within education (Cuban, 2001). The first is the increased focus on constructivist approaches to learning that place an emphasis on students collaborating with others in order to construct knowledge for themselves and then reflecting on their learning processes (Cuban, 2001). By making use of e-portfolios in this way, proponents of their use argue that e-portfolios can help students develop metacognitive and reflective thinking skills which may help to create 'lifelong learners'- students who can continue to learn and develop their skills and knowledge over their lifetime (Barrett, 2005; Cohn \& Hibbetts, 2004). The development of Web 2.0 technologies which allow students more control of their work and provide the opportunity for more sophisticated and personalised use of e-portfolios has also provided further opportunity to support constructivist approaches to learning (Waters, 2009).

The second force that has driven an increase in use of e-portfolios has been the increased focus on ICT use within the current digital environment. There are three aspects of ICT which provide advantages over traditional paper portfolios. The first is the pragmatic advantages such the increased storage ability and the improved access that ICT provide. The second is the perceived need for students to be competent and confident users of digital technologies in order to prepare them for the work environment (Cuban, 2001). Finally, a number of commentators argue that today's students are both very familiar and very 
comfortable with using digital technologies and that in order to engage with students, schools must increasingly make use of these technologies (Prensky, 2001).

However, although the use of e-portfolios has become increasingly popular, research into their use has remained limited and is almost exclusively based on use within university settings (Barrett, 2005) and is most commonly from the perspective of instructors or technologists (Ahn, 2004; Howland \& Moore, 2002; Song, Singleton, Hill, \& Koh, 2004). Similarly, while there have been numerous studies highlighting the educational potential of e-portfolios, there is very little research that reflects how students actually make use of eportfolios and how this may help or hinder their learning (Butler, 2006).

As a result of these gaps in the literature, the key focus of this study is examining the use of an e-portfolio tool by a group of high school students and, in particular, giving a representation of these students' perspectives of the tool. Having said this, it is important to note that the teacher has a crucial role in students' learning and, because of this I have also considered implications for the role of the teacher in supporting the student use of e-portfolios in high schools.

The e-portfolio tool used in this study is a web-based application called MyPortfolio ${ }^{I}$. This application has been developed in New Zealand for school use $^{2}$ and is currently freely available to schools.

\section{$1.2 \quad$ Key terminology}

I will begin this chapter by defining the key terminology utilised in this study; in particular, the terminology surrounding portfolios and e-portfolios and the digital Web 2.0 environment in which e-portfolios exist.

\subsubsection{What is a portfolio?}

The use of e-portfolios in education is the continuation and development of a strategy that has a long history, particularly in areas such as art, where students

\footnotetext{
${ }^{1}$ www.MyPortfolio.school.nz

${ }^{2}$ MyPortfolio is driven by an open-source e-portfolio system named Mahara (www.mahara.org.nz). As well as a version of MyPortfolio designed for school use, there is also a version designed for tertiary use.
} 
often represent the development of their work through the presentation of a portfolio (Forgette-Giroux \& Simon, 2000; Wade \& Yarbrough, 1996). While the use of the digital environment to create the portfolio is new, the actual concept of portfolio learning is not and, consequently, it is useful to draw on literature about portfolio use in order to understand how e-portfolios have developed.

Essentially, portfolios are an organised collection of student work that demonstrates achievement or improvement over time. Goldsmith (2007) describes portfolios as having three basic characteristics. These are:

- The ability to collect material created over a period of time

- The ability to select and organise this material

- The ability to surround work with addition information including introductions and reflections

It is the combination of these features with a portfolio that enables a leaner to present a picture of the way their skills have developed over time and what they have learnt from this (Fox, Britain, \& Hall, 2009).

\subsubsection{Why portfolio learning?}

The two key features of portfolio learning are that it allows students the opportunity to reflect on their work over a period of time and that it provides students with the ability to present rich evidence of what they have learnt and the skills they have developed. In this way, the use of portfolios is more than simply a collection of items of work but becomes the use of $\operatorname{artefacts}^{3}$ which authentically demonstrates what a student has learnt.

Central to the portfolio approach to learning is the idea that portfolios require students to collect work over time and then reflect on this work in order to make sense of it, learn from it, and develop new understanding (Johnson, Mims-Cox, \& Doyle-Nichols, 2006; Wade \& Yarbrough, 1996). Students who utilise a portfolio approach must not only fulfil set tasks but must reflect on what

\footnotetext{
3 'Artefacts' is a term used to refer to any piece of work presented in a portfolio as evidence of learning
} 
to include in the portfolio and make decisions about how it represents what they have learnt and how this reflects the criteria set (Cole, Ryan, \& Kirk, 1995; Johnson et al., 2006). In particular, portfolio learning requires learners to develop a collection of artefacts which demonstrate their skills and understanding for a specific purpose (Cole et al., 1995). It is this focus on reflection that differentiates portfolios from simply being a collection of work and in this way it is often argued that portfolios can be useful in supporting metacognition in students through the use of reflection (Johnson et al., 2006). The fact that portfolios are an ongoing process, completed of an extended period of time, also means that portfolios can afford the opportunity for instructors to provide feedback on student work at various stages and this may also help students to reflect upon and develop their work (Johnson et al., 2006).

The second important aspect of portfolio use is the fact that the use of a range of artefacts gives students the ability to provide rich evidence to support their learning (Johnson et al., 2006) and give students the opportunity to display genuine examples of achievements (Hartnell-Young, 2006). The ability to present work as a portfolio can enable students to demonstrate, rather than simply tell, what they know and have learnt and how this meets the criteria set. In this way, portfolio learning may provide the opportunity for authentic assessment (Johnson et al., 2006; Lambert, DePaepe, Lambert, \& Anderson, 2007). Similarly, portfolios can also demonstrate patterns over time and allow learners multiple opportunities to demonstrate their skills and knowledge (De Rijdt, Tiquet, Dochy, \& Devolder, 2006; Greenberg, 2004; Johnson et al., 2006) and this may also allow students to link their progress to their goals (Goldsmith, 2007).

\subsubsection{Challenges of portfolio learning}

Although there are many advantages to portfolio learning, there are also some disadvantages and these are primarily related to managing the portfolio process. A major issue often identified is the fact that they can be time consuming for both students and teachers (Herman \& Winters, 1994; Underwood, 1998). In particular, portfolio use requires both students and 
teachers to become familiar with a different approach to learning and how to manage the on-going process that it required.

On a practical level, portfolios can be difficult to store and transport and this can limit teachers' and students' access to the portfolios and hinder their effective use (Darling, 2001; Smith \& Tillema, 2003).

Another issue around portfolio learning is that of the management of assessment. Although it is argued that portfolios can provide a more authentic representation of students' learning, the fact that their represent a range of work over time can also mean that they present difficulties when it comes to assessment as grading can often be subjective (Darling, 2001; Gearhart \& Herman, 1998; Tillema \& Smith, 2007).

Finally, portfolios can also be difficult to manage as it is not always possible to include the appropriate artefact in paper portfolios (Barrett, 2005). For example, students may include pictures of a performance but cannot actually include the performance in their portfolio. This can limit students' ability to include authentic examples of the work that they have undertaken and can mean that the work is not always authentically presented.

Overall, the challenges of managing paper portfolios have meant that they have not always been easy to manage within a classroom situation and this has meant that their use has been somewhat limited.

\subsubsection{What is an e-portfolio?}

In the current digital world, a natural development has been the move from paper portfolios has been the move to electronic portfolios. There are a number of definitions of what an e-portfolio is and most refer to their particular purpose. However, Gray (2008) notes that there is an emerging consensus that the term 'eportfolio' refers to both the process of creating a e-portfolio and the final product that results from this process and therefore he defines an e-portfolio as "... the product, created by the learner, a collection of digital artefacts articulating experiences, achievements and learning" (p 6).

Early writing about e-portfolios suggested that they were simply electronic versions of traditional portfolios (Barrett, 2005). However, it has become clear 
that the use of an electronic medium creates a number of pedagogical implications and while initial research into e-portfolio use focused on the portfolio product (Attwell, Chrzaszcz, Hilzensauer, Hornung-Prähauser, \& Pallister, 2007; Barrett, 2007), increasingly e-portfolios have come to be seen as more than a product or a technological system. Greenberg (2004) comments that e-portfolios are not simply a place for displaying work but an opportunity to manage, organise and control work. They have, therefore, increasingly come to encompass a range of teaching and learning ideals which mean that they are better perceived more as a process for learning- that is, a way of helping students manage the functions involved in learning such as organisation and communication- as well as a way of creating an actually product.

\subsubsection{Types of e-portfolios}

One of the aspects of e-portfolio use that makes them difficult to research is the fact that there is wide variety of uses and understandings of the functions of e-portfolios. Writers have described three different types of e-portfolio (Barrett, 2007; Brown, Anderson, Simpson, \& Suddaby, 2007; Zeichner \& Wray, 2001) and these are:

- Credential portfolios- used for certification or registration purposes, such as the portfolios used in nursing and teaching. Barrett (2007) refers to this type of portfolio as 'assessment' and broadens the definition to include the use of the portfolios for a wider range of assessment, including high-stakes summative assessment.

- Showcase portfolios- a showcase of a student's best work. These are most often used to seek employment or entrance into further study.

- Learning portfolios- these are used to evaluate student learning over a period of time. Unlike the other portfolio types, a learning portfolio does not simply display a student's best work, but rather contains work that a student has selected in order to show growth and development over a period of time 
One of the most common purposes for e-portfolios is assessment, particularly in the case of credential and showcase e-portfolios. This area has also been the focus of much research and many studies have suggested ways of appropriately assessing e-portfolios. However, the use of e-portfolios solely for assessment purposes has the potential to lead to the assessment becoming artificial and Barrett (2007) argues that e-portfolios should support assessment for learning rather than simply assessment of learning.

Fox, Britain and Hall (2009) also note that schools need to make use of the type of e-portfolio that best suits the desired purpose as well as the age and developmental stage of students. For these reasons, the focus of this study will be the learning processes involved in the development of learning e-portfolios rather than the assessment of e-portfolios.

\subsubsection{Why e-portfolios?}

Initially, the major advantage of e-portfolios was seen to be the fact that they could overcome some of the physical challenges of paper portfolios, such as the difficulty in storage and organisation. However, as both e-portfolios and ICT have developed, it has become clear that e-portfolios may be more than a solution to the pragmatic problems of paper portfolios. Increasingly, researchers are reporting that e-portfolios have the ability to support communication between students, teachers, parents and the wider community; engage and develop students' technical skills; further support metacognition and reflection through the use of ICT; provide an authentic audience for students' work; and help motivate students through the use of ICT.

One of the most obvious advantages of using e-portfolios is the way in which they can help to deal with the practical issues of storage and access issues that I discussed in the previous section (see page 21). The use of e-portfolios means that teachers and students do not need to carry paper portfolios around, but rather can make use of the digital medium for viewing the portfolios (Goldsmith, 2007). This is particularly the case when the e-portfolios are held online and can be accessed from anywhere with an Internet connection (Greenberg, 2004). This ability to make use of e-portfolios from a range of locations including home and school means that students have much more 
flexible access for using them. Fox et al. (2009) also argue that this use of anytime/anywhere learning may enable students to develop increased skills in using ICT and I will discuss this more later in this section.

Studies have also noted the way in which e-portfolios can support students' organisation and Goldsmith (2007) notes that e-portfolios allow students to keep work over a period of time without having to keep track of pieces of paper. Similarly, in her study of high school students Barrett (2008b) particularly highlights the fact that students felt that the organisational aspects of utilising eportfolios such as the ability to store and access work helped students to stay organised themselves.

The use of e-portfolios also gives students the opportunity to both make use of and develop their skills in using ICT. The digital medium gives an opportunity to make use of a variety of media (Goldsmith, 2007) and Barrett (2008b) makes the point that virtually any type of work can now be converted into a digital artefact in order to be included in an e-portfolio. In this way, eportfolios in a digital medium also give students the opportunity to discover and utilise new ways of presenting their work while at the same time developing new skills in using technology (Barrett, 2008b).

One of the most significant advantages of the electronic medium is the way in which it can support communication and, increasingly, communication tools such as the ability to message and share files and information are being incorporated into e-portfolio applications (Waters, 2009). The ability for students to communicate with their teacher and other students without having to be faceto-face gives both students and teachers additional flexibility in when learning occurs (Greenberg, 2004; Ravet \& Layte, 2003) and can also help students to share knowledge (Ravet \& Layte, 2003). Indeed, Barrett's (2008b) study of high school students noted the way in which students made use of communication functions to develop the quality of their work through collaboration between students and teachers.

Another key argument for the use of e-portfolios is that they have the advantage of being able to support metacognition through the use of hypertext and multimedia functions (Avraamidou \& Zembal-Saul, 2002; Barrett, 2008b). 
The fact that hypertext can link different ideas together can help students to connect different ideas in their work and may also help them to see how different aspects of their work fit together so that students are able to make connections between various aspects of their work (Avraamidou \& Zembal-Saul, 2002, 2003; Blair \& Takayoshi, 1997). Avraamidou \& Zembal-Saul (2003) also note that this use of e-portfolios may help students make links between various aspects of their course work and thus develop a more holistic understanding of work completed.

Several studies have demonstrated the way in which utilising a e-portfolio can help students reflect on their work and develop a deeper understanding of their learning (Stacey \& Gerbic, 2007; Wade, Abrami, \& Sclater, 2005) as students can return to work completed and modify it for different purposes or improve the quality of work completed (Goldsmith, 2007). This ability to reflect on work complete may help students to become more engaged in their own learning as it provides the opportunity for students to exercise control over their learning. While this is also possible with paper portfolios, the technological processes such as the ability to use hypertext and the way in which e-portfolios can deal with storage and organisational issues provide an additional framework within which this can more easily occur.

The use of e-portfolios can provide an authentic audience for student work (Goldsmith, 2007). When on-line portfolios are utilised, students are able to make their work available to a range of audiences and thereby provide authenticity to their work (Barrett, 2005; Greenberg, 2005). This is particularly the case with MyPortfolio, where students develop their own 'views', where they are able to select artefacts for presentation to particular audiences ${ }^{4}$.

Finally, the use of e-portfolios may also provide an opportunity to engage students through the use of ICT and studies into e-portfolio use over time, have found that this use may have the ability to improve student engagement and motivation (Barrett, 2007; British Educational Communication Technology Agency (Becta), 2007). In particular, the Becta study (2007), which made use of data from a mixture of school and tertiary aged students, noted the way in which using technology to support e-portfolio use engaged some previously disengaged

\footnotetext{
${ }^{4}$ I will discuss this use of MyPortfolio briefly on page 30 and then in more detail in Chapter 4.
} 
students. The motivational effects of ICT are an important consideration in the use of digital technologies and I will discuss this further in Chapter 2 (page 40).

\subsubsection{E-portfolios: Creating life-long learners}

Increasingly a key concept in e-portfolio learning is the idea that they can help to create 'life-long learners' (Barrett \& Garrett, 2009; Cohn \& Hibbetts, 2004). Essentially, the term 'life-long learners' has come to refer to the idea that the process of learning should continue throughout a person's life (McCauley, 1993) and that learners need the cognitive skills to understand what they need to know and how to develop these skills (Hartnell-Young, 2006).

Central to this term is the idea that the constantly changing 'knowledge economy' requires workers who are able to adapt and learn in order to continue to develop their skills (Field, 2006) and it is possible that the use of e-portfolios can help to support the development of these skills and also provide a place for learners to demonstrate the skills they have and in this way, e-portfolios can become a repository in which to store and present repositories of work as an online showcase.

\subsubsection{Challenges of e-portfolio learning}

Although e-portfolios provide a number of advantages over traditional paper portfolios, the literature also identifies some disadvantages of using eportfolio and these particularly relate to the nature of using technology. The first major disadvantage with making use of e-portfolios is the fact that it requires the use of ICT and often, as is the case with MyPortfolio, a connection to the Internet. While this is increasingly common in schools, it can pose a difficulty in some situations if students are not able to access the Internet outside of class (British Educational Communication Technology Agency (Becta), 2007).

As well as access to the Internet, studies of e-portfolio use have repeated demonstrated that access to hardware can be an issue (Fournier, Lane, \& Corbett, 2007; Robins, 2006; Tosh, Light, Fleming, \& Haywood, 2005) as limited access can limit the level of integration of e-portfolios into students' learning (Barrett, 2007). Although most schools in New Zealand now have many computers within the school, in high schools, these are largely limited to use with computer 
laboratories and this can limit the integration of the e-portfolios (Harrison, 2005). Similarly, the use of e-portfolios also creates demand for other technology, such as cameras and scanners and this may limit the students' ability to present the work that they would like to in an electronic format (Chang, 2001).

The use of the electronic medium also requires schools to consider issues of student privacy and safety as the presentation of students' work on the Internet can leave students vulnerable to abuse (Hawisher \& Selfe, 1997). While the use of the Internet can provide students with an authentic audience, it also means that students lose control over who views their work. This is a particular issue when students are also making use of communication tools.

As well as the limitations placed by access to hardware, in order to create effective e-portfolios, students also need to be familiar with both the relevant technological processes in order to develop an effective e-portfolios (Batson, 2002). This means that a student who is not as technologically able may not be able to present their work as effectively as one who is more able.

The literature is also clear that new technology can affect students' motivation (Elbow \& Belanoff, 1997; Strudler \& Wetzel, 2005) and although the use of ICT can have a motivating effect for some students (Papert, 1993), new applications can also be time consuming to learn to use for both teachers and students and this can be frustrating for users (Elbow \& Belanoff, 1997; Strudler $\&$ Wetzel, 2005). Some students may find the use of ICT demotivating and can affect the overall level of learning that occurs. I will discuss the motivational affects of technology further in Chapter 2 (see page 40).

Finally, it is important to note that while many commentators write enthusiastically about the possibilities of e-portfolio use, some studies have demonstrated that students do not necessarily automatically make sophisticated use of e-portfolio tools just because they are available. In their study of the use of e-portfolios with pre-service teachers McNair and Galanouli (2002) found that that the students primarily used e-portfolios for organisation of text and images and that the students saw the application as a tool to support organisation and presentation of work. 


\subsubsection{What is Web 2.0?}

Many of the current e-portfolio tools not only make use of traditional electronic technologies such as word processing, the storage of files and the ability to present work, but are increasingly integrating Web 2.0 technologies such as social networking and authoring technology and writers argue that this technology can further support students' learning (Waters, 2009).

'Web 2.0' is the term used to describe web technologies that allow users the ability to create and manage their own content (Buffington, 2008; Greenhow, Robelia, \& Hughes, 2009). Where the first generation of web applications were read-only and largely just allowed users to store and retrieve data, today's Web 2.0 applications rely on user participation and social interaction and allow users to create their own content (Greenhow et al., 2009). This development of Web 2.0 technologies has seen a change in power structures around who can create content for the web (Buffington, 2008; O'Reilly, 2005) and this means that the use of Web 2.0 technologies can increasingly give students more control over their own learning. Where Web 1.0 technologies limited content creation to those with specialist knowledge (such as programming languages), Web 2.0 has opened up the ability to create content to all.

There are many popular examples of Web 2.0 tools and many students today are often familiar with and make use of sites such as Bebo ${ }^{5}$, Facebook $^{6}$ and MySpace $^{7}$ in order to communicate with friends and interact with other users. Similarly, blogging ${ }^{8}$ is another Web 2.0 tool which has become an increasingly popular as users seek to share their ideas and experiences with others (boyd \& Ellison, 2007). Media sharing sites such as YouTube and Flickr ${ }^{10}$ have also become popular mediums for sharing video clips and photographs. Another example of Web 2.0 technology is social bookmarking sites such as Delicious ${ }^{11}$

\footnotetext{
${ }^{5}$ www.bebo.com

${ }_{7}^{6}$ www.facebook.com

${ }^{7}$ www.myspace.com

${ }^{8}$ For examples of applications which support blogging, see www.blogger.com; www.livejournal.com or http://www.opendiary.com/

9 www.youtube.com

${ }^{10}$ www.flickr.com

11 www.delicious.com - Delicious allows users to save and categorise web links. These can then be made available to other users.
} 
and $\operatorname{Digg}^{12}$. Both of these sites allow users to save and categorise content so that others can access and make comment on material posted.

\subsubsection{Web 2.0 and personalisation}

One of the most significant aspects of Web 2.0 tools is the way in which it allows users to personalise their work through the use of audio / visual and design features. Many students today are familiar with social networking sites and a key feature of these is the ability for people to personalise their site- that is, add text, images and videos that represent their personality. Studies have found that this is an aspect of social networking sites that students enjoy and in her study of high school students' use of social networking applications boyd (2007) found that the ability to personalise the site was one of the key features for students. The creation of identity is an essential part of adolescence (Giddens, 1991) and Web 2.0 technology can provide the opportunity for students to reflect this personality to others. While students can make use of public social networking tools, the use of e-portfolios within schools can help students to engage in this identity creation in a relatively safe environment (Livingstone, 2008). The ability to personalise work using Web 2.0 tools can also be a way to engage students in learning (Barrett, 2008b; British Educational Communication Technology Agency (Becta), 2007; Buffington, 2008) and in her study of high school students' e-portfolio use Barrett (2008b) found that students desired the ability to personalise their work and that they were motivated by the ability to personalise their work.

\subsubsection{Introducing.... MyPortfolio}

The particular e-portfolio tool utilised in this study was MyPortfolio ${ }^{13}$ - a web-hosted electronic portfolio tool that “...provides a personal learning environment to record and showcase evidence of achievement, manage development plans, set goals, and create online learning communities" (Flexible Learning, 2009). MyPortfolio is an electronic portfolio tool which combines Web 2.0 technology such as blogging and communication tools with the idea of

\footnotetext{
${ }^{12}$ http://digg.com/ Digg allows users to discover and share information from the Internet. Content is posted by users and is then rated by other users.

${ }^{13}$ www.MyPortfolio.school.nz
} 
portfolio learning in order to help students “...demonstrate their learning, skills and development and record their achievements over time to a selected audience" (Flexible Learning, 2008).

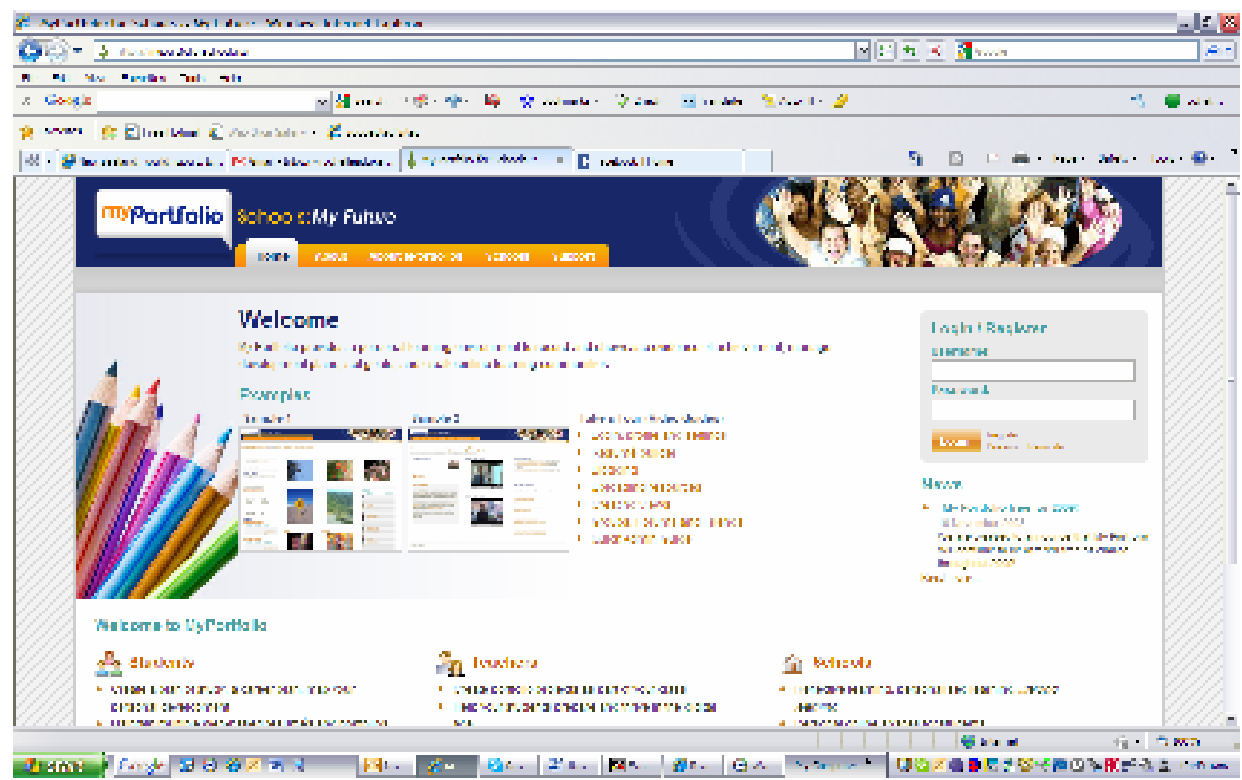

Figure 1 www.MyPortfolio.school.nz- front page

Central to MyPortfolio is the ability for students to create 'views'. In essence, a view is simply a way of allowing students to present their work to other people. Students can create views using a range of media including documents, text, video, pictures and links and can then make these available to a selected audience. In this way, MyPortfolio allows the students to personalise their views not only to represent themselves but also to reflect the focus of the person viewing the view. In order to create a view, student can also make use of other aspects of MyPortfolio such as 'my files', - a tool which allows students to upload a range of file types into MyPortfolio and then add them into a view; blogs which students can update and can also add into their view; and the profile section which is a space where students can include information about themselves. MyPortfolio also contains communication features which students can make use of in order to contact other students and their teacher. The communication features within MyPortfolio are: the messaging function; the ability to create groups and send messages to other members of the group; and the ability to leave comments on other students' views and profiles. I will discuss each of these features of MyPortfolio in more detail in Chapter 4 when I discuss how the students in this study made use of MyPortfolio. 


\subsubsection{ICT in a blended learning environment}

The reality for most high school students in New Zealand is that they learn in a classroom environment with a teacher and other students and this was the case for the students in this study. However, as previously noted, students are increasingly expected to be able to make use of ICT, and consequently, schools are both required and desire to make use of learning environments which makes use of a mixture of internet-based and face-to-face learning in order to optimise the students' learning experience (Alonso, López, Manrique, \& Viñes, 2005; Garrison \& Kanuka, 2004) and the use of MyPortfolio for this study presented the students with a blended learning environment in which they made use of both online learning at home and at school, and face-to-face learning where they interacted with other students and the teacher.

'Blended learning' is an extremely broad term which encompasses any combination of face-to-face learning and ICT and also combines various eventbased activities including self-paced learning; live e-learning; and face-to-face learning (Alonso et al., 2005; Lim, Morris, \& Kupritz, 2000). Of course, 'blended learning' is simply a term for what happens all the time in most classroom settings where the teacher makes use of a range of ICT to facilitate the lesson.

In many ways, blended learning is an attempt to overcome the limitations of both face-to-face learning and online learning (Lim et al., 2000). Firstly, blended learning has the flexibility of online learning in that it connects the learning that occurs within the classroom with other contexts and thus provides an additional level of pedagogical richness (Osguthorpe \& Graham, 2003). Students are also able to make use of the application at home and in other situations outside the classroom and this can allow students increased flexibility in where and when they conduct their learning (Bonk, Olson, Wisher, \& Orvis, 2002; Osguthorpe \& Graham, 2003; Smart \& Cappel, 2006). The use of blended learning technology may also support a degree of personal agency which allows learners to control their own learning and help develop self-directed learning (Osguthorpe \& Graham, 2003). 
However, one of the commonly reported disadvantages of increased use of online learning within the classroom is the social isolation that can occur (Lim et al., 2000; Osguthorpe \& Graham, 2003). While the impact of this is less in blended learning situations than in purely online situations, it still appears to be a significant issue and some students have noted the lack of energy and social support that occurs within group learning as being a disadvantage of increased use of ICT within the classroom (Bonk et al., 2002; Osguthorpe \& Graham, 2003).

This is a difficult area to balance, as different types of blended learning make use of different balances of online and face-to-face learning. However, if it important to note that the move towards more use of online learning environments within the classroom can have an impact social relationships.

\subsection{Key objectives}

The aim of this research, therefore, is to represent the use of the e-portfolio tool MyPortfolio from the perspective of a group of high school students in order to add a missing dimension to the literature on e-portfolio use. In order to understand the students' perspective of MyPortfolio, this study focused on the following research questions:

1. How did students make use of MyPortfolio?

2. What perceptions did the students have of MyPortfolio and how did MyPortfolio help and / or hinder their learning?

Finally, given the fact that one of the forces driving the increased use of both ICT in general and, more specifically, e-portfolios, I also sought to understand:

3. How can MyPortfolio support constructivist approaches to learning?

\subsection{Methodological approach}

In order to achieve these research objectives in this study I have made use of a mixed-methods, descriptive case study approach. I observed a class of high school students over a period of six weeks as they made use of MyPortfolio for the first time and collected a variety of data sources including MyPortfolio 
artefacts, daily logs, observations, interviews and surveys in order to develop a rich description of the students' experiences using MyPortfolio. My methodological approach is discussed in detail in Chapter 3.

\subsection{Summary of the chapters in this thesis}

In this chapter, I have given a brief rationale for my focus on the use of MyPortfolio with a group of high school students and have also defined some of the key terms that are central to this research.

In Chapter 2, I will review some of the key literature relating to the use of ICT in schools, the way this has been shaped by constructivist approaches to learning and how electronic portfolios fit within this.

Chapter 3 will provide the methodological framework for this study and also give an introduction to the key participants and their role within the study. I will also discuss the data analysis that I undertook and the ethical considerations involved in this study.

In Chapter 4, I will describe MyPortfolio in detail and give an explanation of how the students in this study made use of the application through the course of this study. Alongside this, I will introduce the key themes that emerged from the students' use of MyPortfolio.

Having introduced the students' use of MyPortfolio in Chapter 4, Chapter 5 will focus on how the students perceived MyPortfolio and the findings that emerged from the data I collected relating to their perceptions.

In Chapter 6, I will focus on how MyPortfolio supported key aspects of constructivist learning.

The final data chapter, Chapter 7, will introduce the six case study students whose progress I followed closely throughout the course of the study. This chapter will provide an in-depth discussion of the experiences and perceptions of each of the case study students and the themes that emerged from each student in order to provide further detail to the key themes discussed in Chapters 4, 5 and 6.

Finally, in Chapter 8, I will discuss the conclusions and consequent implications that can be drawn from the data in this study. 


\section{Literature Review}

\subsection{The theoretical framework}

In Chapter 1, I discussed the development of portfolio learning and eportfolios as well as some of the key advantages and disadvantages of making use of e-portfolios for learning. However, the rise in popularity of e-portfolios has not been solely driven by the advantages of the e-portfolios themselves, but has occurred within a larger educational context. In particular, the increased focus on the use of e-portfolios has been driven by a move towards constructivist approaches to learning; and ideas about the current digital environment and the way in which today's students can and will operate within this and I will discuss these in this chapter.

I will also discuss the use of e-portfolios within the context of the current policy framework in New Zealand, with a particular focus on current ICT policy within education and its role within the New Zealand Curriculum.

\subsection{ICT and constructivist learning}

The first force that has spurred use of e-portfolios within schools has been a move towards constructivist models of learning which emphasise the need for students to play an active role of the process of learning and knowledge construction (Cuban, 2001; Meeus, Questier, \& Derks, 2006; Osguthorpe \& Graham, 2003; Ritzhaupt, Singh, Seyferth, \& Dedrick, 2008; Strudler \& Wetzel, 2005; Wetzel \& Strudler, 2005).

\subsubsection{What is constructivism?}

Constructivism is not a single theory but a number of overlapping perspectives with the focus on how knowledge is constructed and how people learn (Johansson \& Gärdenfors, 2005; Phillips, 1995; Von Glasersfeld, 1995). Many of constructivism's key concepts are attributed to Piaget (1929) who argued that learners are active and constructive in making sense of their environment. 
In a similar way, John Dewey (1938) suggested that knowledge emerged from situations where learners could draw out meaning out of experiences and emphasised the idea of 'learning by doing'. This idea of individuals constructing knowledge from the experiences they have, and then creating meaning from these experiences, has become central to constructivism (Davis, Sumara, \& Luce-Kapler, 2000; Duffy \& Jonassen, 1992; Forcier \& Descy, 2008; Von Glasersfeld, 1995). Overall, the common thread that ties together the different aspects of constructivism is the notion that that individuals construct their own knowledge, which is made, not acquired (Allen, 2004; Johansson \& Gärdenfors, 2005; Jonassen \& Land, 2000; Piaget, 1929; Von Glasersfeld, 1995).

Consequently, the aim of constructivist education is to develop learners who are able to engage in independent thought and knowledge creation (Johansson \& Gärdenfors, 2005; Stefani, Mason, \& Pegler, 2007).

\subsubsection{Social constructivism}

Two branches of constructivist thought have emerged and as well as the cognitive constructivism that I have just described, the work of Vygotsky (1978) has led to the development of social constructivism. While social constructivists share the constructivist approach to the epistemology of knowledge, social constructivism places more emphasis the importance of community for developing meaning. Social constructivism shares cognitive constructivism's view that knowledge is not acquired and transmitted by individuals. However, it diverges in the sense that social constructivists view knowledge as being embedded in social relations including conversation and social discourse used to make meaning of activity and events (Jonassen, Peck, \& Wilson, 2001). In this way, social constructivists argue that shared meaning occurs through social negotiation and that essential aspects of mental functioning in the individual derive from social life (Jonassen, 2000; Jonassen et al., 2001; Robinson, Molenda, \& Razabek, 2008; Vygotsky, 1978; Wangpipatwong \& Papasratorn, 2007). Social constructivist approaches are, therefore, less concerned with individual sense making and more interested in the way in which groups of people create knowledge within a social context. 
Within constructivist frameworks, the role of the teacher changes significantly. In particular, the teacher is seen more in the role of facilitator or coordinator and the emphasis is more on the teacher knowing 'how', rather than knowing 'what' (Gergen, 1995). Consequently, student learning occurs through experience, rather than direct transmission from the teacher (Allen, 2004; Gergen, 1995). This means that learning becomes more student-centred, rather than teacher-centred and also changes the relationship between students and teachers, with a switch of focus from the teacher to the student and the learning activities (Gao, 2006; Von Glasersfeld, 1995).

An essential aspect of the role of the teacher within a constructivist approach is to help provide students with experiences within which they can construct their own knowledge (Allen, 2004; Davis et al., 2000; Grabe \& Grabe, 2001; Johansson \& Gärdenfors, 2005; Jonassen \& Land, 2000). The use of electronic portfolio applications such as MyPortfolio has the potential to support teachers in facilitating students' learning within a constructivist framework in that it can provide a framework within which students can develop their understanding over a period of time. Web 2.0 applications such as MyPortfolio make significant use of collaborative tools and, within, MyPortfolio, students can help support this.

An important aspect of the role of the teacher within constructivist frameworks is the facilitation on social negotiation so that this exchange can occur and Gergen (1995) particularly notes that one of the primary roles of the teacher is to enable students to participate in a range of conversations so that they are able to construct knowledge for themselves.

\subsection{Drawing it all together- Constructivist learning, ICT and e-portfolios}

As I have already discussed, learning e-portfolios such as MyPortfolio have developed out of a constructivist framework. The idea that ICT can help to support constructivist approaches is not new, however, and there is a significant body of literature that argues that ICT is ideally suited to supporting 
constructivist skills such as knowledge construction, collaboration and reflection (Herring, 2004). Many of the features of ICT that researchers suggest can help support these approaches to learning are also features of e-portfolio tools such as MyPortfolio.

\subsubsection{Knowledge construction}

Central to constructivist approaches to learning is the idea that students should be active in constructing their own understanding of concepts (Von Glasersfeld, 1995; Vygotsky, 1978) and Herring (2004) argues that when knowledge is constructed, the tools that support this construction become important. Similarly, Jonassen, Peck and Wilson (2001) argue that ICT should not just be a tool to help students collect information but, more significantly, should be used to help students construct a coherent mental representation of presented material.

Kozma and Johnston (1991) note that technical aspects of ICT can help construct knowledge though:

- The ability to use a range of symbols and employ them in powerful ways

- Easy access to a range of media

- The ability to transform on symbol system to another

- The ability to connect interrelated information

- And the ability to support collaborative learning through the use of multiple connections and multiple authors

Similarly, Rakes et al. (1999) argue that the use of ICT can help students deal with information making by:

- Helping students demonstrate what they know

- Providing access to information

- Providing tools to analyse information

- Helping students interpret and organise personal knowledge

- Providing students with tools to represent what they know to others 
Central to the use of e-portfolios to help students create knowledge is the way in which they can be used to collect, store and organise ideas (Barrett, 2007; British Educational Communication Technology Agency (Becta), 2007; Wade \& Yarbrough, 1996) and in this way, it can be seen that the use of e-portfolios can provide a space in which these activities can occur. The use of e-portfolios allows students to collect work over time and then to make use of digital technologies such as hyperlink in order to make connections between ideas which can then help students construct their own knowledge.

\subsubsection{Collaboration}

The most obvious ICT tools that support collaboration are communication tools such as email and other messaging tools and I discussed the way in which e-portfolios can support communication in Chapter 1 (see page 23) ${ }^{14}$. However, the use of Web 2.0 tools also provides more sophisticated collaboration tools such as co-authoring technology, video technology and the ability to share files and access shared work spaces. All of these tools can help support students to communicate with others and thus, to work together to construct knowledge. It is important to note that the collaboration that occurs within these spaces may not only involve students but also teachers, parents and members of the wider community and this can help improve the overall quality of students' work (British Educational Communication Technology Agency (Becta), 2007).

However, although the use of ICT provides the opportunity for many different avenues of both communication and, as a consequence, collaboration, Bonk and King (1998b) found that the students did not necessarily make use of the tools in order to collaborate to complete work. However, it is important to note that they also found that students' skills in collaboration using ICT developed over time.

While communication tools are available to students without the use of eportfolios, the use of e-portfolio tools provides the opportunity to bring these tools together in one place and applications such as MyPortfolio make use of a

\footnotetext{
${ }^{14}$ I will discuss the communication tools within MyPortfolio in more specific detail in Chapter 4 (page $\mathrm{xx}$ ).
} 
range of communication options as well as providing the ability to share files and view each others' work.

\subsubsection{Reflection and learning}

In Chapter 1, I discussed the way in which reflection is central to portfolio learning as it is the way in which students are able to learn from their work and develop their skills (see page 19). I also discussed the way in which ICT can help facilitate reflection through the ability to store files over time and then make connections between work completed and reflect on this (see page 19). While this is also possible with paper portfolios, the ability to make use of hyperlinks and 'views' such as those available in MyPortfolio can support this is a more effective way.

These affordances of ICT to help develop reflective thinking skills are also true of e-portfolio use. In particular, e-portfolios can provide students with the opportunity to store work over time and then revisit it which can enable students to see how their work has progressed over time and to see the development in their skills (Avraamidou \& Zembal-Saul, 2002). The digital nature of e-portfolios also means that students are able to complete the e-portfolio over a longer period of time and can take the portfolio with them as they move through the education system (Barrett, 2005; Collis \& Moonen, 2006; Harrison, 2005; Robinson et al., 2008; Sing \& Khine, 2006).

\subsubsection{ICT and learning- a contested area}

Although there are many researchers who argue that ICT can support constructivist approaches in the ways I have described above, not all researchers are agreed on the impact of ICT and writers like Clark $(1983 ; 1994 ; 2005)$ have continued to argue that technology alone can not influence learning and that it is instructional methods and the effect of the teacher, not technology, that affect learning. Similarly, Cuban (2001) also argues that computers have been 'oversold and underused' and that teachers predominately make use of computers in order to support existing teaching practices and have not been used to support constructivist approaches to learning. 
However, Clark's view has been much contested and other writers, such as, Kozma $(1991 ; 1994)$ make the point that learning occurs in the cognitive processes that occur in the interaction between students and their use of technology and, consequently, ICT can impact students' learning and help them develop the skills to become lifelong learners. Jonassen (2000) also makes the point that the key feature of student use of ICT is the fact that they require students to think in a meaningful way in order to use the application to demonstrate what they know and I have discussed the way in which e-portfolios can help students to construct knowledge. Similarly, Harrison (2005) notes that while it is difficult to demonstrate a direct relationship between technology and improved attainment, technology can help to improve student engagement.

\subsubsection{Engaged learning- the motivational aspects of ICT}

A key argument around the use of ICT in schools is that it has the ability to promote more engaged learning as students enjoy making use of ICT (Barrett, 2005; Collis \& Moonen, 2006; Harrison, 2005; Robinson et al., 2008; Sing \& Khine, 2006) and that students often reported finding the use of ICT 'fun' (British Educational Communication Technology Agency (Becta), 2007). Some commentators also suggest that this increased engagement through the use of ICT may have the ability to improve student motivation and, as a consequence, improve student learning (Barrett, 2008c; McLeod \& Vasinda, 2009; Papert, 1993).

In discussing the motivational aspects of ICT, Papert (1993) refers to the idea of 'hard fun' and describes the way in which students can find the use of ICT fun because they are challenged to do something that is difficult. It is this use of ICT that Papert argues can help to motivate students to develop their learning through the use of ICT.

The MOSEP Report (Attwell et al., 2007) also suggests that the use of eportfolios has the ability to engage students through the use of different approaches to learning and notes the fact that e-portfolios allow students to make use of different learning contexts and preferences.

However, it is important to note here that the motivational effects of technology may be somewhat overstated and the Becta study (2007) also found 
that although teachers believed that students enjoyed using ICT, in reality, the students' enjoyment depended on the purpose and type of activity that they undertook using the technology.

Many studies on both e-portfolio use and the use of ICT in general have noted that students may become discouraged if they struggle with technical aspects of using the technology (Papert, 1993) and Harrison (2005) found that technical difficulties and systems defects can significantly impact on both the confidence and motivation students. Similarly, several studies have found that it is important for students to understand the purpose of using the technology so that they do not become discouraged and demotivated (British Educational Communication Technology Agency (Becta), 2007; Wade et al., 2005). These are both aspects of ICT use that the teacher has a clear role in supporting.

\subsection{The digital world}

At the beginning of this chapter I noted that there were two key forces driving the development of e-portfolios within education in New Zealand and I have discussed the way in which e-portfolios can be seen to effectively support constructivist approaches to learning. The second force that has seen e-portfolios emerge as a tool to support learning in today's schools is the drive of the current digital environment in which students are required to be able to make effective use of ICT. In Chapter 1 (page 22), I made the point that there were two aspects of e-portfolio technology which provide an advantage over paper portfolio use. The first of these was the pragmatic advantages of ICT and I discussed these in Chapter 1 (page 22). The second aspect of ICT use I will discuss relates more to fundamental views about the use of ICT, its current role in society and how today's students view and use ICT.

\subsubsection{The 'Net Generation' and 'Digital Natives' debate}

A key argument for the increased use of ICT such as e-portfolios in schools is the idea that the use of ICT is a preferred approach to learning for today's students. Over the last decade, a group of writers has promoted the idea that the exposure and access that today's students have to ICT is significantly different from previous generations of learners and that this familiarity with technology 
means that their approach to learning is also significantly different from previous generations. Two significant writers promoting this idea have been Dan Tapscott (1998) who refers to this generation as the 'Net Generation' and Marc Prensky $(2001 ; 2004)$ who describes them as 'Digital Natives'. Both of these terms refer to the generation of students, born after 1980, who are currently in our schools and universities. Both Prensky and Tapscott have argued that these students are a completely different generation of learners and that their key generational differences centred on the way in which they utilise and understand technology. In particular, Prensky and Tapscott argue that these students have spent their whole lives surrounded by ICT and that they are skilled and enthusiastic users. As a result of this, Prensky suggests that today's students “...think and process information fundamentally differently" (2001, p. 1). He argues that today's students are:

- Adept at processing information rapidly

- Prefer multi-tasking and non-linear access to information

- Prefer active to passive learning

- Rely heavily on ICT to access information and carry out social and professional interaction

These ideas about the way in which today's students approach learning and using ICT have been embraced by many commentators and have, consequently, become a generally accepted phenomenon in some areas of popular commentary.

However, an increasing number of researchers have begun to challenge the idea of the 'digital native' (Bennett, Maton, \& Kervir, 2008; Kennedy et al., 2007; Kennedy et al., 2006; Vaidhyanathan, 2008). In particular, Bennett, Maton and Kervin (2008) argue that Prensky's work lacks scrutiny, is under-theorised and lacks an empirical base. They note that Prensky's sources tend to be anecdotal and that his work is often referenced uncritically. Kennedy's work $(2007 ; 2008)$ also suggests that today's students may not be as technologically able as Prensky and Tapscott would have us believe and Gray (2008) argues that students of any age can lack experience and competence in ICT. Further, Vaidhyanathan (2008) rejects the idea of generational differences entirely and argues that there is as much variety in ability in one generation as in any other. 
There is significant evidence that students make much more use of ICT at home than at school and there is clearly a 'digital disconnect' between how students use ICT at home and how they use it at school (Levin, Arafeh, Lenhart, \& Raninie, 2002; Zemsky \& Massy, 2004). However, although studies like that by Levin, Arafeh, Lenhart, \& Raninie's (2002) show that some students make extensive and effective use of the Internet, their study made use of a group of students who characterise themselves as heavy Internet users and consequently the findings cannot be generalised to all students.

Most importantly, questions also remain as to whether students are able to transfer their use of ICT into an educational setting and, indeed, whether students actually want to make more use of ICT at school and Zemsky and Massy (2004) note that while there is evidence that students' make significant use of ICT in their social lives, there is little evidence that this necessarily translates to an interest in making greater use of ICT in an educational setting. They believe that rather than being creators of media, students want to be:

- Connected- principally to each other

- Entertained

- Able to present themselves and their work

Although these are important skills, they do not necessarily translate directly into educational uses of technology and Somekh (2007) notes that while many students make significant use of technology at home, there is often is a mismatch between students' use of technology at school and their use in the home. This mismatch means that there is a loss of learning potential within schools and it is clear that schools need to begin to understand the ways in which technology can facilitate learning and not assume that students already have competence in this area.

Overall, while the idea of the 'digital native' or the 'net gen' are popular within many areas of dialogue, the reality of students' ability with and desire to use ICT is a contested area of research. Therefore, although the focus of this study is on the way in which students make use of a particular e-portfolio application-MyPortfolio-, the data collected also provides insights into how 
students' experience the use of ICT within the classroom and how this aligns with ideas about the 'net generation' and 'digital natives'.

\subsection{ICT policy in New Zealand schools}

The use of ICT within schools is directed by policy developed by the Ministry of Education and from the very earliest days of computers in schools in New Zealand, Government policy has placed an emphasis on constructivist approaches to using ICT. In 1984, the then Department of Education (was later to become the Ministry of Education) established the 'Computers in Education Development Unit' in order to direct the use of ICT in schools. In 1991 a UNESCO report (Asia and the Pacific Programme of Educational Innovation for Development, 1991) noted that unlike other countries, the use of computers for drill and practice in New Zealand schools was relatively low and that features of policy during this time were that student use of ICT was to empower students to take more control of their learning.

In 2002, the Ministry of Education released Digital Horizons - Learning through ICT (2002) a policy document which focussed on e-learning opportunities and introduced a focus on developing 'life-long learning' (see page 25).

This policy focus on the use of ICT to help students become more independent and life-long learners has continued in New Zealand and can be seen in two documents central to current ICT use in schools- Enabling the $21^{\text {st }}$ Century Learner (Ministry of Education, 2006a) and the ICT strategic framework for education (Ministry of Education, 2007).

In 2006, the New Zealand Ministry of Education introduced their ICT strategy Enabling the 21st Century Learner. In this document, the Ministry identifies ICT as a priority for development in schools and argues that “...elearning has the power to transform the way we learn. It is about exploiting technologies in everything we do and using ICT effectively across the curriculum to connect school and communities and to support evidence-based decision making and practices in schools" (Ministry of Education, 2006a, p. 3). 
Enabling the 21st Century Learner (Ministry of Education, 2006a) gives a number of clear directives about the direction of e-learning in New Zealand schools and identifies key outcomes which include:

- On-line learning environments are widely used to support effective learning and teaching

- High quality digital content is easily accessible across the education sector

- There is an increased number of relevant and engaging educational contexts provided though the medium of ICT

As a result of Enabling the 21st Century Learner (Ministry of Education, 2006a) and the development of new technologies, schools in New Zealand have increasingly placed a significant focus on the development of ICT for teaching and learning within the classroom.

The focus on the way that ICT can support constructivist approaches to learning can also be seen in the ICT strategic framework for education (Ministry of Education, 2006b). This document provides a focus for the use of ICT across all sectors of education, from early childhood through to tertiary and aims to “...improve learner achievement in an innovative education sector, fully connected and supported by the smart use of ICT" (Ministry of Education, 2006b, p. 3). A key aspect of this policy in the idea that the use of ICT should be 'learner-centred'- that is should support individual approaches to learning.

\subsubsection{E-portfolios and ICT Policy in New Zealand}

A recent report by Fox et al. (2009) noted the fact that there has been a great increase in interest in e-portfolio use in New Zealand and that it is expected that this increased interest will continue to grow. One of the reasons that eportfolios have become increasingly popular in New Zealand schools in that they are able to play a part in supporting the objectives of these ICT policies. As I have already described in Chapter 1 the use of the e-portfolios places an emphasis on the learner and can allow students to demonstrate their skills and knowledge in an authentic context (see page 22). 
The use of ICT tools such as MyPortfolio is increasingly becoming a way to integrate a number of the Ministry of Education's goals for ICT as these tools enable students to experience digital environments and, at the same time, engage in knowledge construction, communication and reflection. In this way, the key advantages of making use of e-portfolios such as MyPortfolio are clearly aligned with New Zealand ICT policy in education.

\subsubsection{E-portfolios and the New Zealand Curriculum}

While these policies have shaped the way in which ICT is viewed and utilised in New Zealand schools, it is important to note that e-portfolios have the potential to support wider aims within the New Zealand education policy context. Most significantly, the use of e-portfolios can help teachers achieve the goals of the New Zealand Curriculum (Ministry of Education, 2008). This document provides the framework for all teaching in public schools in New Zealand and also encourages strongly constructivist approach towards learning. This approach can be seen right from, the overarching vision of this document which states its goals as being that students in New Zealand will become... "Young people who will be confident, connected, actively involved, lifelong learners" (Ministry of Education, 2007, p. 7)

It is possible that the use of use e-portfolios may also support not only support the ICT goals of the Ministry of Education but also the wider curriculum goals and there are features of e-portfolios in general and MyPortfolio in particular which can aid in this. In particular, the use of e-portfolios such as MyPortfolio can aid in connecting students with other students, teachers, parents and the wider community through communication tools such as messaging and also the ability to share 'views' which can help students to create knowledge.

\subsection{Conclusion}

Within the context of education in New Zealand, the use of e-portfolios has the potential to support many of the policy goals of the Ministry of Education. Both the New Zealand Curriculum (Ministry of Education, 2007) and the key ICT policy, Engaging the $21^{\text {st }}$ Century learner (Ministry of Education, 2006a) place a strong emphasis on constructivist approaches to learning as well as the 
importance of students making effective use of ICT and the use of e-portfolios may provide a vehicle for achieving both of their goals.

It is easy to see, therefore why the use of e-portfolios has become increasingly popular within education in New Zealand. However, it is also important that these tools are not simply used uncritically, but rather that there is a strong empirical as well as theoretical basis to their use (McLeod \& Vasinda, 2009). 


\section{Methodology}

\subsection{Research objectives and questions}

As I have discussed in the previous two chapters, the main aim of this research was to investigate the use of the e-portfolio application MyPortfolio in an English classroom from the perspective of a group of high school students. In particular, I sought to understand:

1. How did students make use of MyPortfolio?

2. What perceptions did the students have of MyPortfolio and how did MyPortfolio help and / or hinder their learning?

3. How did MyPortfolio support constructivist approaches to learning?

This study followed a class of 25 Year 9 students from a decile $8^{15}$ innercity girls' school in New Zealand as they used an e-portfolio application over six weeks in a unit of study for their English course work.

\subsection{Research design}

This research took the form of a mixed-methods descriptive case study with the aim of developing an in-depth understanding of the use of the Web 2.0 tool MyPortfolio from the perceptions and experiences of students. In this study, the class use of MyPortfolio represented the case being examined and the six case study students gave detailed insight and depth into the study of the case.

The case study approach is appropriate in this case as the study is an indepth study of a contemporary phenomenon within its context (Gall, Gall, \& Borg, 2007; Yin, 2003a). Yin (2003a; 2003b) notes that in a complex context such as a school classroom, the richness of the context will require multiple sources of evidence and this use of different data sources can help to understand

\footnotetext{
${ }^{15}$ Decile ratings relate to the way in which schools in New Zealand are funded and reflect the average family background of the families in a particular school. Schools are given a decile rating from 1-10 with 1 being the schools in the most disadvantaged area and 10 being those with the highest proportion of students from high social-economic backgrounds. The lower a school's decile rating, the more funding they receive from the government (Ministry of Education, 2009a).
} 
emerging trends. The use of multiple methods of data collection can help to gain an in-depth understanding of the case being investigated and can also provide 'thick description' of the particular case (Denzin \& Lincoln, 2005). The use of a range of data collection strategies strengthens the design by cross-checking the emerging themes and this can provide an audit trail to support the validity of the research through the triangulation of multiple voices (Scott \& Morrison, 2005). For this reason, this study makes use of a number of different data sources and interconnected methods (Denzin \& Lincoln, 2005) in order to understand the students' experiences with using MyPortfolio.

Burns (1997) notes that the main techniques used when examining a case are observation, interviewing and document analysis and, consequently, the data sources I obtained from the whole class group were:

- An initial survey which allowed me to gauge the students attitudes towards and abilities with ICT

- Observations of the students working in the computer laboratory during the course of the study

- The students' MyPortfolio portfolios

- A final survey which asked the same attitudinal questions as the initial survey and also asked the students about their use of MyPortfolio and their perspectives of MyPortfolio

All of the comments and work from students in the class group have been kept anonymous throughout the reporting of this study.

In addition to the data sources obtained from the whole class group, I also obtained further data from the six case study students in order to gain a more indepth view and understand the students' experiences in more detail. The additional data sources collected from the case study students were:

- More in-depth observations of the individual students throughout the course of the study

- A daily log kept by each of the case study students 
- A final interview where I discussed the students' experiences and asked the students to reflect on comments in their logs and final surveys

The case study students were all given the opportunity to choose their own pseudonym and I have used these when reporting the experiences of the case study students. This allows the reader to follow the experiences of the individual case study students through my reporting of this study.

A case study approach provided the opportunity to explore the use of this Web 2.0 tool, MyPortfolio, in-depth through the experiences of a small group of novice users. Little research has, to date, been published in this topic and my focus has been to develop in-depth descriptions of how individual students perceive and make use of this new technology. The mixed-methods approach was chosen as it suited the descriptive-orientated aims and objectives of this project (Suter, 2006). In particular, the research sought to give an in-depth description of students' use of a new technology within a high school classroom context. This investigation took place in the context of a single curriculum subject (English) and was limited to a single unit of work set by the class teacher. In this case, the students were researching myths and legends from other countries.

One limitation of the case study approach, and indeed exploratory research, is that it can be difficult to develop generalisability from very specific cases (Denscombe, 2006; Stake, 2005). This was not the purpose of my study. However, although it is not generally possible to generalise to populations through the use of case study, Yin (2003b) notes that it is still possible to build on theoretical concepts and use the data collected in this study to expand existing understanding on the use of e-portfolios specifically and Web 2.0 applications more generally. This notion is supported by the authors of the Becta study (2007) who comment that a case study approach allows an understanding of best practice and how this is utilised in a range of contexts. Although this research represents the use of one e-portfolio tool within a specific context, the use of 'thick description' may allow the reader to make their own judgements as to whether the conclusions drawn are applicable in their context (Gall et al., 2007; Stake, 2005). 


\subsubsection{The school}

The school utilised in this study is a state-run ${ }^{16}$, girls' high school of around 1000 students, which has a significant multicultural roll, with the student population comprising of around 57\% New Zealand European ${ }^{17}, 9 \%$ Maori $^{18}, 8 \%$ Samoan, 7\% Indian and the remaining 19\% coming from around 20 countries $^{19}$. In 2007, the school made the development of ICT a strategic goal (The High School, 2007) and consequently, there has been a significant increase in new technology within the school community. The school has also become a foundation school in a high speed fibre-optic cable project undertaken by a group of nearby schools. This network aims to link the six schools involved and make use of shared resources across the network. MyPortfolio is one of the resources being provided across the network and, consequently, this research may by useful to teachers from other schools within the network.

Becoming involved in the project has required the school to significant upgrade its ICT infrastructure but has also provided the school with the opportunity to reconsider its ICT use and development. Over the last two years the school has added an extra computer laboratory with 28 computers and has also added 2 new pods with 12 computers in each room into the school network. Network access is now available in most of the classrooms throughout the school. However, the design and geography of the school mean that wireless access is largely currently limited to staff areas.

\footnotetext{
${ }^{16}$ There are three types of schools in New Zealand: State, State-Integrated and Independent (or Private). These terms refer to whether the schools are funded by the government or other sources and also affects whether they are required to teach the New Zealand Curriculum. A State school is entirely funded by the Government and must teach the New Zealand Curriculum; a StateIntegrated school (often special character schools such as church schools) has all aspects of funding provided by the State except for funding related to buildings and land, which are privately owned by these schools. These schools used to be Private but are now part of the State system and are required to teach the New Zealand curriculum; Independent schools are almost entirely funded by school fees paid by parents, although they do receive some government funding. They own their own buildings and land and are not required to teach the New Zealand Curriculum (Ministry of Education, 2009b).

${ }^{17}$ A term referring to those New Zealanders who are of European (usually English) descent.

${ }^{18}$ Maori are the indigenous people of New Zealand

${ }^{19}$ www.ero.govt.nz
} 


\subsubsection{The setting for the data collection}

The majority of the data collection for this study took place within the computer laboratories at the school. The computer laboratories were set up with 25-28 computers in each room so that each student had individual access to a computer. I will discuss the layout of the computer room in more detail in Chapter 7 (see page 112). The students worked in groups throughout the course of the study, however, they each had their own computer and individual access to MyPortfolio.

\subsubsection{The class}

The students participating in this research undertook the use of the application MyPortfolio as part of a unit of study on myths and legends. They used MyPortfolio to research myths and legends from different countries; collate the material found; record the research process; and then present this material. This research took place over six weeks, during which time the students had both class and homework time to complete the tasks set. During class time (three hours a week), students had individual access to a computer in the school computer laboratory. Students were also able to make use of school computers before school and during lunchtimes.

This particular unit of work is a common unit at Year 9 level and is always taught within an inquiry framework, in that students are required to investigate and present a myth or legend that they have selected and researched themselves. The unit aims to help students develop critical research skills, information processing skills, and presentation skills. Students are also required to reflect on their learning throughout the unit and consider how their approach to undertaking this inquiry benefited their learning.

The students worked in groups in order to complete the assignment work set for this study. This assignment is usually completed as a group task so this was not a change from the teacher's usual programme of work.

However, this unit does not usually have such a significant ICT component and, in this way, this research differed from the approach usually taken. This unit of work was chosen as the ability to use ICT can support the research process. Further, the features of this unit of work, such as the need to communicate with 
group members and the need to record information and development over time are well supported by electronic portfolio applications such as MyPortfolio. The use of MyPortfolio in this study also allowed a blended learning approach in which students made significant use of technology to prepare, research, organise, store and present their work while still participating in face-to-face classes within the computer laboratory.

\subsubsection{Participants}

The main participants in this research were 26 Year $9^{20}$ mixed-ability ${ }^{21}$ students from one form class ${ }^{22}$ and the research was conducted during their English $^{23}$ lessons. All of the students in the class had both a computer at home and access to the Internet at home. A Year 9 class was chosen in order to minimise the impact of the research on student learning as the students did not have external examinations to sit and so the teacher was able to adjust her normal programme of teaching in order for the students to participate in this study.

The teacher was also a participant in this study and maintained her usual role within the class and was responsible for the planning and development of the unit of work, teaching the lessons throughout the unit, managing the lesson and directing students' work within the lesson. The focus of this study was examining the student experience of using MyPortfolio and for this reason I did not purposefully collect data from the class teacher. However, I did, at times, engage her in informal conversations and in order to clarify my perceptions of what was occurring during the study. This helped me to test my interpretation of what was occurring within the class.

\footnotetext{
${ }^{20}$ Year 9 is the first year of high school- the students were 13 and 14 years of age. The high school students in New Zealand do not sit external examinations until Year 11.

${ }^{21}$ The junior students in this school are not streamed for ability within their form classes

${ }^{22}$ A form class is made up of students of the same year level. In this case, the students are 13-14 years of age. The students are taught together for core subjects including English.

${ }^{23}$ English is a compulsory subject at this year level in New Zealand. Units of work within English classes at this school often include literature studies (novels, short stories, plays, poetry, non-fiction); studies of visual media (films, television, plays, static images); written language including fiction and non-fiction; language study (grammar and structure of language); oral language (speeches and plays); and research. Units of study often focus on several areas of study at a time and the focus of unit of work completed during this study was both research (using a variety of sources to find information), written language (reading and analysing myths and legends) as well as presentation skills used to present the work completed.
} 
A further participant in this study was the trainer ${ }^{24}$ from Flexible Learningthe organisation with the contract to introduce MyPortfolio to schools- who introduced MyPortfolio to the students. The outside trainer was used as he was an expert in the use of MyPortfolio and this provided the opportunity for the students to have a thorough introduction to the use of MyPortfolio. This introduction was the first time that students in this school had made use of MyPortfolio. Neither the teacher nor the students had met the trainer before he came to conduct the initial session.

The trainer introduced the application to the students in the computer laboratory and gave an overview of both MyPortfolio and e-portfolios in general. This session took place during a period of class time and took one hour. Although the trainer was a participant in that he introduced MyPortfolio to the students, he was not with the students after this initial lesson and I did not collect any data from him.

\subsubsection{My role: the participant-observer}

My role in this study was that of participant-observer. For the most part, I simply observed the students and recorded how they made use of MyPortfolio during the course of the study. I also conducted the final interviews after the study had concluded. However, I did interact with the students and, at times, during the lessons in the computer laboratory I also asked the students questions about what they were doing and asked them to show me particular features of MyPortfolio so that I could gauge whether they could make use of the functions within MyPortfolio. I observed all lessons that students undertook in the computer laboratory, including the initial lesson with the trainer.

I also participated by providing technical assistance to students in order to help them learn to use MyPortfolio. In this way, I was an extra resource in the room for the teacher. I was not involved in managing student behaviour or setting tasks for the students to complete- this was the role of the class teacher- but I had

\footnotetext{
${ }^{24}$ The trainer was an employee of Flexible Learning- www.flexible.co.nz-, the organisation responsible running the 2008 trial of MyPortfolio and supporting school use of the application. He was very familiar in using MyPortfolio and has written some of the documentation, including the student user manual.
} 
expertise in using MyPortfolio that the class teacher did not have and so I was able to be an extra resource for her during the study.

I also had a role in helping the class teacher understand how to make use of MyPortfolio within the unit of work that she had planned. Prior to the beginning of the study, I had a purposeful conversation with the class teacher in order to ensure that the use of MyPortfolio would fit within the unit of work that she had planned and understand her objectives for the unit. As the teacher had not made use of MyPortfolio prior to this study, I also showed her how to use MyPortfolio and helped her to understand how she could use MyPortfolio as part of her unit of work. In this way, I participated in the planning of the unit but, once again, my input was limited to the technical use of MyPortfolio and decisions about how to teach the unit were the teacher's responsibility.

It is inevitable that my presence in the classroom affected the students' behaviour during the course of this study, however, as far as possible, I attempted to retain the role of observer and have tried to let the students' work and responses speak for itself.

\subsubsection{Negotiating entry}

The school involved is the school where I am employed and I initially met with the principal in order to discuss my research with her and negotiate entry into the school. Once I had met with the principal, I provided her with a written summary of the project and she then gave written permission for the school to be part of this research. I also provided the Board of Trustees ${ }^{25}$ with a written description of the study and received consent from the Board (see appendix 10). Once I had negotiated entry into the school, I spoke to the teachers in the English Department and outlined the research to them. The class teacher involved volunteered to be a part of this study and also gave informed written consent to participate (see appendix 10).

\footnotetext{
${ }^{25}$ The Board of Trustees is responsible for the overall running of the school. The Board is the legal employer of staff (including the principal) and has legal oversight over all areas of the school, including property, finances, health and safety and curriculum
} 


\subsubsection{Time line of the study}

\begin{tabular}{|c|c|}
\hline \multirow[t]{5}{*}{$\begin{array}{l}\text { Prior to the start of } \\
\text { the study }\end{array}$} & $\begin{array}{l}\text { I negotiated entry into the school through contact with the } \\
\text { principal, Board of Trustees and the class teacher. }\end{array}$ \\
\hline & $\begin{array}{l}\text { I conducted a purposeful conversation with class teacher in order } \\
\text { to understand the teacher's objectives for the unit of work } \\
\text { completed during the study }\end{array}$ \\
\hline & $\begin{array}{l}\text { I spoke to the class in order to introduce the study to them and } \\
\text { gain consent for their participation. Students were also given } \\
\text { written information about the study and had the opportunity to } \\
\text { ask questions }\end{array}$ \\
\hline & $\begin{array}{l}\text { The students completed an initial survey in order to establish } \\
\text { baseline responses }\end{array}$ \\
\hline & $\begin{array}{l}\text { I selected the six case study students from the initial survey data } \\
\text { and sought consent for the collection of additional data from } \\
\text { these students }\end{array}$ \\
\hline Week 1 Lesson 1 & $\begin{array}{l}\text { An outside trainer introduced the students to MyPortfolio and } \\
\text { showed them the aspects of MyPortfolio that they would be using } \\
\text { throughout the study }\end{array}$ \\
\hline Lesson 2 & $\begin{array}{l}\text { The class teacher revised key aspects of MyPortfolio and } \\
\text { introduced the unit of work to the students. The students were } \\
\text { given the opportunity to explore MyPortfolio }\end{array}$ \\
\hline Lesson 3 & The students began work on the unit of work. \\
\hline Week 2 Lesson 4-13 & $\begin{array}{l}\text { The students worked on the assignment and made use of } \\
\text { MyPortfolio to complete the tasks set. During this time I } \\
\text { observed the students and kept screen shots of the work that they } \\
\text { completed. The case study students also kept a daily log during } \\
\text { this time. }\end{array}$ \\
\hline Week 5 Lesson 14-16 & $\begin{array}{l}\text { The students made use of various ICTs including MyPortfolio, } \\
\text { video cameras and PowerPoint in order to complete their final } \\
\text { presentations }\end{array}$ \\
\hline Week 6 Lesson 17-18 & $\begin{array}{l}\text { The students presented their final presentations. They were not } \\
\text { work on MyPortfolio during this week but some groups did make } \\
\text { use of MyPortfolio for their presentations. }\end{array}$ \\
\hline Week 6 Lesson 19 & $\begin{array}{l}\text { The students completed the final survey and I also conducted the } \\
\text { final interviews with the case study students during this week. }\end{array}$ \\
\hline
\end{tabular}




\subsubsection{Data collected from students}

This research used a mixed-methods approach including surveys, interviews, artefact analysis, journals and observations in order to attempt to understand the students' perspective on using MyPortfolio.

\begin{tabular}{|c|c|c|c|c|c|c|}
\hline & $\begin{array}{c}\text { Initial } \\
\text { survey }\end{array}$ & Class observations & $\begin{array}{c}\text { Students' } \\
\text { MyPortfolio use } \\
\text { and artefacts }\end{array}$ & $\begin{array}{c}\text { Students' } \\
\text { logs }\end{array}$ & Final survey & Interviews \\
\hline $\begin{array}{c}\text { Case study } \\
\text { students }\end{array}$ & $\sqrt{ }$ & $\sqrt{ }$ & $\sqrt{ }$ & $\sqrt{ }$ & $\sqrt{ }$ & $\sqrt{ }$ \\
\hline Class group & $\sqrt{ }$ & $\sqrt{ }$ & $\sqrt{ }$ & $\mathrm{X}$ & $\sqrt{ }$ & $\mathrm{X}$ \\
\hline
\end{tabular}

Figure 2 Summary of data sources

\subsubsection{Quantitative data}

The students completed two surveys during the course of the study- an initial survey ${ }^{26}$ conducted at the beginning of the study and a final survey at the end of the study ${ }^{27}$. Both of the surveys were conducted using Survey Monkey ${ }^{28}$.

\subsection{Initial survey}

The purpose of the initial survey was to establish a baseline understanding of the students' skills with and attitudes towards using ICT and it also provided data for the selection of the case study group of students ${ }^{29}$. This survey utilised Likert scale (1-5) responses and was based on the survey developed by HartnellYoung for the REFLECT Initiative (Barrett, 2008c) and the Becta study (2007) and was selected as these projects attempted to understand student perspectives on ICT. The students completed the survey during class time and utilised the online survey application tool Survey Monkey. Each student had their own computer and the survey took 10-15 minutes to complete. Of the class of 26 students, 23 completed the initial survey. Three students were absent from school during the initial period of this study and so did not complete this survey. However, they later completed the first part of the survey in order to ascertain their access to computers at home and school. I did not ask them about their attitudes towards technology as they had already begun using MyPortfolio.

\footnotetext{
${ }^{26}$ See appendix 4

${ }^{27}$ See appendix 5

${ }^{28}$ www.surveymonkey.com

${ }^{29}$ The selection of the case study students is discussed on page $\mathrm{xx}$
} 
The data from this survey enabled me to make comparisons between the students' attitudes towards ICT before and after making use of MyPortfolio.

\subsection{Final Survey}

The final survey was in two parts. The first part was once again based on surveys developed by Hartnell-Young for Barrett's REFLECT e-portfolio study (Barrett, 2008b) and had many of the same Likert Scale (1-5) questions as the initial survey so that I could make comparisons between the students' attitudes towards ICT at the beginning and the end of the study.

The second part of the survey was designed by me in order to gain specific insight into how the students used MyPortfolio and what their perceptions of it were. The second part of the survey made use of a mixture of Likert Scale (1-5) questions and open-ended questions.

The final survey was also conducted in the computer laboratory and took the students 25-25 minutes to complete. Once again, the students had access to an individual computer. Of the 26 students in the class, 25 completed the final survey. The student who did not complete the final survey was absent from school for the final period of this study.

The second survey particularly provided me with data for answering my first research question: What perceptions did the students have of MyPortfolio?

The small size of the sample group in this study $(\mathrm{n}=25)$ means that it is difficult to undertake statistical analysis of the data I collected in these surveys (Denscombe, 2006) however, the use of the survey data did serve as a useful base from which to identify themes that emerged in the research. In this way, the use of the surveys was one of 'discovery' (Glaser \& Strauss, 1967).

\subsection{Selection of the case study students}

Based on the results of the initial survey, six students were purposefully selected for in-depth study. This number of students was been chosen in order to keep data collection manageable and avoid information overload so that an indepth understanding of student use of MyPortfolio could be reached. The students in the case study were selected in order to represent a range of computer 
skills and attitudes. In particular, I chose two students who were high users of computers, two who were medium users and two who were low users. Within this spread I also selected for a range of attitudes towards ICT, noting how positive the students were about their ability to use ICT and their attitude towards the benefits of ICT. Using these criteria, I invited six students (Nancy, Mary, Hannah, Ashleigh, Robina and YoYo) to participate in the case study group. All six students initially selected agreed to be involved in the case study group and provide additional data for the study.

The charts below show some of the views that each of the case study students had about the use of computers and the way in which I selected the students for a range of attitudes towards ICT.

\begin{tabular}{|c|c|c|c|c|}
\hline \multirow[b]{2}{*}{ Strongly agree } & \multicolumn{3}{|c|}{ I enjoy doing things on a computer } & \\
\hline & Agree & Not sure & Disagree & Strongly disagree \\
\hline \multirow{2}{*}{$\begin{array}{l}\text { Mary } \\
\text { YoYo } \\
\text { Nancy }\end{array}$} & $\begin{array}{l}\text { Ashleigh } \\
\text { Robina }\end{array}$ & Hannah & & \\
\hline & \multicolumn{3}{|c|}{ I would work harder if I could use computers more often } & \\
\hline \multirow[t]{2}{*}{ Strongly agree } & Agree & Not sure & Disagree & Strongly disagree \\
\hline & $\begin{array}{c}\text { Ashleigh } \\
\text { Mary } \\
\text { Hannah } \\
\text { Yoyo } \\
\text { Nancy }\end{array}$ & & Robina & \\
\hline
\end{tabular}



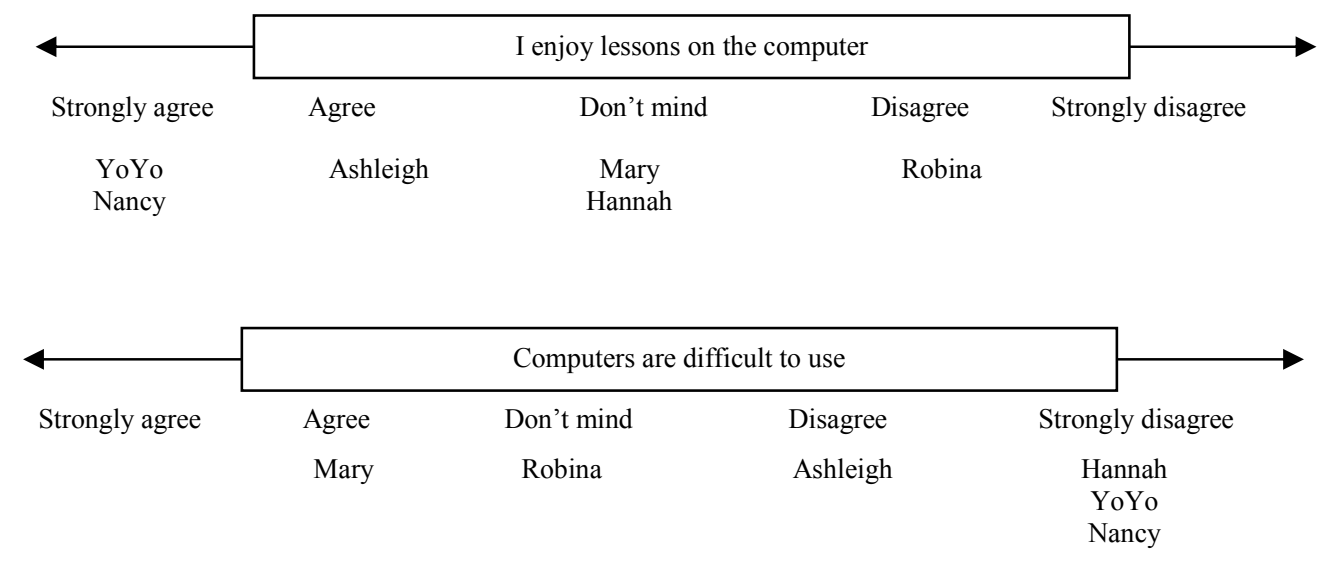

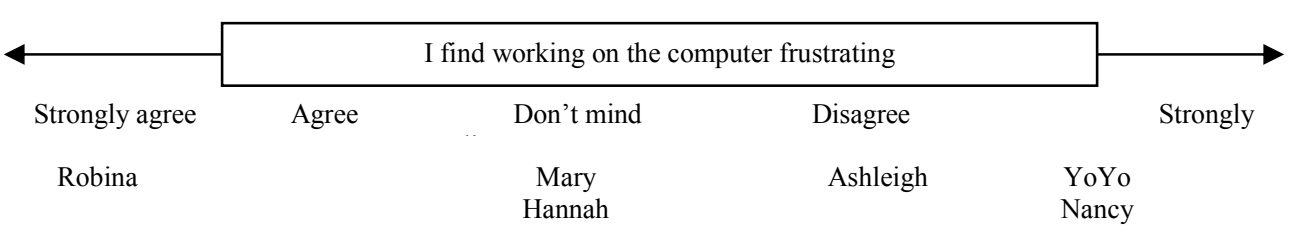

Figure 3 Summary of case study students' initial attitudes ${ }^{30}$

\subsubsection{Qualitative data}

This study made use of a number of different qualitative data sources including:

- Observations of the students making use of MyPortfolio

- Students' daily logs

- Students' MyPortfolio work

- Final interviews with case study students

\subsection{Observations}

Throughout all of the sessions in the computer laboratory, including the initial lesson with the trainer (15 lessons), I made observations of the six sample students. In making the observations, I attempted to observe each of the students at least once during each lesson. During this time, I made used an observation schedule (see appendix 7 ) to make notes about what applications the students were making use of; what parts of MyPortfolio the students made use of; how the

\footnotetext{
${ }^{30}$ A full summary of the questions and responses used to select the case study students can be seen in appendix 3).
} 
students experienced using MyPortfolio and how they went about completing the work set. As far as possible, I tried to minimise the impact of my observations on the students by not interacting with them while I was observing and ensuring that I was far enough away to not be a distraction to them. However, at times, I did ask questions of the students in order to clarify my understanding of what they were doing at any particular time.

While making these observations, I particularly focused on identifying issues that related to my three research questions and I have used data from my observations in order to discuss all three of my research questions.

\subsection{Case study students' daily logs}

The case study students also kept a journal record of the process that they undertook and these also became part of my data for this study. The students were given a booklet with a reflection template designed by me to fill out each period (see appendix 8).

The purpose of these journals was to keep a record of the students' experiences and progress as the study progressed and the data from these logs helped me to develop my understanding of how the students made use of MyPortfolio and how they perceived their use of the application (research questions 1 and 2).

\subsection{Students' MyPortfolio work}

I also analysed the students' MyPortfolio artefacts in order to provide further data for this study and I was able to gather evidence of the work that the students completed and the way that they made use of MyPortfolio through the collection of data from the students MyPortfolio work. I collected the following data from the following aspects of the students' MyPortfolio work:

- Evidence of work completed from the final view- I was able to view each of the students' views and could examine the work that they had completed with MyPortfolio and the artefacts that they included on their view 
- The students' profiles- I viewed the information that students included about themselves in their profiles

- An information that the students included as a blog

- The students' file- I recorded how many files the students uploaded into MyPortfolio; when they uploaded them; and whether they used all of their files in their final view

- The messages that the students sent and received throughout the course of the study.

I was also able to note whether the students had made any use of the features of MyPortfolio that were not involved in this study such as 'My Goals', 'My Skills' and 'My Resumes'.

I made use of the work created by both the case study and the survey group students as data for this study, however, I kept a much more in-depth record of the work completed by the case study students and after every lesson I captured screen shots of the case study students' portfolios and saved these into an MSWord document. In this way, I was able to record how the case study students' work developed over time. At the end of the study I was able to view all of the students' work within MyPortfolio and I also made use of the survey group students' final views, messages, files and profiles as sources of data.

The students all gave consent for me to access their work (see appendix 10) and the fact that I was a 'friend' ${ }^{31}$ on MyPortfolio meant that I was able to observe the students' work as it developed. As well as this, MyPortfolio work is created electronically and available via the Internet and this meant that I was able to continue to refer to the students' work after the study had concluded.

I made particular use of the students' MyPortfolio work in order to try and understand my third research question: How did MyPortfolio support constructivist approaches to learning?

\subsection{Final interviews with case study students}

\footnotetext{
${ }^{31}$ A making someone a 'friend' in MyPortfolio means that they are able to see a users profile and selected views.
} 
Finally, I interviewed the six case study students individually at the conclusion of the unit, using a semi-structured interview guide (see appendix 6) in order to develop a fuller understanding of the students' experiences in using MyPortfolio and also test the other data I collected as this process of listening to the students' explanation can help to increase the reliability of quantitative data (Kincheloe, 2003). The use of the semi-structured interview approach gave me the opportunity to respond to the particular experiences of the students in this study (Merriam, 1998) and thus, develop an rich representation of their experiences.

The interviews were conducted during school time and lasted for 15-20 minutes. The interviews were all taped and later transcribed for analysis. The interviews were held in an office in the school library.

The interview guide I used was in two parts. Firstly, I asked the students predetermined questions about how they experienced using MyPortfolio (see appendix 6). This allowed me to compare and contrast the students' responses in order to identify similarities and differences (Denscombe, 2006). I then asked each student questions related to their individual MyPortfolio work, their responses in the final survey and their daily log. I also gave students the opportunity to discuss any other issues at the end of the interview.

The semi-structured nature of these interviews allowed for emergent issues to be discussed and also allowed the students to elaborate on areas of interest (Denscombe, 2006) and discuss issues from their perspective (Downs \& Moller, 1999). The data from these interviews was used to answer all three of my research questions and enabled me to gain a more in-depth understanding of the information that I had gathered from the other data sources.

\subsubsection{Storage of data}

All of the data collected for this study was stored securely. The electronic MyPortfolio data was password-protected within MyPortfolio and could only be accessed by the students, the class teacher or myself. Similarly, the data collected via Survey Monkey was password-protected within the application and could only be accessed by me. 
All of the data that was held within documents, such as transcripts of the interviews, Excel spreadsheets of the survey data, and screen dumps of the case study students' portfolios and profiles ware password-protected on my computer.

The hard copies of the electronic data and the written data collected such as the students' logs and my observations were kept in a locked filing cabinet when not in use.

\subsection{Data Analysis}

\subsubsection{Qualitative analysis}

Once collected, I analysed the written observations, student artefacts and student journal responses using open coding (Strauss \& Corbin, 1990) in order to identify ideas that related to the key questions and discover insights from this particular case (Creswell, Hanson, Clark Plano, \& Morales, 2007). I also analysed the student journal responses in the same way in order to understand how students made use of the technology; what aspects of MyPortfolio students found particularly helpful or unhelpful; and what thought processes led them to undertake work in the way that they did. In particular, I looked for examples of students making use of functions within MyPortfolio and explored whether students were creating their own understanding of the myths and legends investigated through the use of MyPortfolio as a tool to support constructivist learning (my third research question).

I recorded each of the student interviews using a digital voice recorder and then transcribed each of these so that I could analyse them. When analysing the transcripts, I made use of both open coding (Strauss \& Corbin, 1990) and annotation (Denscombe, 2006). Once I had coded the interviews, I reviewed them for patterns, similarities and differences that emerged (Miles \& Huberman, 1994).

\subsubsection{Quantitative analysis}

The analysis of the quantitative data occurred using Excel. I undertook the analysis of the initial survey immediately after the students completed the survey so that I could make use of this descriptive data to select the six case study 
students $^{32}$. The initial survey was made up entirely of Likert scale (1-5) questions and for this reason, I made use of numerical tables in order to analyse the data.

The final survey was made up of a combination of Likert scale (1-5) questions and open-ended questions. I once again made use of numerical tables in order to examine the Likert scale questions. The first part of the final survey contained the same questions as the initial survey and in order to analyse whether there had been any changes in students' attitudes towards ICT, I created comparative numerical tables using the data from the two surveys.

I analysed the second part of the survey in two ways: The Likert scale questions were organised into numerical tables, as with the first part of the survey and the initial survey. From these tables, I was able to conduct frequency analysis (Denscombe, 2006) in order to examine the students' perspectives on using MyPortfolio.

In order to make sense of the open-ended questions in the final survey, I made use of open coding (Strauss \& Corbin, 1990) and developed categories of emergent themes relating the students' use of MyPortfolio. This included analysis of what functions the students made use of and how they used MyPortfolio to support their learning.

The response rates to quantitative questions are presented numerically within this research and I have also given a related percentage. However, the size of the same group and the use of open-ended questions means that the responses do not have statistically validity (Denscombe, 2006). However, the representation of the numerical values and their related percentages do help to build the 'thick description' of the perspectives of the students represented in this study.

The use of the different data sources allowed me to triangulate the students' voices so that I could test the information that I had gathered. I also found that I needed to return to each piece of data several times throughout the analysis in order to refine my understanding of the data. This also helped me to check the validity of the conclusions I was drawing (Denscombe, 2006).

\footnotetext{
${ }^{32}$ See page 58 for a description of this selection process
} 


\subsubsection{Validity Checking}

Validity checking in this research occurred in several ways. Firstly, the combination of data collection methods (survey results, journal responses, eportfolio artefacts interviews and classroom observations) allowed for a range of ideas to emerge and meant that triangulation between the sources could occur (Denzin \& Lincoln, 2005).

I also used the interviews as an opportunity to check the validity of data with students through member-checking and this proved to be particularly valuable when dealing with the data from case study student, Nancy, who had a completely different opinion about some aspects of MyPortfolio in the interview than in the survey (see Chapter 7). In this way, the use of the variety of data collection methods also allowed me to address some of the ambiguity that occurred within the data (Denscombe, 2006). The fact that the interviews were semi-structured and tailored around the responses given by the individual case study students allowed me to gain further detail about their responses and clarify that I had understood their responses.

Finally, I also made use of the class teacher in order to check the validity of my observations during the study. While I did not collect data from her, I did use her as a source of triangulation and member-checking.

\subsection{Reflexivity and power: Considerations of my role as researcher}

This research presented some challenges in terms of reflexivity in that I was conducting research within my workplace. The teacher and I, as researcher, had discrete roles. The role of managing the class remained with the classroom teacher while my role was as observer and support for answering technical questions if needed. It was important for me to ensure that control of the class remained with the classroom teacher and that, as much as possible, the class continued with its ordinary routines. I was also completely removed from the assessment and evaluation of the students' assignment work.

However, is common practice in professional development for teachers to work collaboratively or as critical friends observing and discussing each others' 
teaching practices. Therefore the students would already have encountered such situations and did not find this unusual.

Further, although I am a teacher at this school, I have been on study leave for the year and therefore have some distance from the students. The use of Year 9 students in their first year in this school for this research also meant that the students did not know me from previous years. These factors meant that I was able to establish distance from the students in order to undertake the research.

The classroom teacher is a colleague who has an interest in educational technologies and is also a member of the school ICT committee. Consequently, it was important for me to ensure that she was an active part of the planning and instigation of this research so that she was able to give constructive feedback and offer insights as the research progressed.

During the consent process, I gave the students, the teacher and the school the opportunity to indicate whether they would like to receive a summary of the finding of this research and it is my intention to provide this to those who indicated that they were interested once this research is complete.

\subsection{Limitations of this study}

This study is subject to a number of limitations. Firstly, it involved a relatively small number of students from one high school. Thus, the generalisability of this study is limited to those who find similarities to their own setting .

Secondly, and perhaps most significantly, the true effect of portfolio use can only really be seen over an extended period of time (Barrett, 2008b). However, although this study was conducted over a relatively short time period, it does allow some insights into how a group of novice users learnt to make use of educational Web 2.0 technologies such as e-portfolios.

\subsection{Ethical considerations}

All of the students in this class gave informed consent to participate in the research. Before study began, the teacher spoke to the class and introduced the study to them. After this, I also spoke to the class and described what would 
happen during the study, what it would require of the students and how I would make use of their work. I also identified the fact that I would be selecting six students to study in-depth and reinforced the fact that all aspects of the study were voluntary, including participation as a case study student. I then gave the students a written summary of the study and asked them to take it home to talk about with their parents and return signed, if they wished to participate in the study. The students' parents were also informed about the study via a letter home.

This study was approved by the Victoria University Ethics Committee and the key ethical considerations covered in this approval were that the students gave informed consent in order to be involved in the study; the students were informed that they had the right to withdraw from the study if they no longer wished to participate; the data from the study was kept secure; and the confidentiality of the students was maintained through the use of pseudonyms for the case study students and anonymised data for the whole class group. 


\section{How did the students make use of MyPortfolio?}

In Chapters and 1 and 2, I discussed some of the suggestions about how eportfolios may be used by students, however, as I have noted in these chapters, it is essential to understand how they actually are utilised. Further, as each different e-portfolio application has a different design, it is important to understand how the specific application may be used. As MyPortfolio is a relatively new application, this is particularly the case. For the students in this study, MyPortfolio was an entirely new application, as was the experience of making use of an e-portfolio application and this study allowed me insight into the way that a group of novice users might make use of MyPortfolio.

In this chapter, then, I will discuss the way in which the students in this study actually made use of MyPortfolio and the themes that emerged from their use. In order to understand how the students made use of MyPortfolio, I primarily made use of my observations of the students while using MyPortfolio; the students' responses in the final survey ${ }^{33}$; and the students' MyPortfolio work.

In order to understand how MyPortfolio was utilised by the students, it is important to first understand how MyPortfolio is structured and what the key aspects of the application are. For this reason, this chapter begins with a description of the structure of the application and definition of each of the features utilised. I will then discuss each of the aspects of MyPortfolio that the students made use of and describe the patterns that emerged from their use. Finally, I will highlight the themes that emerged from my data analysis- the effect of difficulties in learning to use a new technology; the importance of 'justin-time' learning; the students' attitudes towards the best location for MyPortfolio use; and the use of MyPortfolio as a tool for organisation and communication.

\footnotetext{
${ }^{33}$ The data collected from the final survey can be found in Appendix 1 on page 195. The final survey questions can be found in Appendix 5 on page 210.
} 


\subsubsection{Introduction to the students' use of MyPortfolio}

The students in this study were all unfamiliar with MyPortfolio at the beginning of the study. They were introduced to the application as a whole class by an outside trainer and were given individual access to computers in a computer laboratory and individual logins to MyPortfolio. During the first lesson in the computer laboratory, the trainer showed the students how to find and use the aspects of MyPortfolio that they would need to use in order to complete the assignment set by the class teacher as part of this study. These were: the views; the files; the groups; and the messaging sections ${ }^{34}$. It is these sections of MyPortfolio that I will report on throughout my discussion.

The trainer also demonstrated the profile section and showed the students how to upload and download documents from MyPortfolio and how to store their files so that they could add these to their views. The assignment set by the teacher required the students to create a view and add artefacts into it so that the teacher and students could see the development of their work over time.

The trainer did not show the students the 'My Resume', 'My Goals' or 'My Skills' sections as these were not required in order for students to complete the assignment work set during this study ${ }^{35}$

During the lesson with the trainer, the students were also given the opportunity to independently explore MyPortfolio and learn to navigate throughout the application.

\subsubsection{The structure of MyPortfolio}

There are four main tabs for student use within MyPortfolio- 'Profile', 'My Profile', 'Groups' and 'Settings'- and within each of these tabs were further tabs which allowed the students to complete different tasks such as set up groups and views, message, set up and change their view, upload, download and manage files, and manage friends

\footnotetext{
${ }^{34}$ A chart giving an overview of the layout of the different sections of MyPortfolio can be seen on page 71 .

${ }^{35}$ As the students in this study did not make use of these sections of MyPortfolio, I have not discussed them in this chapter. However, I have given a description of each section in Appendix 9 .
} 


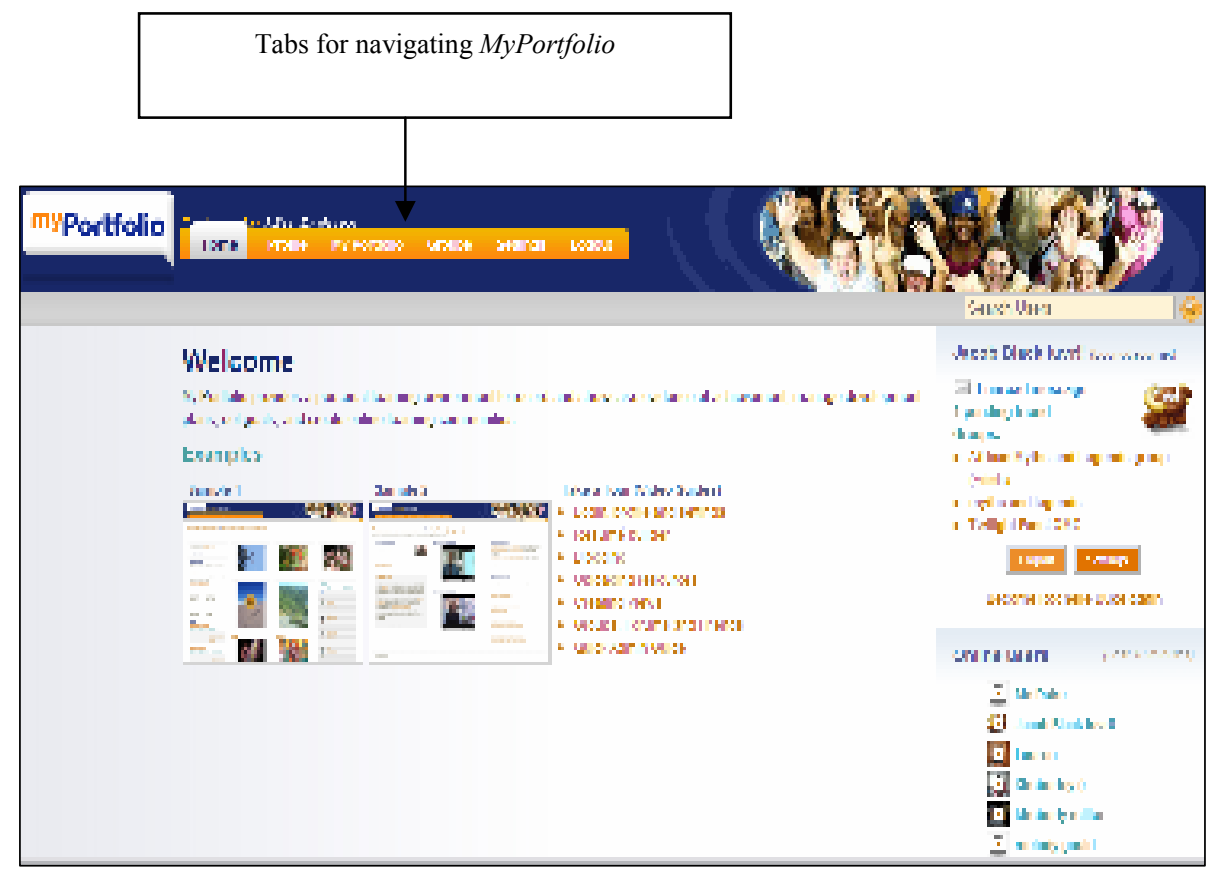

Figure 4 The student view of MyPortfolio- home page 


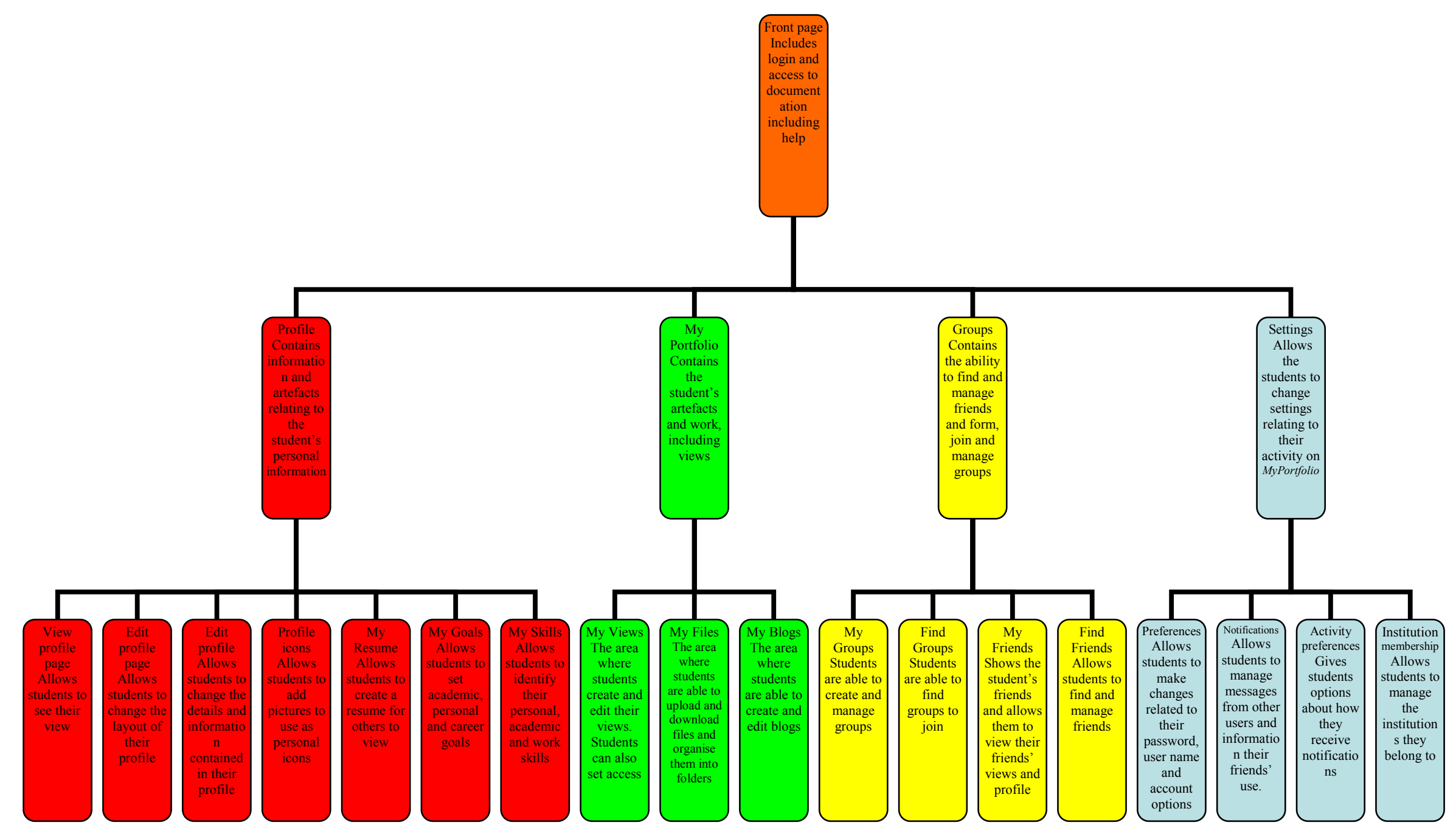

Figure 5 The structure of MyPortfolio 


\subsubsection{Views}

A 'view' within MyPortfolio is a collection of artefacts ${ }^{36}$ that students add to the page for a particular purpose and is the main area that students can use present artefacts to others. Within MyPortfolio, students can create multiple views and arrange their artefacts according to the audience that they wish to present the information to. The views can be created for a variety of purposes and in the case of this study, were used to display the work that the students completed for the assignment they had been set. The types of content that can be added to a view include blogs, RSS feeds, files, web content pages, videos, files for download and profile details (Flexible Learning, 2008). In order to add artefacts into MyPortfolio, students need to 'drag and drop' the appropriate tool into their view. The tools available for this relate to the students' use of blogs; external feeds; files, document and video; text; and the student's personal information including from the profile, resume and goals and skills. The views are central to the students' use of MyPortfolio as it is only through creation of a view that the students can allow others to see their artefacts and each of the students in this study created at least one view so that the teacher and other students could see the work that they had completed.

The students have control over both the design and access of the views and they are able to create different views for different purposes. Once an artefact has been uploaded into 'My Files', that artefact can be used in multiple views.

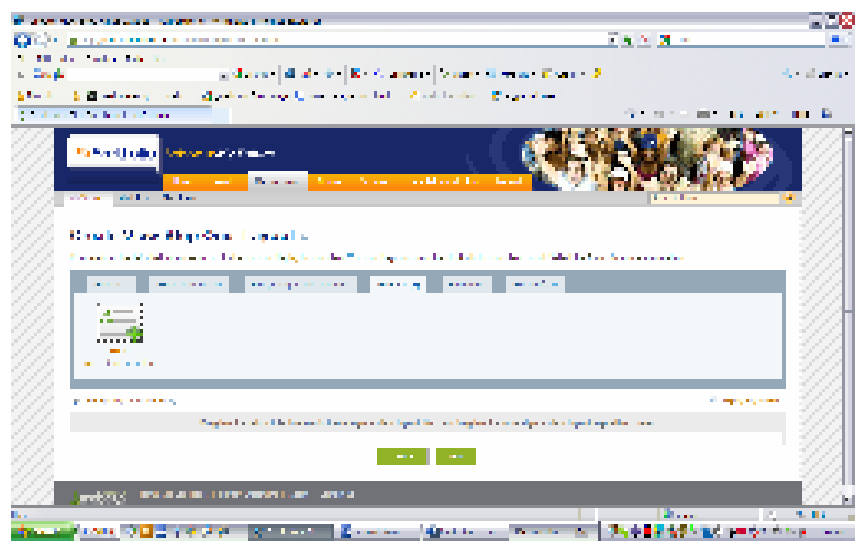

Figure 6 'Drag and drop' options for setting up a view 3/11/09

In order to track the way that the students made use of MyPortfolio, I took a screen shot of each of the case study student's views at the end of each lesson. In this

\footnotetext{
${ }^{36}$ An artefact is any object that the students create and can include documents, images, video and text.
} 
way, I was able to track the progress that each student made throughout the course of the study.

\subsection{How students used the views}

The main reason the students in this study made use of the views was to present the work that they completed for the assignment set by the class teacher. All of the students completed a view and they all placed at least one file on the view.

The way that the students made use of the views varied between students and some students made a number of changes or additions to their view:

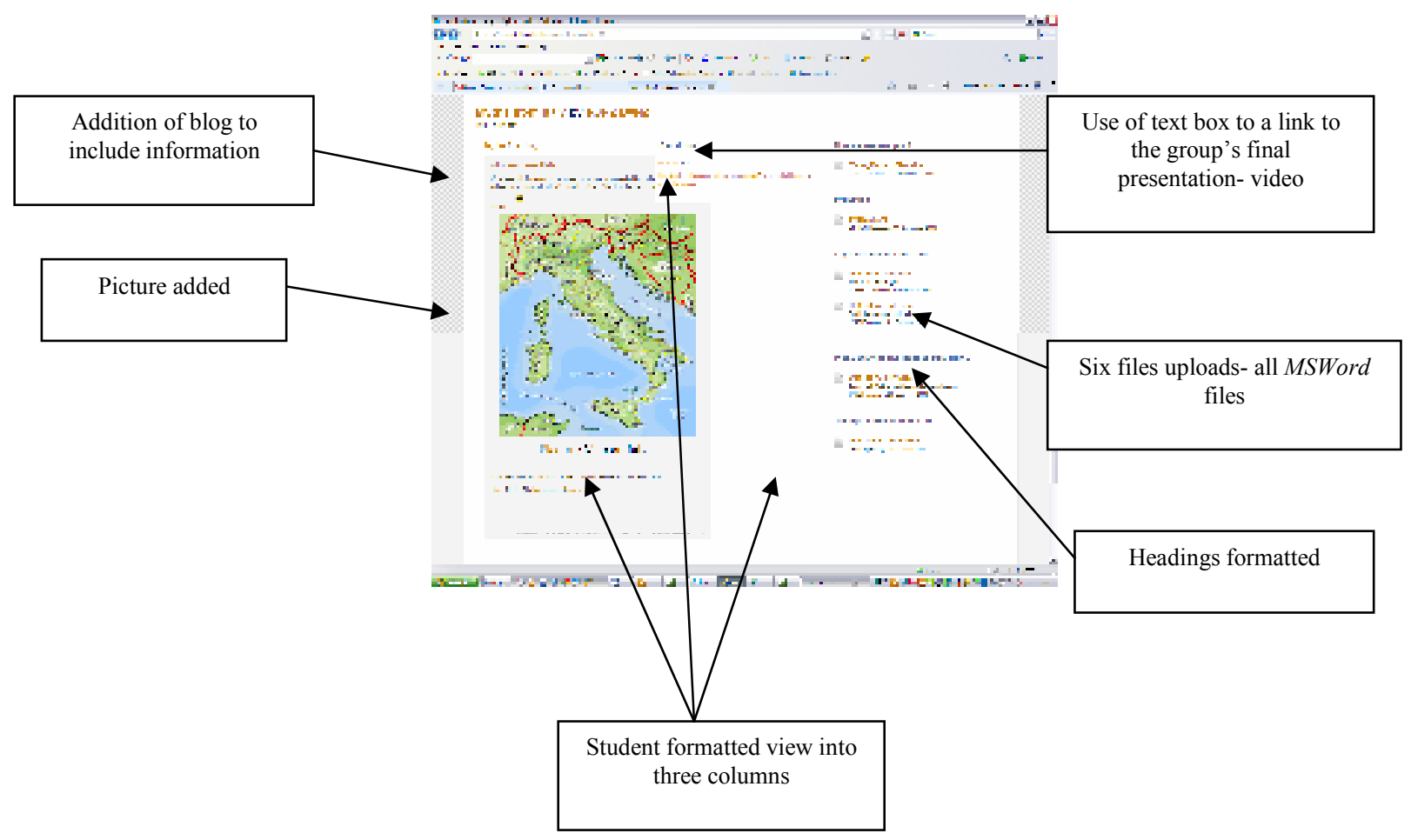

Figure 7 A completed final view (15/11/08) with key features of the student's use highlighted.

However, other students did not make nearly as many changes to their view: 


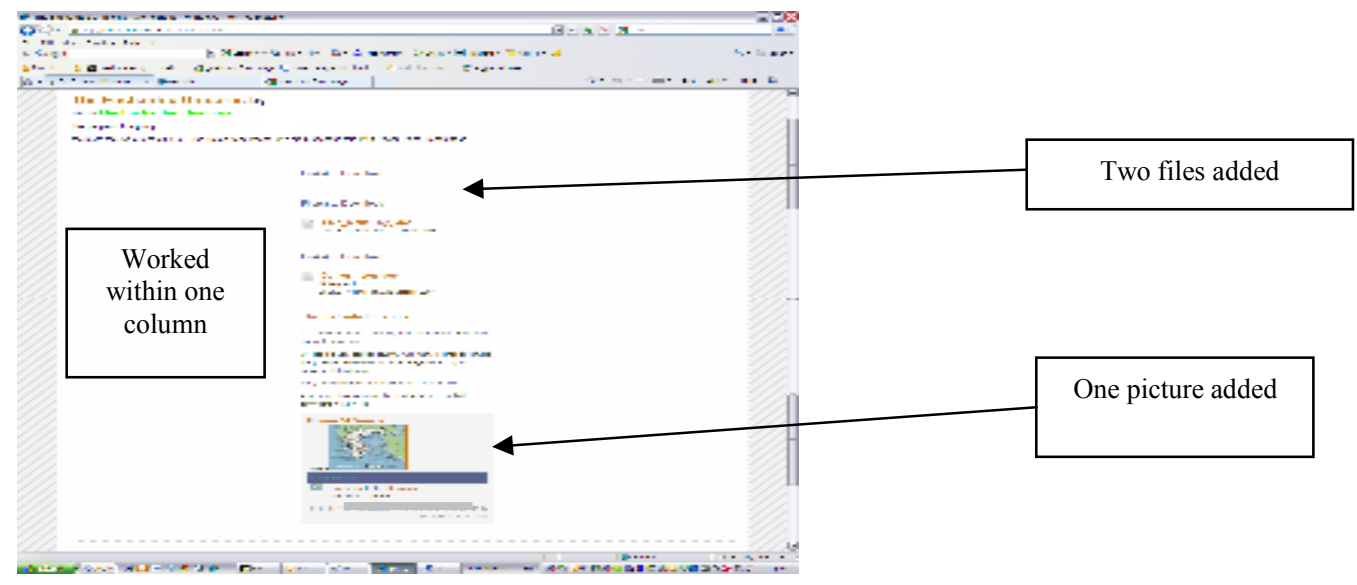

Figure 8 An example of a view (28/11/08) in which the student made few changes

Although the students were required to make use of the view in order to complete the tasks set, it emerged that it was an aspect of MyPortfolio that the students seemed motivated to use and when asked what the best part of MyPortfolio was in the final survey, seven of the 25 students $(28 \%)$ made comments that related to their view of the views:

I liked going on the computer and adding new things to my views (Final Survey) ${ }^{37}$

I will discuss the students' use of the views in greater detail in Chapter 5, where I discuss how the students made use of MyPortfolio and also in Chapter 7 when I give an in-depth discussion of the use and experiences of the six case study students.

\subsubsection{My Files}

'My Files' is the section within MyPortfolio that stores a student's artefacts before they are added to their view. The students are able to upload a variety of types of files including documents, presentations, videos and pictures. Once a student has uploaded files into 'My Files', they are able to add them to a view in order to make the files accessible to other people. Once uploaded into 'My Files' the students are also able to organise their files into folders and use the files as artefacts in their views. The students in this study predominately made use of MSWord files but some also uploaded PowerPoint files and multi-media files such as images and videos.

\footnotetext{
${ }^{37}$ I have maintained the students' spelling, grammar and formatting in all of the quotations taken written data sources (students' logs, surveys and students' work). This includes all spelling, punctuation and syntactical errors.
} 
By viewing the students' 'My Files', I was able to track when students first uploaded artefacts into MyPortfolio, how many they uploaded through the course of the study, what types of files the students uploaded and how many of these artefacts the used in their final view. This information helped me to monitor how the students' skills in using MyPortfolio developed and how they made use of artefacts within MyPortfolio.

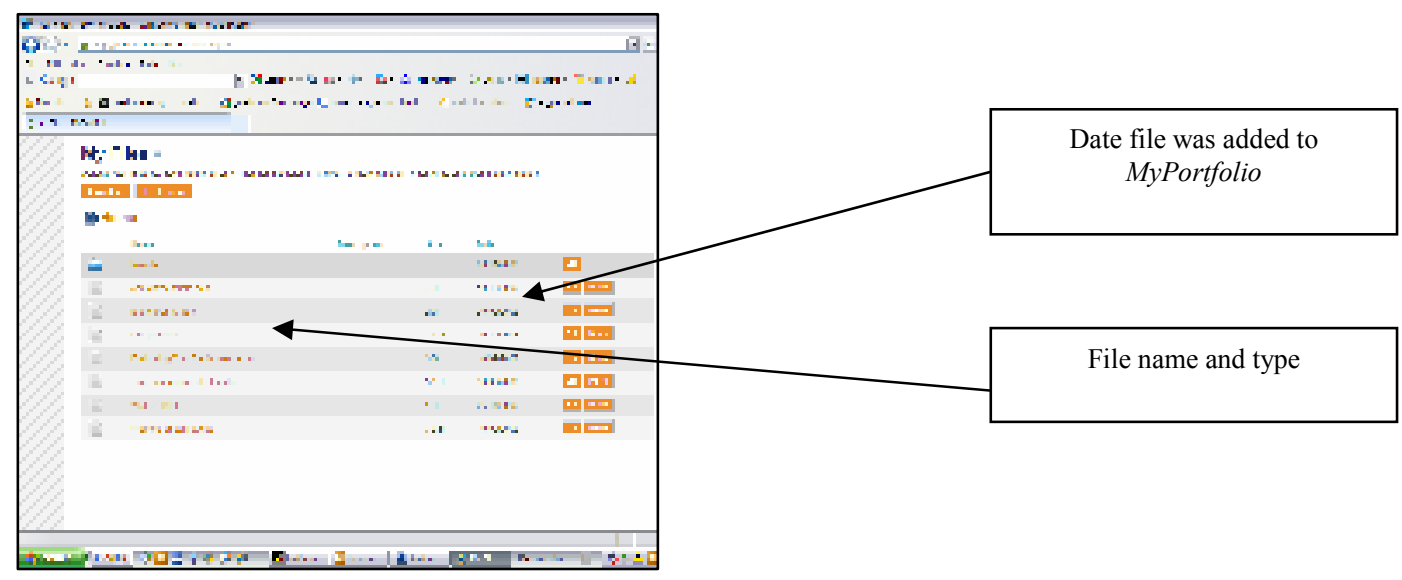

Figure 9 An example of a 'My Files' section of MyPortfolio

\subsection{How the students used 'my files'}

As the students had to make use of 'my files' in order to upload files into their view, all of the students in this study made use of 'my files'. The average number of files uploaded into 'my files' was seven and these files were predominately MSWord documents. The other files types that students uploaded into 'my files' were PowerPoint files, videos and pictures. 16 of the 25 students (64\%) also created folders within their 'my files' and in this way began to organise their work within MyPortfolio. In Chapter 7, I discuss the way in which the case study students added files into their views and give more detail about how these files were included in the views.

\subsection{My Blogs}

The students were able to create their own blogs ${ }^{38}$ so that they could record their thoughts and experiences. The blogs were created in a separate section from the views but students are able to add the blogs as artefacts into their views. The students were

\footnotetext{
${ }^{38} \mathrm{~A}$ blog is a form of online journal where students are able to record their thought and experiences. It is a progressive record and also allows the students to create a dialogue with readers .
} 
shown the blogs and how to add them to their view and could use the blogs to complete on-going aspects of the assignment such as their daily research diaries ${ }^{39}$.

\subsection{How did the students make use of the blogs?}

All of the students in this study created a blog as part of the initial lesson with the trainer. However, the students did not make extensive use of the blogs and the greatest number of entries I observed on any student blog was three. Although the students could have made use of the blogs for aspects of their assignment such as their daily research diary, all of the students chose to complete this work in MSWord instead. This suggests that the students preferred to make use of applications that they were more familiar with and, as with the previous features of MyPortfolio, I will discuss this aspect of the students' use of MyPortfolio in more detail in Chapter 7 when I discuss the case study students in detail.

\subsection{Profile}

The profile area within MyPortfolio stores a student's contact and personal information and allows the students to add artefacts in order to personalise this area (Flexible Learning, 2008). The artefacts that students can add into their MyPortfolio view include text, videos, images and documents. The student can also add any element of their profile into a view in order to personalise their view.

Setting up the profile was not a task required for this assignment set during this study however, the trainer did show this aspect of MyPortfolio to the students at the beginning of the study and all of the students made at least one change to their profile during this time. As with the views, I took screen shots of the case study students' views each day after the lesson and kept a record of how these changed and developed throughout the course of the study.

\subsubsection{How students used the profiles}

During the first lesson, the trainer gave the students some time to explore MyPortfolio and make independent use of the features. During this time, all of the students in the class made at least one change to the profile. In this section of MyPortfolio, the students could add information about themselves; see the views they

\footnotetext{
${ }^{39}$ These diaries were not the same as the daily logs completed by the case study students which recorded the students' experiences with using MyPortfolio. The research diaries were set by the class teacher and all of the students in the study were required to complete them as part of their assignment.
} 
had created and the groups that they belonged to; and could add pictures and videos ${ }^{40}$. Almost all of the students in this study reported making use of the profiles during the course of the study and 22 of the 25 students (88\%) reported changing their profile during the study:

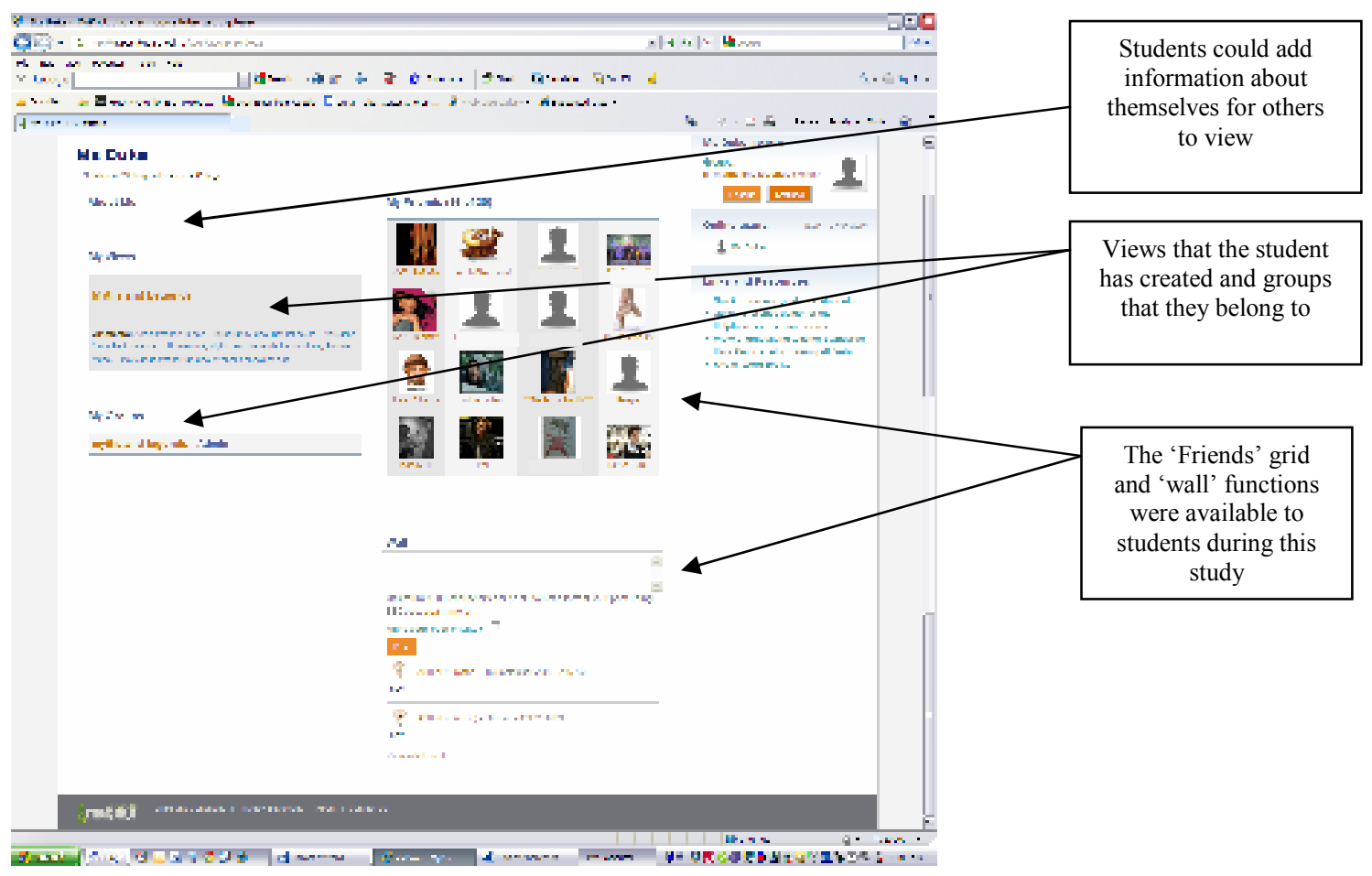

Figure 10 An example of a profile

Using the profiles was also one of the aspects of MyPortfolio that the students identified as being something that they liked about MyPortfolio and in the final survey when asked what aspect of MyPortfolio they most enjoyed, ten of the 25 students (40\%) made specific comments relating to the use of the profiles:

- I also liked the... pictures you could put on your profile.

- looking at my friends profiles

- $\quad$ i enjoyed work on my profile

(Final Survey)

21 of the 25 students $(84 \%)$ who completed the final survey reported that they personalised their view, changed their profile and added videos or images their profile. In the final survey, 12 of the 25 students (48\%) also made particular reference to the

\footnotetext{
${ }^{40}$ In a later version of MyPortfolio, which was introduced after this study concluded, the profile also contained a 'wall' which other students could leave messages on and a grid showing the student's 'friends'. These features were not available to the students during this study.
} 
fact that they believed the ability to create and personalise views and profiles to be the best aspect of MyPortfolio:

I think the best thing on MyPortfolio to use was the views that we could make and the things that we could add on to them. (Final Survey)

In many ways, the profile page within MyPortfolio operated like the profile pages in social networking sites for the students in this study in that the profiles gave the students the ability to create pages which reflected their personalities and interests and a recent study by Fox et al. (2009) also found that students were initially drawn to the social networking features of MyPortfolio. Given that the profile page is central to social networking sites such as Bebo, Facebook and MySpace (boyd \& Ellison, 2007) it was not surprising that the students made use of the pages and liked being able to create their profile for others to see.

Many of the students in this study were familiar with social networking sites and in the initial survey, 20 of the 25 students $(80 \%)$ surveyed reported having a social networking site. However, it was interesting to note that only one student reported having more than one kind of social networking site and 19 of the 20 students (76\%) who had a social networking site made use of Bebo.

Lenhart and Madden (2007) note that one of the main reasons that teenagers are enthusiastic about their use of social networking sites is that it gives them the opportunity to present themselves to their peers and gain feedback and affirmation via the social networking tool. In this way, the use of MyPortfolio functioned like a social networking site and allowed the students to present themselves to others (boyd, 2007).

The sense of audience is an important feature of public spaces, such as an online profile page. In the case of this study, the profile was not available for viewing to the wider public, but was accessible to the students' friends and teacher. However, although the students were presenting aspects of their identities, the fact that their MyPortfolio profile was a public space meant that a number of the students created profiles that reflected a sense of an imagined audience that allows the students to present themselves to others.

While I did not collect data on the exact number of changes each student made to their profile, the final profiles showed that some of the students in this study made 
many changes throughout the course of this study ${ }^{41}$. In making these changes, boyd, Chang and Goodman (2004) suggest that the students are defining how they present themselves to others and negotiating their identities, an essential role of adolescence (Giddens, 1991). The creation of a profile within MyPortfolio may help provide students with the opportunity to construct and experiment with the presentation of their identity within a relatively safe environment (Livingstone, 2008).

Further, boyd (2007) also argues that the creation of profiles within social networking sites as a form of initiation where students are able to get a sense of what sort of online presence is acceptable and also as a way that students are able to develop their skills in using ICT while navigating the social structures of the digital environment.

\subsubsection{Other aspects of MyPortfolio not utilised in this study}

As well as the aspects of MyPortfolio that I have discussed above, there were three other aspects of MyPortfolio that the students did not make use of during the course of this study. These were 'My Resume', 'My Goals' and 'My Skills'. As the students did not make use of these sections in this study I will not discuss them here. However, I have included a brief overview of each in appendix 9.

\subsection{Themes that emerged from the student use of MyPortfolio}

In my analysis of the students' work and the data I collected during the course of the study including my observations, the interviews and the final survey, a number of themes emerged relating to how the students made use of MyPortfolio during the course of the study. The key themes that emerged were: the aspects of using MyPortfolio that were difficult for students to learn to utilise; the importance of 'justin-time' learning; the students' attitudes towards the best location for use of MyPortfolio; and the ability to use MyPortfolio as a tool for communication and organisation;

\subsection{1 'Too hard'- struggles with new technology}

In my analysis of the survey data and the final interviews, there was a clear conflict in perspectives about whether MyPortfolio was easy enough to use and while

\footnotetext{
${ }^{41}$ I did follow the development of the case study students' profiles in detail and this data can be seen the next chapter.
} 
all of the students in this study reported being regular users of technology, they did not all find using MyPortfolio a straightforward experience. In the final survey, three of the 25 students (12\%) reported finding MyPortfolio frustrating to use (see appendix $1.21)$ and two of the 25 students ( $8 \%$ ) found it hard to use (see appendix 1.22). Eight of the 25 students (32\%) also responded 'not sure' when asked whether MyPortfolio was hard to use and this suggests that these students were not entirely comfortable with their use of MyPortfolio. It is also possible that they found using the application difficult but did not want to acknowledge this publically (Carswell, Thomas, Petre, Price, \& Richards, 2000). Two students also commented in the final survey that they would not recommend MyPortfolio for use to other students as they felt it was too hard to use:

It's too hard and it takes up to much time (Final Survey)

Having said this, this was certainly not the case for all of the students and more than half of the students ( 15 of the of the 25 students- 60\%) 'agreed' or 'strongly agreed' that they found MyPortfolio easy to use and one of the students particularly noted in the final survey that they found using MyPortfolio very easy to use and commented:

The best thing about MyPortfolio is that it is very easy to use and it is simillar to bebeo, facebook etc. If $i$ can learn to use MyPortfolio then you can to (Final Survey).

These results highlight the fact that the students' abilities with ICT are not all at the same level and while some of the students found using MyPortfolio easy, others had real difficulty.

Five students also mentioned technical aspects in the final survey and when asked what they did not enjoy about MyPortfolio:

Some of it was a bit confusing and I needed help from the teacher, like uploading work (Final Survey).

\subsubsection{Struggles with learning to navigate}

One of the things that particularly impacted on the students' ability to effectively make use of MyPortfolio was their ability to navigate throughout MyPortfolio. In order make effective use of MyPortfolio, the students needed to be able to navigate throughout the different areas of MyPortfolio and remember which functions to use in order to complete the tasks set. This ability to navigate throughout the different areas 
of MyPortfolio was an important initial step for students when learning to use MyPortfolio as when they could confidently navigate throughout the different aspects of MyPortfolio, they could then find the functions that they needed in order to complete the tasks set. In my observations of this class, most of the students seemed to be confident navigating throughout MyPortfolio within four lessons. During the fourth lesson I asked ten students to navigate throughout MyPortfolio for me and eight were able to do this confidently (my observations lesson 4). The other two students could find their profile and view but had trouble finding more deeply embedded features such as 'My Files' and the view settings.

The students' responses in the final survey showed they final survey also highlighted the impact that learning to navigate MyPortfolio impacted on the students' experience of using the application and when asked in the final survey what the worst part of MyPortfolio was, five students mentioned aspects of navigating MyPortfolio as being difficult:

find my way around to things that $i$ needed to find (Final Survey).

The ability to navigate throughout the different areas of MyPortfolio was an important first step towards using MyPortfolio effectively and three of the five students who commented on aspects of navigation also said that they found MyPortfolio hard to use. Of the five students who commented on aspects of navigation, three said that they were 'not sure' whether they would want to use MyPortfolio again in the future and one student said that she would not want to use MyPortfolio again. This suggests that these students' struggles to learn to navigate MyPortfolio may have impacted on their overall experience with the application and I will discuss the effects of struggles with technology later in this chapter (see page 83). In Chapter 7, I will also discuss the difference in the case study students' experiences in regard to learning to navigate throughout MyPortfolio and the effect that this had one each of their experiences with MyPortfolio.

\subsubsection{Uploading and downloading files}

An aspect of MyPortfolio that students identified as an aspect of using MyPortfolio that they found difficult was the process of uploading and downloading documents to MyPortfolio. This was a new skill for most of the students and some found it a very challenging process to understand. All but four of the students in this 
study made use of social networking sites such as Bebo and most of the processes such as editing and uploading pictures in MyPortfolio functioned in a similar was as it does in Bebo. The fact that these functions mirrored processes that the students were familiar with may have meant that they were more comfortable making use of these functions (Cotterill et al., 2006). However, the process of uploading and downloading files such as MSWord documents and PowerPoint files from MyPortfolio had an additional step, where the students were required to save the documents on their computer. Once the students had uploaded their files into MyPortfolio, they also had to add the file to their view. The fact that this was a process that the students had not encountered in applications such as Bebo meant that some of the students struggled with this aspect of using MyPortfolio and when asked in the final survey what the worst thing about MyPortfolio was, one student responded:

It's to confusing. there's so much you have to do to upload stuff.. it needs to be more simple (Final Survey).

\subsubsection{The effect of struggles with technology}

While most of the students learnt how to use MyPortfolio in 2-3 sessions, the need to develop new technical skills was a stumbling block for some students and three of the five students who said they would not recommend MyPortfolio were students who struggled with using MyPortfolio. A number of studies have noted the way that struggling with technology can have a demotivating effect on students (Kennedy et al., 2007; Wright \& Stallworth, 2002) and Keller and Cernerud (2002) also found that students do not necessarily respond positively to the use of technology and that they can become discouraged by technical problems. An example of this can be seen in the next chapter with case study student Hannah (see page 149). However, if students are given the appropriate support, the experience of developing skills in using a new application can also help develop students' confidence (Gray, 2008; Wright \& Stallworth, 2002) and this can be seen in Ashleigh's experience in the next chapter (see page 141).

While writers such as Prensky (2001) argue that today's students are naturally at home with technology, other researchers such as Kennedy $(2007 ; 2008 ; 2006)$ suggest that patterns of use among students vary widely and that the while the majority of students possess a core set of technological skills, these do not necessarily translate into a sophisticated approach towards using technology. This can particularly be seen in Chapter 7, where I examine the profiles and experiences of six students in depth. 
Although the number of students participating in my study was small (25 students), the findings do reflect studies which suggest that today's students are not necessarily as competent with computers as we might believe. For example, in their study of university students, Zemsky and Massy (2004) found that $41 \%$ of students have some trouble with the technology and $11 \%$ of students had difficulty with the technology.

Overall, while in the initial survey, the students in this study reported feeling comfortable with using technology (see appendix 2.1), it was clear that, as with all aspects of learning, their ability to develop new skills in order to utilise MyPortfolio varied greatly. Further the students in this study did not always manage to transfer the skills that they had in using other applications into using MyPortfolio. The lack of ability to transfer skills between applications was also noted by Ntuli, Keengwe and Kyei-Blankson (2009) who found that careful training was needed in order to ensure that the students made effective use of e-portfolio tools. This highlights the fact teachers cannot assume that all students are competent with all aspects of technology as this greatly oversimplifies today's students' attitudes towards and abilities with technology. Kennedy, Judd, Churchward, Gray, \& Krause (2008) also makes this point that assuming that students are more competent with technology than they are may increase rather than decrease the digital divide as students who lack skills can become further demotivated and fall further behind and this is an issue that teachers must be continually aware of.

While it is clear that teachers cannot assume that students have advanced or even well-developed technical skills (Luckin et al., 2009), it is essential that as well as teaching students technical skills, teachers need to also focus on metacognition and critical awareness so that students are able to transfer the knowledge and skills they gain with particular applications into different domains (Luckin et al., 2009). In this way, careful training is required for both teachers and students in order to ensure that students are able to make effective use of the applications taught and also so that their skills become transferable into other domains (Ntuli et al., 2009).

\subsection{5 'Just in time' learning}

One of the aspects of the students' experience with MyPortfolio that emerged from this study was the way in which students made use of 'just-in-time' learning- a process where the students seek information and instruction as they require in order to complete the tasks set (Duffy \& Jonassen, 1992). Although the students were given 
instructions on using the features that they would need for their assignment during the first lesson, as the study progressed, some of the students needed to be reminded about how to use different aspects of MyPortfolio- that is, they needed the information 'justin-time' to be able to make use of it. In particular, as I have already discussed, some of the students particularly struggled with the process of uploading and downloading documents- a process which was new to most of the students in this study (see page $85)$.

As the ability to upload and download files from MyPortfolio was central to the students' use of MyPortfolio, at the end of the third lesson, the teacher asked all of the students to upload a document to their view for homework so that we could observe how many students were able to complete this task. When I examined the students' surveys, I found that only 10 of the 25 students ( $40 \%)$ were able to complete the tasks. During the next lesson, I asked the students who had not completed the task why they had not completed it and five of the students said that they had forgotten to complete the task; five students reported that they had had trouble uploading the file and although they had uploaded the file into MyPortfolio, had trouble with the final stepadding the file to their view; and the last five students had not managed to upload the file into MyPortfolio at all (my observation lesson 4). The results of this task suggested that the ability to upload and download files was a function of MyPortfolio that many of the students did not find easy to master and needs careful instruction when introduced to students as it is a key aspect of effective use of MyPortfolio.

The students were all shown this process and given the opportunity to practise it during the first lesson. However, the fact that they later struggled to remember how to complete this task this is an example of the way in which learning becomes meaningful when it is a skill that is useful (Edelson, 2001). When the students were introduced to this process at the beginning of the study, the students did not have a practical reason for using this aspect of the application. As the study progressed and the students needed to use this function in order to complete their assignment work, the students revisited the process and those who could not remember what to do needed help so that they could complete the work set and the teacher then reviewed the process with the students.

The experiences of the students in this study with MyPortfolio reinforce the fact that when introducing new Web 2.0 applications such as MyPortfolio, it is important for teachers to make use of 'just-in-time' learning as this approach helps ensure that 
the skills gained are available for future use (Edelson, 2001; Hmelo-Silver, Golan, \& Chinn, 2007).

\subsubsection{Location of use}

One of the themes that emerged from this study related to the location of use that the students felt that MyPortfolio was best suited to. The majority of work completed for this study was undertaken while the students worked in the computer laboratory during class time. However, 24 of the 25 students (96\%) also reported in the final survey that they made use of MyPortfolio at home. In the final survey, I asked the students how often they made use of MyPortfolio at home and the responses varied from once or twice during the course of the study to every night:

- $\quad i$ went on it once of twice to finish some work that i needed to do and for home work

- like every 2 days maxx

- because of homework and $i$ used it 3times a week as my average

- maybe once a week.

- $\quad$ i would go on MyPortfolio every night to work on my groups presentation.....

(Final Survey)

The most common reason common reason that the students gave for using MyPortfolio at home was to complete the homework tasks set in class. However, three students also identified the fact that they used MyPortfolio at home to update their profile or add pictures or videos to their profile:

$i$ used it when $i$ had homework to do. and to purt twilight picture on my folio(Final Survey).

A further two students noted using MyPortfolio at home to send messages to other students.

$$
\text { i used myportpolio... to message my group members (Final Survey). }
$$

Four students also commented that they made use of MyPortfolio at home if they needed to catch up on work set:

to finish off something $i$ didnt finish in class (Final Survey). 
The ability to use MyPortfolio from a range of locations, such as at home was a feature that some of the students identified as a benefit of MyPortfolio and when the students were asked in the final survey what the best aspect of MyPortfolio was, four of the 25 students (16\%) commented on the fact that they could use MyPortfolio from home. In this next chapter, three of the case study students also identify the fact that they liked being able to make use of MyPortfolio from home rather than at school and felt that this was one of the most beneficial aspects of MyPortfolio.

\subsubsection{Communication}

Another important theme of the students' use of MyPortfolio that emerged from my analysis was the way in which students made use of MyPortfolio in order to communicate with other students and the teacher. MyPortfolio has a number of ways in which students and teachers can communicate and these include the creation of 'groups', which enable members to send messages to a preselected group of people; messaging, where users are able to send messages to other specified users; and views, where students can construct and display work and other users can leave messages. Below are examples of each of these forms of communication:

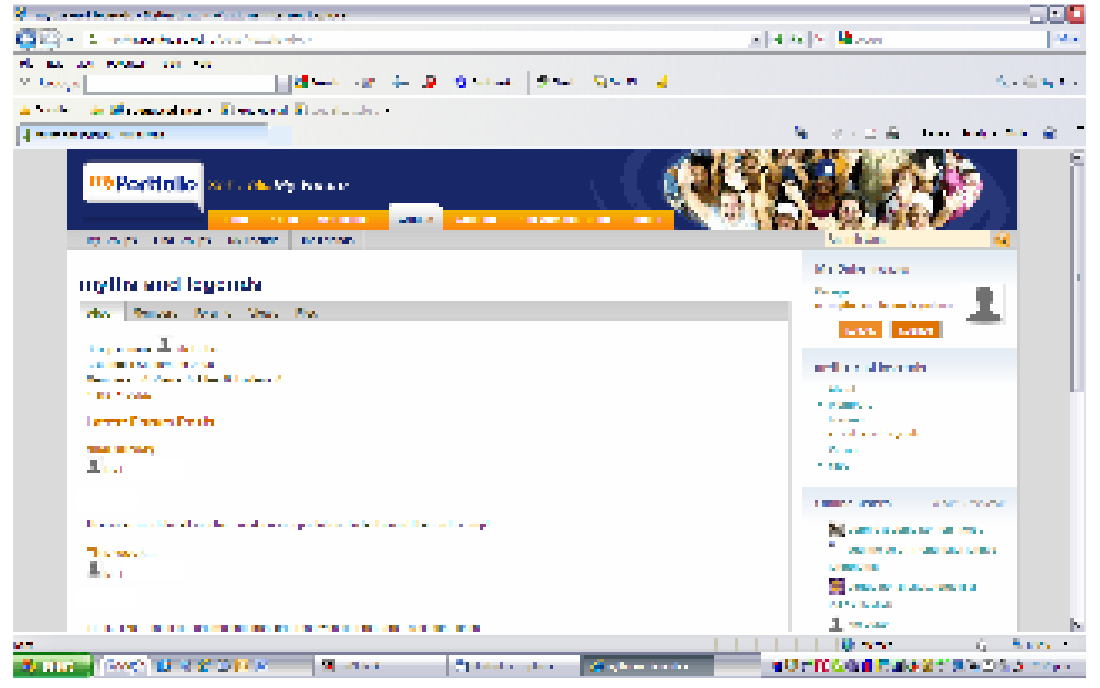

Figure 11 An example of a group page

The 'groups' within MyPortfolio allow students to form groups in order to facilitate collaboration. Once formed, the students can send messages to other members of the group and can make views and files available to the members of a particular group. 


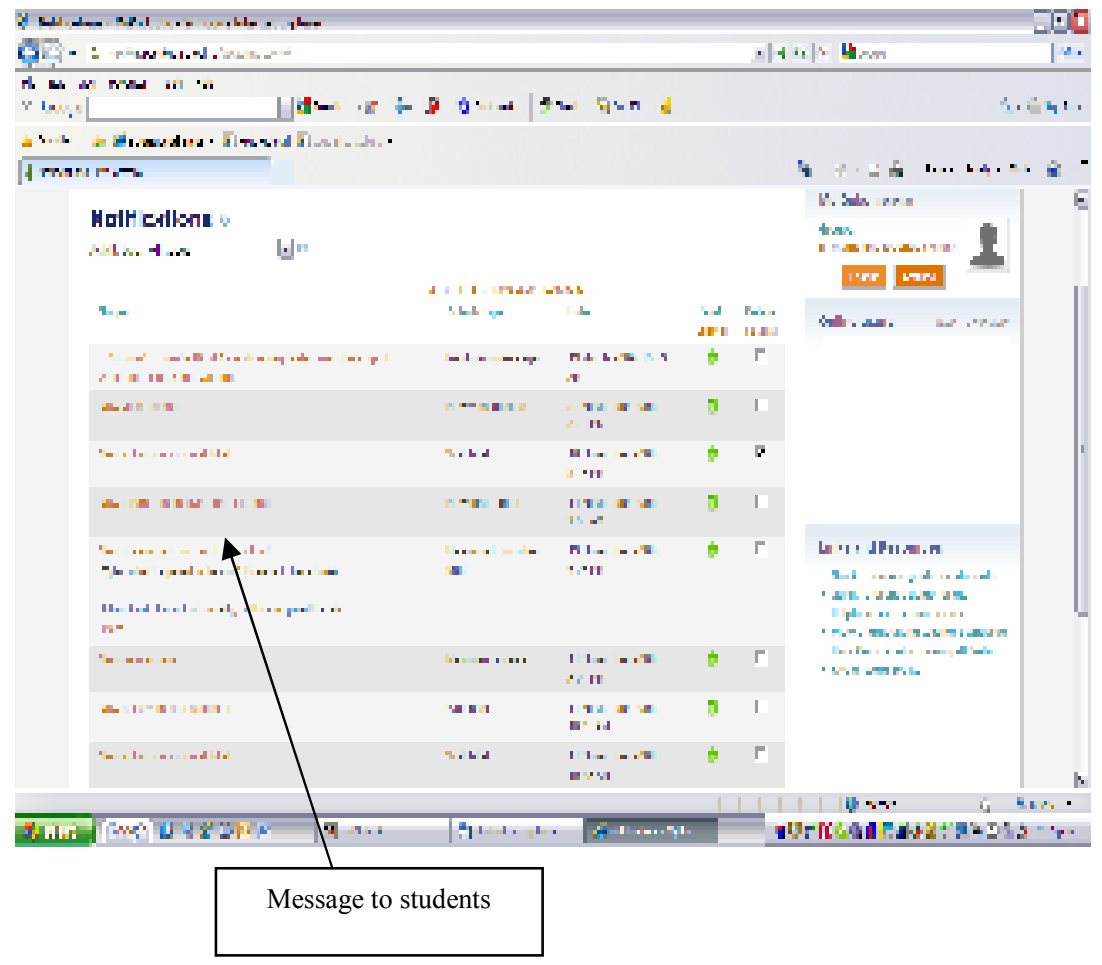

Figure 12 Notifications page- showing messages received

In order to send a message to another student or the teacher, the students need to go to the other person's profile page or the person's listing within MyPortfolio and click the function that says 'send message'. Once a message has been sent to another person, the message will show up on their 'notifications' page. This page also shows activity undertaken by those people whom the students have added as friends.

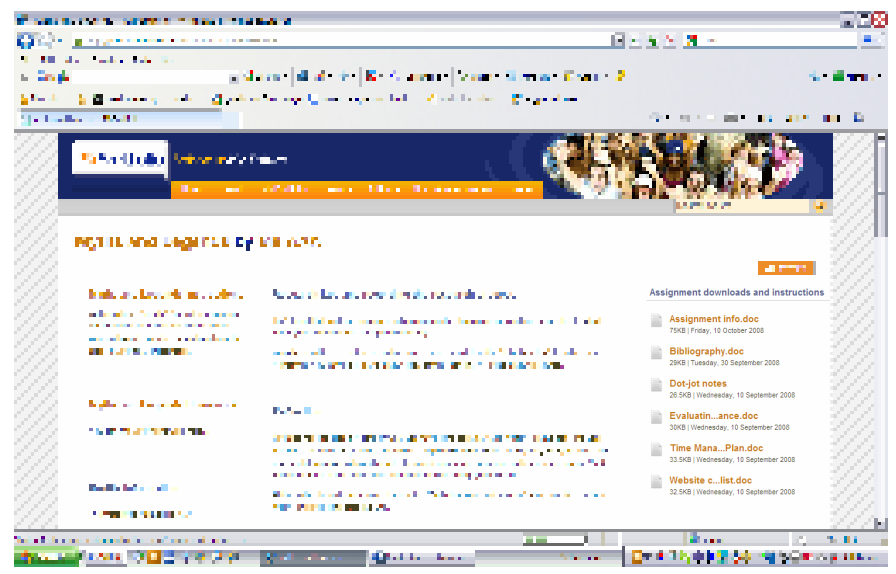

Figure 13 An example of the class view- the teacher was able to post updates and resources on the view for the students to check in their own time

The views allow the students to see the work that their friends have completed. Once a student has set up a view, they are able to specify which friends are able to see it. The views also have a messaging function at the bottom which allows people to comment on particular views. 


\subsubsection{Messaging}

The messaging function was the function that the students in this study most commonly used with 23 (92\%) of the 25 students who completed the final survey reporting that they messaged friends or members of their group during the period of the study (see appendix 1.16). It is impossible to know exactly how many messages the students sent and received during the course of the study as the students were able to delete messages. However, all of the students received at least one message during the course of the study.

The students in this study made use of messaging for both social and task-related reasons and I will discuss each of these types of messaging separately.

\subsection{Social messaging}

The students in this study reported utilising the messaging functions of MyPortfolio for social as well as the educational purposes and when asked in the final survey whether they would recommend MyPortfolio for use to other students, one student responded:

Yes because they can see what their friends are up to with their work and send comments to each other (Final Survey).

Overall, my analysis of the messages that the students sent and received suggests that the students in this study predominately made use of the messaging function for social purposes. The screen shot below is a summary of the messages received by one of the students in the class:

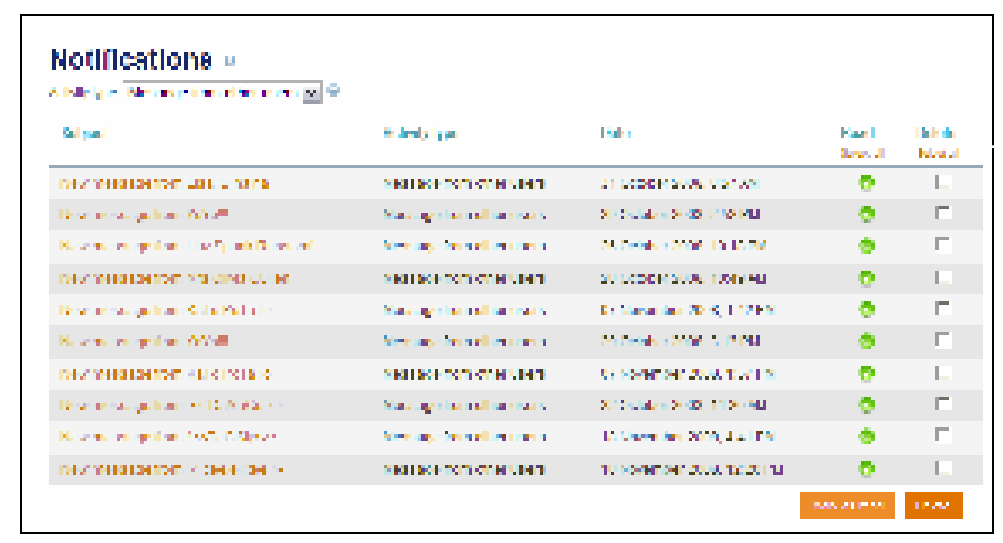

Figure 14 An example of a notifications screen 
Of the ten messages that this student received throughout the course of the study, only one was related to the assignment work and the others were social. When I examined other students' notifications, I found a similar pattern of messages.

The fact that students predominately made use of the messaging for social purposes rather than to aid their learning is also supported by the comments relating to messaging that students made in the final survey when they were asked which aspects of MyPortfolio they liked:

I also like the part were you could send messages to your friends (Final Survey).

When I first began considering the data from this study, I assumed that this social aspect was a distraction from the students' learning. However, Rovai (2002) suggests that within a learning community, students need to feel connected to each other and it may be that the virtual 'chat' that occurred helped the students develop a sense of acceptance and belonging and recognition as part of the learning community. It may be that the 'chat' that occurred within the messaging functions of MyPortfolio occurred in much the same way as students would generally chat in class and that this is a way that students continued to develop a community during the course of this study .

Although the students saw MyPortfolio as having similarities to social networking sites, it was interesting to observe that they did not make their messaging public in the way that they do within social networking sites (Lenhart \& Madden, 2007) and, almost exclusively, the communication that students undertook within MyPortfolio was conducted through the messaging function rather than by leaving messages in public areas of students' profiles or views. One significant reason for this may have been that they were aware of the fact that their teacher was able to see these comments and, in this way, the students may have moderated their use of MyPortfolio according to the perceived audience (boyd, 2007).

\subsection{Task-related messaging}

Although the majority of the students' use of the messaging seemed to be social, students did see benefits to their learning in being able to message each other in order to complete the tasks set. The students in this study were working in groups and made use of the messaging function to communicate with the other members of their group 
and also other students in the class and when the students were asked in the final survey what the best aspect of MyPortfolio was, one student commented:

Being able to msg (message) people in your group about what you are/have completed/ working on (Final Survey).

The messages that the students sent that related to their assignment work was that they tended to be short and related to a particular point, such as updating other members of the group on their progress:

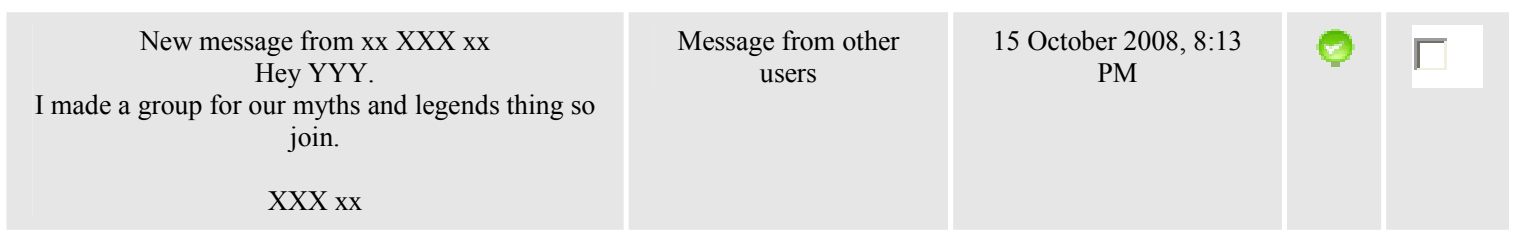

Figure 15 An example of a message from one student to another

Studies suggest that online learning can be a powerful tool for developing communication and that the asynchronous nature of online learning can provide some transactional distance which allows students to consider their ideas and construct carefully written ideas which can enhance their work (Herring, 2004). However, there was little evidence that the students used the messaging functions to construct their ideas and the messaging I observed seemed to be predominately social or related to the group's progress. One reason for this may have been the blended learning situation that the students were working in and the students may have found it easier to develop their ideas in a face-to-face situation rather than via messaging. It is also possible that because the students were relatively new to online learning and only made use of MyPortfolio over a six week period, they did not have time to develop their skills in this area and that over time, the students may have begun to use the messaging more to construct ideas (Walther, 1996).

\subsubsection{Views}

The students in this study also made use of the views to communicate with other students and the teacher and when asked about the benefits of MyPortfolio, six of the students referred to both the views and messaging in combination:

...looking at other people's views (Final Survey).

In particular, the students saw the views as beneficial as they allowed the students to track each others' work and see the progress that their group was making: 
...being able to see where your class mates are up to and what work

they have done (Final Survey).

The students could view the views created by the other members of their group and, in doing so, could see the progress that the other members of their group were making. The ability to see other students' views also enabled some students to see how MyPortfolio could be used in order to complete their work and for some students, this was a non-threatening way of developing their skills without having to ask other students or the teacher for help, for example, case study student Hannah, whose experiences are described in detail in Chapter 7 (see page 147).

Although MyPortfolio allowed the students to comment on each others' views within the view page, I did not find any evidence that the students had used this mechanism to comment on each others' work. While the teacher made of this feature to comment on the students' progress, the students themselves made use of the messaging function of face-to-face communication instead.

Where are your dot-jot notes, ZZZ? did you have trouble uploading them?

Ms XXX | 21 October 2008, 9:38 AM |

Figure 16 An example of feedback from the teacher to a student on a view $(21 / 10 / 08)$

However, I did find examples of messages from one student to another commenting on the student's view. The fact that the students chose to send private messages rather than add their comments in public suggests that although virtually all of the students had experience with public comment forums such as those on Bebo they were not entirely comfortable with undertaking this within the classroom context. In this way, the students' approach to educational use of ICT was quite different from their social use (Monteith \& Smith, 2001)

\subsubsection{Communicating with the teacher}

As well as messaging other students, almost all of the students had some form of contact with the teacher via MyPortfolio during the course of this trial. Of the 25 students, $18(72 \%)$ messaged their teacher and $19(6 \%)$ said that they had received feedback from the teacher while using MyPortfolio (see appendix 1.18). In the final survey, one of the students also commented that having the teacher able to view her work was the best aspect of MyPortfolio. 
As with messaging other students, the communication that occurred between students and the teacher in this study of a brief and functionary nature, for example telling the teacher that they had finished a particular section of work or informing the teacher of their progress.

\begin{tabular}{|c|c|c|}
\hline $\begin{array}{c}\text { New message from XXX } \\
\text { ms AAA, Its XXX XXX i have completed my homework } \\
\text { enjoy!!! }\end{array}$ & $\begin{array}{c}\text { Message from other } \\
\text { users }\end{array}$ & 06 November 2008, 9:52 PM \\
\hline $\begin{array}{c}\text { New message from YYY } \\
\text { I put all my blogs onto new posts- YYY }\end{array}$ & $\begin{array}{c}\text { Message from other } \\
\text { users }\end{array}$ & 31 October 2008, 9:29 AM \\
\hline
\end{tabular}

Figure 17 Messages from students XXX and YYY informing the teacher of their progress

As I discussed earlier, the fact that the students in this study were working in a blended learning environment may have meant that they preferred to deal with more complex issues in a face-to-face context. However, some researchers also suggest that students do not view the communication tools within online learning environments as an essential part of learning (Tunison \& Noonan, 2001). This may certainly be the case in blended learning environments where students have the opportunity to discuss their work face-to-face.

\subsection{Summary}

Overall, the student use of MyPortfolio in this study suggests that the students made use of the application more as a pragmatic tool to help them manage their time, resources and communications than a tool to help them construct knowledge and develop ideas. The relatively short timeframe involved in this study may have played a part in this and it is possible that over a longer period of time, the students may have come to use MyPortfolio more to construct knowledge, however, the students' use in this study suggests that the role of the teacher is important in promoting more sophisticated use of the application.

It is also interesting to note that although the students had access to all aspects of MyPortfolio, their use of the application was largely limited to aspects which were required in order for the students to complete the tasks set. The exception to this was the use of the profile section and it was clear that the ability to personalise this page was something that the students enjoyed. 


\section{The students' perceptions of MyPortfolio}

While there is a large amount of literature exploring issues around online learning and the use of electronic portfolios, many of these studies focus on the use of technology from the perspective of the instructor or educational technologist and tend to focus on technical issues or issues of assessment (Ahn, 2004; Howland \& Moore, 2002; Song et al., 2004). However, it is important that the use of online technologies is also understood from the student perspective as this can provide an in-depth understanding of how students use technology and, consequently, how this can benefit their learning (Song et al., 2004). Gaining a thorough understanding of how students perceive their use of Web 2.0 tools such as MyPortfolio can also help educators to optimise their use of technology so that students are better equipped for the changing information landscape (Vonderwell, 2003). For this reason, authors such as Selwyn, Potter and Cranmer (2008) and Ntuli et al. (2009) urge dialogue with students in regards to the perceived benefits and limitations of educational technologies.

In Chapter 2, I discussed the fact that today's students are often described as 'digital natives' (see page 41) and there is a lot of expectation surrounding students' abilities with ICT. In order to ensure that students are able to make effective use of the ICT tools available, it is important to test these assumptions and examine how students do actually experience using ICT (Kennedy et al., 2007)

The purpose of this chapter, therefore, is to represent the key issues that the students identified through their use of MyPortfolio. This chapter examines the data collected from the whole class group and the way in which the responses that the students provided in the final survey are reflected in way that the students made use of MyPortfolio. In Chapter 4, I described the structure of MyPortfolio and the aspects that the students made use of during the study. In this chapter, I will focus on the students' perceptions of MyPortfolio and how MyPortfolio helped and / or hindered their learning (research question 2).

The focus of this chapter is representing the students' voices and, as previously discussed in Chapter 3, in order to understand this perspective, I made use of a range of data collection methods including student journals, surveys, interviews and observations in order to ensure that I accurately represented the voices of the students in this study. 


\subsection{What were the students' perceptions?}

As well as analysing how the students made use of MyPortfolio, as I did in the previous chapter, it is also important to understand how the students perceived their use of MyPortfolio (Ntuli et al., 2009) (research question 2). In order to answer this research question, I have predominately made use of the final survey data and have then triangulated the survey data with the qualitative data, such as the students' MyPortfolio work and my observations of the students. The themes that emerged from this data were that: the students found using MyPortfolio a 'fun' way to learn; the students both liked and made particular use of the organisational aspects of MyPortfolio; and the effect of using MyPortfolio on the sense of community that occurs within the classroom.

\subsubsection{A 'fun' way to learn- The influence of technology}

One of the themes that emerged from my data was the fact that the students perceived making use of computers as a 'fun' way to learn and this is reflected in comments made by the students about their use of MyPortfolio in the final survey.

Overall, the students in this study were positive about the use of their MyPortfolio and when asked in the final survey whether they would recommend MyPortfolio for use to other students, 19 of the 25 students (76\%) said 'yes'. Similarly, when asked in the final survey whether MyPortfolio had been fun to do, 21 of the 25 students (84\%) either 'agreed' or 'strongly agreed' (see appendix 1.6).

At the end of the final survey, the students had the opportunity to provide openended responses and were asked whether there was anything else they would like to say about MyPortfolio. Eleven students who responded to this question, six gave responses relating to the fact that they found MyPortfolio fun:

\footnotetext{
I found MyPortfolio very easy to use and im just trying to say that it is a fun, exciting website to use and that anyone can join (Final Survey).
}

The fact that students identified using MyPortfolio as an enjoyable experience is not surprising given that the literature is clear that students enjoy utilising technology to support their learning (Barrett, 2008a; British Educational Communication Technology Agency (Becta), 2007; Smart \& Cappel, 2006; Wright \& Stallworth, 2002) 
It was fun using my portfilio at school and it got me well

orginized with my work (Final Survey).

Similarly, McLeod and Vasinda (2009) also found that a number of the primary school students in their study referred to using e-portfolios as 'fun' and that this enjoyment of using the e-portfolios impacted on the students overall high levels of perceived satisfaction with using the e-portfolios tool they assessed.

One of the reasons that the students in McLeod's and Vasinda's (2009) study found using e-portfolios 'fun', was due to the ability to make use of technology and the ability to use ICT tools can be a motivating factor for students (Luckin et al., 2009; McLeod \& Vasinda, 2009).
:) I prefer it to writing!!!!!
:) it was fun! (Final

Survey)

Certainly, many of the students in this study were, at least initially, motivated by the fact that they could use technology to complete their class work and in the initial survey, 13 of the 25 students (52\%) said that they believed they would work harder if they were able to use computers more often (see appendix 1.7).

During the first three weeks I did not observe an occasion when the teacher had to tell the whole class to focus on their work and when she did have to speak to students, they immediately returned to working on their assignments. When I spoke to the teacher about this, she commented that she found the class particularly focussed during this study and was surprised at how quiet the class was when we were working in the computer laboratory (whole group observation lesson 5). A recent study by McLeod and Vasinda (2009) also found that students were more engaged when using e-portfolios and that the use of technology in the classroom can be a way to motivate students.

The fact that students found the use of MyPortfolio 'fun' and that it allowed them to make increased use of technology was a motivating factor for some of the students in this study and it may have led the students to engage in what Papert (1993) refers to as 'hard fun'- that is work that students enjoy but challenges them. The idea that the students were engaging in this 'hard fun' could be seen in the fact that during both the third lesson and fifth lessons, two or three students asked the teacher whether they could stay behind during lunchtime in order to continue to work on their MyPortfolio work (whole group observation 21/10 lesson 3 and 28/10 lesson 5). The 
students felt that there were aspects of their work that they wanted to complete and that by using their own time, they would be able to do this (whole group observation 21/10 lesson 3 and 28/10 lesson 5).

However, the fact that $64 \%$ of the students (16 students) in this study also felt that they would like to continue to use MyPortfolio in the future (see appendix 1.8) suggests that it is not just using technology that the students enjoyed, but that they did feel that there was some benefit to using MyPortfolio and I will discuss these aspects later in this section.

One of the survey group students in this study did, in fact, continue to use MyPortfolio after the study period and made use of MyPortfolio to coordinate a class task for another subject. The student created a new view and added two documents onto it so that it could be accessed by other members of the class.

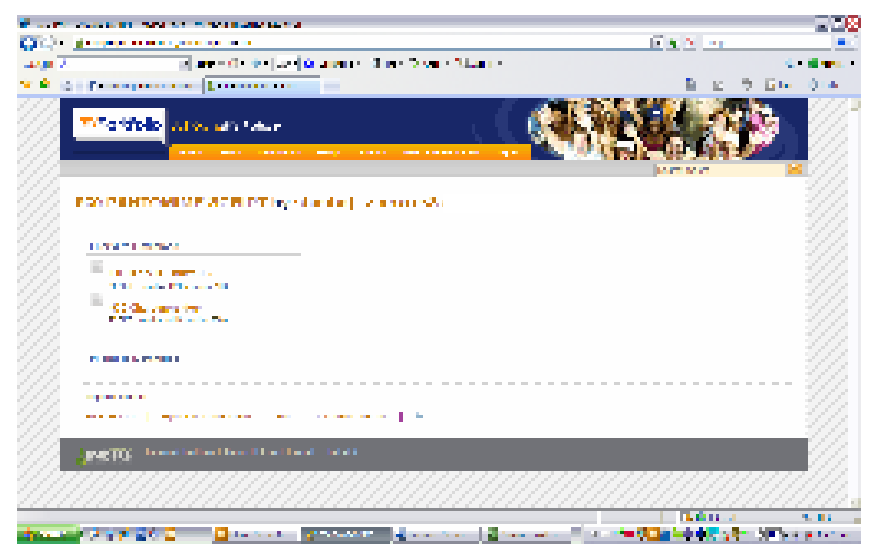

Figure 18 An additional view created by a survey group student (18/12/08)

The fact that the students found MyPortfolio fun meant that they were enthusiastic about their use of the application and keen to complete work by making use of MyPortfolio and when asked in the final survey whether using MyPortfolio had made them more interested in their work, 15 students $(60 \%)$ either 'agreed' or 'strongly agreed'. For some students, the ability to make more use of technology during school time is a motivating factor and the use of applications such as MyPortfolio can be a way to engage in this enthusiasm.

In Chapter 7, the experiences of two of the case study students- YoYo and Mary- clearly demonstrate the way in which technology can be a motivating factor for some students. 


\subsubsection{Creativity}

One reason that the students identified as to why they liked making use of the views within MyPortfolio was the fact that they felt it allowed them to be creative. More than half of the 23 students who responded to the open-ended question 'What did you enjoy about using MyPortfolio?', 14 students or $61 \%$ made comments that related to aspects of creativity such as adding pictures and videos:

Creating views uploading files making MyPortfolio creatiive (Final Survey)

In the final survey, four students of the 25 students (16\%) in this study also identified the fact that MyPortfolio offered them a creative way to present their work as one of reasons why they would recommend MyPortfolio for use to others.

However, not all of the students found this and four other students (16\%) disagreed and, in fact, felt that using MyPortfolio had limited their ability to be creative. It is worth noting that three of the students who 'disagreed' or 'strongly disagreed' in the final survey that MyPortfolio helped them to be creative were also students who reported finding MyPortfolio hard or frustrating to use. It may have been that their students felt limited in how they could express their creativity as they were not able to utilise the functions in order to make use of MyPortfolio creatively.

\subsubsection{Organisational aspects of MyPortfolio}

A common theme in the feedback from the students in this study was that they found that MyPortfolio helped them to be more organised. In the final survey, 18 of the 25 students in this study (72\%) either 'agreed' or 'strongly agreed' that using MyPortfolio had helped them organise their work. Much of the literature relating to student perceptions of online learning supports the idea that often students perceive eportfolios tools as useful for organisational aspects of learning (Chizmar \& Walbert, 1999; Tunison \& Noonan, 2001). In fact, Barrett's REFLECT study (2008b) suggests that students see the primary benefits of electronic portfolios as organisation.

When I analysed the final survey, two aspects of organisation emerged from the students' responses. These were: resource management and organisation of time.

\subsubsection{Organisation - resources}

One of the common criticisms of traditional paper portfolios is the fact that they can be bulky and difficult to store (Goldsmith, 2007; Lambert et al., 2007). The ability 
to efficiently organise and store work is a key advantage of both online learning generally and electronic portfolios in particular (Rovai, 2002) and when asked in the final survey why they would recommend MyPortfolio, three of the 25 students commented on aspects of MyPortfolio that related to managing resources as being the most beneficial aspects of this application:

\section{I would recommend it to people that have trouble sortin out all their paper work and all there homework and stuff like that (Final Survey).}

The students appreciated the fact that using the computer and a web-based application like MyPortfolio meant that they did not have to remember to bring their work to class as it was always available to them whenever they had access to a computer.

It helped me keep all my work together and it was easy to keep it organised (Final Survey).

Using MyPortfolio gave them the opportunity to collect all of their resources together in one place and then access these from a range of locations.

It is easy to use. you have a lot of paper to carry around (Final Survey).

\subsubsection{Access}

One of the aspects of MyPortfolio that helped the students organise their resources was the ability to access their work from a range of locations. The students could upload files at home or in class and work on them from any computer and this meant that their work was always together and they could access it easily and 24 of the 25 students in this study (96\%) reported accessing MyPortfolio from home (see appendix 1.10). In the final survey, 13 of the 25 students made specific comments relating to the fact that they appreciated using MyPortfolio at home and one of these students noted:

I enjoyed being able to be able to access my work from home, work on it, and do things like put on YouTube videos, personalise my profile, etc(Final Survey).

This convenience is one of the key features often reported in the findings of studies of student perspectives of the electronic portfolios specifically and online learning in general (Barrett, 2008b; McMullan, 2006; Ntuli et al., 2009; Reisetter \& 
Bogdan, 2004) and the use of applications like MyPortfolio may help to support students who struggle with managing their resources as they provide a central place to store their work that does not rely on students remembering to bring work to class or home.

The ability to access MyPortfolio from a range of locations may be a way of to help overcome the digital divide that occurs for students who do not have access to computers at home (Tapscott, 1998), as students are able to access their work from any computer that is connected to the Internet, including school computers outside of class time. This may have been true for some of the students in this study group, seven of whom reported accessing MyPortfolio from another school computer (see appendix 1.11) at other times of the day. The fact that students could access MyPortfolio from a variety of locations also may also give the students the opportunity to be independent in space and time and yet work together (Garrison \& Kanuka, 2004).

\subsubsection{Time Management}

The second organisational aspect of MyPortfolio that emerged from my analysis of the data in the study related to time management. When I analysed the data, it became clear that there were a variety of views on how MyPortfolio affected the students' time management and while the students were not specifically asked about time management in the final survey, two students made particular reference to the way that they felt MyPortfolio helped them manage their time. One noted:

It was good for time management because $i$ could do one dot jot note ${ }^{42}$ per session then keep on the portfolio and be able to access it from school or home or anywhere (Final Survey).

However, not all of the students in this study were positive about the way that using MyPortfolio affected their time management. In particular, some of the students commented that they found the use of MyPortfolio time consuming and this affected their ability to manage their time and in the final survey four of the $25(16 \%)$ students agreed with the idea that using MyPortfolio took up too much time.

\subsection{Procrastination}

42 'Dot jot notes' were an aspect of the assignment set by the teacher 
One aspect of MyPortfolio use that may have affected the students' ability to manage their time was fact that it provided the students the opportunity to procrastinate about doing their work. Many studies of online learning suggest that students can struggle to manage their time when working in an online environment (Burge, 1994; Hughes \& Hagie, 2005; Reisetter \& Bogdan, 2004) and Hong, Lai \& Holton (2003) suggest that online learning can lead to students procrastinating and some of the students' comments and my own observations also confirm this. When asked whether they would recommend MyPortfolio for use with other students, two students responded with comments relating to the fact that they found they were easily distracted when using MyPortfolio:

When you are MyPortfolio you get distracted and side tracked more often looking at youtube videos etc (Final Survey).

While some of the literature on online learning suggests that students are very comfortable with multi-tasking (Chizmar \& Walbert, 1999; Tunison \& Noonan, 2001) these comments suggest that at least two students found the use of technology distracting. Tunison and Noonan (2001) also found that some students do not adapt naturally to the more self-directed environment of online learning and that they needed support to transition into this context and this may have been the case for the students who made this comment in the final survey.

\subsubsection{Sense of community}

An interesting paradox occurred for some of the students in this study in that although the students were working together in small groups and were together as a class in the computer laboratory, for some of the students in this study, the fact that they were predominately making use of MyPortfolio and other ICT in the computer laboratory resulted in a lack of sense of belonging and relatedness that they were used to experiencing within the face-to-face classroom situation and this impacted the learning experience for some of the students in this group. In the final survey, I asked the students whether they felt that using MyPortfolio had taken up too much time in class. Four students 'agreed' with this statement and a further nine students were 'not sure' (see appendix 1.27). While 12 of the students 'disagreed' or 'strongly disagreed' with this statement, this does show that some the students in this study were not happy with the amount of time spent working with MyPortfolio. In the final survey, two students particularly noted that they missed the larger class context. One student said that she did not like... 
.... Not learning in a classroom...(Final Survey).

Similarly, another student noted that:

If we hadn't used MyPortfolio for the whole time then it would have been a good balance of computer and class. Personally I would have just preferred to learn in class instead of doing the whole unit on the computer (Final Survey).

In particular, is seems that the aspect of learning that the students identified as missing was the whole class interaction with each and the teacher. While many studies identify the fact that online learning has the potential to connect students and create communities of learning (Palloff \& Pratt, 1999) it is important to also note that online learning can have a negative effect on students' perceptions of interactions with both other students and teachers (Howland \& Moore, 2002; Molesworth, 2004; Reisetter \& Bogdan, 2004; Rice, 2006; Song et al., 2004). In particular, studies have demonstrated that students can feel isolated without face-to-face contact (Lim, 2002) and that students report that a sense of belonging or community is often lacking during online learning experiences (Rovai, 2002). Although this study was conducted in a blended learning mode with the students working in groups and having contact with the teacher during each lesson, several students articulated the fact that they missed the larger group community that occurs in a standard face-to-face classroom situation and this issue is absent from discussion on electronic portfolio use in schools and Reyna, Brainert, Effkin, Bootzin and Lloyd (2001) note the paradox that occurs within use of technology: where some students enjoy the efficiency and relative anonymity of using ICT, for others, it can increase social isolation when it usurps or replaces normal faceto-face interaction.

Rovai (2002) notes that the classroom learning community consists of two important components:

- feelings of connectedness among community members

- and commonality of learning expectations and goals

For some of the students in this study, the feeling of connectedness that they usually enjoyed in the classroom was missing in this study and this was the case for case study student Nancy, who I discuss in more detail in the next chapter (see page 127). While the students did interact with others in their group during the class time, it may be that the asynchronous nature of online learning and the lack of interaction with 
the larger class group affected the students' feelings about being part of a cohesive group (Lim, 2002). For most students, the social interaction that occurs among learners in an important part of the learning process (Howland \& Moore, 2002) and for some of the students in this study, the lack of a wider social interaction had a significant impact on their overall perceptions of their use of MyPortfolio. 


\section{How does MyPortfolio support constructivist approaches to learning?}

One of the strong agreements for e-portfolio use is that it can support constructivist approaches to learning. In particular, it is often argued that the use of eportfolios can help support three key aspects of constructivist learning: the ability for students to collaborate; the ability for students to construct knowledge (often through collaboration); and the ability for students to reflect on the work that they have completed (Jonassen, Davidson, Collins, Campbell, \& Haag, 1995; Jonassen \& Land, 2000; Rakes et al., 1999). Consequently, one of the focuses of this study was to investigate how well the use of MyPortfolio could support constructivist learning approaches to learning and, in particular, how well it supported the students' ability to work together in order to complete the assignment set (collaboration and knowledge construction) and then reflect on the work that they completed.

In following with this study's focus on the student perspective, this chapter draws on a mixture of data sources including my observations of the students during the time in the computer laboratory; the students' MyPortfolio work; and the students' final survey responses. In doing this, I have drawn together the themes that emerged from the data and made some analyses of the way in which MyPortfolio can support student collaboration, knowledge construction and reflection.

\subsubsection{Collaboration}

A key aspect of constructivist learning is the ability of students to work together or collaborate and one of the aspects of the students' use of MyPortfolio that I looked at was the way in which students made use of it in order to work together to complete the tasks set. In the final survey when whether they felt that MyPortfolio had been good to work on with other students, 20 of the 25 students (80\%) (see appendix 1.13) either 'agreed' or 'strongly agreed'. This suggests that many of the students found MyPortfolio a useful tool for collaborating with other students. One of the survey group students also commented on the fact that using MyPortfolio helped them to work together with other students to complete the work set:

MyPortfolio is an excellent way to work together as a team on a project (Final Survey).

Further, $19(76 \%)$ of the students who completed the final survey either agreed 
or strongly agreed that MyPortfolio “... tells me what my friends and other members of my group are learning" (see appendix 1.14). Similarly, 20 (80\%) of the 25 students surveyed either agreed that MyPortfolio was good for showing their progress to other people (see appendix 1.15). This ability to understand what other members of the class are learning is an important feature of students collaborating in order to develop their own learning and the fact that the students could see each others' work helped them to work together to complete the tasks set.

The main area of collaboration that the students in this study identified MyPortfolio as supporting was helping them with the process of learning (Palloff \& Pratt, 1999) in that it helped them to communicate with other members of their group and organise the work that they had completed together. In particularly, seven students in the final survey noted that they appreciated being able to see other group members' work and that at times, this helped them to complete their own work (as discussed in Chapter 5).

Although many of the students in this study appreciated using the communication features of MyPortfolio for collaboration, several students did find that, at times, MyPortfolio did not effectively support group collaboration. In particular the version of MyPortfolio utilised in this study did not allow students to cocreate views. Students were able to create individual views and make these available to their 'friends' for viewing. However, students were not able to co-create the same view as each view required an individual log-in in order to access it. When discussing the limitations of MyPortfolio in the final survey, two of the students commented that they did not like:

- The way you couldn't make a shared view between friends

- The way you can't make shared views for group work...I would make you able to have shared view

(Final Survey)

However, despite the fact that the students reported the fact that they found MyPortfolio good to work on with other students, the extent of the collaboration that occurred using MyPortfolio was in fact limited to using MyPortfolio as a place to share their resources and a vehicle through which to communicate with each other- in effect support the process of learning, rather than knowledge construction (Palloff \& Pratt, 1999) and there was little evidence that the students actually made use of 
MyPortfolio in order to co-create the actual work that they had to complete for the assignment. In this way, the students seemed to prefer face-to-face communication when it came to actually completing the work set.

This seems to be a relatively common phenomenon in both studies of both blended learning situations (Garrison \& Kanuka, 2004) and the use of e-portfolios (McLeod \& Vasinda, 2009; Ntuli et al., 2009) and while Bonk and King (1998b) found that although students heavily engaged in text generation when working together on the Internet, they also found that not much of it could be considered socially interactive or collaborative. Similarly, the students in this study did undertake many social interactions, predominately via the messaging (as discussed on page 89), however, although they created a number of work documents and made use of MyPortfolio in order to store the information that they gathered, they did not utilise the technology collaborate in order to complete their assignments. Rather, the students made much more use of face-to-face communication when it came to the process of collaborating for the final task. One explanation for this may have been that the students found making use of the communication tools time consuming and the fact that they were working in a blended learning environment allowed them to utilise face-to-face communication in preference (Bonk \& King, 1998a). Further, in their study of student collaboration in a blended learning situation, Schweizer, Paechter and Weidenmann (2003) found that if the task set required an exchange of knowledge in order to come to a joint solution, then students achieved better results if working in a synchronous setting and, in this way, the students in this study may have been making use of the most efficient and effective mechanisms for achieving the tasks set.

Vonderwell (2003) comments that the online environment is particularly suited to approaches that emphasise group interaction and in terms of the way that MyPortfolio supported the process of learning, this was true in this study. However, while the students in this study made use of the communication functions within MyPortfolio, the purpose of their communication tended to be task-oriented and related to checking the progress of their group members, informing their group of progress or clarifying information. The students did not make use of the communication mechanisms within MyPortfolio to collaborate on tasks set such as preparing the presentation or making decisions about how to proceed with the work set or to develop ideas and the fact that this study was conducted over a relatively short period of time- six weeks- may have impacted on this. Walther (1996) argues 
that more longitudinal use can provide for extensive interpersonal and social relations and that while less information is contained in each message, the accumulation over time can lead to rich social relations. Similarly, Bonk and King (1998b) note that time appears to be a critical variable when developing effective communication via ICT and they suggest that that this aspect of student communication develops of time. It is possible that the short timeframe of this study meant that the students did not have the opportunity to develop more in-depth communication in order to generate knowledge.

\subsubsection{Knowledge construction}

In many ways, this study was not long enough to fully investigate the way in which the students went about knowledge construction using MyPortfolio. However, there were some aspects of the knowledge construction that emerged from the data that I collected throughout the study. In particular, the Chapter 4 (see page 89), I discussed the way in which the students made use of the communication functions within MyPortfolio in order to complete the tasks set and noted the fact that there was very little evidence of the students making use of the communication functions in order to co-construct knowledge. In this respect, the students seemed to prefer making use of face-to-face contact in order to develop their ideas and create knowledge.

However, although there was little evidence that the students made use of the communication functions to create knowledge, they did develop their ideas through the use of the views and in Chapter 4 (page 91) I discussed the way in which the students' views developed over time. The use of the views allowed the students to keep track of their work as the study progressed and also allowed them to build up a repository of their ideas as can be seen with the way in which the students added files to their 'My files' and their views throughout the course of the study. Although this study was not long enough to make a conclusive statement about how MyPortfolio can support knowledge construction, this use of the application suggests that the use of MyPortfolio over time may help students to organise and develop ideas over time.

\subsubsection{Reflection}

A final key aspect of constructivist learning is the ability for students to reflect on the work they have completed in order for them to be able to learn and improve in the future (Barrett, 2005; Goldsmith, 2007; Gray, 2008). Similarly, in writings about e-portfolio use, it is often argued that a key feature of electronic portfolios is the ability for students to see how their work develops over time and reflect on the 
learning that they have undertaken (Avraamidou \& Zembal-Saul, 2002; Barrett, 2005, 2008b; Johnson et al., 2006). However, increasingly, studies have found that students do not naturally engage in reflective thinking (McLeod \& Vasinda, 2009; Tunison \& Noonan, 2001) and that the level of reflection can often be quite shallow (DevlinScherer, Martinelli, \& Sardone, 2006).

The final outcome of the research that the students undertook as part of this study was a presentation. The students were able to choose what form the presentation took and the students in this study used a mixture of presentation formats including creating a specific view, creating a PowerPoint presentation and creating a video. As well as completing the presentation the students were also required to complete a number of process tasks including keeping a research log and completing a final evaluation. The students in this class are often required to evaluate their work and reflect on their progress so this was not a process that was new to them. While all of the groups completed their presentation, a number of the students did not complete all of the additional tasks and their reflection was predominantly at surface level and tended to be very brief:

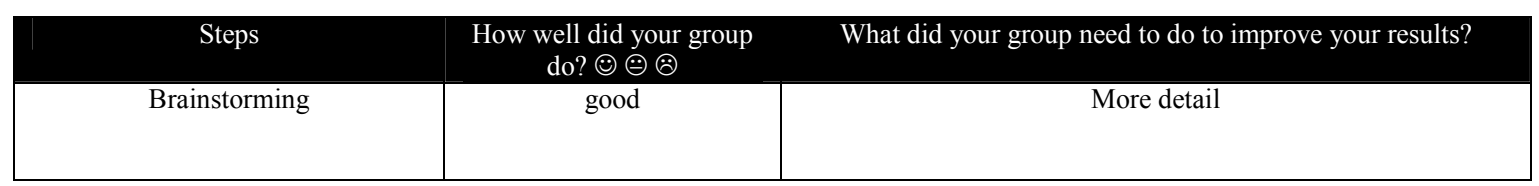

Figure 19 An example of a comment in a student's final evaluation (11/11/08)

This table demonstrates the way in which the reflection completed by students in this study tended to be brief and lack insight into learning processes.

In their study of student use of e-portfolios, McLeod and Vasinda (2009) identified three key aspects features of reflective learning in order to assess how students were reflecting on their work. The aspects that they assessed were:

- Connection to learning- whether students were able to make connections to what they had learnt about the content

- Connections to self as a learner- whether students were able to identify strengths and weaknesses of themselves as learners

- And evaluation of the quality of their work

(McLeod \& Vasinda, 2009) 
In order to examine the level of reflection that students undertook in this study, I assessed the daily logs and final evaluations of the 25 survey group students and looked for evidence of the above three forms of reflective learning.

\subsubsection{Connection to learning}

When I viewed the students' reflections, I did not find any evidence that the students were making connections to their learning. All of the comments that students made related to the processes that they were undertaking, such as learning to use MyPortfolio or how they were collecting information for their assignment. An example of the kinds of comments that the students made can be seen in the daily log of one of the survey group students shown below:

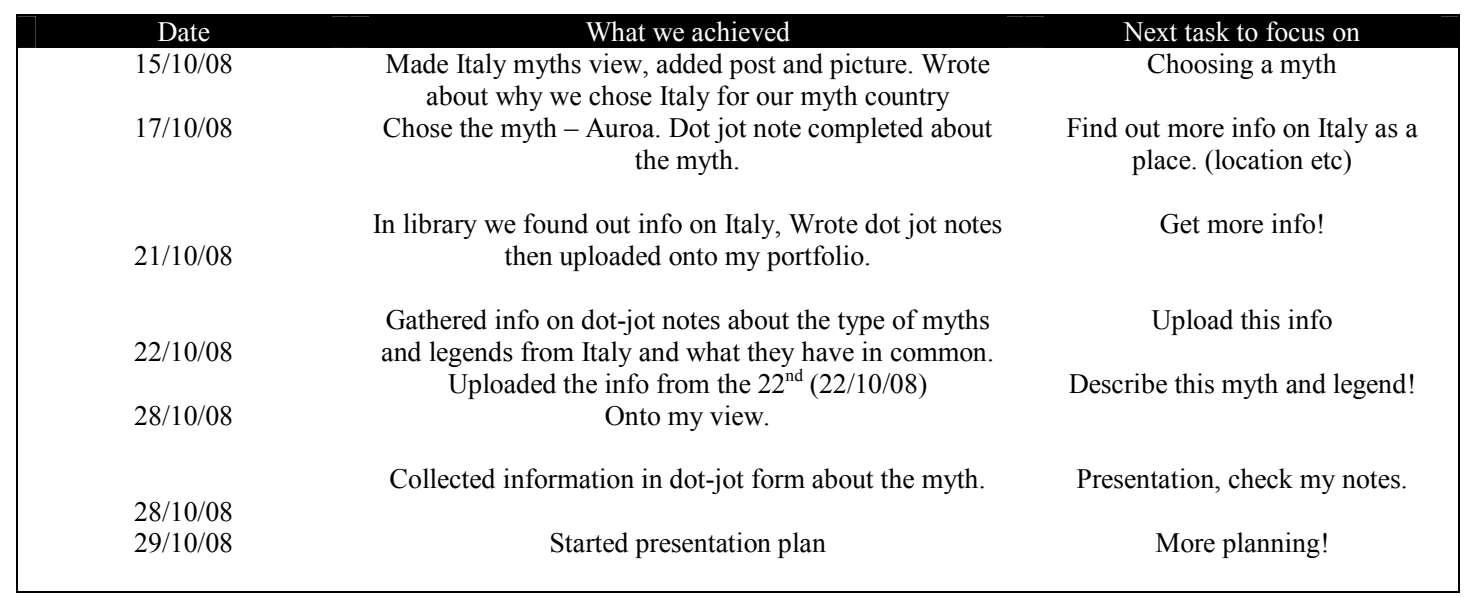

Figure 20 An example of the comments in a survey group student's daily reflective log

This figure shows the way in which the students' reflections during the course of the study lack depth and showed little evidence that they were making connections to their learning.

\subsubsection{Connections to self as learner}

Similarly, there was very little evidence that the students reflected on themselves as learners and when assessing the daily logs that the students kept, I did not find any examples of the students making connections to themselves as learners. The final evaluations asked the students to assess the way that they undertook the research task set and the responses that the students gave were very brief and, again, usually related to the processes that they undertook throughout the course of the study: 


\begin{tabular}{|c|c|c|c|}
\hline Steps & $\begin{array}{l}\text { How well did your group } \\
\text { do? }(;) ;(;)\end{array}$ & How well did you do? & $\begin{array}{l}\text { What did you need to } \\
\text { do to improve your } \\
\text { results? }\end{array}$ \\
\hline Brainstorming & :- & :- & $\begin{array}{l}\text { Work faster and more } \\
\text { as a group. }\end{array}$ \\
\hline $\begin{array}{c}\text { Gathering information from a variety of } \\
\text { sources }\end{array}$ & ;) & ;) & $\begin{array}{l}\text { Gather information } \\
\text { faster. }\end{array}$ \\
\hline $\begin{array}{l}\text { Note-taking using the Dot and Jot } \\
\text { Method }\end{array}$ & ;) & ;) & $\begin{array}{l}\text { Use the dot and jot } \\
\text { method more. }\end{array}$ \\
\hline $\begin{array}{c}\text { Writing the information in your own } \\
\text { words }\end{array}$ & (;) & (;) & nothing \\
\hline $\begin{array}{l}\text { Presentation skills for final presentation } \\
\text { - originality, flair, visual impact, and } \\
\text { completed on time }\end{array}$ & ;) & & nothing \\
\hline Writing the Bibliography & : & : & $\begin{array}{l}\text { Adding it to the } \\
\text { presentation and saving } \\
\text { the Bibliography. }\end{array}$ \\
\hline $\begin{array}{l}\text { What would you change about the way } \\
\text { you did your assignment? }\end{array}$ & $\begin{array}{r}\text { Nothing. Apart from wor } \\
\text { gro }\end{array}$ & $\mathrm{g}$ faster and more as a & \\
\hline
\end{tabular}

Figure 21 An example of a survey student's final evaluation

This student's evaluation was typical of the students in this study and demonstrates the fact that they made little connection to themselves and the way in which they had undertaken learning through the course of the study. While the ongoing nature of the e-portfolio tasks completed during this study gave the students the opportunity to reflect on their work during the course of the study and again at the end of the study, there was little evidence in their evaluation that they made these connections.

\subsubsection{Evaluation of the quality of work}

When I reviewed the students' final evaluations, I only found three examples of students reflecting on the quality of their work and these reflections were brief and lacked detail. An example of this can be seen below:

\begin{tabular}{|c|c|c|}
\hline Steps & $\begin{array}{c}\text { How well did your group } \\
\text { do? }+(;)\end{array}$ & What did your group need to do to improve your results? \\
\hline Brainstorming & $\odot$ & $\begin{array}{c}\text { More detail. Although we made a script, we should have } \\
\text { thought of more possibilities. }\end{array}$ \\
\hline
\end{tabular}

Figure 22 A student's final evaluation- reflection on the quality of work

Although the student has made a comment about the fact that they needed to add more detail to their work in order to improve the quality, they have not give any information about what this would have improved or what kinds of 'possibilities' they could have thought of. 


\subsubsection{Overall levels of reflection}

Overall, the students' reflections contained very little evidence of critical learning and this reflects findings by other writers who note that there is very little evidence that utilising technology such as e-portfolios directly leads to more autonomous work or an improvement in critical thinking skills (Monteith \& Smith, 2001; Ntuli et al., 2009). This seems to be a common phenomenon in portfolio use (Wade \& Yarbrough, 1996; Woodward \& Nanlohy, 2004) and is an issue that teachers must be particularly aware of. Obviously, in this study, the students were working over a relatively short timeframe and this impacted on the students' ability to develop meaningful reflection (Barrett, 2008b) and studies suggest that students do develop better reflective thinking skills over longer periods of time (Avraamidou \& ZembalSaul, 2002; McLeod \& Vasinda, 2009). However, the students in this study did not naturally develop deep reflection of the work that they undertook during the six weeks I followed them. This finding reflects other studies which also suggest that students do not necessarily take advantage of opportunities for deep learning unless they are provided support to do so (Salomon, 1985) and that, in fact, many students lack the higher order thinking skills that would allow them to meaningfully reflect on the work that they have completed (Luckin et al., 2009).

\subsubsection{Summary}

Although there is much commentary about the ways in which e-portfolios can support constructivist approaches to learning, in regards to the three areas of constructivist learning examined in this study, it is clear that the use of MyPortfolio needs to be carefully managed in order to be effectively utilised. While there were some technological limitations to how MyPortfolio could be used to collaborate at the time of this study, particularly in relation to the ability to co-create views, the students did seem to prefer to undertake collaboration in a face-to-face context. Having said this, the students did appreciate the ability to communicate with each other and this helped them both further develop their learning community and make progress on the tasks set during this study. The use of the views also helped the students to collect and organise their ideas in this way, enabled the students to construct their ideas in order to present them to the rest of the class. However, although MyPortfolio mechanisms for students to reflect on their work, by-in-large the students did not make use if these mechanisms and there is a clear role for the teacher in ensuring that students have the skills necessary in order to effectively reflect on the work that they undertake. 


\section{The case study students- an in-depth look at how six students used and perceived MyPortfolio}

\subsection{Introduction}

The previous chapters have detailed the way in which I collected data from the whole class and some of the themes relating to the students' use MyPortfolio and their perceptions of their use that emerged from that data. The aim of this chapter is to give a more in-depth representation of these themes through the perceptions and experiences of six students. In order to give depth to my discussions on the use of the six case study students, I have made use of my observations of the students during class time, the students' MyPortfolio work, the students' daily logs, their final survey responses, and their responses in the final interview. This use of a wide range of data allowed me to consider each of their experiences in detail and reflect the key ideas that emerged.

\subsection{Introduction to the case study students}

From the class group of 25 students, I selected six students to examine in-depth in order to observe their experiences with MyPortfolio in detail. The experiences of each of the case study students provides a different perspective on how students might make use of MyPortfolio and their experiences highlight the way in which students' skills, abilities and interests vary.

Nancy's experience highlights the way in which students are able to make use of MyPortfolio to express their personality and communicate with others. She also suggests that MyPortfolio can be a useful tool for planning and organisation. However, Nancy did miss the social interaction with the wider class group during the course of this study.

Robina's case gives an example of the way in which a student who lacks confidence with ICT can struggle to make use of technology and may need additional support. Robina's experience with MyPortfolio led her to feel that MyPortfolio was too hard to use, however, she did believe that MyPortfolio helped her with her time management skills.

Ashleigh's use of MyPortfolio is a clear example of the way in which some students are motivated by the ability to make use of technology and she felt that 
MyPortfolio helped her to both communicate with other students and organise her work.

Of all of the case study students, Hannah was the least positive about MyPortfolio and felt that it was too hard to use and her experience with MyPortfolio shows the way in which students can become discouraged if their introduction to a new technology is not carefully supported. However, Hannah did find that using MyPortfolio helped her to collaborate with other students in order to achieve the tasks set by the teacher.

YoYo also made use of MyPortfolio to show her personality and she was positive about her experience with the application. Like Ashleigh, YoYo reported that using MyPortfolio helped her organisation and her ability to collaborate with others.

Finally, Mary's experience highlights the way in which students' perceptions of their ability with ICT do not always match the reality. Mary needed additional support in order to make use of MyPortfolio and this is an aspect of student use of technology that teachers must be aware of.

\subsection{Selection of the case study students}

The six case study students were chosen after the students completed an initial survey profiling their attitudes towards and ability with using computers and were selected in order to represent a range of attitudes about computer use from within this class of students. The tables below show some of the differences in attitude that existed between the students in this case study group:

\subsubsection{Time spent using computers}

All of the students in this class reported a relatively low level of computer use at school- between one and four hours a week. The six case study students, therefore, represent a range of levels of usage at home with Ashleigh and Robina reporting the least use at home and YoYo and Nancy reporting the most use:

\begin{tabular}{|c|c|c|c|c|}
\hline & Computer at home & Internet at home & Computer at school & Internet at school \\
\hline Ashleigh & $1-4$ & $1-4$ & $1-4$ & $1-4$ \\
\hline Robina & $1-4$ & $1-4$ & $1-4$ & 0 \\
\hline Hannah & $5-10$ & $1-4$ & $1-4$ & $1-4$ \\
\hline Mary & $5-10$ & $5-10$ & $1-4$ & $1-4$ \\
\hline YoYo & $10-20$ & $10-20$ & $1-4$ & $1-4$ \\
\hline Nancy & $10-20$ & $10-20$ & $1-4$ & $1-4$ \\
\hline
\end{tabular}

Figure 23 Attitudes towards computer use - hours per week using the computer 
In the methodology, I discussed the way in which I also selected the case study students for a range of attitudes towards the use of computers both at home and in the classroom (see page 58).

\subsubsection{The computer laboratory}

The students worked in one of the school's computer laboratories throughout the course of the study.

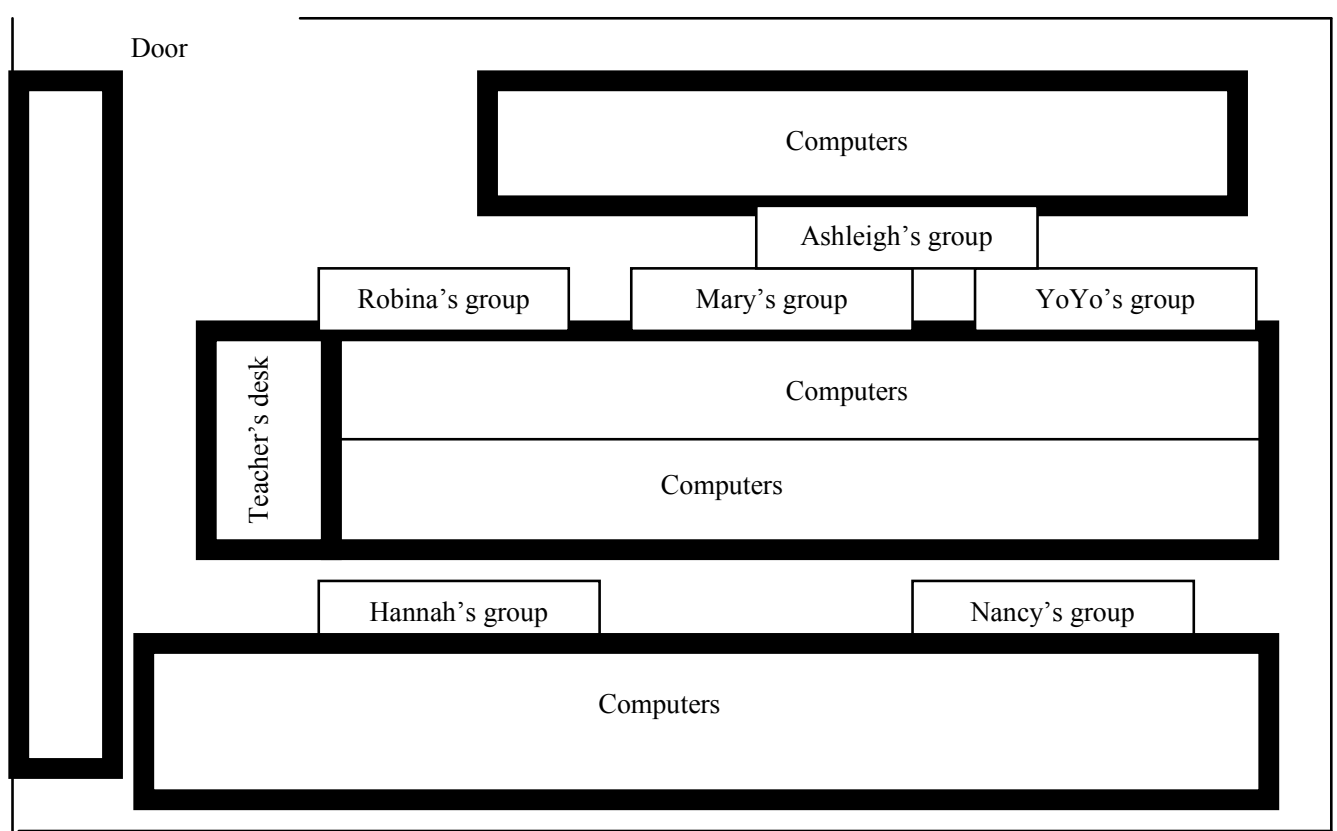

Figure 24 Layout of the computer laboratory at the school and the case study students locations through out the course of the study

The students work in assigned groups of 3-4 students, as established by the class teacher, however, although they were working together to complete the tasks set for the assignment, they were also required to complete individual tasks. For this reason, the students tended to sit together as a group but make use of one computer each. The students did not have assigned seating and so their positions each lesson varied.

However, by the end of the study, each group tended to make use of a particular area of the laboratory (see figure 24).

The case study students completed the same work as the rest of the members of the class, however in addition to the initial and final surveys and the assignment tasks completed by all the members of the class, the case study students also completed daily logs and I observed each student during class time. I also negotiated permission to closely view their MyPortfolio work and I conducted an interview with each student at the end of the study. As a result of this, I have a complete data set on each of the six 
students- Nancy, Robina, Hannah, Ashleigh, YoYo and Mary. The descriptions of each of the case study students summarised in this chapter provide an in-depth insight into the issues raised during this study.

\subsection{Nancy}

Nancy saw herself as a confident and competent computer user who enjoyed making use of computers. In the initial survey she 'strongly agreed' that she felt comfortable using computers and made use of a range of applications including using blogs and writing her own computer programmes (see appendix 3.1). Nancy had a computer and Internet access in her bedroom and reported using the computer at home for approximately 10-20 hours a week as well as 1-4 hours a week at school. Of all of the case study students examined, Nancy was the most enthusiastic about using computers and when I discussed her use of computers with her in the final interview, she said:

\section{I love computers, if you ask me "What's my hobby?" I'll say "A computer" (Nancy's final interview).}

Nancy had a mixed experience with using MyPortfolio and her final survey suggested that she did not enjoy making use of the application. However, when I interviewed her, I found that the social aspects of this blended learning situation had a significant impact on Nancy. Nancy's experience with MyPortfolio also demonstrates the way in which even students who feel confident with ICT may need support in order to effectively make use of new applications.

\subsubsection{Initial use}

Nancy was the first of the case study students to finish the initial tasks set by the trainer $^{43}$ and by the end of the first lesson; she was able to create and edit a view and had set up the view she then made use of during the rest of the study (see page 94). Once Nancy had completed all of the tasks assigned by the trainer during the introductory session (see page 67) she took the opportunity to explore other parts of MyPortfolio that had not been discussed by the teacher, such as the 'goals' and 'resume' section. However, in my observations during lesson two, she did not add any information to any of these. She was the only one of the case study students I observed

\footnotetext{
${ }^{43}$ The trainer asked the students to set up an initial view and then to send a message to the teacher to demonstrate that they could do this.
} 
looking at these sections of MyPortfolio during this lesson although I did observe other students looking at these sections later in the study. Nancy was also the first student in the class to send a message to the teacher:

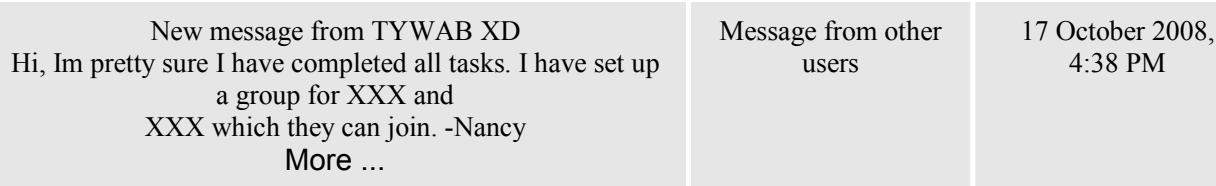

Figure 25 A message to the teacher from Nancy- updating the teacher on her progress

(After Lesson 1)

Nancy sent this message after school on the day that MyPortfolio was introduced to the students and she reported back to the teacher so that the teacher would know that she had completed all of the tasks set. Nancy also informed the teacher that she had gone beyond the tasks set and set up a 'group' so that she could communicate about the assignment with the other members of her group. Both of the other members of Nancy's group joined the group that she set up.

However, despite the fact that Nancy completed all of the tasks set before the other case study students, when asked in the final survey whether MyPortfolio was easy to use, Nancy responded 'not sure' and in her daily log at the end of the first lesson, she noted that she found that the instructor went a little too fast when initially explaining how to use MyPortfolio:

\section{I found it was taught a little too fast, and was hard to catch up- but no technicall problems (Nancy's Log-lesson 1).}

Nancy's comment in her log suggests that even when students feel confident in their ability to make use of computers, it is important not to overestimate their ability and to ensure that students are given plenty of opportunity to learn to use new applications at a speed that is appropriate to their skills.

Although Nancy felt that some of the initial instruction went too fast at times, when I interviewed her several days after the work in the classroom had concluded and we discussed how she found using MyPortfolio, she noted that although she had trouble occasionally, she generally found MyPortfolio easy to use:

Well, like I was pretty confident the whole way through, it was just, you might have given me a bit of homework to do and I was like, uh oh, I don't quite know how to upload this thing and then I'd ask and it'd be like this and I'd be, like "Dude, I knew that". I was pretty confident all the way along; it was just little things I needed help 
with every now and again. But otherwise, really easy (Nancy's final interview).

When discussing the aspects of MyPortfolio that Nancy felt she needed help with in this final interview, Nancy did note that main area that she had found difficult to master was learning to upload and download documents. This was a common theme among the case study students that I investigated and suggests that this is an aspect of ICT use that the students had not encountered before. The trainer showed the students how to complete this task during the initial lesson, however, during the next lesson, Nancy asked me to review how to complete this task. Once she had clarified her use of this process with me she was then able to make use of the process in order to upload documents to her view and download documents for use and in her log for that day she wrote:

Ifound the 'process easier now that I have done it twice (Nancy's log-lesson 2).

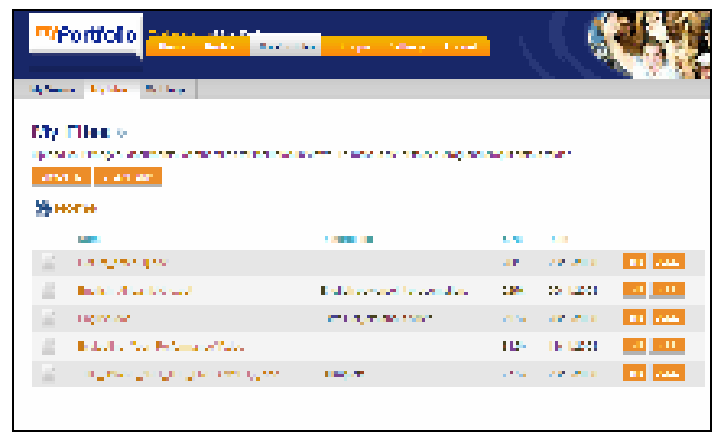

Figure 26 Nancy's 'My files' section (15/11/08) showing the artefacts Nancy had uploaded by the end of the study

By the end of the study, Nancy's 'My Files' contained five artefacts that she had uploaded on four different occasions. Of the files that Nancy uploaded, four were MSWord documents that recorded her research notes and her progress through the study and the other file was a PowerPoint file which contained her group's final presentation. Nancy added all five of these files to her final view and the other two members of Nancy's group also added this PowerPoint file to their views.

\subsubsection{Navigating MyPortfolio}

Nancy had mastered navigating throughout MyPortfolio by the third lesson and could confidently show me how to access different sections of MyPortfolio (My observation Lesson 3). Nancy's growing confidence in using MyPortfolio could also be seen in her log and at the end of the third lesson she commented: 
It was all pretty simple today-nothing really challenging (Nancy's

log-lesson 3).

\subsubsection{Nancy's use of MyPortfolio}

During part of every lesson while working in the computer laboratory, I observed Nancy working independently from the other members of her groupchoosing to work on a computer by herself rather than with the other two members of her group. While all of the students worked by themselves at some point during the study, Nancy did so more often than the other case study students and was the only one of the case study students who sat physically apart from the rest of their group during some of the lessons- which Nancy did on at least three occasions. In this way, Nancy was quite an independent student.

At the beginning of the study, a view had been set up for the whole class to access and on this view the teacher placed instructions for the students for the whole unit of work. This meant that when students had finished the work set, they could go to this view in order to find out what the next task was. During one of the lessons when I observed Nancy, she had finished all of the tasks set and was working ahead of the rest of the class on the next task. She had made use of the class view to find the instructions for what to do next and had begun to do the next task before this task had been explained to the class as a whole (my observation lesson 5). Nancy was the first student I observed making use of the class view without prompting from the teacher.

Nancy was also able to help others learn to use MyPortfolio and the other members of her group made use of Nancy to help them to complete the tasks set. I first observed Nancy helping other members of her group during the third lesson and noted her helping other members of her group or members of the rest of the class on four occasions throughout the course of the study (my observation lesson 3). The ability to help others suggests that Nancy felt confident enough in her ability to use MyPortfolio and to explain its functions to other students.

As well as making use of MyPortfolio at school during class time, Nancy reported that she also made use of MyPortfolio from home. When she made use of MyPortfolio from home, she was particularly interested in checking for messages:

(I used MyPortfolio at home quite)... often, probably a couple of times a week. Even if I just checked if I got any messages from people (Nancy's final interview). 
In the final survey, Nancy 'disagreed' that using MyPortfolio had taken up too much time at home and the fact that she reported using MyPortfolio 'a couple of times a week' at home suggests that she found the application engaging.

\subsubsection{Nancy's final view}

By the time she had completed her final view, Nancy had made use of a number of functions within MyPortfolio and within her assignment view had inserted two pictures, created a blog, inserted text boxes and uploaded four documents. Nancy added entries to her blog twice during the study and was the only one of the case study students who made entries in her blog on more than one occasion.

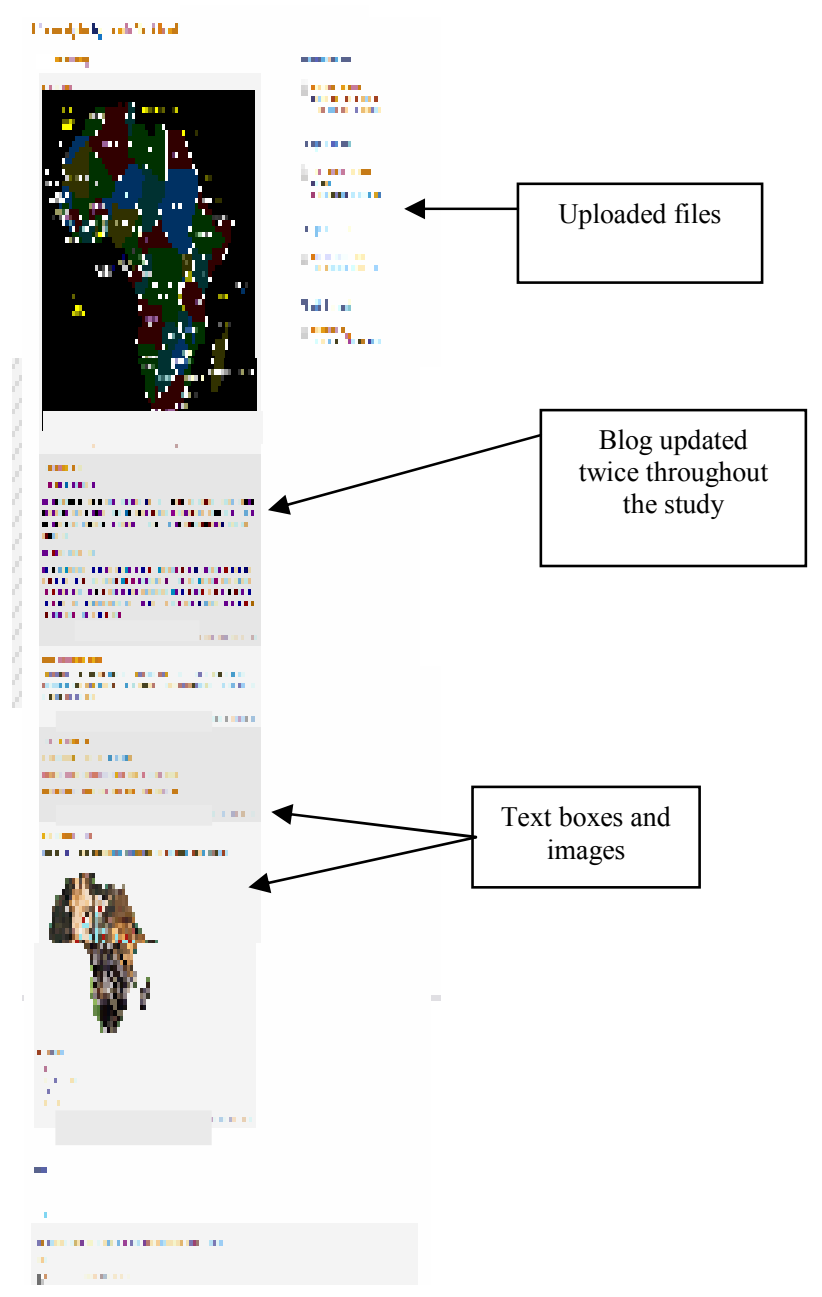

Figure 27 Nancy's final view (25/11/08) showing the artefacts that Nancy added throughout the course of the study

However, when examining her final view, it was obvious that she did not fully utilise some of the functionality of MyPortfolio. 


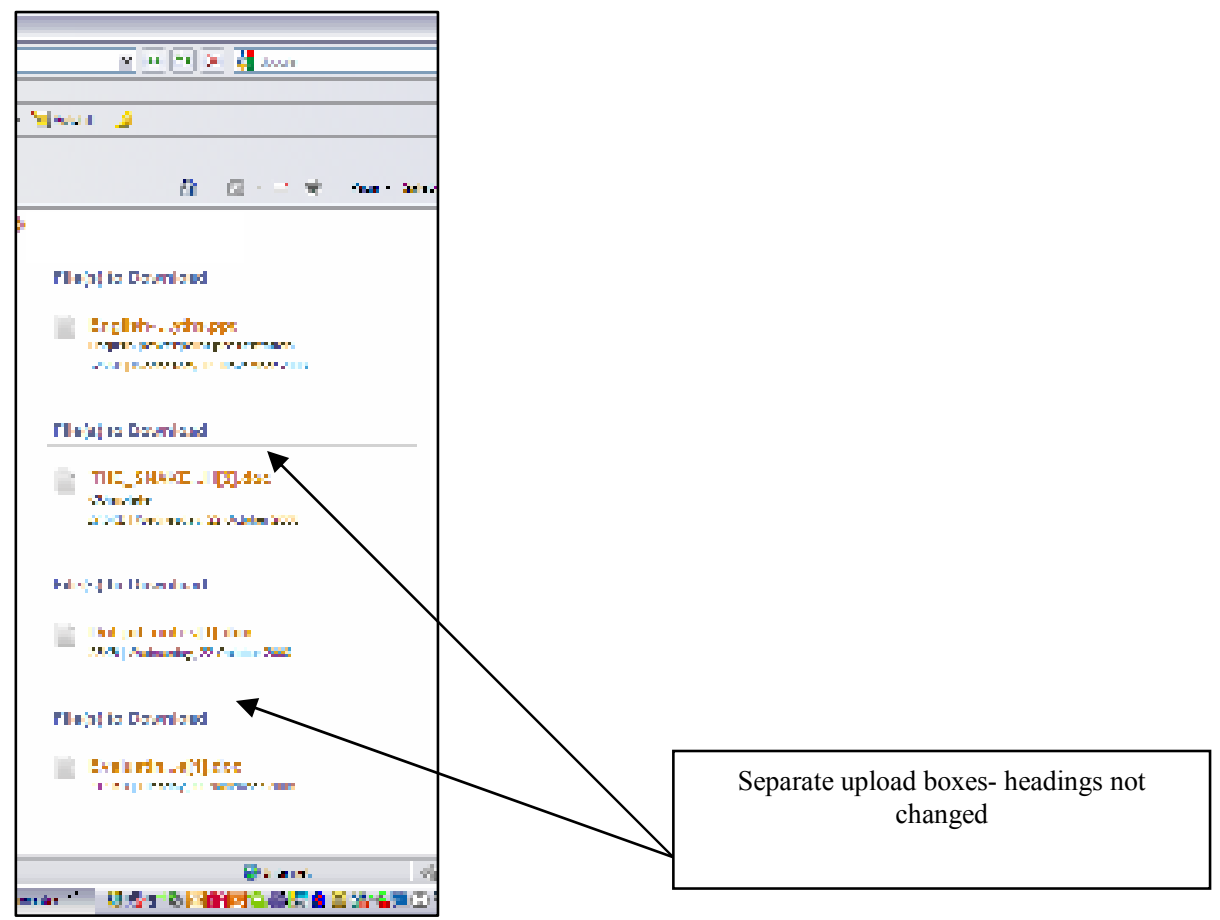

Figure 28 Detail from Nancy's final view (25/11/08) showing her use of the file download tool

In particular, Nancy did not seem to realise that she was able to add all the files in the same upload box, and, consequently, added 4 boxes- one for each of the files that she uploaded. As with her profile, Nancy also worked in one column when completing her final view. While these things did not affect the quality of her work, it does demonstrate the way in which even competent students can benefit from guidance at times in order to fully master new applications.

It was also interesting to note that although Nancy spent time exploring the different aspects of MyPortfolio, made significant use of it throughout the six week trial in order to complete the class work set, and continued to use it after the study had concluded, there is no evidence that she made use of any additional functions, such as the resume tools. The students were not required to use these during the study and, in fact, the teacher did not even show these to the class as a whole so there was no reason that the students should have added information into these, however, Nancy did investigate these functions early in the study and so knew that they were available. The fact that Nancy did not add anything to these parts of the application suggests that they did not interest her in the way that the ability to personalise the profile did.

\subsubsection{Nancy's profile}

Nancy made updates to her profile both at home and at school and I recorded substantial changes to Nancy's profile four times throughout the study. These changes 
included changes to the text she had included in her profile and changes of images posted. Nancy made the most changes to her profile of any of the case study students and her profile also had the largest number of objects (text and pictures) of any of the students in this study.

In the final interview, Nancy noted that she was very interested in the 'Twilight' books $^{44}$ and most of the aspects of her initial profile reflected this interest. For Nancy, using the profile within MyPortfolio was a way to put her interests clearly into view for the other students in the class. Nancy's initial profile was almost exclusively related to the 'Twilight' books and film and she went as far as to change her 'preferred name' within MyPortfolio to 'Jacob Black luvr'- referring to one of the central characters in the 'Twilight' books. Nancy also included pictures from the up-coming film and also her own response to these pictures- for example 'Huh-huh-huh-hot'.

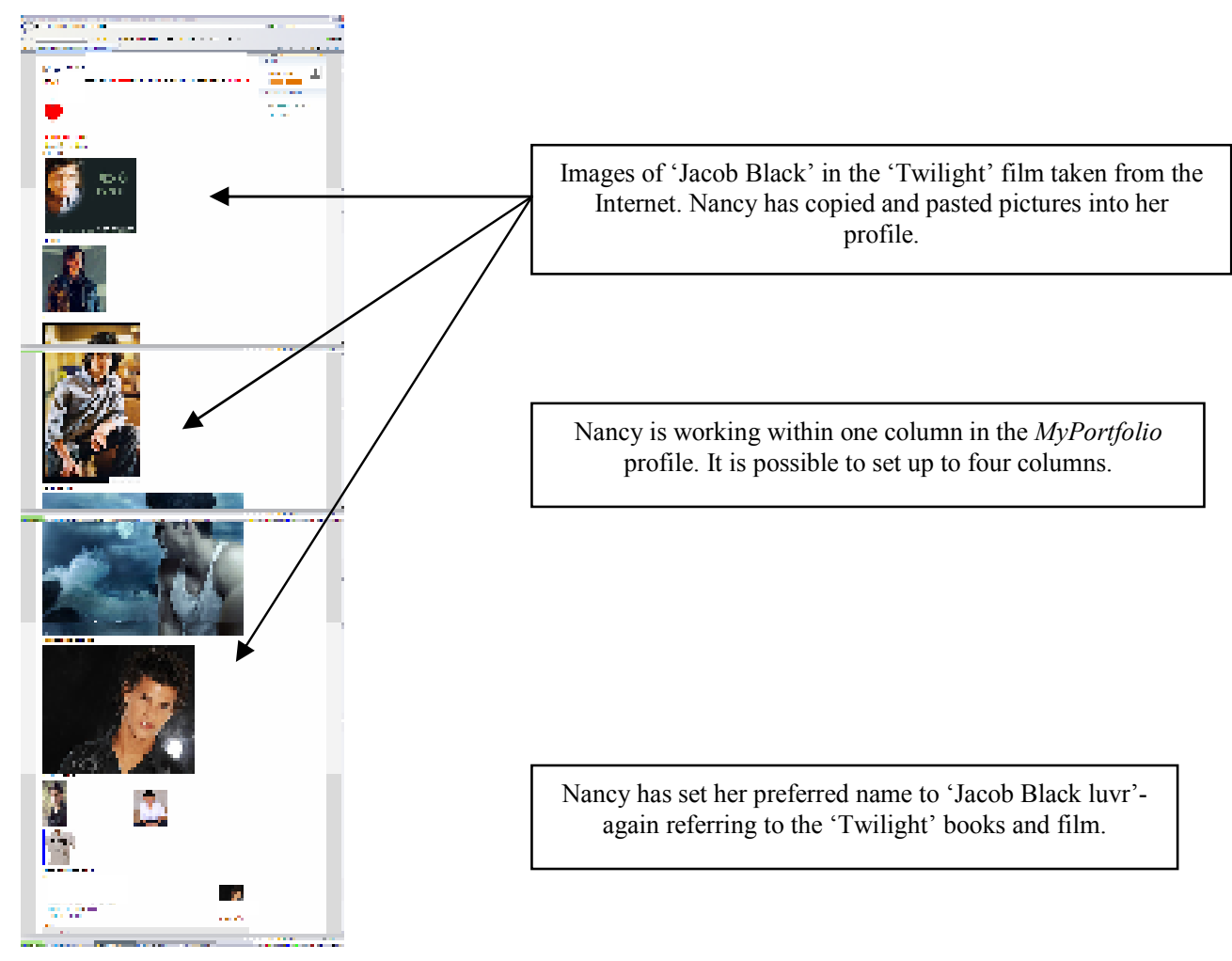

Figure 29 Nancy's profile at the beginning of the study (Lesson 2)

Nancy noted that she also made changes at home and that she enjoyed adding media such as pictures and videos from the Internet to her profile:

\footnotetext{
44 The 'Twilight books' books about a teenage girl named Bella who meets (and falls in love with) a teenage vampire named Edward Cullen. She also has a friend named Jacob Black who is a werewolf. The books are written by Stephanie Meyer and the first book in the series is called 'Twilight'. http://www.stepheniemeyer.com/twilight.html
} 
Yeah, and like it's one of those things that I would go on at home in my spare time to update and stuff. So I really enjoy the profile and also, you know, people uploaded videos so you could watch them and you didn't have to go on YouTube (Nancy's final interview).

Between the beginning and end of this study five weeks later, Nancy significantly updated her profile four times and by the end of the study, it looked quite different from her original profile. In particular, Nancy changed almost all of the content on her profile and by the end of the study, her profile had less focus on 'Twilight' and a wider range of pictures. While Nancy left four pictures from 'Twilight' on her profile, she also added a series of odd pictures of animals; cartoon pictures; text about herself and developed the text addressing her audience. Nancy's profile continued to have a strong sense of audience and her final profile has a large 'Welcome' at the top of the screen. She also added other direct addresses such as 'This font is cool, I dare you to eat it hahaha!'. 


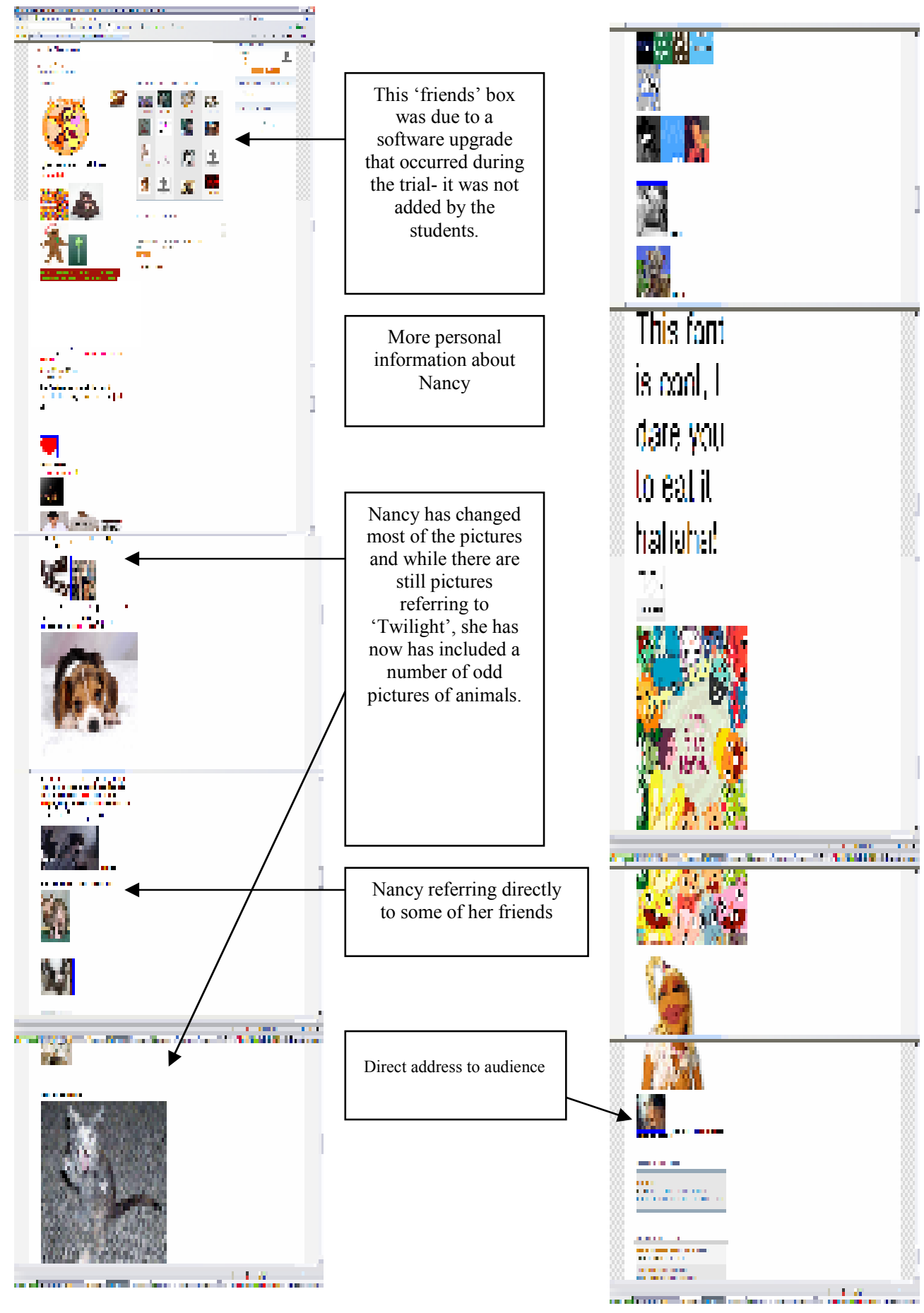

Figure 30 Nancy's profile at the end of the study (7/11/08) with detail showing the development in her profile.

When I interviewed Nancy, I asked her about her profile and why she changed it so often, she identified the fact that the sense of audience was important to her and that changing her profile was a way to engage her audience:

Ijust like change. I just like the whole change, not to be able to keep the same page. I've got one of those Bebo pages and I change it quite often. Cos otherwise if you've got the same page, it's like, they've got the same page, not going to look at their page. But if it 
always changes then it's like “Oh my gosh, Nancy's changed her page again, let's go and look at it" and I really like changing it. I probably will change it again in the future, maybe (Nancy's final interview).

Although Nancy made many changes to the content of her profile, obviously spent time uploading images to her profile and used a number of different fonts, she did not make any use of the design features with MyPortfolio to adjust her profile. An example of this is the fact that she continued to work down the page rather than adding additional columns to her profile. She also did not add any additional contact information to her profile or make use of any other functions such as adding personal blogs to it. Although the content of Nancy's profile developed, she did not appear to make any additional use of the functionality within the profile as the study progressed. The fact that she did not make any additional use of the tools available suggests that the content of her profile was more important to Nancy than the ability to make use of the tools available. For Nancy, using her MyPortfolio profile gave her to opportunity to make her interests public and interact with her friends and this was the part of MyPortfolio that seems to have engaged her most.

\subsubsection{Nancy's perspective of MyPortfolio}

\subsubsection{Planning and organisation}

One of the uses of MyPortfolio that Nancy identified was the ability for it to help her with her planning and organisation and in the final interview she discussed the way in which she used MyPortfolio to help her organise her information and her ideas:

\footnotetext{
It's a lot more easy cos it's like, set out and laid out easier than if you were going to go through a whole lot of paper or whatever, you've just got it on one single web page...it was really organised (Nancy's final interview).
}

In the final interview, Nancy commented that she liked the fact that she could include all of the aspects of her assignment work on her view and that she could incorporate a range of artefacts such as documents, pictures and text information in one place. She felt that this helped her to organise her resources and also to be able to see all of her work in one place which helped her to organise her ideas. When I asked Nancy about whether she would want to continue to make use of MyPortfolio in the 
future, it was the planning and organisational aspects that she particularly noted, as she felt that this aspect of MyPortfolio had helped her to complete her work:

I'd probably use the whole planning, uploading things to so that it's all organised on one page. So that definitely helped. I'll probably use that again. That definitely helped a lot (Nancy's final interview).

\subsubsection{Communication}

A second aspect of MyPortfolio that Nancy found useful was the messaging functions. During the final interview, Nancy reported sending messages to a range of different people, including the members of her group, other students in the class and the teacher. When I asked her about why she sent messages, she noted that most of her messages were in order to support the process of learning, for example, informing the other members of the group about progress she had made with the assignment:

I, like, needed to message people outside of groups and also,

for my group... And I could just easily message them saying you can do this, I've done that (Nancy's final interview).

Nancy also made use of the messaging functions to communicate with the teacher and, at times, asked questions in order to solve problems while using MyPortfolio:

Hi miss- Im done with Q-4a+b you can find them in my veiws and blogs. I have done my reflection which is in my blog :) Nancy More
Message from other users

Figure 31 A message from Nancy to the teacher (28/10/08) showing one of the ways in which Nancy communicated with the teacher

This message, sent in the evening, allowed Nancy to attempt to solve problems while using MyPortfolio out of class time and also kept the teacher informed about her progress. Throughout the study, Nancy sent ten messages to the teacher - the most of any student in this class.

Nancy also found the view a useful tool for communication as it allowed her to see the progress that her group had made and also to communicate her progress to the rest of the group.

... and also I found, like the view, that was really handy cos then instead of having to say to **** and **** "you have to do this, this and this, cos I've done this, this and this" they can just look at my 
page and think, "right, she's done, that, that, I need to do this". I

found that really handy (Nancy's final interview).

Overall, Nancy felt that the combination of tools on MyPortfolio helped her to co-ordinate her group's efforts and that this supported their collaboration as a group:

... probably easier because then I get to talk to **** outside of school, like, we don't really text or ring each other so if I want to talk to her, I can and, like, and also I can upload things to my view and then she can copy it and put it to hers. That was definitely easier, presentation-wise, it was (Nancy's final interview).

This use of collaboration is one of the ways in which MyPortfolio can support constructivist approaches to learning and Nancy's experience shows the way in which students can make use of MyPortfolio to undertake independent learning.

\subsubsection{Lack of social interaction}

Nancy's experience with MyPortfolio presented an interesting dichotomy. In many ways, Nancy was a very independent student who, during my observations, generally worked alone on the assignment. While she conducted face-to-face interactions with the other members of the group when she needed to, she sent the most messages of any of the case study students and chose to work at a separate computer from the rest of her group and sent them messages via MyPortfolio. Nancy also reported a strong enthusiasm for the use of computers and showed that she was able to learn new applications quickly. However, in both the final survey and the interview that I conducted, Nancy expressed a strong desire for more face-to-face contact with both the teacher and other students in the class. In the final interview, Nancy discussed the fact that she did not have a good experience with her group and felt that she had had to complete more than her fair share of the work set. As a result of this, she was quite angry when she completed the final survey and her responses towards MyPortfolio were very negative, for example, in the final survey, Nancy responded that she 'disagreed' with the statement that using MyPortfolio has been fun to do. I was quite surprised by this survey response as I did not observe this reaction during class time. However, by the time I interviewed Nancy several days later, she had reflected more on her experiences and was able to separate her experience with MyPortfolio from her experience with her group and was much more positive about her use of MyPortfolio: 
Now I disagree with it cos that (filling in the survey) was, like, straight after the presentation and I was probably a bit 'thing' about me having to do all the work. But I definitely have a different perspective on that. ...there's nothing I'd improve with MyPortfolio. I think it was really fun (Nancy's final interview).

Nancy's experience with her group meant that although she enjoyed using MyPortfolio and felt that it had the potential to support her learning, especially when used at home, the use of MyPortfolio for a significant component of class time resulted in Nancy missing the interaction with the wider class and the teacher that occurs in a normal classroom setting.

I like doing work, especially English cos it's my favourite subject, in the classroom, like, cos I like that whole more interaction with the teacher. Cos you get more face-to-face interaction, which I like more (Nancy's final interview).

Although this study was conducted with a mixture of face-to-face and use of ICT, the students predominately worked within their groups and this meant that there was not as much opportunity to interact with the teacher and the rest of the class. For Nancy, a key aspect of the interactions that occur within the classroom was the immediate support and encouragement that she felt the other students gave her and she commented:

... Cos, if you type it onto a computer, you get, like "that was really good" and everything but if you say it in the classroom, you'll get claps and everything. You get the love and you get more, like you said, feedback. And people will say "Oh, that was really good, you did this well" but you might not get that so much with computers, which I found (Nancy's final interview).

Nancy clearly valued the social interactions that occur within the classroom and, as discussed earlier, when she was at home, Nancy made use of her profile in order to engage others and in this way, attempted to create an asynchronous community online. The fact that Nancy valued the face-to-face interaction so highly meant that she preferred to make use of the computer at home than at school:

Yeah, I mean like, at home I prefer to go on the computer. But I like the classroom, you get more interaction, you can talk with the teacher and the rest of the class (Nancy's final interview). 
Overall, the lack of social interaction had a significant impact on Nancy's experience with MyPortfolio and this demonstrates the fact that it is not always easy to find the right blend of face-to-face learning and ICT-based learning. For Nancy, this study relied too much on ICT and although she enjoyed making use of technology, she did not want to forsake face-to-face contact with the wider class group in order to make more use of ICT at school.

\subsection{Robina}

In the initial survey at the beginning of this study Robina reported herself to be a confident user of computers and 'strongly agreed' that she felt comfortable using computers. In the same survey, Robina claimed to be able to use a range of applications on the computer, however, when she identified which she was able to use, she listed Microsoft applications such as a MSWord and MSExcel. Despite the fact that she felt comfortable using computers, Robina was not a high user either at home or at school and reported using a computer approximately 1-4 hours a week at home and 1-4 hours a week at school.

Although Robina considered herself to be a confident user, in many ways she had a rather ambivalent attitude towards using computers at school and answered 'don't mind' when asked whether she enjoyed using computers for lessons and whether using computers at school would motivate her to work harder (see appendix 3.2). Robina's initial survey also indicated that she had some trouble using computers at times and when asked whether she found using computers frustrating, Robina 'strongly agreed'. Similarly, when asked whether computers were difficult to use, Robina responded 'don't mind'.

Robina's experience with MyPortfolio particularly demonstrates the way in which support from the teacher can help students develop skills in using ICT.

\subsubsection{Initial use}

When I interviewed Robina at the end of the study, she noted that she had a lot of trouble learning to use MyPortfolio and in particular had initial difficulties with understanding how to use functions such as the blog, the view, and adding friends, as well as uploading and downloading files:

Well, I didn't really understand the view and the file and the blog thing. I didn't really, like, get that at first... and, like editing them. 
Because I had to reedit them because we couldn't find any on our first ones... And also adding friends was a bit, like... (Robina's final interview)

Robina was absent for the third lesson of this study and this meant that she felt that she was behind the rest of the class and struggled to catch up. Her early frustration with learning to use MyPortfolio is reflected in her journal comments:

(what will you work on next period?) Everything- I'm behind and confused (Robina's log-Lesson 4).

Although she reported being a confident user of computers, Robina seemed to lack confidence in her ability to master the new skills and make use of MyPortfolio. An example of this occurred during the fourth lesson (Robina's third lesson). The students were given several written tasks to complete for the assignment and asked to put their work onto their MyPortfolio view. However, rather than completing the written tasks using the blogs or text boxes within MyPortfolio as Nancy did, Robina reverted to using an application she was comfortable with- MSWord (my observation lesson 4).

During the first six lessons, Robina had difficulty making use of MyPortfolio to complete tasks and during the course of the second lesson, had trouble setting up her access and navigating throughout MyPortfolio (my observation lesson 2). She also needed additional support in order complete the tasks set and needed affirmation once she had completed the tasks. In particular, she would check with the teacher or other members of her group to ensure that she had completed tasks correctly (my observation lesson 6).

During this time, Robina not only had difficulty with using MyPortfolio but was also indecisive about what country she would select her myth from and twice changed her mind about this. This meant that she continued to be behind the other students in completing the tasks set (my observation lesson 4). By the end of the fourth lesson, Robina had not made any progress in adding information to her view or changed any aspect of her profile (my observation lesson 4)

Robina's reluctance to work in MyPortfolio can also be seen in the lack of development of her view. During the first session, Robina set up her view and added a picture and two lines of text: 


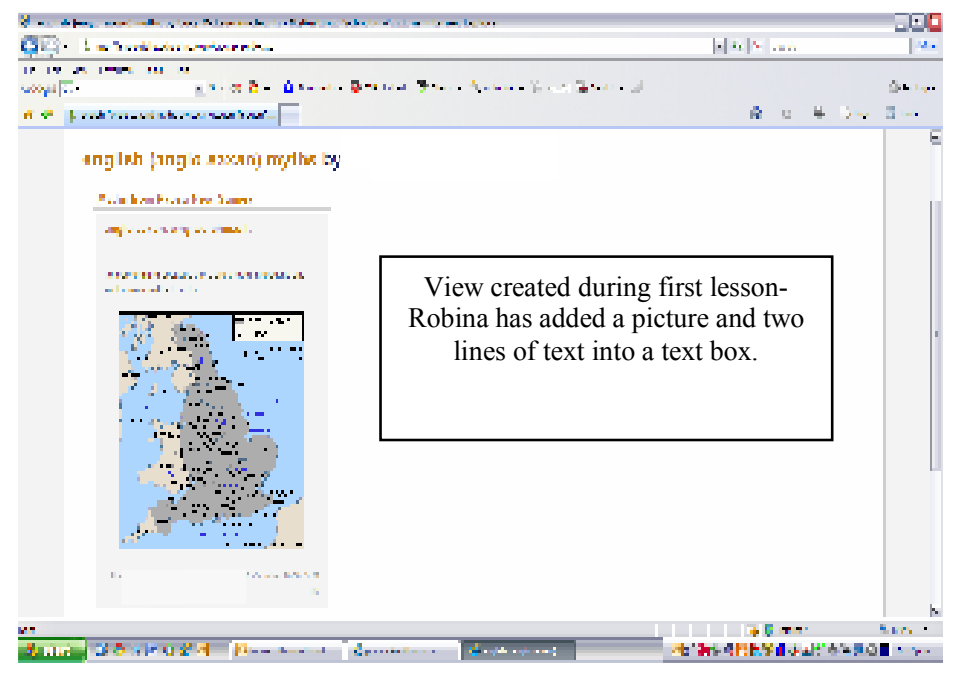

Figure 32 Robina's view at the beginning of the study (17/10/08)

However she did not change her view again until the fifth lesson of the study when she changed the picture and text because her group had changed the type of myths that they wanted to investigate and they were now focussing on Melanesian myths:

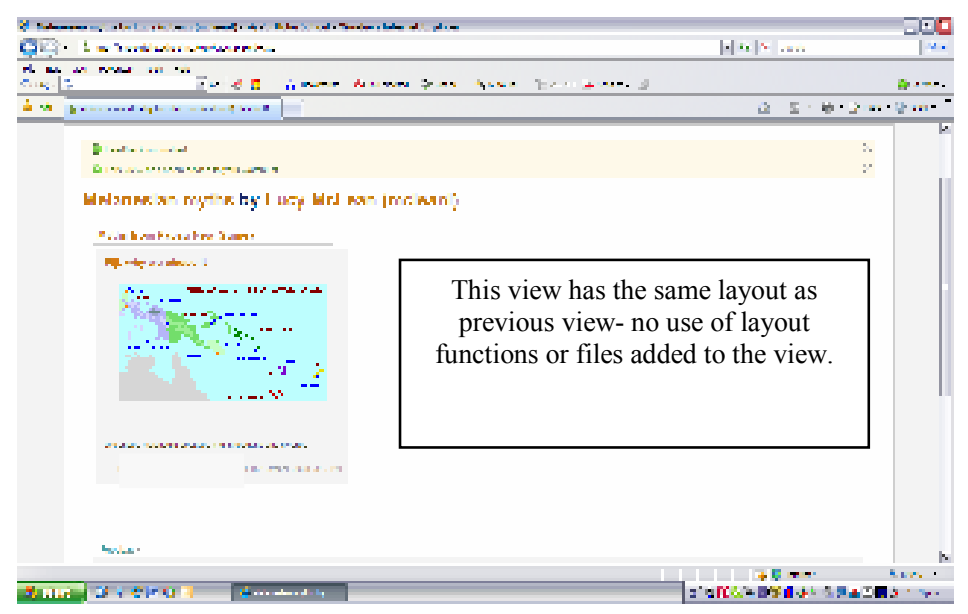

Figure 33 Robina's view at the end of the second week of the study (28/11/08)

Although Robina changed the picture and the text, the layout of her view remained almost exactly the same as before and at the end of this lesson, there was no evidence that Robina had made use of any of the other functions of MyPortfolio.

Robina continued to struggle with using MyPortfolio for the first six lessons and after the sixth lesson; she chose to stay behind during two interval periods in order to gain a better understanding of MyPortfolio. During these sessions, the class teacher worked with her to ensure that she was able to navigate throughout MyPortfolio, add features to her view and upload and download files. After these sessions, Robina could navigate throughout the various areas of MyPortfolio and had pasted a picture into her 
view. She could also upload files to her 'My Files' folder and add them to her view (my observation lesson 8)

During my interview with Robina, she noted that the fact that it had taken her a number of lessons to become comfortable with using MyPortfolio had impacted on her ability to complete her work:

It took me a long time to work out how to do it, so I didn't, really,

like do that much work for the first (Robina's final interview)

In this respect, Robina's initial trouble with using MyPortfolio impacted on both her confidence and her ability to complete the work set.

Throughout this time, Robina created four MSWord documents, however she did not upload them until after she had had extra help from the class teacher. On the $29^{\text {th }}$ of November, Robina uploaded three files into her 'My Files' space and on four other occasion throughout the study added files into her 'My File'.

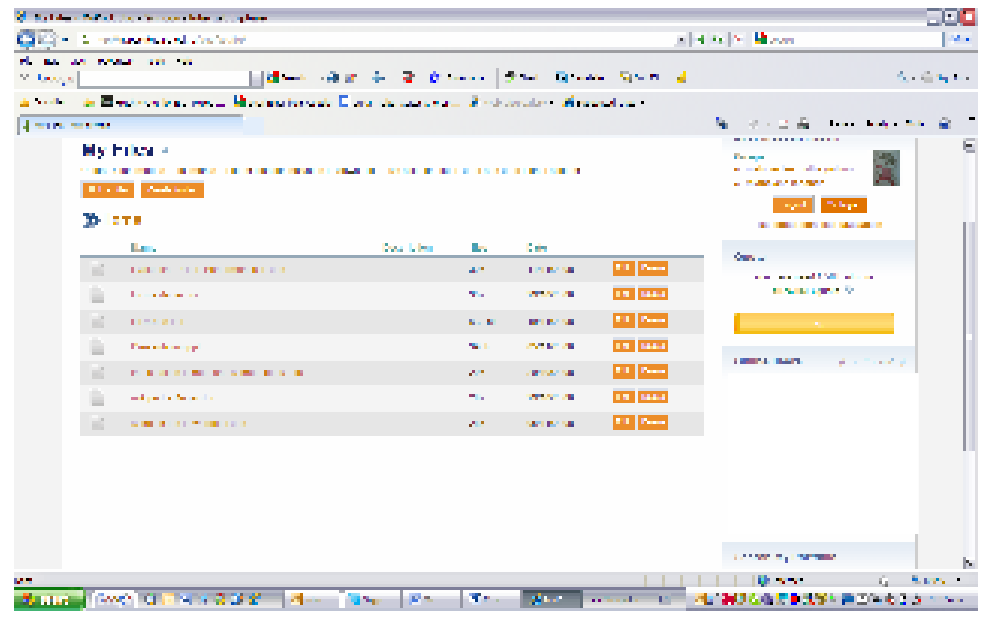

Figure 34 Robina's 'My Files' (28/11/08)- showing the different files that Robina uploaded throughout the study

The extra tuition that Robina received from the class teacher seems to have helped her develop the skills that she needed in order to complete the tasks set.

One of the aspects of the assignment that Robina struggled with was finding an appropriate myth to base her work on. From my observations it appeared that the main reason for this was that she lacked advanced search skills when using Google. In order to find the information that she was looking for, Robina would simply type key words into the Google search bar. Once she had done this, she looked at the first three or four results and if these were not what she was looking for Robina did not continue to search (my observation lesson 5). 
I did not observe Robina attempt to refine her search or use other search terms in order to carry out a more successful search and, during the fourth lesson, the teacher encouraged Robina twice to continue searching rather than give up. The fact that Robina did not seem to be able to effectively search using Google meant that she took longer than any of the other case study students to select her myth and, consequently, begin the tasks set.

Robina's difficulties with trying to find information using Google suggest that she lacked the skills required to effectively make use of this application and during the fourth lesson, the class teacher spent time with Robina suggesting additional search terms and helping her to develop her search skills by using a wider range of search words and making use of Boolean search terms.

Robina's experience with learning to use MyPortfolio reinforces the fact that it is important not to assume that students are more capable with technology than they really are. Based on her own reporting in the initial survey, Robina seemed to be a competent user of technology. However, in reality, her skills were limited to a relatively small number of applications and she struggled to transfer these skills into using MyPortfolio.

\subsubsection{Robina's use of MyPortfolio}

By the end of the study, Robina had developed her skills and confidence in using MyPortfolio and felt that she would recommend it to other students, particularly for helping them to manage their time. However, she also felt that it had taken up too much time both in class and at home and was reasonable ambivalent about her use of it in the final survey, for example, answering 'not sure' to a number of the attitudinal questions about MyPortfolio such as '.. has made me more interested in my work' and '...has been fun to do'.

While students like Nancy reported enjoying making use of MyPortfolio at home, in the final survey, Robina 'agreed' that using MyPortfolio had taken up too much time, both at home and at school and she would have preferred not to make so much use of it at home:

...Cos if I was going to do it in class, I think that would be my choice not to do so much but this I actually had to do it more at home, I think (Robina's final interview). 
Despite her initial difficulties, Robina did not feel that using MyPortfolio had affected the overall quality of her work and in the final survey 'disagreed' that using MyPortfolio had '“... stopped her from doing her best in this assignment'. She felt that it was of similar quality than if she had completed the assignment without using MyPortfolio:

I thought it was quite good but it wasn't amazing, really... (If I had

done it without MyPortfolio...) it would have been the same,

probably (Robina's final interview).

However, an interesting point about MyPortfolio was made by Robina, who noted that she was not sure whether using MyPortfolio had helped her to be more creative or not and commented that:

It didn't stop me from being more creative; it just didn't make any difference (Robina's final interview).

Robina was experienced at making use of technology such as PowerPoint to present her work and, consequently, she did not feel that MyPortfolio offered her anything different than she was used to.

As with Nancy, Robina also used the messaging function to contact her teacher and update her on her progress and, in the final interview, Robina noted the fact that she liked being able to contact her teacher via MyPortfolio. An example of the messages that Robina sent the teacher can be seen below:

i did as much as i could of the home work but I couldn't finish it. More ...
Message from other users
16 October 2008, 6:17 PM

Figure 35 A message from Robina to teacher (16/10/08) showing Robina's contact with the teacher after school

In this message, Robina informed the teacher that she had completed as much as she could of the homework but that she had some trouble with it. This allowed Robina to communicate some of her difficulties while working on the assignment at home.

Overall, Robina's MyPortfolio use was limited to the tasks that she had to complete in order to complete the assignment set and she did not make use of any additional sections of MyPortfolio such as the 'resume' and 'skills' sections; add any additional blogs or personal views; or create or join any additional 'groups'. The fact that she initially found MyPortfolio difficult to use may have had a role in this and it is possible that once Robina become more confident with using MyPortfolio that she 
would make more use of some of the other feature. However, Robina's initial survey also suggested that she was less interested in using computers than students like Nancy, so it is possible that making further use of MyPortfolio simply did not appeal to her.

\subsubsection{Robina's final view}

Although Robina struggled with MyPortfolio at the beginning of the study, she did eventually make effective use of her view in order to present her work.

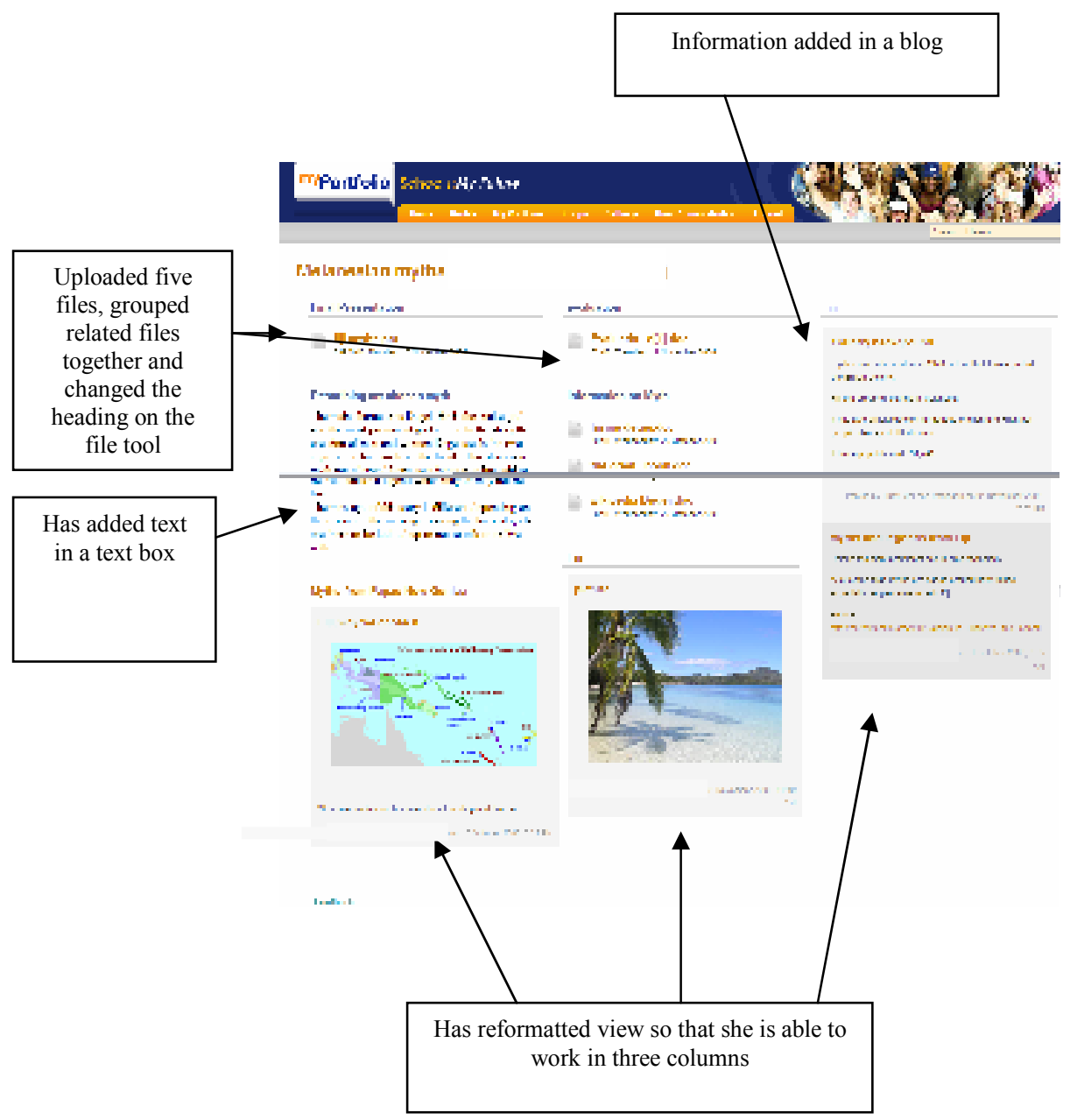

Figure 36 Robina's final view (28/11/08) with detail showing the development of her view throughout the course of the study

Robina's final view shows that her skills developed significantly and in completing her final view, Robina made use of text boxes, a blog, images and uploaded files. She also reformatted her view into three columns and was then able to make better use of the space within the view and this made Robina's work easier to view on the screen than Nancy's work.

Given the fact that Nancy initially learnt to make use of MyPortfolio faster than 
Robina, it is interesting to note that it was Robina who made more sophisticated use of some aspects of MyPortfolio such as changing the layout of her view into three columns. Similarly, Robina was one of only two of the case study students who made use of the ability to change the headings of the file upload boxes:

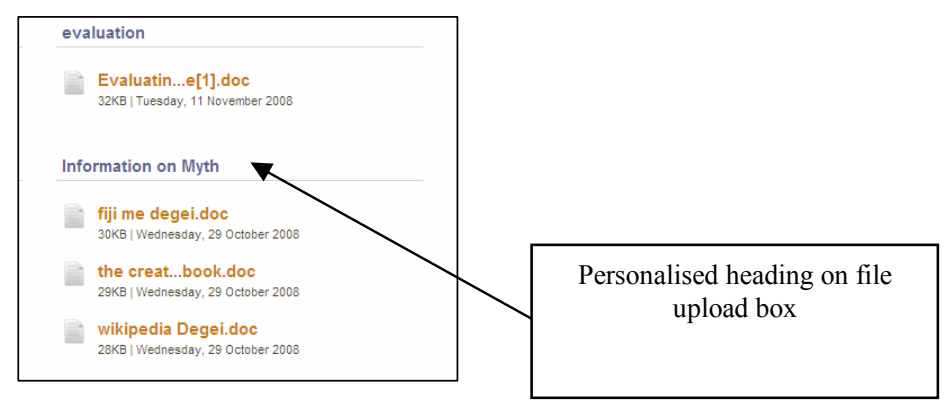

Figure 37 Detail from Robina's final view (28/11/08) showing the way her skill in using MyPortfolio developed

The fact that Robina had extra tuition in using MyPortfolio, whereas Nancy preferred to explore the application on her own, may have meant that Robina had the opportunity to be shown some of the finer details of using MyPortfolio that Nancy did not discover alone. If this is the case, it presents a dilemma for teachers when introducing new applications as while some students may prefer to learn new applications on their own, this may mean that they do not always discover all of the functionality of an application. The relatively short timeframe of this study (six weeks) may also have impacted on this and it is possible that as Nancy utilised MyPortfolio more, she would further hone her skills in using the application and make more use of other features.

\subsubsection{Robina's profile}

All of the students in this study made at least one change to their profile and some, like Nancy, made many changes throughout the study. While Robina added a picture to her profile during the first lesson, after the initial set-up Robina did not make any further changes through the study. She did not add any personal messages or comments to her profile. Overall, Robina's is the least developed profile of all of the case study students: 


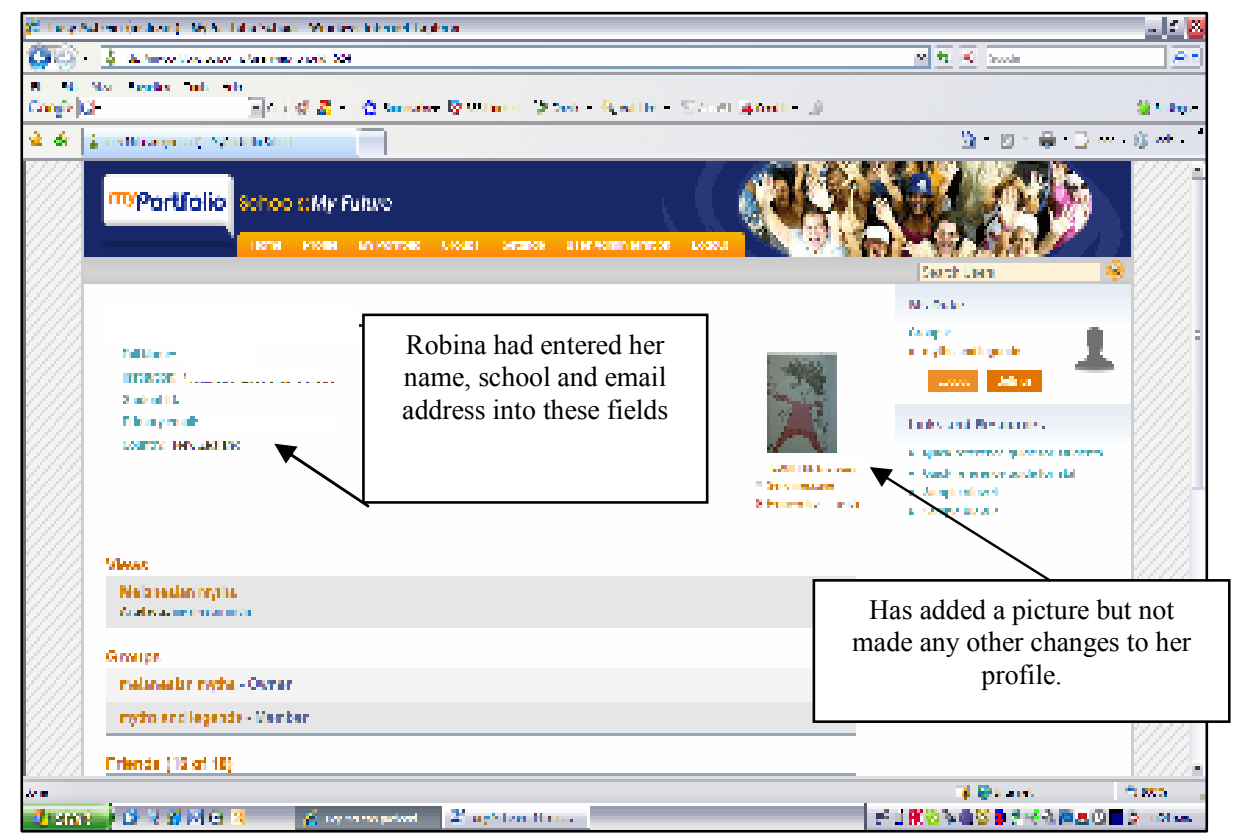

Figure 38 Robina's profile (28/10/08) showing the lack of development in her profile throughout the study

When I asked Robina in the interview why she had not made more changes, she noted that this aspect of MyPortfolio had not really interested her:

I don't know... I just wasn't really that into it ... I couldn't really see the point (Robina's final interview).

The fact that Robina struggled to completed the tasks set may also have discouraged her from making use of MyPortfolio for anything other than the work set. Where Nancy often completed tasks before other students in the class and consequently had spare time to explore MyPortfolio and develop her profile, Robina was more likely to be slower in finishing tasks and therefore may not have had spare time in class.

\subsubsection{Robina's perspective of MyPortfolio}

\subsubsection{Time management}

Although she did not feel that using MyPortfolio improved the quality of her work, the one aspect of MyPortfolio that Robina did particularly appreciate was the way that it helped her to manage her time.

The only thing I found that really worked for me was that it helped me, like, time manage my work because that's what I always have problems with (Robina's final interview). 
Robina felt that this was the area of her learning that she struggled with and found that there were aspects of MyPortfolio that helped her to manage this. The first aspect of MyPortfolio that Robina felt supported her time management was the ability to keep all her resources in one place. She felt this helped her to take a more organised approach and that this helped her manage her time:

... It helped me learn how to time manage and, like, research in an organised way... (Robina's final interview).

Robina also found that the ability to conduct asynchronous communication with her teacher through the view helped her to manage her time and she appreciated the way that the teacher could look at her work and give her feedback about this:

(What helped you manage your time? The way that the teachers could look at your progress and tell you what you needed to do (Robina's final interview).

An example of this communication can be seen below:

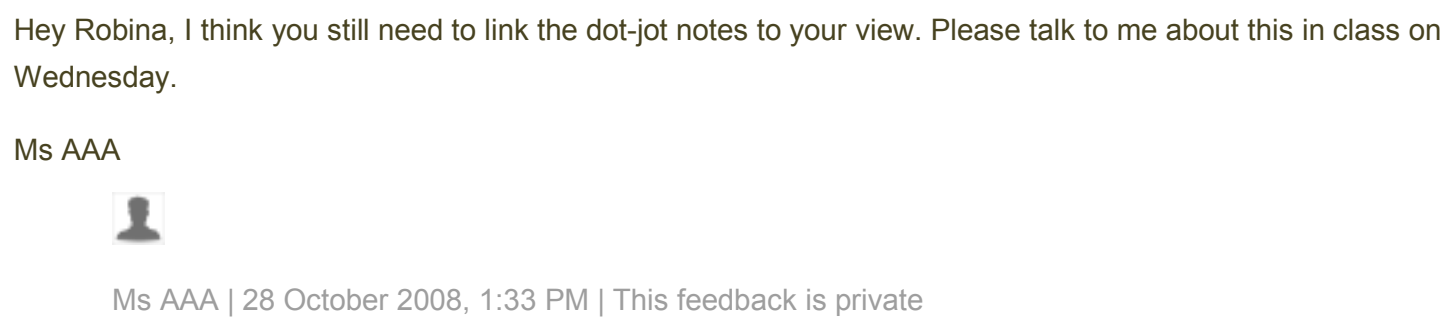

Figure 39 An example of a message that the teacher sent Robina (16/10/08)

In this message, the teacher has looked at Robina's work and provides feedback about what Robina needs to do to complete the tasks set.

When we discussed future use of MyPortfolio, Robina felt that she would like to continue to make use of MyPortfolio and, like Nancy, she was clear that she felt that it was more useful as a tool at home than at school. However, Robina's rationale for this was that she felt the most useful aspect of using MyPortfolio was helping her manage her time and resources, and consequently, MyPortfolio was more suited to project work and working independently than it was to working in class:

I would like to keep doing it for projects but not really for anything else... (I would not want to use it).... all the time but, oh well, I like the fact that your teachers can look at your progress so they can set something for you and you have to do that instead of just "Here's a project, it's due in two weeks" So I'd recommend it, like, just for 
getting the class organised so they can do a project well and then they can use that, if they want, to use that again (Robina's final interview).

\subsubsection{Too hard to use}

I have described the frustrations that Robina had learning to use MyPortfolio and in the final survey Robina 'strongly agreed' that MyPortfolio was "...hard to use”. She felt that she had to do too much work at home to keep up with what the class was doing and as a result of this, Robina felt that she had not been able to complete the quality of work she would have liked. Robina's experience with MyPortfolio reinforces the fact that teachers must carefully manage the introduction of new technology so that students are able to make effective use of it to support their learning.

\subsection{Ashleigh}

In the initial survey at the beginning of this study, Ashleigh reported herself as being a moderately keen computer user who 'agreed' that she enjoyed doing things on a computer and that she felt comfortable working with a computer (see appendix 3.3). Although Ashleigh had access to computers at home and school, she was not a high user of computers and she reported using the computer approximately 1-4 hours a week at home and 1-4 hours a week at school. Of all of the case study students, Ashleigh was particularly enthusiastic about her use of MyPortfolio at the end of the study, noting several times during both the final survey that she found using MyPortfolio 'fun':

\section{It was a fun learning experience (Ashleigh's final survey)}

Ashleigh and Nancy were the only case study students to specifically comment in the final interview that they found using MyPortfolio 'fun':

\section{It's just really fun (Ashleigh's final interview)}

Overall, although Ashleigh enjoyed the experience of making use of MyPortfolio and found the ability to use ICT motivating, she was particularly motivated by the social aspects of MyPortfolio. However, Ashleigh did also appreciate the organisational aspects of MyPortfolio. 


\subsubsection{Initial use}

Although Ashleigh was positive about her use of MyPortfolio, she also initially struggled with learning to use MyPortfolio and when I interviewed her about this, she noted that in the beginning she felt MyPortfolio was hard to use:

(Was MyPortfolio hard or easy to use?) Hard. I didn't know how to do it at the beginning (Ashleigh's final interview).

Ashleigh felt that she was comfortable with using computers, however, like Robina, her skills were limited to a small number of applications such as MSWord. An example of this was the way in which Ashleigh initially found it difficult to perform functions such as switching between applications and sought help from other students in order to do this (my observation lesson 4). Ashleigh also found the process of uploading and downloading documents difficult (my observation lesson 3).

However, as the study progressed, Ashleigh became more competent in her use of both MyPortfolio and the computer generally and by the third lesson was able to confidently switch between applications and by the fourth lesson could navigate throughout the different aspects of MyPortfolio and could easily switch between applications (my observation lesson 5 and 6).

When I interviewed Ashleigh at the end of the study about the process of learning to use MyPortfolio she noted that although she found it hard to begin with but that once she got the hang of it, she found the application quite easy to use:

Once I got the hang of it, yeah, (it was) easy (Ashleigh's final interview)

Ashleigh also sought help from the teacher in order to help her understand how to use MyPortfolio but she was able to solve her problems within the class time and did not need the extra tuition outside of class time that Robina received (my observation lesson 5).

In Robina's case, the fact that she found using MyPortfolio difficult to use made her feel confused and as a result, she initially favoured using applications she was familiar with such as MSWord. However, Ashleigh persisted with using MyPortfolio and, as a consequence became confident in her use of the application faster than Robina did and was able to confidently navigate throughout MyPortfolio by the third lesson (my observation lesson 5). Ashleigh found the fact that she persevered and learnt to use MyPortfolio gave her more confidence (final survey and final interview) 
and when I asked her why she felt more confident after using MyPortfolio, she commented that it was because she now knew that she could learn new skills on the computer:

To know that I can do new stuff on the computer (Ashleigh's final interview).

Ashleigh's experience with MyPortfolio highlights the importance of ensuring that students get appropriate support when developing new skills in using ICT as this can help to build students' confidence. When Ashleigh had specific questions relating to the aspect of the assignment she was currently working on, the teacher was able to answer these and Ashleigh was then able to put these skills to use in order to complete the tasks set. In this way, Web 2.0 tools like MyPortfolio may allow students to develop more general skills in using the computer as well as the specific skills involved in learning to use the specific application.

\subsubsection{Ashleigh's use of MyPortfolio}

While Ashleigh developed confidence in her skills with MyPortfolio as the study progressed, she did not make use of MyPortfolio beyond the use that was required to complete her assignment and, like Nancy and Robina, made no effort to add information to any other part of MyPortfolio, such as the 'goals' and 'resume' sections.

Ashleigh did make use of MyPortfolio at home and in the final survey she noted that she particularly used MyPortfolio at home in order to complete homework tasks and check messages (Ashleigh's final survey).

As with the previous two students, the main reason that Ashleigh made use of MyPortfolio at home was to help manage the process of learning and she saw MyPortfolio as a way to manage her home work and also to keep in contact with other students in this class.

\subsubsection{Ashleigh's final view}

Although Ashleigh was enthusiastic about using MyPortfolio and enjoyed the experience, her work suggests that she did not master all of the functions within MyPortfolio. In particular, Ashleigh made use of MSWord for virtually all aspects of the assignment rather than using functions in MyPortfolio such as the blog or text boxes. Not only this, but there is also little evidence that Ashleigh explored any of the 
creative aspects within MyPortfolio such as adjusting the view layout. For example, Ashleigh did not seem to have realised that it was possible to work in three columns across the view and, consequently had completed her work within one column on the left hand side of the view.

By the end of the study, in reality, Ashleigh's final view showed very little development from the view that she set up during the second lesson of this study and the only real difference between the two views is the addition of the eight files that she has uploaded:

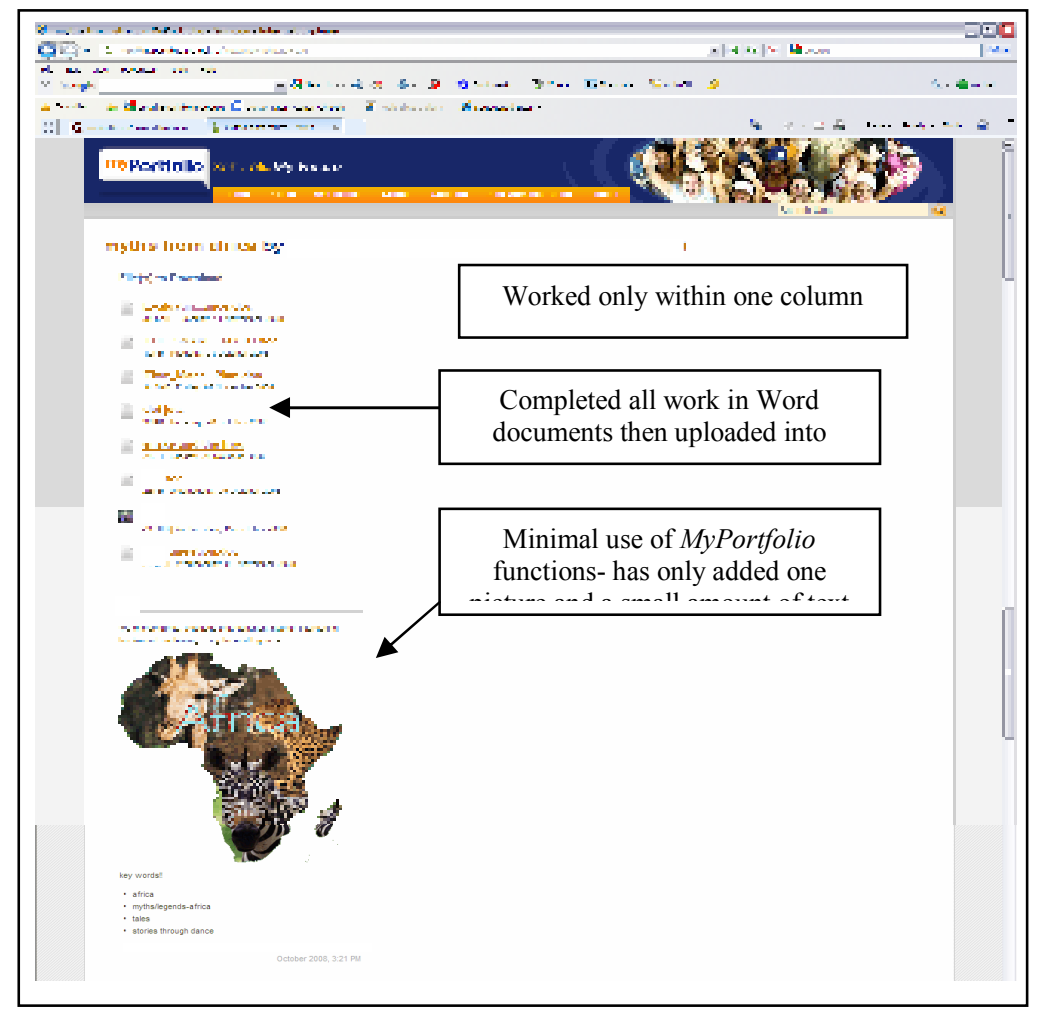

Figure 40 Ashleigh's final view (17/10/08) with detail showing the way she made use of MyPortfolio

Although Ashleigh felt that she was a confident user of computers, she seemed unable to transfer her skills into using MyPortfolio and, like Robina, in reality made more use of applications she felt confident using, such as MSWord. Ashleigh's work is another example of the way in which students can become reliant on entrenched technologies and, although enthusiastic about the prospect of using ICT, can fail to make effective use of new technologies to support their learning. Although Ashleigh sought help for specific problems she had with using MyPortfolio, her use of the features within MyPortfolio was still limited and she may have benefited from additional tuition like Robina received. 


\subsubsection{Ashleigh's profile}

Although she set up her profile during the first lesson, she only updated it once throughout the study and these changes were limited to some minor changes to the comments:

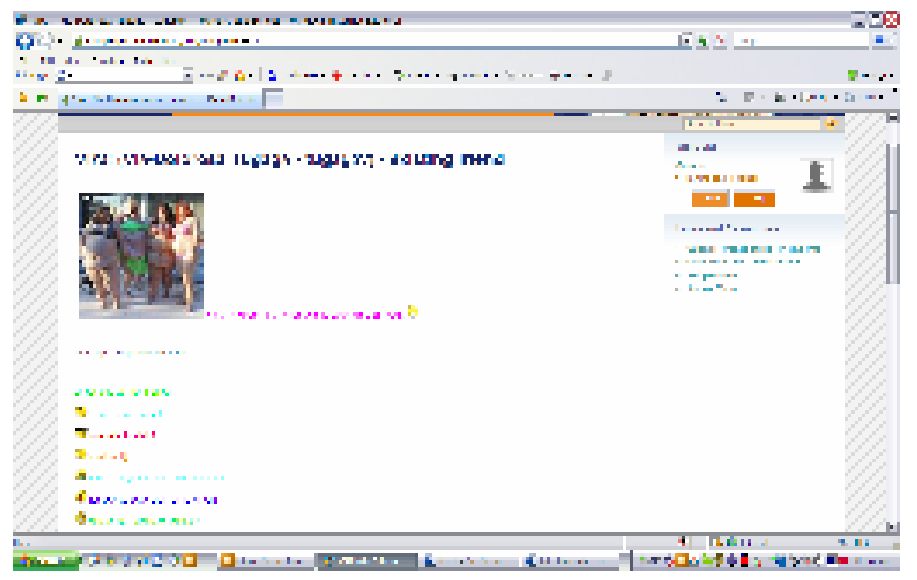

Figure 41 Ashleigh's profile in MyPortfolio at the beginning of the study (21/10/08)

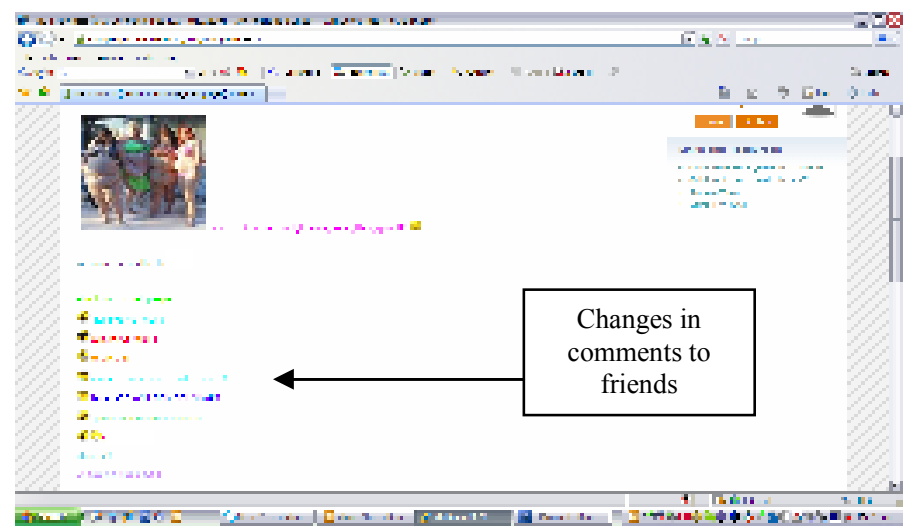

Figure 42 Ashleigh's profile in MyPortfolio at the end of the study (7/11/08)

Despite the fact that she only made a few changes and when asked what she enjoyed about MyPortfolio commented on this in the final survey:

I enjoyed changing my profile (Final survey)

When I spoke to Ashleigh about this in the final interview, she noted that it was the fact that she liked the fact that she was able to personalise her work and this is reflected in her profile. She also commented that this aspect of MyPortfolio was similar to her use of Bebo and that she enjoyed this. 


\subsubsection{Ashleigh's perspective of MyPortfolio}

\subsubsection{Using technology}

Ashleigh was a student who enjoyed making use of the computer to complete work and the initial survey she 'agreed' that she would work harder if I could use computers more often and when I asked her to reflect on her use of MyPortfolio, Ashleigh highlighted the fact that she felt that she worked better when using a computer:

I work better on the computer than writing down on a piece of paper (Ashleigh's final interview).

When I asked her about why she liked using the computer, she noted that she felt it made completing the work easier as she had access to a range of information:

\section{It's easier... having all the information and stuff (Ashleigh's final} interview).

Although Ashleigh enjoyed her experience using MyPortfolio, she was clear that she felt that it had not affected the overall quality of her work- either for the better or worse. When asked in the final survey whether she felt that using MyPortfolio had helped her complete better work than usual, Ashleigh responded 'not sure' and when I asked her about this in the final interview, Ashleigh said that she did not think that using MyPortfolio had made her work either better or worse. When I questioned Ashleigh a little more about this, she did note that she appreciated being able to present her work electronically as she felt this improved the presentation of her work:

\section{Doing it on the computer-it would look better (Final interview).}

However, this was the only aspect of her work that Ashleigh felt was improved through the use of MyPortfolio. In this way, Ashleigh's experience exemplifies the fact that although students may be positive about using computers and motivated by the ability to make use if computers to complete class work, this does not necessarily lead to better learning outcomes.

\subsubsection{Organisation}

Ashleigh also appreciated the fact that using MyPortfolio gave her easy access to her resources and, like Robina, liked being able to access and keep all of her resources together. In the final interview, Ashleigh noted the way in which the view allowed her to keep all of her work together: 
Cos it's just on your page and you can, like, just click on it and it comes up instead of having to look for it... instead of everything everywhere, it just kept it in the same place (Ashleigh's final interview).

The ability to keep all of her work together was a feature of MyPortfolio that Ashleigh particularly appreciated and it was also a feature of MyPortfolio that she felt helped her to be more organised herself (final survey).

\subsubsection{Communication}

Another aspect of MyPortfolio that Ashleigh commented on was the ability to communicate asynchronously with others and when I asked Ashleigh whether she would recommend MyPortfolio to others, this was the area that she highlighted and in the final interview, she said that she thought it was useful for:

\section{Just keeping in touch (Ashleigh's final interview)}

However, when Ashleigh discussed 'keeping in touch', it was clear that she was referring to the social aspect of communication rather than for the purposes of completing her class work and she said that:

I think the best thing about MyPortfolio was messaging friends (Ashleigh's final survey).

Two examples of the social messages that Ashleigh sent can be seen below:

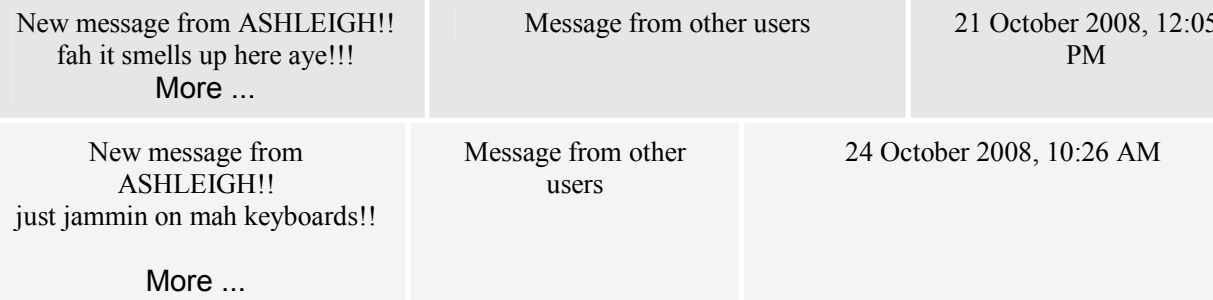

Message from other users

(12:05 PM

Message from other users

24 October 2008, 10:26 AM

\section{Figure 43 Social messages sent from Ashleigh to other students}

Ashleigh sent a number of messages to her friends during each lesson and it is interesting to note the way that Ashleigh made use of much more informal language in the messages that she sent to her friends as compared to the language that she used on her view. It may have been that in this way, Ashleigh was developing a sense of an online presence.

While Ashleigh's use of the communication tools within MyPortfolio was primarily social, she did make use of the communication tools within MyPortfolio through the study to contact other members of her group and as with Nancy's use of 
the messaging, Ashleigh commented that her group made use of the messaging function in order to help make decisions about how they were going to proceed with the assignment.

Just, like, um, deciding what myth or legend we were going to do (Ashleigh's final interview).

Ashleigh did not send any messages to the teacher throughout the course of this study.

\subsection{Hannah}

Of the six case study students examined, Hannah was the least positive about computers at the beginning of the study. Although she reported being a moderate userusing the computer approximately 5-10 hours a week at home and 1-4 hours a week at school, she had a largely ambivalent towards using computers and she answered 'don't mind' to most of the attitudinal questions about computer use such as 'I enjoy doing things on a computer' and 'I would work harder if I could use computers more often' (see appendix 3.4).

Hannah's experience with using MyPortfolio clearly demonstrates the way in which students can become discouraged and demotivated if they feel unable to effectively make use of ICT tools.

\subsubsection{Initial use}

In the initial survey, Hannah seemed to be a confident user of computers and 'strongly disagreed' that computers were difficult to use and also 'strongly agreed' that she felt comfortable using computers. However, she had difficulty learning to use MyPortfolio and particularly found learning to navigate MyPortfolio challenging.

\footnotetext{
Well, it's sort of hard to use in some ways. There's like so many things to click on to get stuff and upload stuff (Hannah's final interview).
}

Hannah was the least enthusiastic about using computers of the case study students I investigated and unlike for Ashleigh and Nancy, the idea of using computers at school did not add interest for Hannah and she answered 'don't mind' when asked whether she would work harder if she could use computers more often and also when asked whether she enjoyed lessons on the computer. This lack of enthusiasm could also be seen in Hannah's use of the computers during this study and, even in the early 
lessons, making use of the computers did not seem to hold her attention and she would talk to those around her instead (my observation lesson 2).

During the initial lessons, Hannah had difficulty with navigating throughout the different areas of MyPortfolio and while most of the students in this study reported being able to confidently navigate throughout the different aspects of MyPortfolio within 2-3 lessons, Hannah took six lessons to become confident in navigating throughout the application (my observation lesson 6).

According to the initial survey data and my interview with Hannah, she considered herself to be a reasonably able user of ICT and felt that she usually picked up new applications quickly. Thus, she felt annoyed that she struggled to learn to effectively use MyPortfolio:

Well, it was like annoying cos usually I can just learn how to use things, like on the Internet, like real quick. But MyPortfolio's quite hard (Hannah's final interview).

\subsubsection{Hannah's use of MyPortfolio}

Hannah's struggles with learning to use MyPortfolio continued throughout the study and she did not seek extra assistance in order to overcome these in the way that Robina did and, in fact, on at least two occasions, Hannah refused help from the teacher when it was offered. As a result of this, Hannah's skills in using MyPortfolio did not develop. During class time she often talked to friends rather than making use of MyPortfolio and in doing so avoided having to use MyPortfolio. During the seventh lesson, Hannah did not log in to MyPortfolio until 30 minutes into the lesson and at the end of the lesson, I overheard her commenting that "I've hardly used my view" (my observation lesson 7).

By the end of the study, Hannah had also withdrawn from her group and predominantly worked alone. She also stopped making use of MyPortfolio, and predominately made use of applications such as MSWord and Internet Explorer (my observation lesson 10).

The fact that Hannah struggled to understand how to use MyPortfolio meant that she also struggled to develop the skills required to complete the tasks set for this assignment and, as a result of this, did not finish all of the tasks required for the assignment set by the class teacher. Hannah's difficulties with mastering MyPortfolio are also reflected in her log: 
15/10: I had a bit of trouble with making my view because it was

hard.

17/10: Today I had difficulty with safety in settings. I couldn't

change it. I found it hard.

21/10: I had problems with uploading my dot jot notes to my files.

28/10: (Did you have any problems? What with?) Uploading my

view. I found it hard and confusing but then I had help so it was

easier (Hannah's log).

During each of the first four lessons, Hannah noted difficulties in her log.

However, she did not seek help from the teacher or other students and instead, chatted with friends (my observation lesson 3 and 4).

Overall, Hannah struggled with using MyPortfolio and she felt that it needed to be simpler to use:

Like, make it more simple, like to upload files and stuff in 'my views' instead of having to click on groups and stuff (Hannah's final interview).

However, she did say that she would recommend continued use of MyPortfolio as she appreciated the ability to access MyPortfolio from home and also the ability to communicate with her teachers. As with both Nancy and Robina, Hannah saw the main use of MyPortfolio as being organisational. She noted that it was a way of organising her work and enabling her to communicate with her teacher and, thus, could help her manage her work:

... assignments and stuff because usually I always have to say that my printer's broken when I can't get assignments and stuff in but I can just send it or let my teacher view it so that they can just know that I've actually done it (Hannah's final interview).

Although Hannah did have trouble with using MyPortfolio, she could still see that there were situations where making use of it could be useful and, as with the previous students, these particularly related to working at home.

\subsubsection{Hannah's final view}

Hannah's failure to master MyPortfolio can be seen in her final view. As with Ashleigh, Hannah chose to complete virtually all of the tasks set in MSWord rather 
than in MyPortfolio and the only tasks that she completed in MyPortfolio were completed during the first lesson, when students were introduced to MyPortfolio:

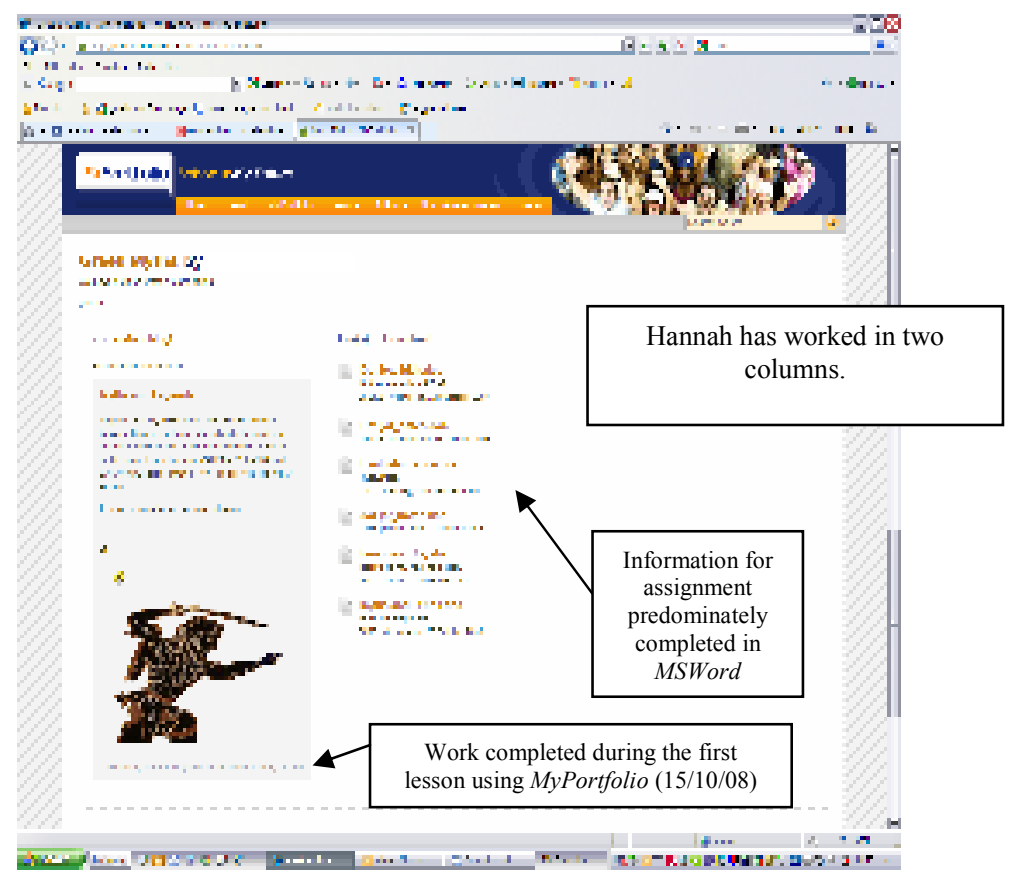

Figure 44 Hannah's final view (15/11/08) showing the way in which she made use of MyPortfolio

Hannah's final view reflects the lack of enthusiasm that Hannah had for MyPortfolio in that she completed the tasks set but did not utilise the features within MyPortfolio more than she had to. When I asked Hannah about this, she commented that her concern about learning to use MyPortfolio impacted on her ability to use MyPortfolio:

I think it was because, like, I was too worried about trying to get my assignment, my thing done in time so I just didn't really use MP and try and be creative and stuff (Hannah's final interview).

It is interesting to note that Hannah completed a similar amount of work on MyPortfolio as Ashleigh and both students experienced similar frustrations in learning to make use of MyPortfolio at the beginning of the study. However, Ashleigh persisted with trying to learn to use MyPortfolio and felt more confident at the end of the study, whereas Hannah became disengaged and, as a consequence, did not develop her skills in using MyPortfolio. Despite their different approached, however, the quality of the work that Hannah and Ashleigh produced was very similar and the students both made similar use of the functions within MyPortfolio. 


\subsubsection{Hannah's profile}

At the beginning of the study, Hannah set up an initial profile but made very few changes throughout the rest of the course of the study. She did not change any of the images, however, did change some of the text in her profile and changed some of the comments that she made to her friends.

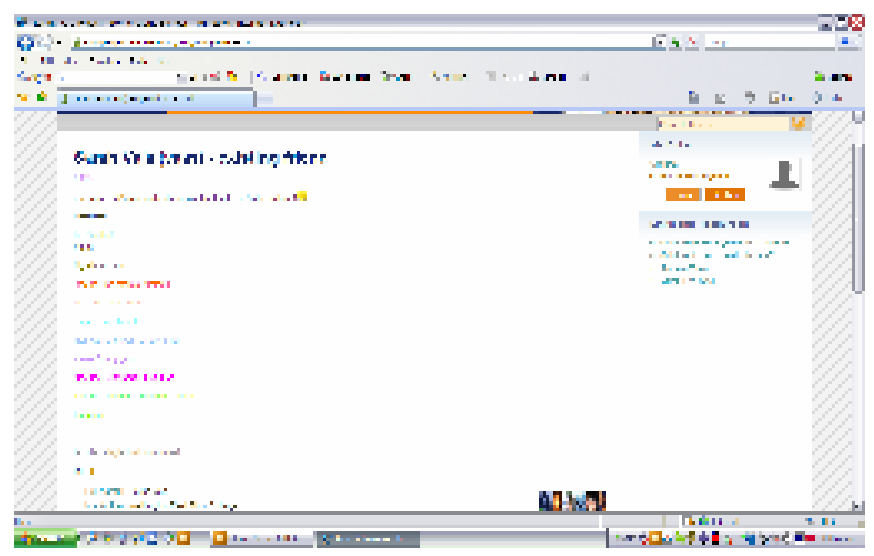

Figure 45 Hannah's profile at the beginning of the study (18/11/08)

Although Hannah's profile was more developed than Robina's and Mary's, she did not add images to it at any point and also did not make any attempt to present her interests in the way that students like Nancy did.

Between the $29^{\text {th }}$ of October and the end of the study on the $15^{\text {th }}$ of November, Hannah did not make any further changes to her profile. However, it was surprising to discover that she had made changes to her profile some months later:

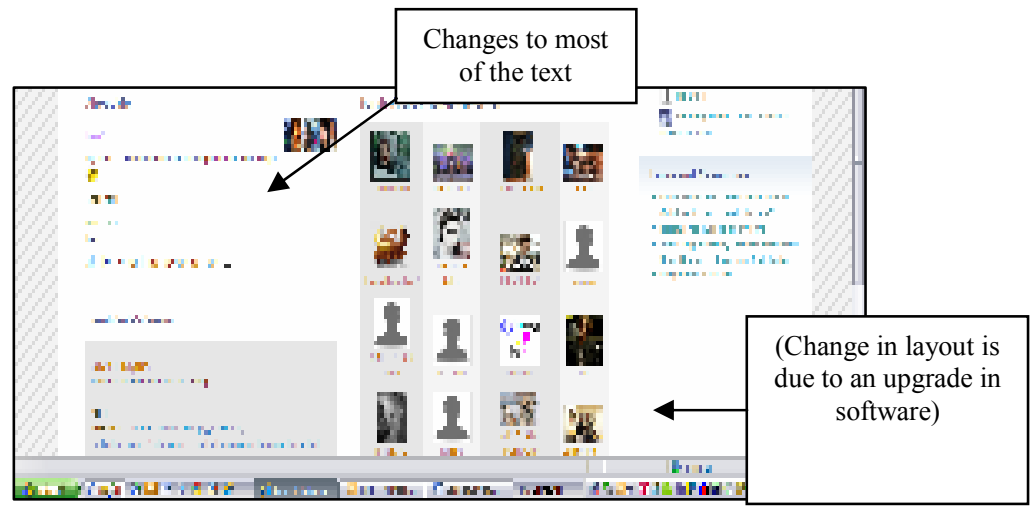

Figure 46 Hannah's profile (1/9/09) showing the changes in text that Hannah made after the study had concluded

Hannah's profile was unchanged when I checked it in May 2009 so she had obviously accessed it between May 2009 and the beginning of September 2009- at least six months after this study concluded. I cannot fully explain this as this study had concluded long before this occurred, however, it is worth noting as although using 
MyPortfolio did not appear to engage Hannah and she was the least enthusiastic of the case study students about using MyPortfolio at the end of the study, the profile obviously engaged Hannah enough to want to return to it some months later.

\subsubsection{Hannah's perspective of MyPortfolio}

\subsubsection{Collaboration}

One aspect of MyPortfolio that Hannah did appreciate was the ability to collaborate with other members of her group and she noted the way that the views allowed her to check her ideas and give and receive feedback:

If I was like confused with like what to do for dot-jots or something, then I could go and look on Lindsay's or Kate's...then they can give you advice and stuff and you can give other people advice with your work and stuff (Hannah's final interview).

It may have been that Hannah found that checking other students' views enabled her to check on her own progress in a non-threatening way in order to see how the work to be completed should look without having to admit to others that she was struggling.

As well as using the views to monitor her progress, Hannah also made use of the messaging functions to check on her group's progress:

Figure 47 A message sent by Hannah to another group member (22/10/08)

In this message, Hannah is checking on whether another member of her group has uploaded their work into their view. This allowed her to check on the progress that another member of her group was making and also meant that Hannah could make use of the work that the other student had completed for her final assignment.

In this way, Hannah made use of the both the views and the messaging functions in order to gauge her progress against the other members of her group.

\subsubsection{Too hard to use}

As I have already discussed, Hannah felt that MyPortfolio was too hard to use and this discouraged her from making effective use of it to complete the work set. The difficulties Hannah had with using MyPortfolio also affected her overall attitude towards the application: 
Um, sort of... it wasn't a waste of time because it does keep my work and stuff on it but it was hard to use. If it was easier then I would probably've found it more better. Like more funner, sort of thing (Hannah's final interview).

The fact that Hannah found using MyPortfolio hard meant that she did not find the experience fun and this affected her overall feelings about the applications and Hannah's overall experience and frustrations with trying to effectively use MyPortfolio meant that she felt that she would not recommend MyPortfolio:

I think some people might find it complicated to use, compared to others. Like, some people might find it easy, some people might find it hard (Hannah's final interview).

Like Robina, Hannah also found that she felt less confident in her ability to use the computer by the end of this study. The fact that she found it difficult to use was a challenge for her as she felt that she was usually quite competent in using the computer:

It's like challenging and hard to use compared to other sites I've tried to use (Hannah's final interview).

Hannah's experience suggests that while applications such as MyPortfolio allow students the ability to express their creativity in different ways, it is important that students are carefully supported when learning to use the application so that they are fully able to make use of the functionality available. Hannah's early frustrations with using MyPortfolio led to her become discouraged and, consequently, disengaged with the application and this further highlights the fact that the process of introducing new technologies to students needs to be carefully managed so that students do not become discouraged. 


\subsection{YoYo}

YoYo was very positive about using computers and reported using computers approximately 10-20 hours a week at home and 1-4 hours a week at school. In the initial survey, YoYo 'strongly agreed' that she enjoy doing things on the computer' and that she felt comfortable using the computer (see appendix 3.5). She also noted that she enjoyed making use of the computer for a range of reasons including: completing presentations, doing school work, creating web sites and using Bebo.

YoYo's use of MyPortfolio particularly showed the way in which students made use of aspects of the application to reflect their personalities and communicate with friends.

\subsubsection{Initial use}

Overall, YoYo was positive about her experiences using MyPortfolio and when asked in the final survey, 'agreed' that MyPortfolio had been fun to do.

When I asked YoYo in the final interview how long she thought it took her to become familiar with MyPortfolio, she said that she felt it was around two lessons. My observations of YoYo also show that she seemed confident in her use of MyPortfolio by the third lesson (my observation lesson 3). Having said this, like Nancy, YoYo did need help with using specific functions such as uploading documents at times. When this occurred, she sought help from either the classroom teacher so that she could continue with the work set. Once she had received the help she needed, she resumed working on the tasks set (m observation lesson 5).

When YoYo did learn how to complete tasks such as downloading documents, she found that the ability to complete these tasks added to her enjoyment of using the application. In her log, she noted that:

We had a few problems with downloading the dot-jot-notes but when they did download, it really did make it fun (YoYo's log-lesson 2).

The fact that YoYo sought help in order to help her overcome the problems she had meant that she was able to work ahead of where the rest of the class was and made use of the additional resources within the class MyPortfolio view in order to continue her work (my observation lesson 4). 


\subsubsection{YoYo's final view}

YoYo's final view shows that she developed her skills in using MyPortfolio as the study progressed. While she needed some support to feel comfortable with tasks such as uploading and downloading documents, her view shows that she was able to make use of many of the elements available within MyPortfolio including the text boxes and the file upload tool and also changed the layout in order to work in two columns in her view.

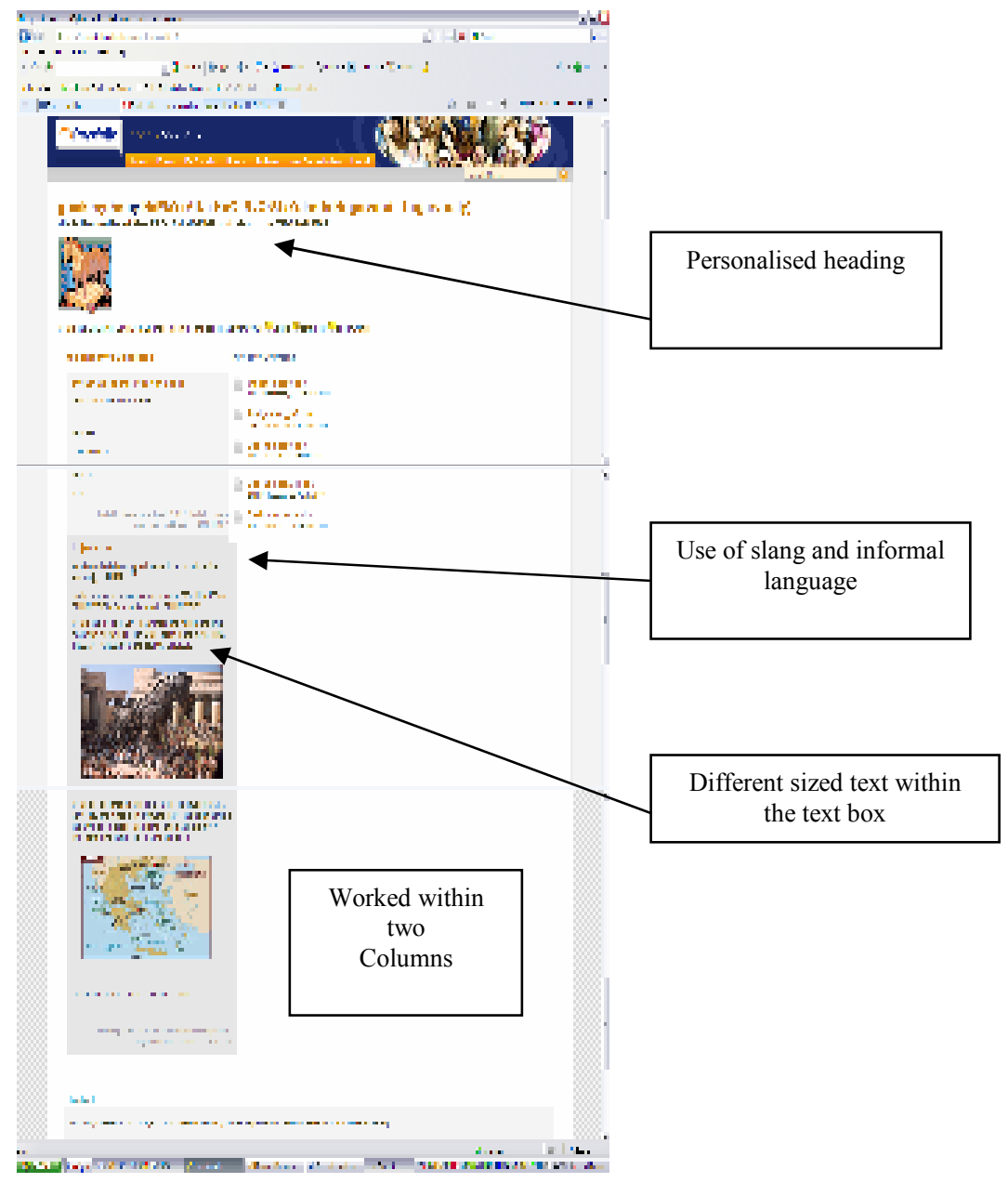

Figure 48 YoYo's final view (18/11/08) showing the way in which YoYo made use of MyPortfolio

Of all the case study students, YoYo has made the most use of the creative elements within the text such as changing text size and font and adding personal headings and this gave her final view more of a sense of YoYo's personality than any of the other case study students' views. YoYo was the only student to make use of the ability to vary the font and size of the text within her text boxes and, in this way, she was the only one of the case study students whose work reflected the fact that she was working within a digital medium in which visual changes can emphasis aspects of the 
text. YoYo's attempts to emphasise text can be seen in the way that she adjusted the text size to emphasise various words such as 'greece!!!'.

YoYo was also the only one of the case study students to personalise her view with reference to herself and her view included a personalised heading as well as the names of the members of her group at the top of the view.

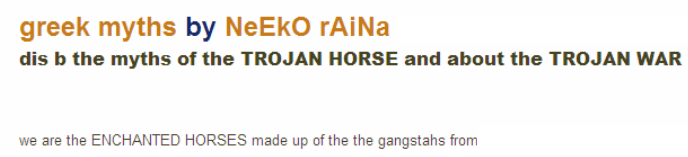

Figure 49 Detail from YoYo's view (18/11/08) showing the way in which YoYo personalised her view

In the final survey, YoYo 'agreed' that using MyPortfolio had helped her to be more creative and when I discussed this with YoYo, she noted that she liked the fact that she could add pictures to her view and work on the overall presentation and

On the computer, most people, they want their page to look nice.

And when on a piece of paper it's just writing... (you can)...make it

look how you wanted it to look. Yeah, and on a piece of paper you can't (YoYo's final interview).

Similarly, when I asked YoYo in the final interview about whether she felt that using MyPortfolio had affected the overall quality of her work, she commented that she felt that using MyPortfolio had improved the quality of the presentation of her work:

It made our work more neater than it usually would have been. And, yeah, it just looked better than what we would have usually done on a poster or something (YoYo's final interview).

Another interesting aspect of YoYo's work is the way that she has made use of slang in the text of her view. She was the only one of the case study students to do this and when I asked her about this in the final interview, YoYo noted that she probably would not use this kind of language if she were completing the same work on paper. This suggests that students do not always automatically make the transfer from social contexts into educational contexts and part of the role of teachers in managing online learning is to ensure that students understand the way that they must adjust their use of technology for different contexts. 


\subsubsection{YoYo's profile}

YoYo set up her profile during the first lesson of the study and, as with Nancy's profile, YoYo used her profile to highlight her interests- in YoYo's case, in rugby, wresting and softball. During my observations, YoYo commented that she played both rugby and softball to a representative level (lesson 2) and in her initial profile she made reference to being a rugby player. She also added messages to her friends and a comment to the whole class group- ' (:) 9xx jst keep smiling !!!'.

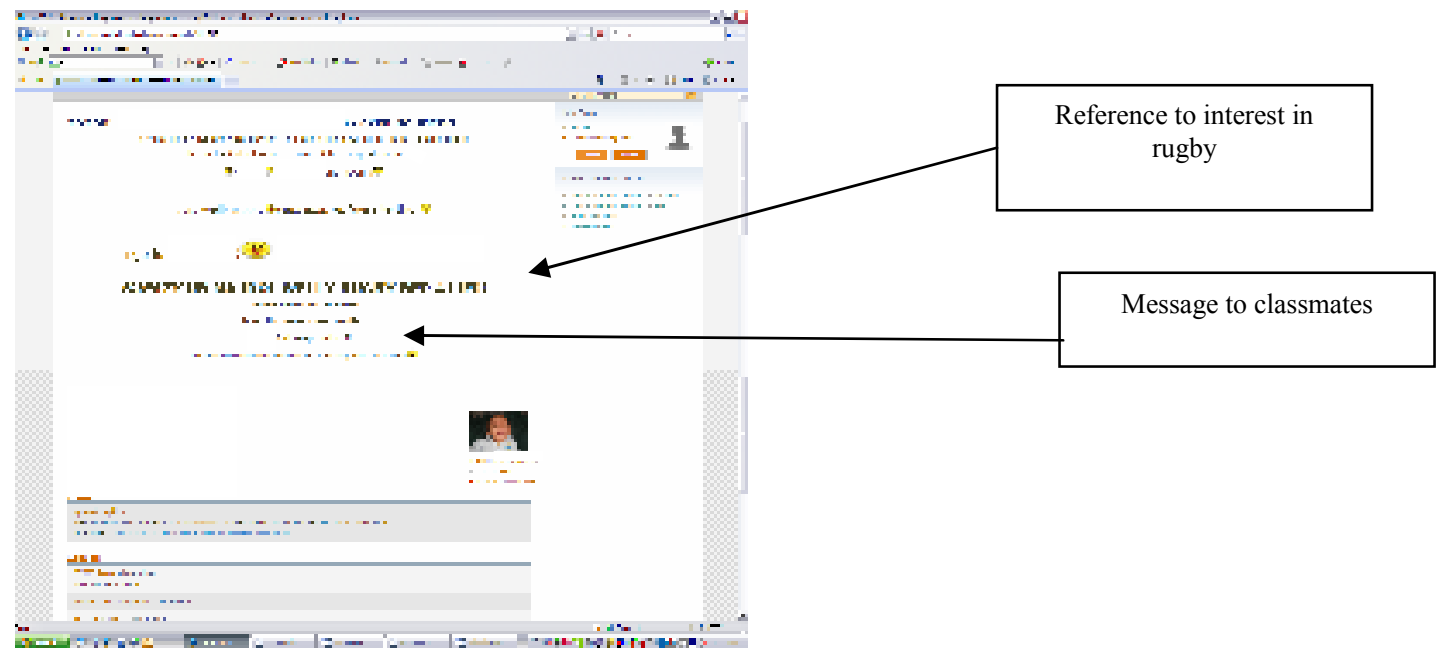

Figure 50 YoYo's profile (17/10/08) showing the way in which her profile reflected her interests

YoYo made changes to her view that I observed twice throughout the course of the study. In the first change, she added images to her profile, including an animation of a softball player. In this first change in her profile, YoYo added four images however the text was almost unchanged from her original profile. 


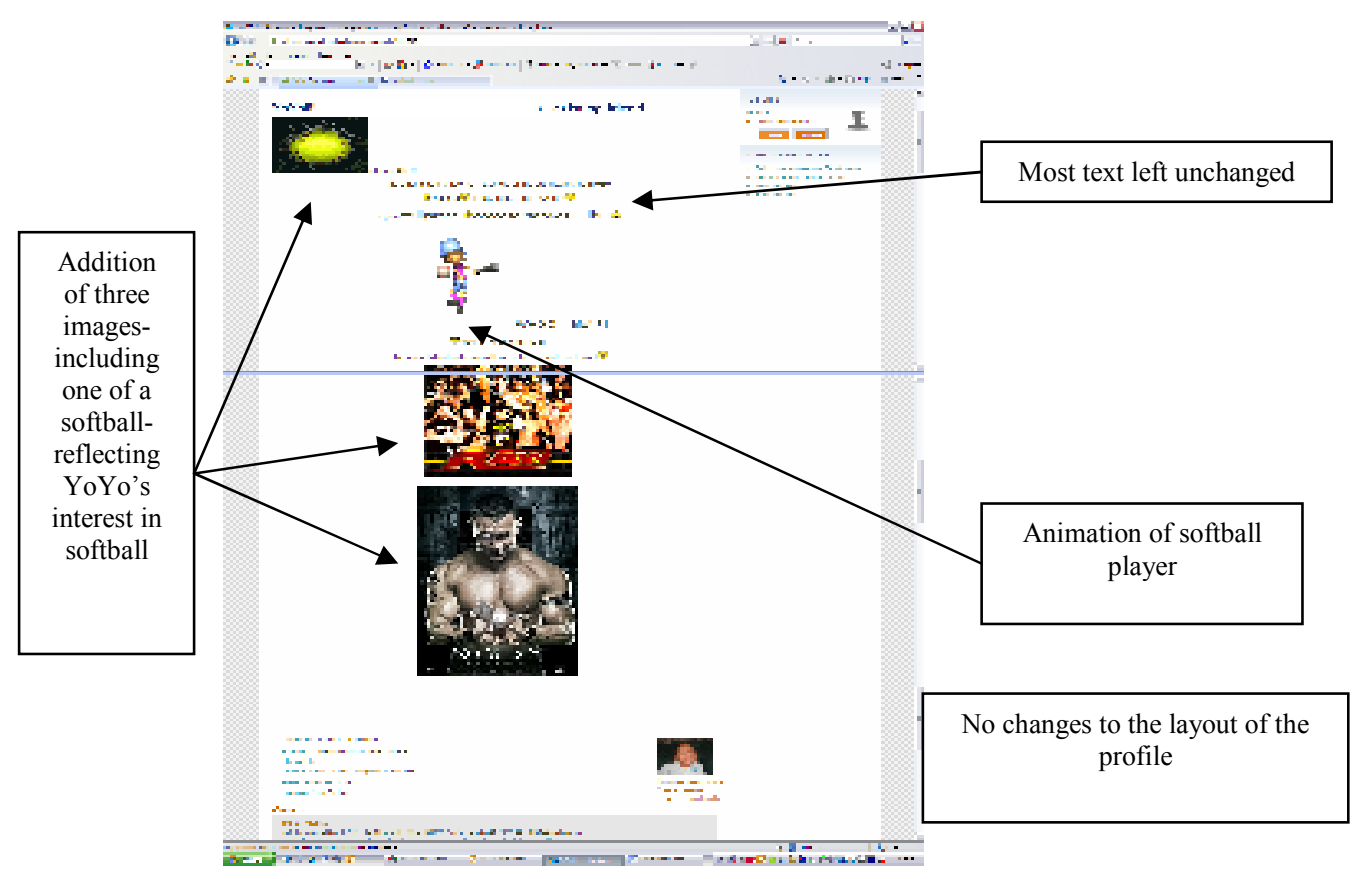

Figure 51 YoYo's profile mid way through the study $(29 / 10 / 08)$ showing the changes she had made

The third time YoYo changed her profile was a week later and this was the last time she made changes to her profile during the study. Once again, the changes YoYo made added to what was already on her profile rather making large changes in the way that Nancy did. However, YoYo's use of her MyPortfolio profile was similar to Nancy's in that she used it as a mechanism to display her interests and in this change, 
YoYo added a picture of rugby player Dan Carter and the text 'rugby for life'.

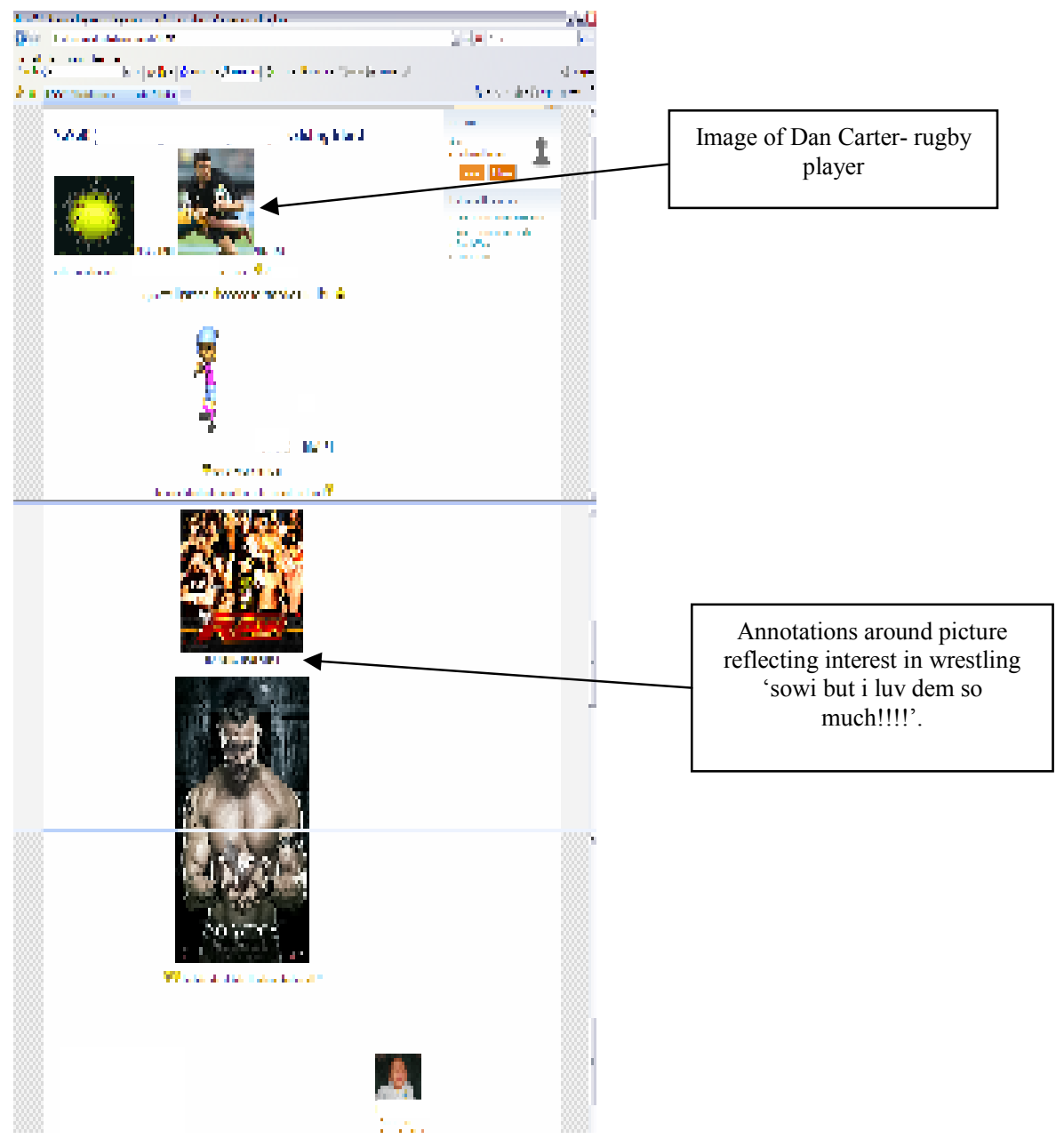

Figure 52 YoYo's profile at the end of the study (7/11/08) showing further changes that reflected YoYo's interests

One of the interesting aspects of YoYo's final view is the fact that she does not refer to her friends in the way that the other students who made changes to their profiles did. In the earlier versions of her profile, YoYo referred to the other members of her group, however, by the end of the study, she had removed this reference from her profile. In this respect, YoYo seems more interested in displaying her interests than engaging other students in the way that Nancy was.

\subsubsection{YoYo's perspective of MyPortfolio}

\subsubsection{Organisation}

When I asked YoYo to talk to me about what she understood MyPortfolio to be, her ideas predominately focused on the fact that she saw it as a tool for collecting things together and organising them. 
It's something where you can put your, instead of having all these papers of homework, you put it on there (YoYo's final interview).

YoYo also felt that MyPortfolio was most useful for managing work at home and when I asked her whether she would like to continue to use MyPortfolio, she specifically noted that she thought it was useful for helping her to organise her homework:

Yeah, cos I'm not very good with organising my homework. So I can just organise it all on computer (YoYo's final interview).

Although YoYo was very positive about using MyPortfolio, she also saw it as more of a tool for at home than for significant use at school. This idea that using MyPortfolio as a tool at home to help organise work and manage resources was a strong theme from the case study students in this study. This perspective is highlighted by a comment that YoYo made in the final survey. When asked whether she would recommend MyPortfolio for use to other students, she noted particularly highlighted the organisational aspects of using MyPortfolio, particularly for home use:

$i$ would recommend it to people that have trouble sortin out all their paper work and all there homework and stuff like that (YoYo's final survey).

As with the other students who have commented about their use of MyPortfolio to help them with their organisation, YoYo's comments also suggest that she found using MyPortfolio most useful for supporting the process of learning, rather than helping her construct knowledge.

\subsubsection{Communication}

One of the aspects of MyPortfolio that YoYo she particularly commented on when I interviewed her was the fact that she enjoyed using MyPortfolio for communicating with their friends and other members of their group:

And I liked sending... instead of talking to your friends you could just go on the computer (YoYo's final interview).

YoYo used the communication tools for a mixture of social and educational purposes and during the final interview, she commented that she used the messaging in order to communicate with both members of her group and other students in the class. 
When communicating with other members of her group, YoYo used the messaging function within in MyPortfolio in order to check on their progress and also to clarify how they were going to complete the work set:

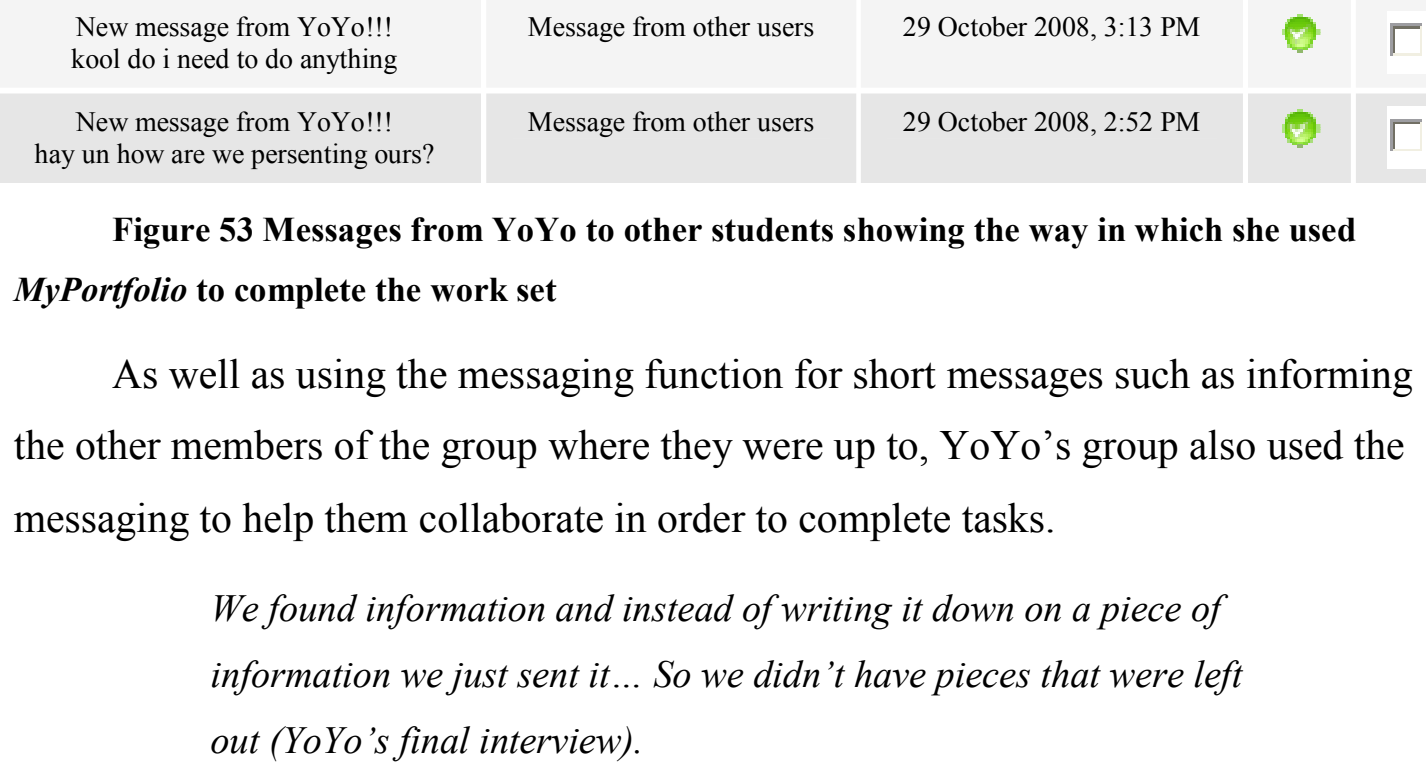

Figure 53 Messages from YoYo to other students showing the way in which she used MyPortfolio to complete the work set

As well as using the messaging function for short messages such as informing the other members of the group where they were up to, YoYo's group also used the messaging to help them collaborate in order to complete tasks.

We found information and instead of writing it down on a piece of information we just sent it... So we didn't have pieces that were left out (YoYo's final interview).

In the final interview, YoYo gave this the ability to communicate using MyPortfolio as one of the reasons that she would recommend MyPortfolio to other students.

YoYo also made use of MyPortfolio to send messages to the teacher and when I asked her if she could imagine continuing to send messages to her teacher Ashleigh MyPortfolio, she again referred to the idea of using MyPortfolio from home:

For homework... Yeah (YoYo's final interview).

YoYo's comments suggest she found MyPortfolio more useful as a tool for at home than for use at school and this was a common theme from the case study students in this study. 
In the initial survey, Mary presented herself as a student who enjoyed using ICT and reported typically spending 5-10 hours a week at home on the computer as well as 1-4 hours a week at school on the computer. In the initial survey, Mary also 'strongly agreed' that she enjoy doing things on a computer and that she felt comfortable working with a computer (see appendix 3.2).

However, while Mary considered herself to be comfortable using computers, some of her initial survey responses also suggested that her skills were not advanced and although she 'strongly agreed' that she could complete tasks such as sending email or conducting a search on the Internet, she responded 'not sure' to when asked whether she could use bookmarks or upload images (see appendix 3.6) Mary was also one of only four students in the class $(16 \%)$ who did not make use of social networking sites such as Bebo and Facebook.

Mary's experience with MyPortfolio shows the way in which students' perceptions of their ability with ICT does not always match the reality of their ability.

\subsubsection{Initial Use}

When MyPortfolio was initially introduced to the class by the trainer, Mary appeared focused on using of the application and followed the instructions given ( $\mathrm{m}$ observation of Mary 15/10 Lesson 1). However, despite her attention, during the initial lesson, Mary found using MyPortfolio difficult and during the second lesson asked for help from the class teacher three times during the lesson in order to finish setting up her profile and initial view (my observations lesson 2).

Along with Hannah, Mary also took six lessons to be able to confidently navigate throughout the different sections of MyPortfolio (my observation lesson 6).

It is interesting to note that when I interviewed Mary about her use of MyPortfolio, she said that she commented that she though she felt comfortable with using MyPortfolio after about three lessons. However, in my observation, she still struggled with navigating throughout MyPortfolio until the sixth lesson.

\subsubsection{Mary's use of MyPortfolio}

Even once Mary was able to navigate throughout MyPortfolio she still struggled with tasks such as uploading and downloading files and particularly found it difficult 
to remember to save updated versions of the MSWord documents she was working on (my observation lesson 6)

One of the key differences between Mary's approach and Hannah's approach to using MyPortfolio was the fact that Mary continued to seek help in order to complete the tasks set when she felt unsure about what to do. Mary made use of the class teacher, other students and myself in order to find out how to complete the tasks set and, as a result of this, was able to complete tasks that she initially struggled with. An example of this can be seen during my observation of the fifth lesson when Mary needed reminding how to upload documents into her view. She had completed two MSWord documents but could not remember how to upload these into her MyPortfolio so that she could add them to her view (my observation lesson 5). By later in that lesson, Mary had uploaded her documents into MyPortfolio and had added them into her view (my observation lesson 5). During the same lesson I also observed Mary asking other members of her group for help in order to access the class myths view and she needed step-by-step instructions from the other student in order to find this (my observation lesson 5).

The fact that Mary asked others to help her meant that her skills developed as the study progressed. While Mary felt that she was a confident user of ICT, as with Hannah, the reality of Mary's ability with computers was quite different from her beliefs about her skills. Mary felt confident using a small number of applications such as MSWord and Google, however, her skills were not developed enough for her to be able to transfer this knowledge into her use of MyPortfolio. Unlike Hannah, however, Mary did not become discouraged when she struggled to use MyPortfolio effectively. While she did respond 'not sure' when asked in the final survey whether she felt that using MyPortfolio had helped her to feel more confident, when I interviewed Mary about learning to use MyPortfolio, she noted that although she struggled to begin with but that she felt she got better at using MyPortfolio as the study progressed and, as a consequence, felt that her confidence has improved:

It wasn't that easy at the start but I got to know it and I got better at it... (did it make you feel more or less confident?)... A little bit more (Mary's final interview).

Mary's experience of using MyPortfolio also reflects Robina's and YoYo's in that all three students struggled with aspects of using MyPortfolio. However, they all received help either from the teacher, other students or me an as a consequence, both 
their skills and confidence in using MyPortfolio developed. In contrast, Hannah did not seek help in order to solve the problems she had using MyPortfolio and, of all the case study students, she was the student who least enjoyed her experience with using MyPortfolio and when asked in the final survey, said that she 'disagreed' that using MyPortfolio had made her more interested in her work.

Mary was a student who was very keen on using computers to complete her class work. As I discussed earlier, she enjoyed making use of the computer and welcomed the opportunity to make more use of computers during class time. Mary also enjoyed making use of MyPortfolio and in the final survey 'strongly agreed' that using MyPortfolio had been fun to do. When I discussed this with Mary it become clear that it was the opportunity to make use of the computers Mary enjoyed and when I asked her in the final interview whether it was using MyPortfolio or computers in general that she enjoyed, she said:

I think it was the computers (Mary's interview).

For Mary, the opportunity to use the computers was the aspect that most engaged her and her responses emphasis the fact that, for some students, the ability to make use of computers motivates them in their learning, as I have discussed in chapter (see page 95).

While Mary noted that using the computers generally, as opposed to MyPortfolio specifically was enjoyable for her, she was positive about her use of MyPortfolio and in the final survey 'agreed' that using MyPortfolio had '...made her work harder to complete this assignment' than she would usually have done. Although Mary did not get all the work finished, she felt pleased with the work that she did complete and felt that using MyPortfolio had helped her complete better work than usual (final survey).

One aspect of using MyPortfolio that Mary did feel affected her work was the way that the views made her work more public. She felt that the fact that she was using the view in MyPortfolio to make her work more public helped motivate her to complete better work and, in the final interview, noted that the fact that other people, including the teacher and the rest of her group could see her work meant that she worked harder:

I had to work a little bit harder to be up to date, because you guys were going to see it (Mary's interview). 
The fact that Mary's work could be seen by others meant that she was more aware of the need to keep up with the work set. In this way, using MyPortfolio may also have helped Mary manage her work better.

\subsubsection{Mary's final view}

While Mary struggled with using MyPortfolio to begin with and continued to seek help as the study progressed, her final view was one of the most developed views of the case study students in that she made use of more features of MyPortfolio than students like Ashleigh and Hannah, who predominately worked within MSWord and more use of the layout features than Nancy. Although Mary did not quite complete the assignment work set, she did make creative use of her view and added six pictures, adjusted the layout of her page in order to create three columns, changed headings and worked within both text boxes and a blog.

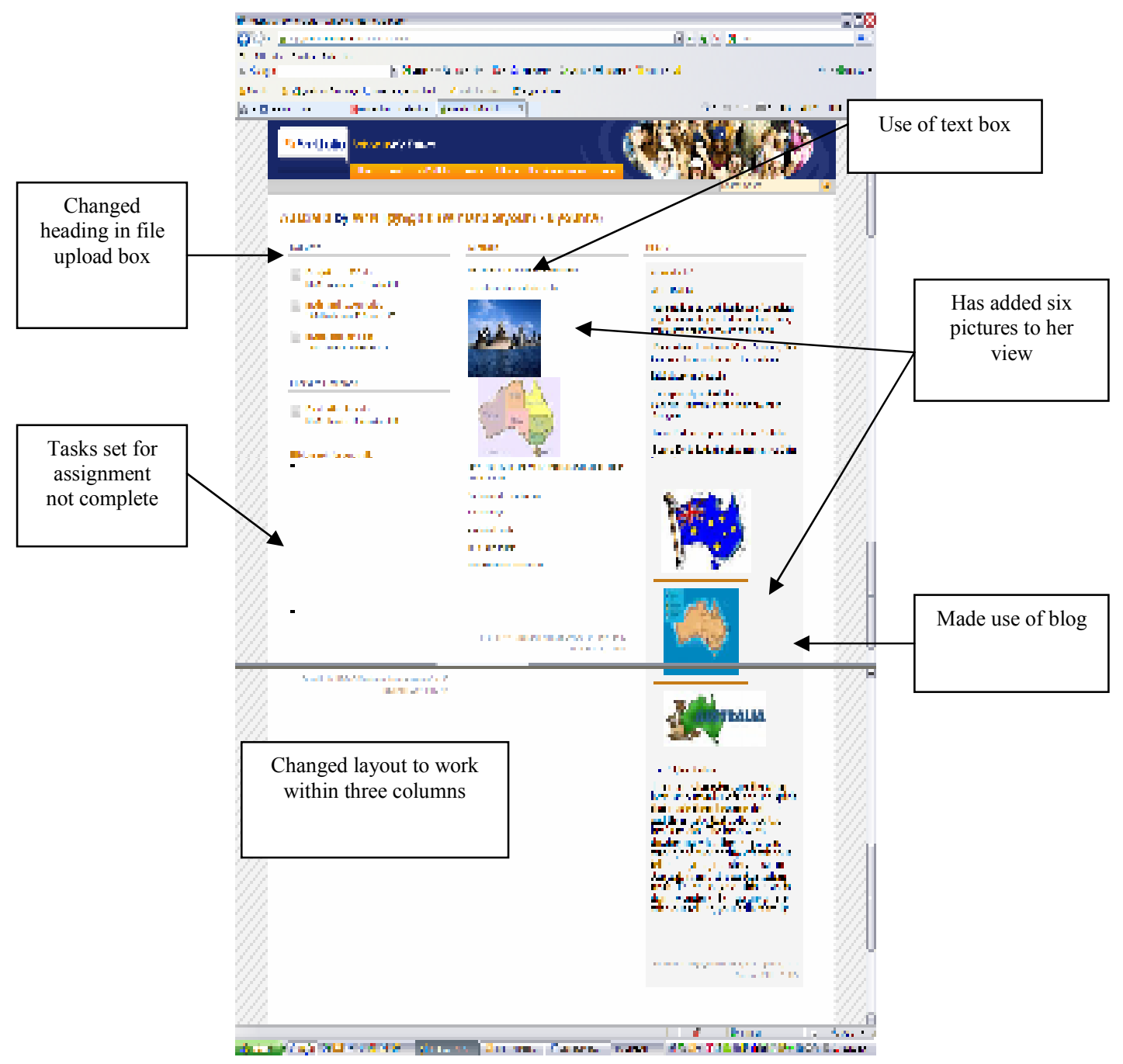

Figure 54 Mary's final view (15/11/08) showing the way in which she made use of MyPortfolio 
Although Mary made many changes to her view and showed that her skills in using MyPortfolio had developed by the end of the study, the fact that she did not actually finish the work set shows the way in which Mary was more engaged by the use of the technology than in the work set and this is a potential danger that teachers must be aware of. At times, the technology can become a distraction for students and this seems to have been what happened with Mary.

\subsubsection{Mary's profile}

Although Mary's final view showed that she had developed her skills in using MyPortfolio, Mary did not make significant use of her profile and once she had set it up did not update it at all:

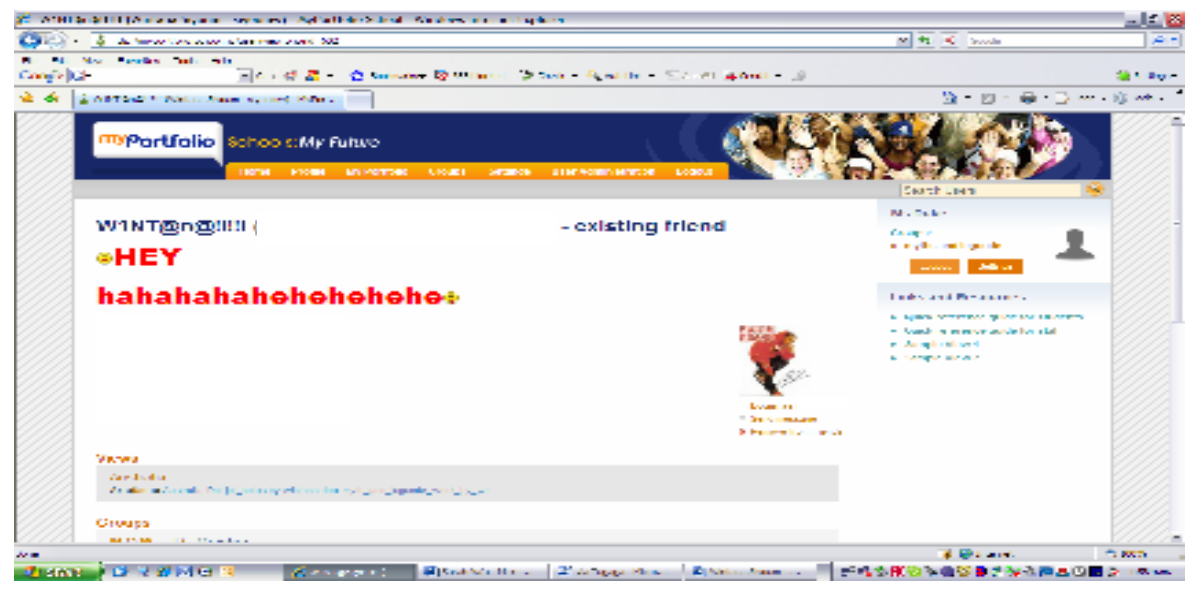

Figure 55 Mary's profile (24/11/08)- Mary did not make any changes throughout the study after the initial lesson

Mary did initially add slightly more information to her profile than Robina and added comments saying 'Hey' and 'hahahahahehehehe' but, unlike Ashleigh, YoYo, Nancy and Hannah, did not make any attempt to interact with other friends or classmates through the use of her profile and her profile does not reflect any of her interests. The fact that Mary did not already make use of social networking sites such as Bebo may have meant that she was not as familiar with this way of interacting with her friends as the other students and this may have affected the way that Mary utilised her profile.

Although Mary did not make use of her profile to display her interests, she did set up an additional view where she posted three pictures and commented on each. However, Mary did not make this view accessible to any of the other students. 


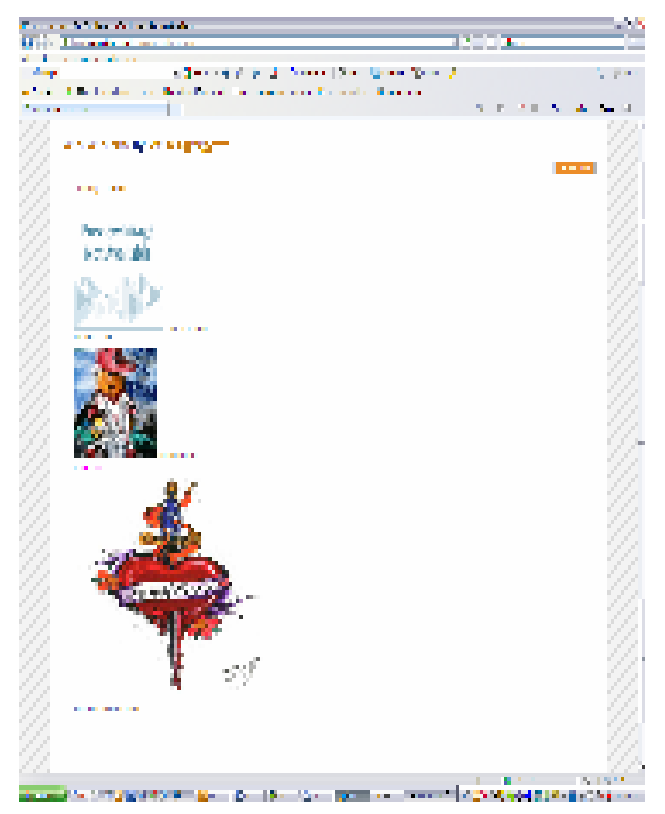

Figure 56 Mary's second view (26/11/08) showing the way in which Mary created a second view that was not related to the class work

When I asked Mary why she did not make her second profile available to others to see, she commented that she had been busy trying to finish the work required for her assignment view (final interview). By doing this, Mary showed that she was able to prioritise her school use of MyPortfolio over her social use.

\subsubsection{Mary's perception of MyPortfolio}

\subsubsection{Organisation}

As with Nancy, Ashleigh and YoYo, Mary also appreciated the fact that using MyPortfolio could help her organisation and, in the final survey, 'agreed' that MyPortfolio had helped to organise her work. When Mary and I discussed this in the final interview, Mary particularly identified the fact that MyPortfolio kept all her work in one place as the feature that she found most helped her to organise her work:

I had just, like, one view for everything I did on Australia and like, my myth and legend. Yeah, I organised (my work) like that (Mary's interview).

As I have already noted, this perception that MyPortfolio was a useful tool for organising resources was a common theme amongst the case study students I followed. 


\subsubsection{Access}

Mary also appreciated being able to access MyPortfolio and when I asked her why she would want to continue to use MyPortfolio, this was the aspect of the application that she highlighted.

Cos it, like helps me, oh, cos if I do my work at, like home (Mary's final interview).

Mary found the fact that she could assess MyPortfolio from a range of locations helpful as she did not have access to a printer at home. Instead, she was able to access the school computers and printers and was able to access and print out work that she had completed at home when she came to school:

I can just come and, like save it on MP and print it out cos my printer doesn't work (Mary's final interview).

\subsubsection{Communication}

In the final survey, when asked what the best aspect of MyPortfolio was, one of the features that Mary identified was the ability to message friends and members of her group:

The best thing is you can email (send messages to) your friends and other people in your group (Mary's final interview)

When we discussed this in the final interview, Mary noted that she felt that the messaging function within MyPortfolio helped enable her to work better with the other members of her group (15/11/08). Mary's group made use of the messaging tools within MyPortfolio to help process their work and they sent messages updating each other on their progress. In the final interview I asked Mary about this and she said she felt that this was a helpful way to keep track of the progress that her group was making:

It was helpful to know where everybody was up to (Mary's final interview).

As well using the messaging to help track the group's progress, Mary's group also made use of the messaging tools in order to collaborate on their work and make decisions about their group assignment. When I asked Mary what kinds of things they sent messages about, she said: 
Like, what kind of myth we were going to pick. And, like how we were going to present it and, like, what information we were going to put on it, from our dot-jot notes. And to see if we actually finished our dot-jot notes (Mary's final interview).

An example of the way that the Mary communicated with other members of her group in order to collaborate on her work can be seen in the following message:

read this (its our myth)i think. what do you think?

The Dolphin Children

Dolphins with Heads Out of Water

The day was so hot it sapped the people's strength to the point that daily activities became virtually impossible. So it was decided that they move camp and make for the coast.

Their journey would be hard for both the elderly and infant children, but the elder children viewed it as an exciting adventure. They took every opportunity to make the most of

it, but were constantly being cautioned to stay close.

More .

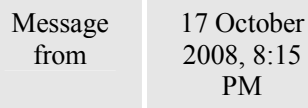

Figure 57 A message from Mary to another member of her group showing the way in which Mary's group collaborated in order to complete the tasks set

In this message, Mary emailed a myth that she had found to the other members of her group and asked them to response and say whether they thought that was an appropriate myth for them to use for their assignment. The use of the messaging within MyPortfolio allowed Mary to send this myth from home in the evening and continue to make progress on her assignment outside of class time. In this way, the students were able to work independently but also continue to collaborate while they were apart (see page $\mathrm{xx}$ ).

\subsection{Summary}

The six case study students I discuss represent a variety of the views that were present in this class during this study and they demonstrate the way in which different students, with different approaches to, and experiences with ICT, can have different responses to its use in class. This can be seen in the themes that emerged from these students and the way in which they view both the use of MyPortfolio during this study and its potential future use. In many ways, the variety of experiences, skills and perceptions of the students in this study demonstrate the way in which it is difficult to generalise about the skills and interests of students when it comes to the use of ICT and this challenges Prensky's (2001) ideas about how students want to make use of ICT at school. 


\section{Conclusions and Implications}

Amid the hype and speculation, education researchers need to keep educational aims in the foreground yet remain transparently curious about manifestations of learning beyond what we currently know" (Greenhow et al., 2009, p. 256)

While it is important that students develop skills in using technology, it is essential that teachers also understand how the technology can be used to support learning with the experiences of the students in the forefront of investigations. In this way, teachers can begin to understand how students make use of emerging technology and how this can enhance their learning (Ntuli et al., 2009; Selwyn et al., 2008).

\subsection{Conclusions}

The overarching purpose of this study has been to understand how this group of students experienced using the Web 2.0 application MyPortfolio and how this use impacted on their learning. While this study was conducted over a relatively short time frame, the combination of a range of data sources from the students and the particular focus on the six case study students presents a clear picture of the students' view of their experience with using MyPortfolio within the classroom.

In particular, it emerged that while the students in this study enjoyed using this web-based activity, they were not necessarily particularly skilled in the use of Web 2.0 applications with this emphasis on user-generated content and features that enable user interaction and sharing of content. Nor were they necessarily interested in forsaking the face-to-face interaction with their peers and the teacher that normally occurs within the classroom for increased use of digital media. In this way, the students in this study challenge ideas about 'digital natives' and the overall level of interest and skill that today's students have with these new communication technologies.

A clear conclusion from the students in this study was that MyPortfolio provided a tool to help the students organise their time and work. This perception of MyPortfolio meant that some of the students in this study tended to see MyPortfolio as better suited for use at home to support the process of learning, rather than for everyday use within the classroom.

The combination of these first two findings- the way in which students felt the lack of social interactions and the perception that MyPortfolio was more suited to use at home- highlights the fact that it is not always easy to balance the use of ICT within 
the classroom and still maintain meaningful relationships between students and the teacher. This does not mean that it is not a useful tool for schools, however, and access to technologies such as MyPortfolio may provide students with the opportunity to access learning outside the walls of schools and see more learning occur in home and community situations.

This study also highlights the fact that although students may be provided with the opportunity to engage in constructivist approaches to learning and, in particular, metacognitive thinking and reflection, they do not always do this naturally and may require support from the teacher in order to undertake this. Although this study was conducted over a relatively short time period and may not have been sufficient to see changes, it does suggest that students will continue to need the support of teachers in order to effectively develop these skills.

\subsection{Implications}

Although this study was focused around the experiences of the students, when analysing my data and considering the implications, time and time again, I found myself coming back to the role of the teacher and the importance of the role of the teachers has emerged as an underlying theme throughout the findings of this study. While ICT does offer many opportunities for students to work independently, there is no doubt that there is still a very clear role for teachers in both teaching subject specific skills and also skilled use of ICT for educational purposes (Jonassen, Howland, Moore, \& Marra, 2003). Consequently, as well as findings relating to the students' learning and experience in using MyPortfolio, each of the key findings of this study has implications for how teachers can help students to become better equipped for making use of technology and also how schools support both students and teachers in this.

\subsubsection{A tool to process knowledge}

Although the literature around e-portfolios is still developing, a clear theme around their use is emerging: The primary use of e-portfolios relates to supporting the process of learning rather than the construction of knowledge. While much writing around e-portfolio use suggested that it has the potential to provide students with the ability to engage in 'deep learning' online (Devlin-Scherer et al., 2006), the findings of this study support those who suggest that e-portfolios are best suited as a resourcing tool which can support students in organising, communicating and presenting their 
work (Barrett, 2008c; McNair \& Galanouli, 2002). Although it is possible that students may develop more skills in knowledge construction over time, the fact that Barrett (2008b) felt her two year trial was too short to observe this suggests that it may not be realistic to expect such outcomes within the framework of most current-day high school settings. It is also interesting to note that studies have found that the aspects of e-portfolio tools that students value are different from what teachers value (Devlin-Scherer et al., 2006). Although teachers identify the possibility that eportfolios can support knowledge construction, studies repeatedly suggest that it is the organisational and communication aspects of e-portfolios that students particularly appreciate (Abrami \& Barnett, 2005; Barrett, 2008c) and this was certainly the case for the students in this study where, overall, the most significant use of MyPortfolio made by students in this study was to help them with the process of learning. In particular, the students used MyPortfolio as a repository for storing work in progress; a place to keep track of the work that they and other members of their group had completed; and a way to communicate the progress of their work with other members of their group.

While Riedinger (2006) suggests that without reflection, e-portfolios simply become a mechanism for storage, this findings of this study suggest that this is not necessarily the case. The students did appreciate the ability of MyPortfolio to store their work and many of the students felt that MyPortfolio helped them manage time and resources better. It was this organisational aspect of MyPortfolio that provided particular affordances over paper portfolios.

\subsubsection{On-line or face-to-face- how blended should the learning be?}

The findings of this study present a mixed picture of these students' experience with using MyPortfolio. While in many cases the students reported that they enjoyed making use of the tool, other students were clear that they did not wish to make increased use of MyPortfolio at school and that in their experience with MyPortfolio in this study, they missed the sense of community and wider class social interaction that usually occurs within the classroom. While one of the key features of Web 2.0 technology is the way in which it can enable communication, the fact remains that the students in this study were more used to experiencing face-to-face communication. Although the communication tools within MyPortfolio offer the opportunity to engage students in continued communication outside the classroom, they does not offer the 
richness and immediacy of face-to-face communication and, thus, may not fully engage students.

Social interaction among learners plays an important part in the learning process and can have a significant impact on the learning outcome (Vonderwell, 2003) and writers such as Chizmar \& Walbert (1999) argue strongly that the use of online learning tools should be used as part of a well-balanced learning environment. One of the features of high schools that much of the research relating to online learning does not refer to is the fact that students enjoy interacting with their teachers about more than just the class work set (Lim \& Barnes, 2002) and Garrison and Kanuka (2004) suggest that the real test of blended learning is managing the balance and integration of face-to-face learning and internet technology- such as MyPortfolio. In this study, some of the students' responses suggest that the correct balance was not found for them. As this study demonstrates, the real challenge for teachers is finding the right 'blend' in order to ensure that the students are able to make effective use of both ICT and face-to-face learning (Stacey \& Gerbic, 2007).

There is no doubt that today's students must be able to confidently and competently use technology (Tapscott, 1998). However, the challenge for traditional high schools making use of blended learning environments is to ensure that the best elements of all forms of learning are maintained. One of the things that this study made most clear was that these students still desired face-to-face contact with both their teacher and the other students in this class. While there are many reasons why students may choose or be required to undertake distance and on-line study, the high school students in this study echoed the findings of other researchers who have found that students tend to express a preference for maintaining regular face-to-face contact with the teacher and other students (Oliver \& Omari, 1999) and moderate use of ICT (Caruso, Kvavik, \& Morgan, 2005). For many students, the face-to-face experience remains one of the most valuable aspects of learning and although the students in this study saw MyPortfolio as a valuable tool for helping support the process of learning, they did not wish to forsake the face-to-face contact that normally occurs in the classroom. However, the students did enjoy making use of ICT and the motivational aspect of this can help support learning but this must be balanced with adequate faceto-face learning (Papert, 1993).

It is particularly interesting to note that the students in this study were working in small groups and made use of the computers together as a class in the computer 
laboratories, however, they still felt the loss of the whole class interaction that occurs within a traditional classroom setting. One of the challenges for teachers in a blended learning environment will be ensuring that students are able to regularly interact with a wide range of other students and also that students are able to have regular face-toface interaction with the teacher and Zemsky and Massy argue strongly for the importance of “... an actual, physically intact learning community” (2004, p. 51). In order to achieve this, Garrison and Kanuka assert that the key issue in blended learning is "...the quality and quantity of the interaction and the sense of engagement in a community of inquiry and learning, achieved through the effective integration of Internet communication technology" (2004, p. 97).

Many high schools have been slow to integrate technology into everyday learning and this poses part of the problem when attempting to find the correct blend of ICT into classroom teaching. With the exception of schools that make use of laptops for every student, access is often an issue at high schools and student use is often limited to class trips to the computer laboratory. This was the case in with the school in this study and is reflected in the relatively low level of use at school reported by these students at the beginning of this study (see appendix 2.2). Having said this, the digital landscape is constantly changing and as ICT becomes smaller, more userfriendly and more accessible, it is possible that the nature of student access and use will change dramatically. However, if schools are to be places where students are comfortable using technology to support their learning it will be important for technology to be integrated into all curriculum subjects and ease of access ensured (Roblyer, 2006; Tosh \& Werdmuller, 2004) while meaningful face-to-face contact is still maintained.

\subsubsection{Digital Natives?}

Similarly, while many writers give enthusiastic accounts of the abilities and interests of today's students (Prensky, 2001) it is possible that some of this is an overromanticised view that it really only represents a few very talented students (Kennedy et al., 2007; Kennedy et al., 2008; Kennedy et al., 2006; Romeo, 2006), in the same way that any aspect of school life contains some students with special skills and abilities (Luckin et al., 2009). Certainly, the students in this study represented a broad range of both skills with and interest in ICT, as with any generation of students (Kennedy et al., 2008) and the findings of this research seem to support the findings of those who challenge the idea that this current generation of students is more 
technologically able, or indeed, interested in ICT than their teachers or previous generation (Kennedy et al., 2007; Kennedy et al., 2008; Kennedy et al., 2006; Selwyn et al., 2008). Further, several recent studies have argued that the students who are able to make use of Web 2.0 technologies in the ground-breaking ways described by authors such as Tapscott (1998) and Prensky $(2001 ; 2004)$ are actually in the minority (Green \& Hannon, 2007; Luckin et al., 2009) and this certainly reflects the findings of this study.

Contrary to Tapscott's (1998) assertions about the fact that students are comfortable with media and their mastery of it, virtually all of the students in this study failed to fully master MyPortfolio during the course of this study. For the most part the students in this study made almost exclusive use of very entrenched applications such as MSWord and PowerPoint during the course of the study and a number of students chose to make use of MSWord and then upload these files into MyPortfolio rather than complete their work within MyPortfolio (as discussed in Chapter 4,5 and 7). In this way, some of the students resisted making use of MyPortfolio and limited their use of MyPortfolio as far as possible.

While there were several students in this study who were very keen on making use of ICT and certainly had skills beyond the others in their class, they also predominately made use of applications they were familiar with rather than developing a sophisticated approach towards their use of MyPortfolio.

Overall, this study does not support the idea that a high level of skill in using ICT is a reality for most students. While we do know that today's teenagers are high users of ICT and have high levels of access (British Educational Communication Technology Agency (Becta), 2007; Caruso et al., 2005; OECD, 2005), this does not necessarily mean that most students are making sophisticated use of ICT outside of their use of entrenched technologies such as cell phones, Internet and email (Kennedy et al., 2008) and reporting on their study of student ICT use, Selwyn, Potter and Cranmer (2008) comment that:

While our data depict a generation of young people for whom ICTs are part of their everyday lives, close inspection shows many primary pupils actual engagement with ICT to be often perfunctory and unspectacular (page 10). 
While it is important that teachers do not underestimate the skills that students have (British Educational Communication Technology Agency (Becta), 2007), it is also clear that not all students are vastly more technologically competent than teachers, particularly when making use of technology for more than a basic set of core tasks (Selwyn et al., 2008), and Hong, Lai and Holton (2003) note that a lack of basic ICT skills can result in both a lack of ability to solve technical problems and an associated anxiety that further demotivates students. This was certainly the case for some of the students in this study and this is an issue that teachers must be aware of.

Zemsky and Massy (2004) also argue that e-learning has not trumped students' desire for entertainment and social interaction and these aspects of ICT seem much more interesting to students than more specifically educational approaches (Zemsky \& Massy, 2004). Vaidhyanathan (2008) also argues that students make use of Web 2.0 tools such as Facebook and MySpace because they are easy to use and fun, rather than because they are powerful tools However, it possible that the use of Web 2.0 tools such as MyPortfolio is able to build on the previous experience of students, and several students in this study made reference to the fact that MyPortfolio reminded them of social networking tools (Williams \& Chinn, 2009). It is clear, however, that teachers need to support students in making the transition from social use to use that effectively supports learning (Williams \& Chinn, 2009) and Greenhow el al. (Greenhow et al., 2009) contend that a stronger research focus on students' everyday use and learning with Web 2.0 technologies both in and out of the classroom is required in order to fully understand how student use of these technologies can intersect with or support learning.

While Web 2.0 tools offer much promise as educational tools, the fact remains that the students in this study did not seem to have a strong desire to make significantly more use of ICT in the classroom and the skills that students do have do not necessarily translate easily into using technology for effective learning (Green \& Hannon, 2007). While the students in this study enjoyed using ICT to some extent and were enthusiastic about using ICT in their class work, most of the students were not interested in forsaking the face-to-face social interaction that usually occurs within a classroom setting in order to make more use of ICT tools such as MyPortfolio. 


\subsubsection{Supporting constructivist approaches to learning}

In many ways, the use of MyPortfolio clearly supports constructivist approaches to learning in that it clearly places the learner in the centre of the learning context (Wangpipatwong \& Papasratorn, 2007), allowing them to make decisions about how they prepare and present work and how this relates to the skills and knowledge that they are developing (Stefani et al., 2007).

While commentators such as Clark (1994) question whether the use of ICT makes any difference in learning, this study suggests that ICT can be a significant tool for helping support the process of learning. While the students in this study did not make significant use of ICT to generate knowledge, they did, independently of the teacher, make use of MyPortfolio to support the process of learning. In this way, the technology alone did influence the students' learning. This finding supports Molesworth's (2004) suggestion that the most clear benefits of online learning relate to academic support or, what Palloff and Pratt (1999) refer to as process management and demonstrates that although students are not learning from the media, they are able to learn with the media (Robinson et al., 2008).

As with any tool used in education, the key to using MyPortfolio lies in the way in which it is exploited in order to help students' develop their learning(Owston, 1997). In the case of MyPortfolio, the students seem to have clearly identified that they saw it as a way to support the process of learning, particularly to help them organise their work and communicate with other students. While this does not immediately transfer into knowledge construction, giving students tools to support the learning process can help them to develop skills in order to support knowledge construction and become more independent learners (Palloff \& Pratt, 1999). In this way, the use of MyPortfolio is not an end in itself, but rather a way to facilitate educational processes (Branch \& Deissler, 2008).

Many claims have been made about the way that the use of ICT can help foster metacognition in students and literature relating to e-portfolio use particularly highlights their ability to engage students in reflective thinking (Avraamidou \& Zembal-Saul, 2002, 2003; Barrett, 2005, 2008b; Jonassen, 2000). However, the students in this study did not naturally engage in reflective thinking through the use of MyPortfolio and while a requirement for reflection was built into the tasks that the students completed, the students showed little evidence of actually engaging in reflective thinking and the 'reflection' that they did complete was largely shallow and 
demonstrated very little thought or strategy (McLeod \& Vasinda, 2009). While the blogging and view functions of MyPortfolio provided tools that may allow students to develop metacognitive skills, the students in this study did not make any use of these tools for metacognitive purposes unless it was required by the class work. In fact, as discussed in Chapters 6 and 7, even when students did make use of the tools, they engaged in very shallow reflection and there was little sense that the students were making use of MyPortfolio in order to improve their metacognitive thinking. While it is impossible to measure developments in student metacognition over such a short time frame, it is clear that just because tools to support the development of metacognition are available to students, does not mean that they will naturally make use of them.

Consequently, the use of MyPortfolio alone is unlikely to ensure that students are developing metacognitive skills and this is one area in which the teacher has a particular role (Weigel, 2002). Roschelle and Pea (1999) make the point that teachers must support students in developing metacognitive skills so that they can make the most of the learning opportunities- both digital and more traditional. It is clear that the use of the technology alone does not mean that students will necessarily engage metacognitive skills and it is important in this area, as in all areas of learning, that they are taught to engage these skills so that they can continually make use of them in new contexts (Barnes, Marateo, \& Ferris, 2007). Barrett (2008a; 2008b; 2008c) also argues that reflective learning skills need to be taught, modelled and practised over time in order to effectively develop.

Although this study did not demonstrate students making use of metacognitive and reflective thinking skills in order to complete the work that was set, it is still possible to see that the use of Web 2.0 tools such as MyPortfolio can help students develop metacognitive skills through the need to problem-solve in order to make use of applications such as MyPortfolio in order to achieve learning outcomes (Roschelle \& Pea, 1999) In this way, although the use of MyPortfolio alone is unlikely to ensure that students develop metacognitive skills, it is still possible to see that students might develop these skills through the use of ICT as ICT requires these skills.

Overall, the ability for MyPortfolio to support constructivist approaches to learning remains unsupported from this study. There are clearly aspects of MyPortfolio such as the view which support constructivist approaches to learning in that they allow students to construct their knowledge over a period of time and present 
this to an audience for a particular purpose. Similarly, many features such as the communication tools and the blogs remain possibilities for supporting constructivist approaches through the use of collaborative work and the development of reflection over a period of time in the blog. However, at this time, these remain more of a possibility and this study suggests that students will not naturally come to these tools on their own. The role of the teacher remains highly significant within both constructivist and blended learning environments and the teacher has two particular roles to play. The first is in helping scaffold the students' learning (Hmelo-Silver et al., 2007) so that they are able to develop both their skills and knowledge. Kirshner, Sweller and Clark (2006) note that it is important that teachers provide strong guidance for learners so that students are able to develop strong problem solving skills. The second role of the teacher involves establishing relationships with the students and, as I have already noted, the use of blended learning situations requires careful management in order to ensure that the students' relationships with both the teacher and other students are not jeopardised.

\subsubsection{The role of the teacher}

In the early days of ICT use, it was suggested that ICT would eventually replace the teacher altogether (C. P. Lim \& Barnes, 2002). However, throughout this study, the significance of the role of the teacher has been continually reinforced and this reflects the findings of other studies (Barrett, 2008b; British Educational Communication Technology Agency (Becta), 2007). Each of the points made above relies on careful management by the teacher in order to ensure that students have the support they need to develop their learning. If students are to make use of Web 2.0 based software such as MyPortfolio to support other aspects of constructivist learning such as knowledge generation and collaboration, then it is clear that teachers must play a significant role in supporting this. As already noted, students need significant support to develop metacognitive skills and the use of ICT alone will probably not see students develop advanced skills in this area. However, if students are able to use MyPortfolio to collect their work over time and are given clear guidelines about how to reflect and develop their work over a period of time, then it may become a tool that can help support students' metacognitive skills. However, that the teacher must play a significant role in this and Bull et al. (2008) suggest that one reason that ICT technologies such as MyPortfolio are not widely integrated into education is the lack of modelling by instructors and suggest that a key role of instructors is to bridge the 
gap between learners' use of ICT outside the classroom and making effect use of ICT for the purposes of learning.

Aspden and Helm (2004) note that students need a lot of preparation in order to effectively make use of the blended learning environment. As already noted, students need to have the technical skills to adequately make use of the technology and teachers should not assume that the students already know or will naturally learn how to make use of new ICT tools and a way that meaningfully supports learning. Further, this study clearly identifies the fact that students do not necessarily engage in deep learning or make use of metacognitive skills just because the tools are available to support this are available to this. Teachers must explicitly teach metacognitive skills and must also support students in making use of these in new contexts. Although MyPortfolio provides tools where students can develop their metacognitive skills, it is important that teachers model and facilitate the use of these so that students are able to see how these tools can be used in order to support their learning.

Gifford (1996) provides a useful model for understanding the interaction of that occurs in blended learning environments:

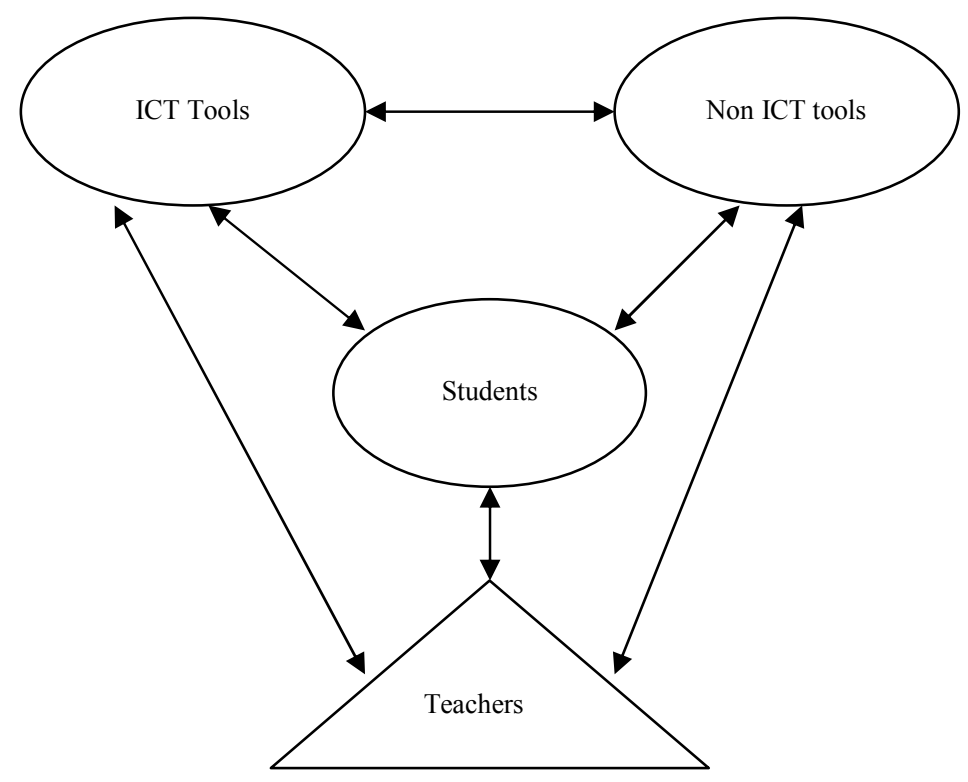

Figure 58 Gifford's (1996) mediated learning model

The key aspect of this model is the fact that it demonstrates the way in which nothing is unidirectional; there is always interaction between the teacher, the students and both ICT and non-ICT tools used within the classroom. Similarly, this model 
illuminates the way in which the role of the teacher remains crucial to learning and Lim and Barnes (2002) make the point that the teacher is essential in designing and planning the learning environment. In this way, the teacher must make intentional use of the ICT in order to support learning but also be able to teach student how to make use of the metacognitive skills so that they can make use of these skills within a range of learning contexts.

While this study has highlighted the crucial role of the teacher in supporting effective use of ICT, it is also important to point out that this has implications for schools in that teachers will also require support in order to effectively make of ICT and, as a consequence, be able to support students' learning.

\subsubsection{Conclusion}

"E-portfolios are about people, rather than technology" (Gray, 2008, p. 10).

Although most of the students in this study enjoyed their experience using MyPortfolio; would recommend it to other students; and would like to continue to use it in some capacity, they did not see it as an essential part of their learning, but rather a way to supplement the learning that they were undertaking. Web 2.0 technologies such as MyPortfolio have the potential to engage students and to help support student learning. In this regard, Osguthorpe and Graham (2003) suggest that blended learning situations should try to "...maximise the benefits of both face-to-face and online methods- using the web for what it does best and using class time for what it does best" (p. 277).

The debates over the use of ICT within the classroom will continue and in some ways, this study does suggest that ICT tools do have the power to support students' learning through aiding organisation and communication. However, although this was a small study of 25 students in a specific context, it does reflect findings from writers who argue that "Technology doesn't teach. People do" (Price, 1996, p. 17) as it is clear that the teacher is required to play a pivotal role in supporting students' learning with ICT- particularly in helping them develop metacognitive skills.

This does not mean that students and teachers should forsake the use of technology- indeed, it is clear that it is important for today's learners to be confident and competent users of technology. However, this study suggests that the technology alone will not create skilled users. While Web 2.0 technologies such as MyPortfolio may have an important role in students' learning- particularly in supporting the 
process of learning- they are unlikely, at least in their current form, to replace the faceto-face contact that occurs in the classroom and the facilitation and mediation that teachers provide.

This study was conducted with a small group over a relatively short timeframe of six weeks and it may have been that over a longer timeframe, the outcomes may have been different- in particular, students may have begun to engage more in the metacognitive aspects of using MyPortfolio. However, this study does provide insight into the way in which a novice group of users learnt to use MyPortfolio and the areas in which teachers can help support students in making use of this tool. Further research will be required in order to continue to develop an understanding of students' perspectives of e-portfolio tools such as MyPortfolio over a longer period of time and this may also provide more insight into how e-portfolio tools can support the development of constructivist approaches to learning.

Technology is not an end in itself but should be seen as a means towards an end, with that end being improved learning outcomes for students of all ages. (Fox et al., 2009, p. 12). 


\section{References}

Abrami, P. C., \& Barnett, H. (2005). Directions for research and development on electronic portfolios. Canadian Journal of Learning and Technology, 31(3).

Ahn, J. (2004). Electronic portfolios: blending technology, accountability and assessment. T.H.E. Journal, 31(9), 12.

Allen, L. Q. (2004). Implementing a Culture Portfolio Project within a Constructivist Paradigm. Foreign Language Annals, 37(2), 232.

Alonso, F., López, G., Manrique, D., \& Viñes, J. M. (2005). An instructional model for web-based e-learning education with a blended learning process approach. British Journal of Educational Technology, 36(2), 217-235.

Asia and the Pacific Programme of Educational Innovation for Development. (1991). Preparing ASEAN for the Information Century: A comparative study of policies and programmes on computers in science and mathematics in education. Bangkok: UNESCO.

Aspden, L., \& Helm, P. (2004). Making the connection in a blended learning environment. Educational Media International, 41(3), 245-252.

Attwell, G., Chrzaszcz, A., Hilzensauer, W., Hornung-Prähauser, V., \& Pallister, J. (2007). Grab your future with an e-portfolio [Electronic Version]. Retrieved 1 April 2008 from http://www.mosep.org/study/mosep study.pdf

Avraamidou, L., \& Zembal-Saul, C. (2002). Making the case for the use of web-based portfolios in support of teaching to learn The Journal of Interactive Online Learning, 1(2), 1-19.

Avraamidou, L., \& Zembal-Saul, C. (2003). Exploring the influence of web-based portfolio development on learning to teach elementary science. Journal of Technology and Teacher Education, 11(3), 415-442.

Barnes, K., Marateo, R. C., \& Ferris, S. P. (2007). Teaching and learning with the Net Generation [Electronic Version]. Innovate Journal of Online Education, 3(4). Retrieved 23/7/09 from http://innovateonline.info/index.php?view=article\&id=382\&action=article.

Barrett, H. (2005). White paper: Researching electronic portfolios and learner engagement [Electronic Version]. Retrieved 14 January 2008 from http://www.taskstream.com/reflect/whitepaper.pdf.

Barrett, H. (2007). Researching electronic portfolios and learner engagement: the REFLECT initiative. Journal of Adolescent \& Adult Literacy, 50(6), 438-449.

Barrett, H. (2008a). The electronic portfolio development process [Electronic Version]. Retrieved 12/9/08 from http://electronicportfolios.com/portfolios/aahe2000.html.

Barrett, H. (2008b). The REFLECT Initiative Research Project. Paper presented at the American Educational Research Association. Retrieved 4 April 2008, from http://electronicportfolios.org/portfolios.html.

Barrett, H. (2008c). The REFLECT initiative: A research project to assess the impact of electronic portfolios on student learning, motivation and engagement in secondary schools. Paper presented at the National Educational Computing 
Conference. Retrieved 1/9/08, from

http://electronicportfolios.org/reflect/NECC08.pdf.

Barrett, H., \& Garrett, N. (2009). Online personal learning environments: Structuring electronic portfolios for lifelong and life-wide learning. On the Horizon, 17(2), 142-152.

Batson, T. (2002). The electronic portfolio boom: What's it all about? [Electronic Version]. Campus Technology, December 2002. Retrieved 4 April 2008 from http://campustechnology.com/articles/39299/.

Bennett, S., Maton, K., \& Kervir, L. (2008). The 'digital natives' debate: A critical review of the evidence. British Journal of Educational Technology, 39(5), 775786.

Blair, K. L., \& Takayoshi, P. (1997). Reflections on reading and evaluating electronic portfolios. In K. B. Yancey \& I. Weiser (Eds.), Situating Portfolios: Four perspectives. Logan, Utah: Utah State University Press.

Bonk, C. J., \& King, K. S. (1998a). Computer conferencing and collaborative writing tools: Starting a dialogue about student dialogue. In C. J. Bonk \& K. S. King (Eds.), Electronic collaborators: Learner centered technologies for literacy, apprenticeship and discourse. Mahwah NJ: Lawrence Erlbaum.

Bonk, C. J., \& King, K. S. (1998b). Electronic collaborators: Learner-centered technologies for literacy, apprenticeship, and discourse. Mahwah, NJ: Lawrence Erlbaum Associates.

Bonk, C. J., Olson, T. M., Wisher, R. A., \& Orvis, K. L. (2002). Learning from focus groups: An examination of blended learning. Journal of Distance Education, 17(3), 97-118.

boyd, d. (2007). Why youth (heart) social network sites: The role of networked publics in teenage social life. In D. Buckingham (Ed.), MacArthur Foundation series on digital learning- Youth, identity and digital media volume (pp. 119-142). Cambridge, MA: MIT Press.

boyd, d., Chang, M., \& Goodman, E. (2004). Representations of Digital Identity. Paper presented at the Conference on Computer Supported Cooperative Work (CSCW 2004), Workshop Organizer's Proposal. Retrieved 22/11/09, from http://www.danah.org/papers/CSCW2004Workshop.pdf.

boyd, d., \& Ellison, N. B. (2007). Social network sites: definition, history, and scholarship [Electronic Version]. Journal of Computer-Mediated Communication, 13(1). Retrieved 27/8/09 from http://jcmc.indiana.edu/vol13/issue1/boyd.ellison.html.

Branch, R. M., \& Deissler, C. H. (2008). Processes. In A. Januszewski \& M. Molenda (Eds.), Educational Technology: A definition with commentary. New York: Lawrence Erlbaum Associates

British Educational Communication Technology Agency (Becta). (2007). Impact study of e-portfolios on learning [Electronic Version]. Retrieved 14th of April 2008 from http://partners.becta.org.uk/index.php?section $=$ rh\&catcode $=$ re $\mathrm{rp} 02 \&$ rid $=14$ $\underline{007}$.

Brown, M., Anderson, B., Simpson, M., \& Suddaby, G. (2007). Showcasing Mahara: A new open source eportfolio. Paper presented at the ICT: Providing choices 
for learners and learning, Ascilite Singapore 2007. from

http://www.ascilite.org.au/conferences/singapore07/procs/brown-poster.pdf

Buffington, M. L. (2008). What is Web 2.0 and how can it further art education? Art Education, 61(3), 36-41.

Bull, G., Thompson, A., Searson, M., Garofalo, J., Park, J., Young, C., et al. (2008). Connecting informal and formal learning: Experiences in the age of participatory media. Contemporary Issues in Technology and Teacher Education, 8(2).

Burge, E. J. (1994). Learning in computer conferenced contexts: The learners' perspective. The Journal of Distance Education, 9(1), 19-43.

Burns, R. B. (1997). Introduction to research methods. South Melbourne: Addison Wesley Longman.

Butler, P. (2006). A review of the literature on portfolios and electronic portfolios. [Electronic Version]. Retrieved 14 January 2008 from http://eduforge.org/docman/?group id=176

Carswell, L., Thomas, P., Petre, M., Price, B., \& Richards, M. (2000). Distance education via the Internet: The student experience. British Journal of Educational Technology, 31(1), 29-46.

Caruso, J. B., Kvavik, R. B., \& Morgan, G. (2005). Students and information technology, 2005: Convenience, connection, control and learning [Electronic Version] from http://www.educause.edu/ir/library/pdf/ers0405/rs/ers0405w.pdf.

Chang, C.-C. (2001). A study on the evaluation and effectiveness analysis of webbased learning portfolio (EBLP). British Journal of Educational Technology, 32(4), 435-458.

Chizmar, J. F., \& Walbert, M. S. (1999). Web-based learning environments guided by principles of good teaching practice. Journal of Economic Education, 30(3), 248-259.

Clark, R. E. (1983). Reconsidering research on learning from media. Review of Educational Research, 53(4), 445-459.

Clark, R. E. (1994). Media will never influence learning. Educational Technology Research and Development, 42(2), 21-29.

Clark, R. E., \& Feldon, D. F. (2005). Five common but questionable principles of multimedia learning. In R. E. Mayer (Ed.), The Cambridge handbook of multimedia learning. Cambridge: University of Cambridge Press.

Cohn, E. R., \& Hibbetts, B. J. (2004). Beyond the electronic portfolio: A lifetime personal web space. EDUCASE Quarterly, 27(4), 7-10.

Cole, D. J., Ryan, C. W., \& Kirk, F. (1995). Portfolios across the curriculum and beyond. Thousand Oaks, California: Corwin Press.

Collis, B., \& Moonen, J. (2006). The contributing student: Learners as co-developers of learning resources for reuse in web environments. In D. Hung \& M. S. Khine (Eds.), Engaged learning with emerging technologies. Dordrecht: Springer.

Cotterill, S. J., Aiton, J. F., Bradley, P. M., Hammond, G. R., McDonald, A. M., Struthers, J., et al. (2006). A flexible component-based ePortfolio: Embedding 
in the curriculum. In A. Jafari \& C. Kaufman (Eds.), Handbook of research on ePortfolios. Hershey, PA: Ideas Group Reference.

Creswell, J. W., Hanson, W. E., Clark Plano, V. L., \& Morales, A. (2007). Qualitative research designs: Selection and implementation The Counseling Psychologist, $35(2), 236-264$.

Cuban, L. (2001). Oversold and underused: Computers in the classroom. Cambridge, MA: Harvard University Press.

Darling, L. F. (2001). Portfolio as practice: The narratives of emerging teachers. Teaching and Teacher Education, 17(1), 107-121.

Davis, B., Sumara, D., \& Luce-Kapler, R. (2000). Engaging minds: Learning and teaching in a complex world. Mahwah, NJ: Lawrence Erlbaum Associates.

De Rijdt, C., Tiquet, E., Dochy, F., \& Devolder, M. (2006). Teaching portfolios in higher education and their effects: An explorative study. Teaching and Teacher Education, 22(8).

Denscombe, M. (2006). The good research guide (2nd ed.). Maidenhead: Open University Press.

Denzin, N. K., \& Lincoln, Y. S. (Eds.). (2005). The Sage handbook of qualitative research (3rd ed.). Thousand Oaks, California Sage Publications.

Devlin-Scherer, R., Martinelli, J., \& Sardone, N. (2006). Twisting the kaleidoscope: Making sense of ePortfolios. In A. Jafari \& C. Kaufman (Eds.), Handbook of research on ePortfolios. Hershey, PA: Ideas Group Reference.

Dewey, J. (1938). Logic, the theory of inquiry. London: Allen \& Unwin.

Downs, M., \& Moller, L. (1999). Experiences of Students, Teachers, and Administrators in a Distance Education Course. International Journal of Educational Technology, 1(2), 1-13.

Duffy, T. M., \& Jonassen, D. H. (Eds.). (1992). Constructivism and the technology of instruction. New Jersey: Lawrence Erlbaum Associates.

Edelson, D. C. (2001). Learning-for-use: A framework for integrating content and process learning in the design of inquiry activities. Journal of Research in Science Teaching, 38(3), 355-385.

Elbow, P., \& Belanoff, P. (1997). Reflections on an explosion: Portfolios in the '90s and beyond. In K. B. Yancey \& I. Weiser (Eds.), Situating Portfolios: Four perspectives. Logan, Utah: Utah State University Press.

Field, J. (2006). Lifelong Learning and the New Educational Order. Stoke on Trent: Trentham Books.

Flexible Learning. (2008). MyPortfolio FAQs [Electronic Version]. Retrieved 3/11/09 from http://myportfolio.school.nz/artefact/file/download.php?file=25212

Flexible Learning. (2009). MyPortfolio front page. Retrieved 9/8/09, from http://myportfolio.school.nz/

Forcier, R. C., \& Descy, D. E. (2008). The computer as an educational tool: Productivity and problem solving (5th ed.). Upper Saddle River, N.J.: Pearson/Merrill/Prentice Hall. 
Forgette-Giroux, R., \& Simon, M. (2000). Organizational issues related to portfolio assessment implementation issues in the classroom. Practical Assessment, Research \& Evaluation, 7(4).

Fournier, J., Lane, C., \& Corbett, S. (2007). The journey to best practices: Results of a two-year study of e-portfolio implementation in beginning composition courses. In C. Montgomerie \& J. Seale (Eds.), Proceedings of World Conference on Educational Multimedia, Hypermedia and Telecommunications 2007 (pp. 2008-2016). Chesapeake, VA: AACE.

Fox, I., Britain, S., \& Hall, V. (2009). ePortfolios - Celebrating learning. Wellington: Ministry of Education.

Gall, M. D., Gall, J. P., \& Borg, W. R. (2007). Educational research (8th ed.). Boston: Allyn \& Bacon.

Gao, P. (2006). Teaching with technology: Creating constructivist classrooms. In M. S. Khine (Ed.), Teaching with technology. Singapore: Prentice Hall.

Garrison, D. R., \& Kanuka, H. (2004). Blended learning: Uncovering its transformative potential in higher education. The Internet and Higher Education, 7(2), 95-105.

Gearhart, M., \& Herman, J. L. (1998). Portfolio assessment: Whose work is it? Issues in the use of classroom assignments for accountability. Educational Assessment, 5(1), 41 - 55

Gergen, K. J. (1995). Social construction and the educational process. In L. P. Steffe \& J. Gale (Eds.), Constructivism in education. New Jersey: Lawrence Erlbaum Associates

Giddens, A. (1991). Modernity and self-identity: Self and society in the late modern age. Cambridge: Polity Press.

Gifford, B. R. (1996). Mediated learning: A new model of technology-mediated instruction and learning. Mountain View, CA: Academic Systems Corporation.

Glaser, B., \& Strauss, A. (1967). The discovery of grounded theory. Chicago: Aldone.

Goldsmith, D. J. (2007). Enhancing learning and assessment through e-portfolios: A collaborative effort in California. New Directions for Student Services, Fall 2007(119), 31-42.

Grabe, M., \& Grabe, C. (2001). Integrating technology for meaningful learning. Boston: Houghton Mifflin.

Gray, L. (2008). Effective practice with e-Portfolios [Electronic Version]. Retrieved 22/11/09 from

http://www.jisc.ac.uk/media/documents/publications/effectivepracticeeportfoli os.pdf

Green, H., \& Hannon, C. (2007). Their Space: Education for a digital generation [Electronic Version]. Retrieved 1/11/09 from http://www.gowild.org.uk/NR/rdonlyres/BEAA7909-9D03-4AEE-A614738AF69BD7E7/0/Their space web.pdf

Greenberg, G. (2004). The digital convergence: Extending the portfolio model [Electronic Version]. EDUCASE Review, 39(4), 29-36. Retrieved 1 April 2008 from 
http://connect.educause.edu/Library/EDUCAUSE+Review/TheDigitalConverg enceExte/40483.

Greenberg, G. (2005). Can we talk? Electronic portfolios as collaborative learning spaces. In A. Jafari \& C. Kaufman (Eds.), Handbook of research on ePortfolios. Hershey, PA: Ideas Group Reference.

Greenhow, C., Robelia, B., \& Hughes, J. E. (2009). Learning, teaching and scholarship in a digital age. Educational Researcher, 38(4), 246-259.

Harrison, C. (2005). ICT and classroom pedagogies. In M. Leask \& N. Pachler (Eds.), Learning to use ICT in the secondary school (2nd ed.). London: RoutledgeFalmer.

Hartnell-Young, E. (2006). ePortfolios for knowledge and learning. In A. Jafari \& C. Kaufman (Eds.), Handbook of research on e-portfolios. Hershey, PA: Idea Group Reference.

Hawisher, G. E., \& Selfe, C. L. (1997). Wedding the technologies of writing portfolios and computers: The challenges of electronic classrooms. In K. B. Yancey \& I. Weiser (Eds.), Situating Portfolios: Four perspectives. Logan, Utah: Utah State University Press.

Herman, J. L., \& Winters, L. (1994). Portfolio research: A slim collection. Educational Leadership, 52(2), 48-55.

Herring, M. C. (2004). Development of constructivist-based distance learning environments. The Quarterly Review of Distance Education, 5(4), 231-242.

Hmelo-Silver, C. E., Golan, R. D., \& Chinn, C. A. (2007). Scaffolding and achievement in problem-based and inquiry learning: A response to Kirschner, Sweller and Clark (2006). Educational Psychologist, 42(2), 99-107.

Hong, K.-S., Lai, K.-W., \& Holton, D. (2003). Students' satisfaction and perceived learning with a web-based course [Electronic Version]. Educational Technology and Society, 6(1). Retrieved 11/5/09 from http://www.ifets.info/journals/6 1/hong.html.

Howland, J. L., \& Moore, J. L. (2002). Student perceptions as distance learners in Internet-based courses. Distance Education, 23(2), 183-195.

Hughes, M., \& Hagie, C. (2005). The positive and challenging aspects of learning online and in traditional face-to-face classrooms: A student perspective. Teacher Education, 20(2), 52-59.

Jafari, A., \& Greenberg, G. (Eds.). (2003). Electronic portfolio white paper, version 1.0 [Electronic Version]. Retrieved 17/9/08 from http://www.eportconsortium.org/Uploads/whitepaperV1 0.pdf

Johansson, P., \& Gärdenfors, P. (2005). Introduction to cognition, education and communications technology. In P. Gärdenfors \& P. Johansson (Eds.), Cognition, education and communications technology. Mahwah, NJ: Lawrence Erlbaum.

Johnson, R. S., Mims-Cox, J. S., \& Doyle-Nichols, A. (2006). Developing portfolios in education: a guide to reflection, inquiry, and assessment. Thousand Oaks, California: SAGE Publications

Jonassen, D. H. (2000). Computers as mindtools for schools: Engaging critical thinking (2nd ed.). Upper Saddle River: Merrill. 
Jonassen, D. H., Davidson, M., Collins, M., Campbell, J., \& Haag, B. B. (1995). Constructivism and Computer-mediated Communication in Distance Education [Electronic Version]. American Journal of Distance Education, 9(2). Retrieved 19/05/09 from http://www.c31.unioldenburg.de/cde/media/readings/jonassen95.pdf.

Jonassen, D. H., Howland, J., Moore, J., \& Marra, R. M. (2003). Learning to solve problems with technology: A constructivist perspective (2nd ed.). Upper Saddle River, NJ: Pearson Education.

Jonassen, D. H., \& Land, S. M. (Eds.). (2000). Theoretical foundations of learning environments. Mahwah, N.J.: Lawrence Erlbaum.

Jonassen, D. H., Peck, K. L., \& Wilson, B. G. (2001). Learning with technology: A constructivist perspective. Upper Saddle River, N.J.: Merrill.

Keller, C., \& Cernerud, L. (2002). Students' perceptions of e-learning in university education. Journal of Educational Media, 27(1-2), 55-67.

Kennedy, G. E., Dalgarno, B., Gray, K., Judd, T., Waycott, J., Bennett, S., et al. (2007, 2-5 December). The net generation are not big users of Web 2.0 technologies: Preliminary findings. Nanyang Technological University, Singapore. In R. J. Atkinson, C. McBeath, S. K. A. Soong \& C. Cheers (Eds.), Proceedings of the ICT: Providing choices for learners and learning.(517525). ASCILITE

Kennedy, G. E., Judd, T. S., Churchward, A., Gray, K., \& Krause, K.-L. (2008). First year students' experiences with technology: Are they really digital natives? Australasian Journal of Educational Technology, 24(1), 108-122.

Kennedy, G. E., Krause, K.-L., Gray, K., Judd, T. S., Bennett, S., Maton, K., et al. (2006). Questioning the net generation: A collaborative project in Australian higher education. Sydney. In L. Markauskaite, P. Goodyear \& P. Reimann (Eds.), Proceedings of the 23rd Annual Conference of the Australasian Society for Computers in Learning in Tertiary Education: Who's Learning? Whose Technology?(413-417). Sydney University Press

Kincheloe, J. L. (2003). Teachers as researchers (2nd ed.). London: Routledge Falmer.

Kirschner, P., Sweller, J., \& Clark, R. E. (2006). Why minimally guidance during instruction does not work: An analysis of the failure of constructivist, discovery, problem-based, experiential, and inquiry-based teaching. Educational Psychologist, 41(2), 75-86.

Kozma, R. B. (1991). Learning with media. Review of Educational Research, 61(2), 179-211.

Kozma, R. B. (1994). Will media influence learning? Reframing the debate. Educational Technology Research and Development, 42(2), 7-19.

Kozma, R. B., \& Johnston, J. (1991). The technological revolution comes to the classroom. Change, 23(1), 10-23.

Lambert, C., DePaepe, J., Lambert, L., \& Anderson, D. (2007). e-Portfolios in action. Kappa Delta Pi, 43(2), 76-81.

Lenhart, A., \& Madden, M. (2007). Teens, privacy and online social: How teens manage their online identities and personal information in the age of MySpace 
[Electronic Version]. Retrieved 23/11/09 from

http://www.pewinternet.org/pdfs/PIP Teens_Privacy_SNS Report_Final.pdf

Levin, D., Arafeh, S., Lenhart, A., \& Raninie, L. (2002). The digital disconnect: The widening gap between Internet-savvy students and their schools [Electronic Version]. Retrieved 17/8/09 from http://www.pewinternet.org/ /media//Files/Reports/2002/PIP Schools Interne t Report.pdf.pdf

Lim, C. P., \& Barnes, S. (2002). "Those who can, teach"- The pivotal role of the teacher in the information and communication technologies (ICT) learning environment. Journal of Educational Media, 27(1-2), 19-40.

Lim, D. H. (2002). Perceived differences between classroom and distance education: Seeking instructional strategies for learning applications. International Journal of Educational Technology, 16(2), 61-64.

Lim, D. H., Morris, M. L., \& Kupritz, V. W. (2000). Online vs. Blended Learning: Differences in Instructional Outcomes and Learner Satisfaction. Paper presented at the Academy of Human Resource Development International Conference (AHRD). Retrieved 13/5/09, from http://www.eric.ed.gov/ERICDocs/data/ericdocs2sq1/content_storage 01/0000 019b/80/1b/df/c3.pdf.

Livingstone, S. (2008). Taking risky opportunities in youthful content creation: Teenagers' use of social networking sites for intimacy, privacy and selfexpression. New Media \& Society, 10(3), 393-411.

Luckin, R., Clark, W., Graber, R., Logan, K., Mee, A., \& Oliver, M. (2009). Do Web 2.0 tools really open doors to learning? Practices, perceptions and profiles of 11-16 year-old students. Learning, Media and Technology, 34(2), 87-104.

McCauley, F. (1993). The white paper on adult education: Learning for life [Electronic Version] from http://eric.ed.gov/ERICDocs/data/ericdocs2sql/content storage 01/0000019b/ 80/1a/c6/5e.pdf.

McLeod, J. K., \& Vasinda, S. (2009). Electronic portfolios: Perspectives of students, teachers and parents. Education and Information Technologies, 14(1), 29-38.

McMullan, M. (2006). Students' perceptions on the use of portfolios in pre-registration nursing education: A questionnaire survey. International Journal of Nursing Studies, 43(3), 333-343.

McNair, V., \& Galanouli, D. (2002). Information and communications technology in teacher education: Can a reflective portfolio enhance reflective practice? Technology, Pedagogy and Education, 11(2), 181-196.

Meeus, W., Questier, F., \& Derks, T. (2006). Open source eportfolio: Development and implementation of an institution-wide electronic portfolio platform for students. Educational Media International, 43(2), 133-145.

Merriam, S. (1998). Qualitative research and case study applications in education. San Francisco: Jossey-Bass.

Miles, M., \& Huberman, A. (1994). Qualitative data analysis. Thousand Oaks: California.

Ministry of Education. (2002). Digital Horizons - Learning through ICT. Wellington: Ministry of Education. 
Ministry of Education. (2006a). Enabling the 21st century learner-An e-Learning Action Plan for Schools 2006-2010. Wellington: Ministry of Education.

Ministry of Education. (2006b). ICT strategic framework for education 2006/2007. Retrieved 3 April 2008. from http://www.minedu.govt.nz/web/downloadable/d111734_v1/web-version---ictstrategic-framework-for-educatio.pdf.

Ministry of Education. (2007). The New Zealand curriculum [Electronic Version]. Retrieved 7 April 2008 from http://nzcurriculum.tki.org.nz/the new zealand_curriculum/key_competencies

Ministry of Education. (2008). The New Zealand curriculum [Electronic Version]. Retrieved 7 April 2008 from http://nzcurriculum.tki.org.nz/the_new_zealand_curriculum/key_competencies

Ministry of Education. (2009a). School decile ratings [Electronic Version]. Retrieved 15/11/09 from http://www.minedu.govt.nz/Parents/AllAges/EducationInNZ/SchoolsInNewZe aland/SchoolDecileRatings.aspx

Ministry of Education. (2009b). Types of schools [Electronic Version]. Retrieved 15/11/09 from http://www.minedu.govt.nz/Parents/AllAges/EducationInNZ/SchoolsInNewZe aland/SchoolTypes.aspx

Molesworth, M. (2004). Collaboration, reflection and selective neglect: Campus-based marketing students' experiences of using a virtual learning environment. Innovations in Education and Teaching International, 41(1), 79-92.

Monteith, M., \& Smith, J. (2001). Learning in a virtual campus: The pedagogical implications of students' experiences. Innovations in Education and Teaching International, 38(2), 119-132.

Ntuli, E., Keengwe, J., \& Kyei-Blankson, L. (2009). Electronic portfolios in teacher education: A case study of early childhood teacher candidates. Early Childhood Education Journal, 37(2), 121-126.

O'Reilly, T. (2005). What is Web 2.0? Retrieved 15/8/09, from http://oreilly.com/web2/archive/what-is-web-20.html

OECD. (2005). Are students ready for a technology-rich world? What PISA Studies Tell Us [Electronic Version]. Retrieved 25/8/09 from http://www.oecd.org/dataoecd/28/4/35995145.pdf.

Oliver, R., \& Omari, A. (1999). Using online technologies to support problem based learning: Learners' responses and perceptions. Australasian Journal of Educational Technology, 15(1), 58-79.

Osguthorpe, R. T., \& Graham, C. R. (2003). Blended learning environments: Definitions and directions. The Quarterly Review of Distance Education, 4(3), 227-233.

Owston, R. D. (1997). The World Wide Wed: A Technology to enhance teaching and learning. Educational Researcher, 26(2), 27-33.

Palloff, R. M., \& Pratt, K. (1999). Building learning communities in cyberspace. San Francisco: Jossey-Bass. 
Papert, S. A. (1993). Mindstorms: Children, Computers, And Powerful Ideas. New York: Basic Books.

Phillips, D. C. (1995). The good, the bad, and the ugly: The many faces of constructivism. Educational Researcher, 24(7), 5-12.

Piaget, J. (1929). The child's conception of the world. London: Paul, Trench \& Trubner.

Prensky, M. (2001). Digital Natives, Digital Immigrants [Electronic Version]. On the Horizon, 9(5). Retrieved 13 May 2008 from http://www.marcprensky.com/writing/Prensky\%20\%20Digital\%20Natives, \%20Digital\%20Immigrants\%20-\%20Part1.pdf.

Prensky, M. (2004). The emerging online life of the digital native: What they do differently because of technology and how they do it [Electronic Version]. Retrieved 23/7/09 from The emerging online life of the digital native: What they do differently because of technology and how they do it

Price, R. V. (1996). Technology doesn't teach. People do. Tech Trends for Leaders in Education and Training, 41(6), 17-18.

Rakes, G. C., Flowers, B. F., Casey, H. B., \& Santana, R. (1999). An analysis of instructional technology use and constructivist behaviors in K-12 teachers. International Journal of Educational Technology, 1(2), 1-18.

Ravet, S., \& Layte, M. (2003). ePortfolios: Revolutionising elearning. Retrieved 16 January, 2008, from http://www.learningcitizen.net/articles/ePortfoliosRevolutio.shtml

Reisetter, M., \& Bogdan, R. C. (2004). What works: Student perceptions of effective elements in online learning. The Quarterly Review of Distance Education, 5(4), 277-291.

Reyna, V. F., Brainerd, C. J., Effken, J., Bootzin, R., \& Lloyd, F. J. (2001). The psychology of human-computer mismatches. In C. R. Wolfe (Ed.), Learning and teaching on the worldwide web. San Diego: Academic Press.

Rice, K. L. (2006). A comprehensive look at distance education in the K-12 context. Journal of Research on Technology in Education, 38(4), 425-448.

Riedinger, B. (2006). Mining for meaning: Teaching students how to reflect. In A. Jafari \& C. Kaufman (Eds.), Handbook of research on ePortfolios. Hershey, PA: Ideas Group Reference.

Ritzhaupt, A. D., Singh, O., Seyferth, T., \& Dedrick, R. F. (2008). Development of the electronic portfolio student perspective instrument: An ePortfolio integration initiative. Journal of Computing in Higher Education, 19(2), 47-71.

Robins, J. (2006). Electronic portfolios as a bridge. Intervention in School and Clinic, 42(2), 107-113.

Robinson, R., Molenda, M., \& Razabek, L. (2008). Facilitating learning. In A. Januszewski \& M. Molenda (Eds.), Educational technology: A definition with commentary. New York: Lawrence Erlbaum Associates.

Roblyer, M. D. (2006). Integrating educational technology into teaching (4th ed.). Upper Saddle River, NJ: Pearson / Prentice Hall. 
Romeo, G. (2006). Engage, Empower, Enable: Developing a shared vision for technology in education. In D. Hung \& M. S. Khine (Eds.), Engaged learning with emerging technologies. AA Dordrecht, The Netherlands: Springer.

Roschelle, J., \& Pea, R. D. (1999). Trajectories from today's www to a powerful educational infrastructure. Educational Researcher, 28(5), 22-25+43.

Rovai, A. P. (2002). Sense of community, perceived cognitive learning, and persistence in asynchronous learning networks. The Internet and Higher Education, 5(4), 319-332.

Salomon, G. (1985). Information technologies: What you see is not (always) what you get. Educational Psychologist, 20(4), 207-216.

Schweizer, K., Paechter, M., \& Weidenmann, B. (2003). Blended learning as a strategy to improve collaborative task performance. Journal of Educational Media, 28(2-3), 211-224.

Scott, D., \& Morrison, M. (2005). Key ideas in education research. London: Continuum.

Selwyn, N., Potter, J., \& Cranmer, S. (2008). Primary pupils' use of information and communication technologies at school and home. British Journal of Educational Technology.

Sing, C. C., \& Khine, M. S. (2006). Understanding ICT integration in schools. In M. S. Khine (Ed.), Teaching with technology: Strategies for engaging learners. Singapore: Prentice Hall.

Smart, K. L., \& Cappel, J. J. (2006). Students' perceptions of online learning: A comparative study. Journal of Information Technology Education, 5, 201-219.

Smith, K., \& Tillema, H. (2003). Clarifying different types of portfolio use. Assessment and Evaluation in Higher Education, 28(6), 625-648.

Somekh, B. (2007). Pedagogy and learning with ICT: researching the art of innovation. New York: Routledge.

Song, L., Singleton, E. S., Hill, J. R., \& Koh, M. H. (2004). Improving online learning: Student perceptions of useful and challenging characteristics. The Internet and Higher Education, 7, 59-70.

Stacey, E., \& Gerbic, P. (2007). Teaching for blended learning- Research perspectives from on-campus and distance students. Education and Information Technologies, 12, 165-174.

Stake, R. E. (2005). Qualitative case studies. In N. K. Denzin \& Y. S. Lincoln (Eds.), The Sage handbook of qualitative research (pp. 443-466). Thousand Oaks, California: SAGE Publications

Stefani, L., Mason, R., \& Pegler, C. (2007). The educational potential of e-portfolios: Supporting personal development and reflective learning. London: Routledge.

Strauss, A., \& Corbin, J. M. (1990). Basics of qualitative research: Grounded theory procedures and techniques. Thousand Oaks, CA: Sage Publications.

Strudler, N., \& Wetzel, K. (2005). The diffusion of electronic portfolios in teacher education: issues of initiation and implementation. Journal of Research on Technology in Education, 37(4), 411.

Suter, W. N. (2006). Introduction to educational research: A critical thinking approach. Thousand Oaks, California: SAGE Publications 
Tapscott, D. (1998). Growing up digital. New York: McGraw Hill.

The High School. (2007). Strategic Plan.

Tillema, H., \& Smith, K. (2007). Portfolio appraisal: In search of criteria. Teaching and Teacher Education, 23(4), 442-456.

Tosh, D., Light, T. P., Fleming, K., \& Haywood, J. (2005). Engagement with electronic portfolios: Challenges from the student perspective. Canadian Journal of Learning and Technology, 31(3).

Tosh, D., \& Werdmuller, B. (2004). ePortfolios and weblogs: One vision for ePortfolio development [Electronic Version]. Retrieved 4/9/08 from http://eduspaces.net/bwerdmuller/files/61/178/ePortfolio_Weblog.pdf.

Tunison, S., \& Noonan, B. (2001). On-line learning: Secondary students' first experience. Canadian Journal of Education, 26(4), 495-514.

Underwood, T. (1998). The consequences of portfolio assessment. Educational Assessment, 5(3), 147-194.

Vaidhyanathan, S. (2008). Generational myth. The Chronicle of Higher Education, $55(4)$, B.7.

Von Glasersfeld, E. (1995). A constructivist approach to teaching. In L. P. Steffe \& J. Gale (Eds.), Constructivism in education. New Jersey: Lawrence Erlbaum Associates.

Vonderwell, S. (2003). An examination of asynchronous communication experiences and perspectives in an online course: A case study. The Internet and Higher Education, 6, 77-90.

Vygotsky, L. S. (1978). Mind in Society: Development of Higher Psychological Processes (14th ed.). Cambridge, MA: Harvard University Press.

Wade, A., Abrami, P. C., \& Sclater, J. (2005). An electronic portfolio to support learning. Canadian Journal of Learning and Technology, 31(3).

Wade, R. C., \& Yarbrough, D. B. (1996). Portfolios: a tool for reflective thinking in teacher education? Teaching and Teacher Education, 12(1), 63-79.

Walther. (1996). Computer-mediated communication: Impersonal, interpersonal, and hyperpersonal interaction. Communication Research, 23(1), 3-43.

Wangpipatwong, T., \& Papasratorn, B. (2007). The influence of constructivist elearning system on student learning outcomes. International Journal of Information and Communications Technology Education, 3(4), 21-33.

Waters, J. (2009). E-portfolios come of age. T.H.E. Journal, 36(10), 24-28.

Weigel, V. B. (2002). Deep learning for a digital age: Technology's untapped potential to enrich higher education. San Francisco: Jossey-Bass.

Wetzel, K., \& Strudler, N. (2005). The diffusion of electronic portfolios in teacher education: Next steps and recommendations from accomplished users. Journal of Research on Technology in Education, 38(2), 231-243.

Williams, J., \& Chinn, S. J. (2009). Using web 2.0 to support the active learning experience. Journal of Information Systems Education, 20(2), 165-174.

Woodward, H., \& Nanlohy, P. (2004). Digital portfolios: Fact or fiction. Assessment and Evaluation in Higher Education, 29(2). 
Wright, V. H., \& Stallworth, B. J. (2002). Challenges of electronic portfolios: Student perceptions and experiences. Journal of Technology and Teacher Education, 10(2), 49-61.

Yin, R. K. (2003a). Applications of case study research (2nd ed.). London: SAGE Publications.

Yin, R. K. (2003b). Case study research: Design and methods (3rd ed.). London: SAGE Publications.

Zeichner, K., \& Wray, S. (2001). The teaching portfolio in US teacher education programs: what we know and what we need to know. Teaching and Teacher Education, 17(5), 613-621.

Zemsky, R., \& Massy, W. F. (2004). Thwarted innovation: What happened to elearning and why [Electronic Version] from http:/www.irhe.upenn.edu/Docs/Jun2004/ThwartedInnovation.pdf. 


\section{Appendices}

\section{Appendix 1: Additional data from the final survey}

$1.1 \ldots$ was easy to use

$$
\begin{gathered}
\text { Strongly agree } \\
\text { Agree } \\
\text { Not sure } \\
\text { Disagree } \\
\text { Strongly disagree }
\end{gathered}
$$

$1.2 \ldots$ was hard to use

$$
\begin{gathered}
\text { Strongly agree } \\
\text { Agree } \\
\text { Not sure } \\
\text { Disagree }
\end{gathered}
$$

Strongly disagree

1.3 Would you recommend MyPortfolio to other students?

$$
\begin{aligned}
& \text { yes } \\
& \text { No }
\end{aligned}
$$

1.4 ... has helped me complete better work than usual

$\begin{array}{ccc} & \# & \% \\ \text { Strongly agree } & 2 & 8 \\ \text { Agree } & 7 & 28 \\ \text { Not sure } & 10 & 40 \\ \text { Disagree } & 5 & 20 \\ \text { Strongly disagree } & 1 & 4 \\ & 25 & 100\end{array}$

1.5 Would you recommend MyPortfolio to other students?

$\begin{array}{ccc} & \# & \% \\ \text { Yes } & 19 & 76 \\ \text { No } & 6 & 24 \\ & 25 & 100\end{array}$

1.6 ...has been fun to do

Strongly agree
Agree
Not sure
Disagree
Strongly disagree

$\begin{array}{cc}\# & \% \\ 9 & 36 \\ 12 & 48 \\ 2 & 8 \\ 1 & 4 \\ 1 & 4 \\ 25 & 100\end{array}$


1.7 I would work harder if I could use computers more often

$\begin{array}{ccc} & \begin{array}{c}\text { Initial } \\ \text { survey \# }\end{array} & \text { Final survey \# } \\ \text { Strongly agree } & 1 & 2 \\ \text { Agree } & 12 & 9 \\ \text { Don't mind } & 6 & 8 \\ \text { Disagree } & 4 & 4 \\ \text { Strongly disagree } & 0 & 1 \\ \text { No response } & 0 & 1 \\ & 23 & 25\end{array}$

$1.8 \ldots$ is something I would like to do again in the future

$\begin{array}{ccc} & \# & \% \\ \text { Strongly agree } & 7 & 28 \\ \text { Agree } & 9 & 36 \\ \text { Not sure } & 6 & 24 \\ \text { Disagree } & 2 & 8 \\ \text { Strongly disagree } & 1 & 4 \\ & 25 & 100\end{array}$

1.9 ... has helped me organise my work

$\begin{array}{ccc} & \# & \% \\ \text { Strongly agree } & 3 & 12 \\ \text { Agree } & 15 & 60 \\ \text { Not sure } & 2 & 8 \\ \text { Disagree } & 3 & 12 \\ \text { Strongly disagree } & 0 & 0 \\ \text { no response } & 2 & 8 \\ & 25 & 100\end{array}$

1.10 Did you use MyPortfolio at home?

$\begin{array}{lc}\text { Yes } & 24 \\ \text { No } & 1\end{array}$

1.11 Did you use MyPortfolio at school outside of English lessons?

$\begin{array}{lc} & \# \\ \text { Yes } & 7 \\ \text { No } & 18\end{array}$

$1.12 \ldots$ has helped me plan how to improve my work

$\begin{array}{ccc} & \# & \% \\ \text { Strongly agree } & 3 & 12 \\ \text { Agree } & 11 & 44 \\ \text { Not sure } & 9 & 36 \\ \text { Disagree } & 2 & 8 \\ \text { Strongly disagree } & 0 & 0 \\ & 25 & 100\end{array}$

$1.13 \ldots$ has been good to work on with other students 


$\begin{array}{ccc} & \# & \% \\ \text { Strongly agree } & 9 & 36 \\ \text { Agree } & 11 & 44 \\ \text { Not sure } & 4 & 16 \\ \text { Disagree } & 1 & 4 \\ \text { Strongly disagree } & 0 & 0 \\ & 25 & 100\end{array}$

1.14 ... tells me what my friends and other members of my group are learning

$$
\begin{gathered}
\text { Strongly agree } \\
\text { Agree } \\
\text { Not sure } \\
\text { Disagree }
\end{gathered}
$$

Strongly disagree
$\%$

16

4

00

$1.15 \ldots$ is good for showing my progress to other people

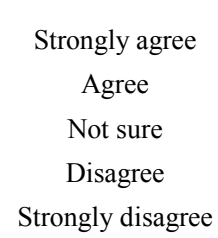

$\begin{array}{cc}\# & \% \\ 4 & 16 \\ 15 & 60 \\ 6 & 24 \\ 0 & 0 \\ 0 & 0 \\ 25 & 100\end{array}$

Strongly disagree

$\begin{array}{cc}\# & \% \\ 4 & 16 \\ 16 & 64 \\ 5 & 20 \\ 0 & 0 \\ 0 & 0 \\ 25 & 100\end{array}$

1.16 Messaged my group members or friends

Yes
No

$\begin{array}{cc}\# & \% \\ 23 & 92 \\ 2 & 8 \\ 25 & 100\end{array}$

1.17 I enjoy using social sites such as Bebo, Facebook or MySpace

$\begin{array}{ccccc} & \begin{array}{c}\text { Initial } \\ \text { Survey } \#\end{array} & \begin{array}{c}\text { Initial } \\ \text { Survey } \%\end{array} & \begin{array}{c}\text { Final } \\ \text { Survey } \#\end{array} & \begin{array}{c}\text { Final } \\ \text { Survey } \%\end{array} \\ \text { Strongly agree } & 12 & 52 & 12 & 48 \\ \text { Agree } & 4 & 17 & 8 & 32 \\ \text { Don't mind } & 0 & 0 & 3 & 12 \\ \text { Disagree } & 7 & 31 & 0 & 0 \\ \text { Strongly disagree } & 0 & 0 & 1 & 4 \\ \text { no response } & 0 & 0 & 1 & 4 \\ & 23 & 100 & 25 & 100\end{array}$

\subsection{Contact with teacher}

$\begin{array}{ccc}\text { Received feedback from your teacher } & \# & \% \\ \text { Yes } & 19 & 76 \\ \text { No } & 6 & 24 \\ & 25 & 100 \\ \text { Messaged my teacher } & \# & \% \\ \text { Yes } & 19 & 76 \\ \text { No } & 6 & 24 \\ & 25 & 100\end{array}$


$1.19 \ldots$ has helped me be creative

Strongly agree
Agree
Not sure
Disagree
Strongly disagree

$\begin{array}{cc}\# & \% \\ 2 & 8 \\ 15 & 60 \\ 4 & 16 \\ 4 & 16 \\ 0 & 0 \\ 25 & 100\end{array}$

1.20 Features of MyPortfolio changed

$\begin{array}{ccc}\text { Personalised a view } & \# & \% \\ \text { Yes } & 21 & 84 \\ \text { No } & 4 & 16 \\ & 25 & 100 \\ \text { Changed my profile } & \# & \% \\ \text { Yes } & 21 & 84 \\ \text { No } & 4 & 16 \\ & 25 & 100 \\ \text { Added videos or images } & \# & \% \\ \text { Yes } & 21 & 84 \\ \text { No } & 4 & 16 \\ & 25 & 100 \\ & 25 & 100\end{array}$

$1.21 \ldots$ has been frustrating to use

\section{Strongly agree \\ Agree \\ Not sure \\ Disagree}

Strongly disagree

no response

$1.22 \ldots$ was hard to use
$\%$
60
0

16

16 
$1.24 \ldots$ has helped me learn

Strongly agree
Agree
Not sure
Disagree
Strongly disagree

$\begin{array}{cc}\# & \% \\ 4 & 16 \\ 12 & 48 \\ 6 & 24 \\ 2 & 8 \\ 1 & 4 \\ 25 & 100\end{array}$

$1.25 \ldots$ has taken up too much time in class

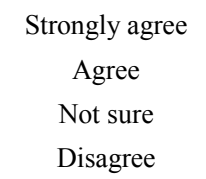

Strongly disagree

\subsection{5... has taken up too much time in class}

Strongly agree
Agree
Not sure
Disagree
Strongly disagree

$\begin{array}{cc}\# & \% \\ 0 & 0 \\ 4 & 16 \\ 9 & 36 \\ 9 & 36 \\ 3 & 12 \\ 25 & 100\end{array}$

$1.26 \ldots$ has taken up too much time outside of class

Strongly agree
Agree
Not sure
Disagree
Strongly disagree
no response




\section{Appendix 2: Initial Survey results}

2.1 I feel comfortable using computers

\begin{tabular}{|c|c|c|}
\hline & $\#$ & $\%$ \\
\hline Strongly agree & 15 & 65 \\
\hline Agree & 8 & 35 \\
\hline Not sure & 0 & 0 \\
\hline Disagree & 9 & 0 \\
\hline Strongly disagree & 0 & 0 \\
\hline & 23 & 100 \\
\hline
\end{tabular}

2.2 Student use of computers at home and school

\begin{tabular}{|c|c|c|c|c|}
\hline & 0 hours a week & $1-4$ hours a week & $5-10$ hours a week & $10-20$ hours a week \\
\hline $\begin{array}{c}\text { Computer use at } \\
\text { home }\end{array}$ & 1 & 11 & 10 & 4 \\
\hline $\begin{array}{c}\text { Internet use at } \\
\text { home }\end{array}$ & 0 & 12 & 9 & 5 \\
\hline $\begin{array}{c}\text { Computer use at } \\
\text { school }\end{array}$ & 1 & 23 & 2 & 0 \\
\hline $\begin{array}{c}\text { Internet use at } \\
\text { school }\end{array}$ & 2 & 23 & 1 & 0 \\
\hline
\end{tabular}




\section{Appendix 3: Case Study students' initial survey data}

\subsection{Nancy's initial survey data}

I enjoy doing things on a computer

Strongly agree

I am tired of using a computer

Strongly disagree

I would work harder if I could use computers more often

Agree

Using the computer gives me the chance to learn new things

\section{Agree}

I enjoy lessons on the computer

Strongly agree

I believe it is very important for me to learn to use the computer well

Strongly agree

I can use bookmarks to keep track of the pages I like

Strongly agree

I can create my own web page

Strongly agree

I can send an attachment on an email

Strongly agree

I can send an email to a friend

Strongly agree
I feel comfortable working with a computer Strongly agree

I do not enjoy using a computer

Strongly disagree

I find working on the computer frustrating

Strongly disagree

Computers are difficult to use

Strongly disagree

Computers do not scare me at all

Strongly agree
I can upload pictures to a website, blog, Bebo, Facebook or MySpace page

Strongly agree

I can create my own blog

Strongly agree

I can do a search on the Internet to find the information I want

Strongly agree

I can send an email to several people at once

Strongly agree 


\subsection{Robina's initial survey data}

I enjoy doing things on a computer

Agree

I feel comfortable working with a computer

Strongly agree

I will get a good job if I cam use a computer well

$$
\text { Don't mind }
$$

I would work harder if I could use computers more often

$$
\text { Disagree }
$$

I enjoy lessons on the computer

$$
\text { Disagree }
$$

I find working on the computer frustrating

Strongly agree

Computers do not scare me at all

Strongly agree

I can send an email to a friend

Strongly agree

I can send an email to a friend

Strongly agree

I can create my own web page

$$
\text { Disagree }
$$

I can use bookmarks to keep track of the pages I like
I am tired of using a computer

$$
\text { Don't mind }
$$

I do not enjoy using a computer

$$
\text { Disagree }
$$

I enjoy playing computer games

$$
\text { Don't mind }
$$

Using the computer gives me the chance to learn new things

$$
\text { Agree }
$$

I believe it is very important for me to learn to use the computer well

$$
\text { Agree }
$$

Computers are difficult to use

$$
\text { Don't mind }
$$

I enjoy using social sites such as Bebo, Facebook or MySpace

Undecided

I can send an email to several people at once Strongly agree

I can send an email to several people at once Strongly agree I can create my own blog

Agree

I can upload pictures to a website, blog, Bebo, Facebook or MySpace page

Strongly agree 


\subsection{Ashleigh's initial survey data}

I enjoy doing things on a computer

Agree

I feel comfortable working with a computer

Agree

I will get a good job if I cam use a computer well

Agree

I would work harder if I could use computers more often

Agree

I enjoy lessons on the computer

Agree

I do not enjoy using a computer

$$
\text { Disagree }
$$

Computers are difficult to use

Disagree

I can send an email to a friend

Strongly agree

I can send an attachment on an email

Not sure

I can create my own web page

Strongly agree

I can use bookmarks to keep track of the pages I like

Agree
I am tired of using a computer

$$
\text { Disagree }
$$

I do not enjoy using a computer

$$
\text { Disagree }
$$

I enjoy playing computer games

Agree

Using the computer gives me the chance to learn new things

Agree

I believe it is very important for me to learn to use the computer well

Don't mind

I find working on the computer frustrating

$$
\text { Disagree }
$$

Computers do not scare me at all

Strongly agree

I can send an email to several people at once

Strongly agree

I can do a search on the Internet to find the information I want

Strongly agree

I can create my own blog

Disagree

I can upload pictures to a website, blog, Bebo, Facebook or MySpace page

Agree 


\subsection{Hannah's initial survey data}

I enjoy doing things on a computer

Don't mind

I will get a good job if I cam use a computer well

Don't mind

I would work harder if I could use computers more often

$$
\text { Don't mind }
$$

I enjoy lessons on the computer

Don't mind

I feel comfortable working with a computer

Strongly agree

I find working on the computer frustrating

$$
\text { Don't mind }
$$

Computers do not scare me at all

Strongly disagree

I can send an email to a friend

Strongly agree

I can send an attachment on an email

Not sure

I can create my own web page

Agree

I can use bookmarks to keep track of the pages I like

Not sure
I am tired of using a computer

Don't mind

I enjoy playing computer games

Strongly disagree

Using the computer gives me the chance to learn new things

Agree

I believe it is very important for me to learn to use the computer well

$$
\text { Don't mind }
$$

I do not enjoy using a computer

$$
\text { Don't mind }
$$

Computers are difficult to use

Strongly disagree

I enjoy using social sites such as Bebo, Facebook or MySpace

Strongly agree

I can send an email to several people at once

$$
\text { Not sure }
$$

I can do a search on the Internet to find the information I want

Strongly agree

I can create my own blog

\section{Not sure}

I can upload pictures to a website, blog, Bebo, Facebook or MySpace page

Strongly agree 


\subsection{YoYo's initial survey data}

I enjoy doing things on a computer

Strongly agree

I will get a good job if I cam use a computer well

Agree

I would work harder if I could use computers more often

Agree

I enjoy lessons on the computer

Strongly agree

I feel comfortable working with a computer

Strongly agree

I find working on the computer frustrating

Strongly disagree

Computers do not scare me at all

Strongly agree

I can send an email to a friend

Strongly agree

I can send an attachment on an email

Strongly agree

I can create my own web page

Agree

I can use bookmarks to keep track of the pages I like

Strongly agree
I am tired of using a computer

Disagree

I enjoy playing computer games

Strongly agree

Using the computer gives me the chance to learn new things

Agree

I believe it is very important for me to learn to use the computer well

Strongly agree

I do not enjoy using a computer

Strongly disagree

Computers are difficult to use

Strongly disagree

I enjoy using social sites such as Bebo, Facebook or MySpace

Strongly agree

I can send an email to several people at once

Strongly agree

I can do a search on the Internet to find the information I want

Strongly agree

I can create my own blog

Strongly agree

I can upload pictures to a website, blog, Bebo, Facebook or MySpace page

Strongly agree 


\subsection{Mary's initial survey data}

I enjoy doing things on a computer

Strongly agree

I will get a good job if I cam use a computer well

Agree

I would work harder if I could use computers more often

Agree

I enjoy lessons on the computer

Don't mind

I feel comfortable working with a computer

Strongly agree

I find working on the computer frustrating

$$
\text { Don't mind }
$$

Computers do not scare me at all

Agree

I can send an email to a friend

Strongly agree

I can send an attachment on an email

Agree

I can create my own web page

Agree

I can use bookmarks to keep track of the pages I like

Not sure
I am tired of using a computer

$$
\text { Don't mind }
$$

I enjoy playing computer games

Strongly agree

Using the computer gives me the chance to learn new things

$$
\text { Agree }
$$

I believe it is very important for me to learn to use the computer well

Strongly agree

I do not enjoy using a computer

$$
\text { No response }
$$

Computers are difficult to use

Agree

I enjoy using social sites such as Bebo, Facebook or MySpace

Undecided

I can send an email to several people at once

Strongly agree

I can do a search on the Internet to find the information I want

Strongly agree

I can create my own blog

Agree

I can upload pictures to a website, blog, Bebo, Facebook or MySpace page

Not sure 


\section{Appendix 4: Initial survey questions}

\begin{tabular}{|c|c|c|c|}
\hline \multicolumn{2}{|l|}{ 1a) Do you have a computer at home? } & Yes & No \\
\hline \multicolumn{2}{|l|}{ 1b) Do you have a computer in your bedroom? } & Yes & No \\
\hline \multicolumn{2}{|l|}{ 1d) Do you have the internet at home? } & Yes & No \\
\hline \multicolumn{2}{|c|}{ 1e) Do you have a Bebo / Facebook or MySpace page? List which you have } & Yes & No \\
\hline 1f) How many hours a week do you use the computer at school? & \multicolumn{3}{|c|}{$\begin{array}{c}\square \text { 1-4 hours a week } \\
\square \text { 5-10 hours a week } \\
\square \text { 10-20 hours a week } \\
\square \text { More than } 20 \text { hours a week }\end{array}$} \\
\hline 1g) How many hours a week do you spent on the internet at home? & \multicolumn{3}{|c|}{$\begin{array}{c}\square 0 \text { hours a week } \\
\square \text { 1-4 hours a week } \\
\square \text { 5-10 hours a week } \\
\square \text { 10-20 hours a week } \\
\square \text { More than } 20 \text { hours a week }\end{array}$} \\
\hline 1h) How many hours a week do you use the computer at school? & \multicolumn{3}{|c|}{$\begin{array}{l}\square 0 \text { hours a week } \\
\square \text { 1-4 hours a week } \\
\square \text { 5-10 hours a week } \\
\square \text { 10-20 hours a week } \\
\text { More than } 20 \text { hours a week }\end{array}$} \\
\hline 1i) How many hours a week do you use the internet at school? & \multicolumn{3}{|c|}{$\begin{array}{c}\square \text { 0 hours a week } \\
\square \text { 1-4 hours a week } \\
\square \text { 5-10 hours a week } \\
\square \text { 10-20 hours a week } \\
\text { More than } 20 \text { hours a week }\end{array}$} \\
\hline 2a) Which ethnic group do you belong to? & \multicolumn{3}{|c|}{$\begin{array}{c}\square \text { New Zealand European } \\
\square \text { Māori } \\
\square \text { Pacific Island } \\
\square \text { Other (please identify) }\end{array}$} \\
\hline 2b) Is English the main language you use at home? & \multicolumn{3}{|c|}{$\begin{array}{c}\square \text { Yes } \\
\square \text { No } \\
\text { If no, what is the main language you use at home? }\end{array}$} \\
\hline
\end{tabular}

Select one answer only for each question:

\begin{tabular}{|c|c|}
\hline 3a) I enjoy doing things on a computer & $\begin{array}{l}\square \text { Strongly disagree } \\
\square \text { Disagree } \\
\square \text { Undecided } \\
\square \text { Agree } \\
\square \text { Strongly agree }\end{array}$ \\
\hline 3b) I am tired of using a computer & $\begin{array}{l}\square \text { Strongly disagree } \\
\square \text { Disagree } \\
\square \text { Undecided } \\
\square \text { Agree } \\
\square \text { Strongly agree }\end{array}$ \\
\hline 3c) I will get a good job if I can use a computer well & $\begin{array}{l}\square \text { Strongly disagree } \\
\square \text { Disagree } \\
\square \text { Undecided } \\
\square \text { Agree } \\
\square \text { Strongly agree }\end{array}$ \\
\hline 3d) I enjoy computer games a lot & $\begin{array}{l}\square \text { Strongly disagree } \\
\square \text { Disagree } \\
\square \text { Undecided } \\
\square \text { Agree } \\
\square \text { Strongly agree }\end{array}$ \\
\hline 3e) I would work harder if I could use computers more often & $\begin{array}{l}\square \text { Strongly disagree } \\
\square \text { Disagree } \\
\square \text { Undecided } \\
\square \text { Agree } \\
\square \text { Strongly agree }\end{array}$ \\
\hline 3f) Computers give me the opportunity to learn new things & $\begin{array}{l}\square \text { Strongly disagree } \\
\square \text { Disagree } \\
\square \text { Undecided } \\
\square \text { Agree } \\
\square \text { Strongly agree }\end{array}$ \\
\hline $3 \mathrm{~g})$ I enjoy lessons on the computer & $\begin{array}{l}\square \text { Strongly disagree } \\
\square \text { Disagree } \\
\square \text { Undecided } \\
\square \text { Agree } \\
\square \text { Strongly agree }\end{array}$ \\
\hline
\end{tabular}




\begin{tabular}{|c|c|}
\hline 3h) I believe it is very important for me to learn to use the computer well & $\begin{array}{l}\square \text { Strongly disagree } \\
\square \text { Disagree } \\
\square \text { Undecided } \\
\square \text { Agree } \\
\square \text { Strongly agree }\end{array}$ \\
\hline 3i) I feel comfortable working with a computer & $\begin{array}{l}\square \text { Strongly disagree } \\
\square \text { Disagree } \\
\square \text { Undecided } \\
\square \text { Agree } \\
\square \text { Strongly agree }\end{array}$ \\
\hline 3j) I do not enjoy using a computer & $\begin{array}{l}\square \text { Strongly disagree } \\
\square \text { Disagree } \\
\square \text { Undecided } \\
\square \text { Agree } \\
\square \text { Strongly agree }\end{array}$ \\
\hline 3k) I find working with the computer frustrating & $\begin{array}{l}\square \text { Strongly disagree } \\
\square \text { Disagree } \\
\square \text { Undecided } \\
\square \text { Agree } \\
\square \text { Strongly agree }\end{array}$ \\
\hline 31) Computers are difficult to use & $\begin{array}{l}\square \text { Strongly disagree } \\
\square \text { Disagree } \\
\square \text { Undecided } \\
\square \text { Agree } \\
\square \text { Strongly agree }\end{array}$ \\
\hline $3 \mathrm{~m})$ Computers do not scare me at all & $\begin{array}{l}\square \text { Strongly disagree } \\
\square \text { Disagree } \\
\square \text { Undecided } \\
\square \text { Agree } \\
\square \text { Strongly agree }\end{array}$ \\
\hline 3n) Tick the things that you like to do on a computer & $\begin{array}{l}\square \text { Word processing } \\
\square \text { Play games } \\
\square \text { Use educational software } \\
\square \text { Do school work } \\
\square \text { Use the internet } \\
\square \text { Create presentations } \\
\square \text { Write my own programmes } \\
\square \text { Create Web pages } \\
\square \text { Other } \\
\text { Write down what else you do }\end{array}$ \\
\hline 3o) I can send an email to a friend & $\begin{array}{l}\square \text { Strongly disagree } \\
\square \text { Disagree } \\
\square \text { Undecided } \\
\square \text { Agree } \\
\square \text { Strongly agree }\end{array}$ \\
\hline 3p) Send an email to several people at once & $\begin{array}{l}\square \text { Strongly disagree } \\
\square \text { Disagree } \\
\square \text { Undecided } \\
\square \text { Agree } \\
\square \text { Strongly agree }\end{array}$ \\
\hline 3q) Send an attachment on an email & $\begin{array}{l}\square \text { Strongly disagree } \\
\square \text { Disagree } \\
\square \text { Undecided } \\
\square \text { Agree } \\
\square \text { Strongly agree }\end{array}$ \\
\hline 3r) Do a search on the internet to find a web page I am interested in & $\begin{array}{l}\square \text { Strongly disagree } \\
\square \text { Disagree } \\
\square \text { Undecided } \\
\square \text { Agree } \\
\square \text { Strongly agree }\end{array}$ \\
\hline 3s) Create my own web page & $\begin{array}{l}\square \text { Strongly disagree } \\
\square \text { Disagree } \\
\square \text { Undecided } \\
\square \text { Agree } \\
\square \text { Strongly agree }\end{array}$ \\
\hline 3t) Use bookmarks to keep track of pages I like & $\begin{array}{l}\square \text { Strongly disagree } \\
\square \text { Disagree } \\
\square \text { Undecided } \\
\square \text { Agree } \\
\square \text { Strongly agree }\end{array}$ \\
\hline 3u) Enjoy using social sites like Bebo, Facebook or MySpace & $\begin{array}{l}\square \text { Strongly disagree } \\
\square \text { Disagree } \\
\square \text { Undecided } \\
\square \text { Agree } \\
\square \text { Strongly agree }\end{array}$ \\
\hline
\end{tabular}




\section{Part 2}

\begin{tabular}{|c|c|}
\hline $\begin{array}{c}\text { 4a) Number these } 1-5 \text { in order of which you enjoy most- } 1 \text { is the most } \\
\text { enjoyable, } 5 \text { is the least enjoyable }\end{array}$ & $\begin{array}{l}\square \text { Read a book } \\
\square \text { Write } \\
\square \text { Watch television } \\
\square \text { Use the computer }\end{array}$ \\
\hline $\begin{array}{l}\text { 4b) Number these 1-5 in order of which you find hardest- } 1 \text { is the most } \\
\text { difficult, } 5 \text { is the least difficult }\end{array}$ & $\begin{array}{l}\square \text { Read a book } \\
\square \text { Write } \\
\square \text { Watch television } \\
\square \text { Use the computer }\end{array}$ \\
\hline $\begin{array}{l}\text { 4c) Number these 1-5 in order of which you would learn the most from } 1 \text { is the } \\
\text { most, } 5 \text { is the least }\end{array}$ & $\begin{array}{l}\square \text { Read a book } \\
\square \text { Write } \\
\square \text { Watch television } \\
\square \text { Use the computer }\end{array}$ \\
\hline
\end{tabular}




\section{Appendix 5: Final survey questions}

Part A

\begin{tabular}{|c|c|c|c|c|c|}
\hline Rate questions on a scale of 1 to 5 . & 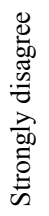 & 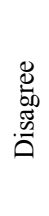 & $\begin{array}{l}\underset{\pi}{ \pm} \\
\stackrel{\Xi}{0}\end{array}$ & 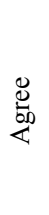 & 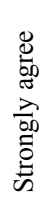 \\
\hline Overall, creating my portfolio... & 1 & 2 & 3 & 4 & 5 \\
\hline 1) Has been fun to do & $\square$ & $\square$ & $\square$ & $\square$ & $\square$ \\
\hline 2) Has made me more interested in my work & & $\square$ & $\square$ & $\square$ & $\Pi$ \\
\hline 3) Has taken up too much time in class & $\square$ & $\square$ & $\square$ & $\square$ & $\square$ \\
\hline 4) Has taken up too much time outside class & $\square$ & $\square$ & $\square$ & $\square$ & \\
\hline 5) Has been good to do with other students & $\square$ & $\square$ & $\square$ & $\square$ & $\square$ \\
\hline 6) Tells me about what my friends are learning & $\square$ & $\square$ & $\square$ & $\square$ & $\square$ \\
\hline 7) Helps me think more about my own learning & $\square$ & $\square$ & $\bar{\square}$ & $\square$ & $\bar{\square}$ \\
\hline 8) Gives me enough space to store all the stuff I want & $\square$ & $\square$ & $\square$ & $\square$ & $\square$ \\
\hline 9) Makes me take more care with my work & $\square$ & $\square$ & $\square$ & $\square$ & $\square$ \\
\hline 10) Helps me be better organized in my work & $\square$ & $\square$ & $\square$ & $\square$ & $\square$ \\
\hline 11) Helps me to show people what I'm really good at & $\square$ & $\square$ & $\square$ & $\square$ & $\square$ \\
\hline 12) Gives me new ways of presenting my work using technology & $\square$ & $\square$ & $\square$ & $\square$ & $\square$ \\
\hline 13) Helps me think more about my own learning & $\square$ & $\square$ & $\square$ & $\square$ & $\bar{\square}$ \\
\hline 14) Gives me enough space to store all the stuff I want & $\square$ & $\square$ & $\square$ & $\square$ & $\bar{\square}$ \\
\hline 15) Makes me take more care with my work & $\square$ & $\square$ & $\bar{\square}$ & $\square$ & $\bar{\square}$ \\
\hline 16) Helps me be better organized in my work & $\square$ & $\square$ & $\square$ & $\square$ & $\square$ \\
\hline 17) Helps me to be creative & $\square$ & $\square$ & $\square$ & $\square$ & $\square$ \\
\hline 18) Helps me to be confident & $\square$ & $\square$ & $\square$ & $\square$ & $\square$ \\
\hline 19) Helps me to plan how to improve & $\square$ & $\square$ & $\square$ & $\square$ & $\square$ \\
\hline 20) Helps me judge whether I have improved over time & $\square$ & $\square$ & $\square$ & $\bar{\square}$ & $\square$ \\
\hline 21) Is good for showing my progress to other people & $\square$ & $\square$ & $\square$ & $\square$ & $\square$ \\
\hline 22) Has helped me understand my work better & $\square$ & $\square$ & $\square$ & $\square$ & $\square$ \\
\hline 23) Has made me pleased with my progress & $\square$ & $\square$ & $\square$ & $\square$ & $\square$ \\
\hline 24) Is something I would like to do again in the future & $\square$ & $\square$ & $\square$ & $\square$ & $\square$ \\
\hline 25) Has helped me to learn & $\square$ & $\square$ & $\square$ & $\bar{\square}$ & $\square$ \\
\hline 26) Was easy to do because teachers helped me & $\square$ & $\square$ & $\square$ & $\bar{\square}$ & $\square$ \\
\hline 27) Forced me to do things that teachers should have done for me & $\square$ & $\square$ & $\bar{\square}$ & $\bar{\square}$ & $\square$ \\
\hline 28) Has helped us to give feedback on each other's work & $\square$ & $\square$ & $\square$ & $\square$ & $\bar{\square}$ \\
\hline
\end{tabular}

Part B

\begin{tabular}{|c|c|}
\hline 3a) I enjoy doing things on a computer & $\begin{array}{l}\square \text { Strongly disagree } \\
\square \text { Disagree } \\
\square \text { Undecided } \\
\square \text { Agree } \\
\square \text { Strongly agree }\end{array}$ \\
\hline 3b) I am tired of using a computer & $\begin{array}{l}\square \text { Strongly disagree } \\
\square \text { Disagree } \\
\square \text { Undecided } \\
\square \text { Agree } \\
\square \text { Strongly agree }\end{array}$ \\
\hline 3c) I will get a good job if I can use a computer well & $\begin{array}{l}\square \text { Strongly disagree } \\
\square \text { Disagree } \\
\square \text { Undecided } \\
\square \text { Agree } \\
\square \text { Strongly agree }\end{array}$ \\
\hline 3d) I enjoy computer games a lot & $\begin{array}{l}\square \text { Strongly disagree } \\
\square \text { Disagree } \\
\square \text { Undecided } \\
\square \text { Agree } \\
\square \text { Strongly agree }\end{array}$ \\
\hline 3e) I would work harder if I could use computers more often & $\begin{array}{l}\square \text { Strongly disagree } \\
\square \text { Disagree } \\
\square \text { Undecided } \\
\square \text { Agree } \\
\square \text { Strongly agree }\end{array}$ \\
\hline
\end{tabular}




\begin{tabular}{|c|c|}
\hline 3f) Computers give me the opportunity to learn new things & $\begin{array}{l}\square \text { Strongly disagree } \\
\square \text { Disagree } \\
\square \text { Undecided } \\
\square \text { Agree } \\
\square \text { Strongly agree }\end{array}$ \\
\hline $3 \mathrm{~g})$ I enjoy lessons on the computer & $\begin{array}{l}\square \text { Strongly disagree } \\
\square \text { Disagree } \\
\square \text { Undecided } \\
\square \text { Agree } \\
\square \text { Strongly agree }\end{array}$ \\
\hline 3h) I believe it is very important for me to learn to use the computer well & $\begin{array}{l}\square \text { Strongly disagree } \\
\square \text { Disagree } \\
\square \text { Undecided } \\
\square \text { Agree } \\
\square \text { Strongly agree }\end{array}$ \\
\hline 3i) I feel comfortable working with a computer & $\begin{array}{l}\square \text { Strongly disagree } \\
\square \text { Disagree } \\
\square \text { Undecided } \\
\square \text { Agree } \\
\square \text { Strongly agree }\end{array}$ \\
\hline 3j) I do not enjoy using a computer & $\begin{array}{l}\square \text { Strongly disagree } \\
\square \text { Disagree } \\
\square \text { Undecided } \\
\square \text { Agree } \\
\square \text { Strongly agree }\end{array}$ \\
\hline 3k) I find working with the computer frustrating & $\begin{array}{l}\square \text { Strongly disagree } \\
\square \text { Disagree } \\
\square \text { Undecided } \\
\square \text { Agree } \\
\square \text { Strongly agree }\end{array}$ \\
\hline 31) Computers are difficult to use & $\begin{array}{l}\square \text { Strongly disagree } \\
\square \text { Disagree } \\
\square \text { Undecided } \\
\square \text { Agree } \\
\square \text { Strongly agree }\end{array}$ \\
\hline 3m) Computers do not scare me at all & $\begin{array}{l}\square \text { Strongly disagree } \\
\square \text { Disagree } \\
\square \text { Undecided } \\
\square \text { Agree } \\
\square \text { Strongly agree }\end{array}$ \\
\hline 3n) Tick the things that you like to do on a computer & $\begin{array}{l}\square \text { Word processing } \\
\square \text { Play games } \\
\square \text { Use educational software } \\
\square \text { Do school work } \\
\square \text { Use the internet } \\
\square \text { Create presentations } \\
\square \text { Write my own programmes } \\
\square \text { Create Web pages } \\
\square \text { Other } \\
\text { Write down what else you do }\end{array}$ \\
\hline 3o) I can send an email to a friend & $\begin{array}{l}\square \text { Strongly disagree } \\
\square \text { Disagree } \\
\square \text { Undecided } \\
\square \text { Agree } \\
\square \text { Strongly agree }\end{array}$ \\
\hline 3p) Send an email to several people at once & $\begin{array}{l}\square \text { Strongly disagree } \\
\square \text { Disagree } \\
\square \text { Undecided } \\
\square \text { Agree } \\
\square \text { Strongly agree }\end{array}$ \\
\hline 3q) Send an attachment on an email & $\begin{array}{l}\square \text { Strongly disagree } \\
\square \text { Disagree } \\
\square \text { Undecided } \\
\square \text { Agree } \\
\square \text { Strongly agree }\end{array}$ \\
\hline 3r) Do a search on the internet to find a web page I am interested in & $\begin{array}{l}\square \text { Strongly disagree } \\
\square \text { Disagree } \\
\square \text { Undecided } \\
\square \text { Agree } \\
\square \text { Strongly agree }\end{array}$ \\
\hline 3s) Create my own web page & $\begin{array}{l}\square \text { Strongly disagree } \\
\square \text { Disagree } \\
\square \text { Undecided } \\
\square \text { Agree } \\
\square \text { Strongly agree }\end{array}$ \\
\hline
\end{tabular}




\begin{tabular}{|c|l|}
\hline 3t) Use bookmarks to keep track of pages I like & $\square$ Strongly disagree \\
$\square$ Disagree \\
$\square$ Undecided \\
$\square$ Agree \\
$\square$ Strongly agree \\
\hline 3u) Enjoy using social sites like Bebo, Facebook or MySpace & $\square$ Strongly disagree \\
$\square$ Disagree \\
$\square$ Undecided \\
$\square$ Agree \\
$\square$ Strongly agree \\
\hline
\end{tabular}

\section{Part 3}

\begin{tabular}{|c|c|}
\hline $\begin{array}{l}\text { 4a) Number these } 1-5 \text { in order of which you enjoy most- } 1 \text { is the most } \\
\text { enjoyable, } 5 \text { is the least enjoyable }\end{array}$ & $\begin{array}{l}\square \text { Read a book } \\
\square \text { Write } \\
\square \text { Watch television } \\
\square \text { Use the computer }\end{array}$ \\
\hline $\begin{array}{l}\text { 4b) Number these 1-5 in order of which you find hardest- } 1 \text { is the most } \\
\text { difficult, } 5 \text { is the least difficult }\end{array}$ & $\begin{array}{l}\square \text { Read a book } \\
\square \text { Write } \\
\square \text { Watch television } \\
\square \text { Use the computer }\end{array}$ \\
\hline $\begin{array}{l}\text { 4c) Number these 1-5 in order of which you would learn the most from } 1 \text { is the } \\
\text { most, } 5 \text { is the least }\end{array}$ & $\begin{array}{l}\square \text { Read a book } \\
\square \text { Write } \\
\square \text { Watch television } \\
\square \text { Use the computer }\end{array}$ \\
\hline
\end{tabular}

\section{Part 4}

\begin{tabular}{|c|c|}
\hline $\begin{array}{l}\text { 5a) What features of MyPortfolio did you make use of while completing the } \\
\text { Myths and Legends unit? }\end{array}$ & $\begin{array}{l}\square \text { Messaging } \\
\square \text { Personalised a view } \\
\square \text { Videos } \\
\square \text { Images } \\
\square \text { Documents } \\
\square \text { Feedback from your teacher } \\
\square \text { Other- Please list }\end{array}$ \\
\hline \multicolumn{2}{|l|}{ 5b) List anything you enjoyed doing on MyPortfolio } \\
\hline \multicolumn{2}{|l|}{ 5c) List anything you found hard to do on MyPortfolio } \\
\hline 5d) Would you recommend MyPortfolio to other students? Why? Or Why not? & $\begin{array}{l}\square \text { Yes } \\
\square \text { No } \\
\square \text { Unsure }\end{array}$ \\
\hline
\end{tabular}


Appendix 6: Learner interview schedule

\begin{tabular}{|c|l|}
\hline Theme & \multicolumn{1}{|c|}{ Line of questioning } \\
\hline Context of use & $\begin{array}{l}\text { Can you explain to me what an e-portfolio is? } \\
\text { How easy was it to use MyPortfolio? } \\
\text { Are there things on the computer that you can do now that } \\
\text { you could not before creating your e-portfolio? If so, what? }\end{array}$ \\
\hline Functionality & $\begin{array}{l}\text { What features of MyPortfolio did you use in creating your } \\
\text { e-portfolio? (examples- views, files, images, videos, } \\
\text { feedback, personalising the portfolio) } \\
\text { How useful did you find these features? Are there other } \\
\text { features you would have like MyPortfolio to have? }\end{array}$ \\
\hline Engagement and & $\begin{array}{l}\text { Do you think creating an (e-portfolio) as a good use of your } \\
\text { time? Why or why not? } \\
\text { motivation }\end{array}$ \\
$\begin{array}{l}\text { Would you want to continue your portfolio or create a new } \\
\text { portfolio in the future? } \\
\text { Did you enjoy creating your (e-portfolio)? Why or why not? } \\
\text { How often do you access your (e-portfolio) or those of other } \\
\text { people? Did you access your e-portfolio at home? How } \\
\text { often? Other places at school? How often? }\end{array}$ \\
\hline Feedback and \\
collaboration
\end{tabular}


Appendix 7: Student Observations sheet

Name:

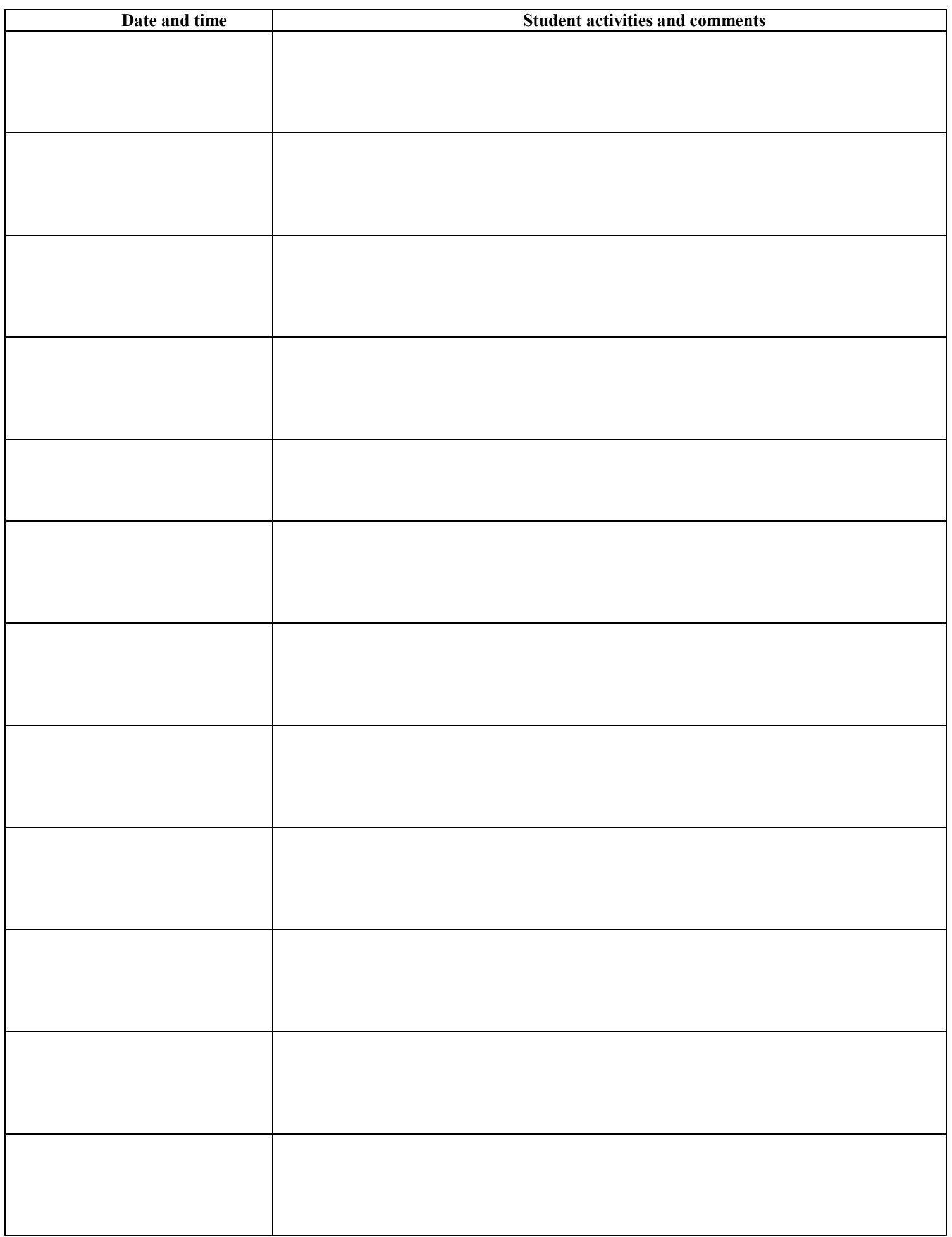


Appendix 8: Case study students' daily log

MyPortfolio log

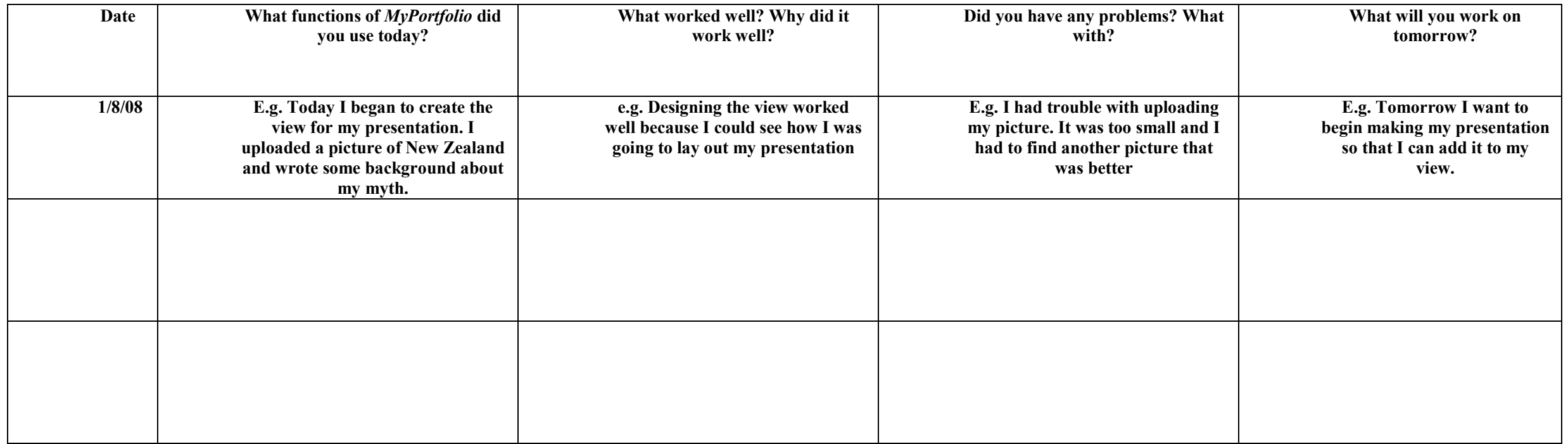




\section{Appendix 9: Additional functions within MyPortfolio}

\subsection{My Resume}

One key aspect of electronic portfolios is the fact that they allow the user to keep a record of their progress over time (Ministry of Education, 2007b, p. 6) and one of the specific uses that has been identified for this is career development. For this reason, MyPortfolio contain three sections -'My Resume', 'My Goals' and 'My Skills' that can help students plan their career path, identify the steps that they need to take and skills that they have.

'My Resume' allows students to build and online curriculum vitae that they can maintain and develop over time. As with the views, the students can control who is able to access their resume and they can also create different resumes for different purposes. The assignment work that the teacher set for this study did not involve careers information and so the students were not required to use this section during the study. For this reason, although the trainer referred to this area, he did not give the students any instructions about making use of it. This is also the case for the 'My Goals' and 'My Skills' sections of MyPortfolio.

\subsection{My Goals}

'My Goals' allows students to identify goals relating to school, career and their own personal goals. These can be added to any view.

\subsection{My Skills}

This section allows the students to identify personal, academic and work skills and add these to any view. 
Appendix 10: Information letters and consent forms

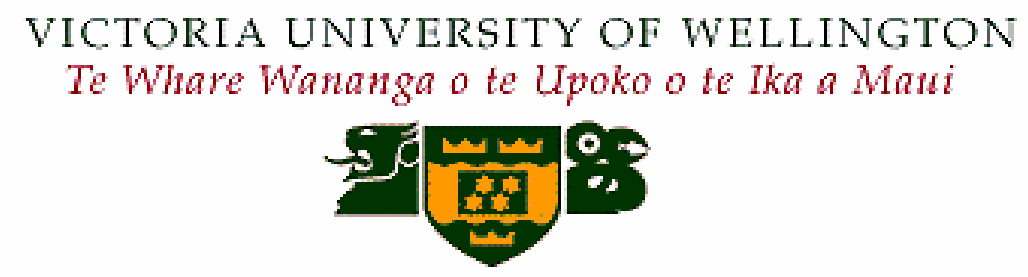

Rochelle Duke

MEd Candidate

c/o Postgraduate Office

Faculty of Education

Victoria University of Wellington

PO Box 17-310

Karori, Wellington

Friday, 28 May 2010

Dear parents / caregivers

Title of Project: Using MyPortfolio in a high school setting

Researcher: Rochelle Duke, School of Education, Victoria University of Wellington / (The School)

Research Information sheet: Parents of the survey group

My name is Rochelle Duke and I am a teacher at (The School). However, in 2008 I am undertaking a Masters of Education through Victoria University of Wellington. As part of this degree, I am undertaking a research project leading towards a thesis. The project involves examining the use of e-portfolios in a high school context. My research is supervised by Barbara Craig, Faculty of Education, Victoria University. This research has been assessed and approved by Victoria University College of Education Ethics Committee.

The aim of the research is to investigate how high school students use the e-portfolio tool MyPortfolio (www.MyPortfolio.school.nz) and how this can affect student learning. As part of the research, all students in 9.. English will take part in creating and presenting an e-portfolio using the web-based application MyPortfolio. Involvement in the research is not compulsory for students, however, all students will be required to complete the tasks set as part of their usual class work. 
As part of this research, I would like to survey students in 9.. This will involve students participating in two surveys- the first related to their general use of technology and the second related to both their use of technology and their experiences with MyPortfolio. The surveys will be conducted at school, during class time and I will work closely with your daughter's teacher to ensure that the interviews do not disrupt her learning. The surveys will not be anonymous, but the results will be aggregated and it will not be possible to identify individual students from the results. The surveys will be stored in a locked cabinet and will be destroyed at the end of the research project.

Your daughter's participation in this research is voluntary and all material will be kept confidential. The only people able to access the surveys will be me and my supervisor, Barbara Craig. However, your daughter's English teacher, (The teacher) will also have access to the e-portfolio work as part the normal course of class work. Your daughter will have the opportunity to withdraw from the project at any stage, no questions asked, up until when the research data is analysed.

The information from this research will be published in my MEd thesis and some articles will be submitted for publication in academic journals and conferences. The final report will also be made available to the Board of Trustees, (The School), the Wellington Loop Project and Flexible Learning (the organisation managing MyPortfolio). If you would like to see a copy of the results of this research, I would be happy to provide this, once it is complete. Please tick the box on the consent form if you would like to receive a copy.

This project has been explained to your daughter's class and she has had the opportunity to ask questions relating to her participation. The University requires that ethical approval be obtained for research involving human participants so in order for your child to participate in this research, please would both you and your child sign the attached consent form and return it to (The teacher) as soon as possible.

If you have any further questions about this project please feel free to contact me by email rochelle.duke@the.school.nz, leave a message at school on 3858514 or contact my supervisor, Barbara Craig at the School of Educational Studies, Victoria University of Wellington, P O Box 600, Wellington, phone 463 5404.

Yours sincerely,

Rochelle Duke 


\section{VICTORIA UNIVERSITY OF WELLINGTON \\ Te Whare Wananga o te Upoko o te Ika a Maui}

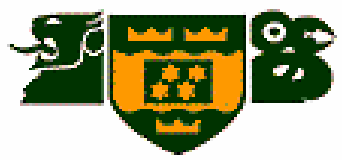

\section{Consent to participate in research}

\section{Survey group}

Title of Project: Using MyPortfolio in a high school setting

Researcher: Rochelle Duke, School of Education, Victoria University of Wellington / (The School)

I have been given information about this research project and I have understood an explanation of this research project. I have had an opportunity to ask questions and have them answered to my satisfaction.

I understand that I may withdraw myself (or any information I have provided) from this project (before data collection and analysis is complete) without having to give reasons or without penalty of any sort.

I understand that any information I provide will be kept confidential to the researcher, the supervisor, the published results will not use my name, and that no opinions will be attributed to me in any way that will identify me.

I would like to receive feedback on the findings of this research.

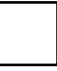

Name of student

Signed (student)

I agree that my guardianship, may take part in this research , who is my son/daughter/under

Signed (parent/guardian)

Date 


\section{VICTORIA UNIVERSITY OF WELLINGTON \\ Te Whare Wananga o te Upoko o te Ika a Maui}

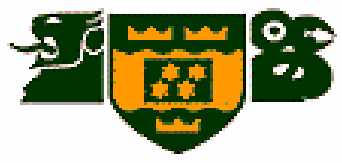

Rochelle Duke

MEd Candidate

c/o Postgraduate Office

Faculty of Education

Victoria University of Wellington

PO Box 17-310

Karori, Wellington

Friday, 28 May 2010

Dear parents / caregivers

Title of Project: Using MyPortfolio in a high school setting

Researcher: Rochelle Duke, School of Education, Victoria University of Wellington / (The school)

\section{Research Information sheet: Parents of focus group students}

My name is Rochelle Duke and I am a teacher at (The School). However, in 2008 I am undertaking a Masters of Education through Victoria University of Wellington. As part of this degree, I am undertaking a research project leading towards a thesis. The project involves examining the use of e-portfolios in a high school context. My research is supervised by Barbara Craig, Faculty of Education, Victoria University. This research has been assessed and approved by Victoria University College of Education Ethics Committee.

Your daughter has already participated in a survey for this research and his indicated that she is willing to be surveyed and interviewed about their experiences with MyPortfolio and have their e-portfolio work used for analysis. I will also be observing and taking notes as your daughter uses MyPortfolio during class time. The surveys and interviews will be conducted at school, during class time. The interviews will last around 20 minutes and I will work closely with your daughter's teacher to ensure that the interviews do not disrupt her learning. The interviews will be taped so I am able to transcribe what is said and your daughter will be able to view this transcript if she would like to. All work and 
comments will be made anonymous in order to protect your child's identity. The research data will be securely stored in a locked cabinet and will be destroyed at the end of the research project.

Your daughter's participation in this research is voluntary and all material will be kept confidential. The only people able to access the audiotapes of the interviews will be me and my supervisor, Barbara Craig. However, your daughter's English teacher, (The teacher) will also have access to the e-portfolio work as part the normal course of class work. Your daughter will have the opportunity to choose a 'code name' (pseudonym) and to check how her words appear (if she is quoted directly) before the final report. She will also have the opportunity to withdraw from the project at any stage, no questions asked, up until when the research data is analysed.

The information from this research will be published in my MEd thesis and some articles will be submitted for publication in academic journals and conferences. The final report will also be made available to the Board of Trustees, (The School), the Wellington Loop Project and Flexible Learning (the organisation managing MyPortfolio).

If you would like to see a copy of the results of this research, I would be happy to provide this, once it is complete. Please tick the box on the consent form if you would like to receive a copy.

This project has been explained to your daughter's class and she has had the opportunity to ask questions relating to her participation. The University requires that ethical approval be obtained for research involving human participants so in order for your child to participate in this research, please would both you and your child sign the attached consent form and return it to (The teacher) as soon as possible.

If you have any further questions about this project please feel free to contact me by email rochelle.duke@the.school.nz, leave a message at school on 3858514 or contact my supervisor, Barbara Craig at the School of Educational Studies, Victoria University of Wellington, P O Box 600, Wellington, phone 463 5404.

Yours sincerely,

Rochelle Duke 


\section{VICTORIA UNIVERSITY OF WELLINGTON \\ Te Whare Wananga o te Upoko o te Ika a Maui

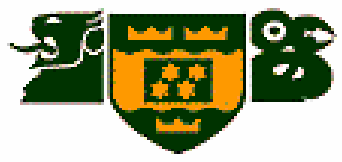

\section{Consent to participate in research}

\section{Student focus group}

Title of Project: Using MyPortfolio in a high school setting

Researcher: Rochelle Duke, School of Education, Victoria University of Wellington / (The School)

I have been given information about this research project and I have understood an explanation of this research project. I have had an opportunity to ask questions and have them answered to my satisfaction.

I understand that I may withdraw myself (or any information I have provided) from this project (before data collection and analysis is complete) without having to give reasons or without penalty of any sort.

I understand that any information I provide will be kept confidential to the researcher, the supervisor, the published results will not use my name, and that no opinions will be attributed to me in any way that will identify me.

I understand that the tape recording of the interviews will be electronically wiped at the end of the project.

I would like to view the transcript of my interview

I would like to receive feedback on the findings of this research.

Name of student

Signed (student)

I agree that , who is my son/daughter/under

my guardianship, may take part in this research

Signed (parent/guardian)

Date 


\section{VICTORIA UNIVERSITY OF WELLINGTON \\ Te Whare Wananga o te Upoko o te Ika a Maui}

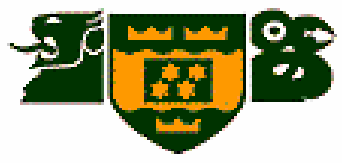

Friday, 28 May 2010

Dear students,

Title of Project: Using MyPortfolio in a high school setting

Researcher: Rochelle Duke, School of Education, Victoria University of Wellington / (The school)

\section{Research Information sheet: Survey students}

My name is Rochelle Duke and I am a teacher at (The School). However, in 2008 I am undertaking a Masters of Education through Victoria University of Wellington. As part of this degree, I am undertaking a research project leading towards a thesis. The project involves examining the use of e-portfolios in a high school. My research is supervised by Barbara Craig, Faculty of Education, Victoria University. This research has been assessed and approved by Victoria University College of Education Ethics Committee.

As part of the research, all students in 9.. English will take part in creating and presenting an e-portfolio using the web-based application MyPortfolio. Involvement in the research is not compulsory for students, however, you all will be required to complete the tasks set as part of your usual class work.

In order to understand how you use the e-portfolios, I will be surveying the whole class about their use of MyPortfolio. This survey will take place during class time and I will work with (The teacher) to make sure that it does not affect your course of study. The surveys will not be anonymous, but it will be impossible to identify individual students from the results. The surveys will be kept in a locked cabinet and will be destroyed at the end of the research project.

The information from this research will be published in my MEd thesis and some articles will be submitted for publication in academic journals and conferences. The final report will also be made available to the Board of Trustees, (The School), the Wellington Loop Project and Flexible Learning (the organisation managing MyPortfolio). 
If you would like to see a copy of the results of this research, I would be happy to provide this, once it is complete. Please tick the box on the consent form if you would like to receive a copy.

The University requires that ethical approval be obtained for research involving human participants so in order for you to participate in this research, please would both you and your parents sign the attached consent form and return it to (The teacher) as soon as possible.

If you have any further questions about this project please feel free to contact me by email rochelle.duke@the.school.nz, leave a message at school on 3858514 or contact my supervisor, Barbara Craig at the School of Educational Studies, Victoria University of Wellington, P O Box 600, Wellington, phone 463 5404.

Yours sincerely,

Rochelle Duke 


\section{VICTORIA UNIVERSITY OF WELLINGTON \\ Te Whare Wananga o te Upoko o te Ika a Maui}

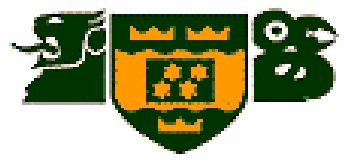

Friday, 28 May 2010

Dear students,

Title of Project: Using MyPortfolio in a high school setting

Researcher: Rochelle Duke, School of Education, Victoria University of Wellington / (The school)

\section{Research Information sheet: Focus group students}

Thank you for participating in the survey of your ICT use. I would now like to invite you be part of a focus group looking at the use of the web-based application MyPortfolio. Involvement in the research is not compulsory for students, however, you all will be required to complete the tasks set as part of your usual class work.

In order to understand how you use the e-portfolios, I will be surveying the whole class and then would like to interview six students and study their eportfolio work. I would like to invite you to be part of this group of students. Being part of this group, would mean that I observe and take notes of what you do while using the e-portfolio, take notes from the work you produce and interview you once you have finished your portfolio. You would also complete the surveys with the rest of the class.

The interviews will be done individually during class time and I will organise with (The teacher) to make sure that this does not affect your class work. The interviews will take around 20 minutes and will be taped so that I can transcribe what has been said. You will be able to view this transcript if you would like to. All work and comments will have your name taken off them so that you are anonymous and will be kept confidential and the only people able to access the audiotapes of the interviews will be me and my supervisor, Barbara Craig. Your teacher, (The teacher) will also have access to the e-portfolio work as part the normal course of class work. You will have the opportunity to choose a 'code name' (pseudonym) and to check how your words appear (if you are quoted directly) before the final report is presented. The research data will be 
securely stored in a locked cabinet and will be destroyed at the end of the research project.

The information from this research will be published in my MEd thesis and some articles will be submitted for publication in academic journals and conferences. The final report will also be made available to the Board of Trustees, (The school), the Wellington Loop Project and Flexible Learning (the organisation managing MyPortfolio).

My research is supervised by Barbara Craig, Faculty of Education, Victoria University. This research has been assessed and approved by Victoria University College of Education Ethics Committee. If you would like to see a copy of the results of this research, I would be happy to provide this, once it is complete. Please tick the box on the consent form if you would like to receive a copy.

The University requires that ethical approval be obtained for research involving human participants so in order for you to participate in this research, please would both you and your parents sign the attached consent form and return it to (The teacher) as soon as possible.

If you have any further questions about this project please feel free to contact me by email rochelle.duke@the.school.nz, leave a message at school on 3858514 or contact my supervisor, Barbara Craig at the School of Educational Studies, Victoria University of Wellington, P O Box 600, Wellington, phone 463 5404.

Yours sincerely,

Rochelle Duke 


\section{VICTORIA UNIVERSITY OF WELLINGTON \\ Te Whare Wananga o te Upoko o te Ika a Maui}

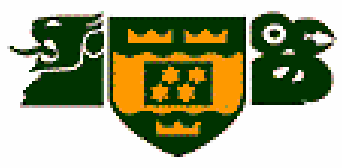

13 Hayward Tce

Waiwhetu

Lower Hutt

rochelle.duke@,the.school.nz

Friday, 28 May 2010

Sally Haughton

(The School)

Wellington

Title of Project: Using MyPortfolio in a high school setting

Researcher: Rochelle Duke, School of Education, Victoria University of Wellington / (The school)

\section{Research Information sheet: Principal}

\section{Dear Principal,}

As you know, I am currently on study leave from (The school) to complete a Masters of Education through Victoria University of Wellington. As part of this, I wish to undertake a research project looking at the use of e-portfolios and would like to conduct this research at (The school). My research is supervised by Barbara Craig, Faculty of Education, Victoria University. This research has been assessed and approved by Victoria University College of Education Ethics Committee.

The research would involve a class of students utilising the e-portfolio application MyPortfolio as part of their class work and I have spoken to (The teacher) who is willing for her Year 9 English class to be involved in this project. The research should take around five weeks and will only involve time in English. I am hoping to recruit students for this research during the last week of 
Term 3 and begin the data collection at the beginning of Term 4. All research data will be securely stored in a locked cabinet and will be destroyed at the end of the project.

As well as forming the basis for my thesis, this research could also provide part of (The School)'s deliverables for the Loop project and could give some useful direction to future ICT developments within the school. The team from the Wellington Loop Project has also offered to support this project and is willing to be involved in setting up and supporting MyPortfolio for use in the school.

I have included copies of information sheets and consent letters for students and parents. If you have any further questions about this project please feel free to contact me by email rochelle.duke@the.school.nz, or contact my supervisor, Barbara Craig at the School of Educational Studies, Victoria University of Wellington, P O Box 600, Wellington, phone 4635404.

Yours sincerely,

Rochelle Duke 


\section{VICTORIA UNIVERSITY OF WELLINGTON}

Te Whare Wananga o te Upoko o te Ika a Maui

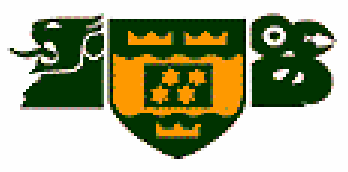

\section{Consent to participation in research: Principal}

Title of Project: Using MyPortfolio in a high school setting

Researcher: Rochelle Duke, School of Education, Victoria University of Wellington / (The school)

I give consent for Rochelle Duke, Masters student at Victoria University of Wellington Education Faculty, to use students in 9.. English, (The school) to participate in her research project.

I understand that I may withdraw students from this project (before data collection and analysis is complete) without having to give reasons or without penalty of any sort.

Name of Principal

Signed (Principal)

Date 


\section{VICTORIA UNIVERSITY OF WELLINGTON \\ Te Whare Wananga o te Upoko o te Ika a Maui}

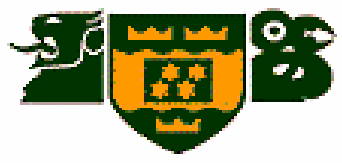

13 Hayward Tce

Waiwhetu

Lower Hutt

rochelle.duke@the.school.nz

Friday, 28 May 2010

(The Teacher)

(The School)

Wellington

Title of Project: Using MyPortfolio in a high school setting

Researcher: Rochelle Duke, School of Education, Victoria University of Wellington / (The School)

\section{Research Information sheet: Class teacher}

Dear (Teacher),

As you know, I am current on study leave from (The School) to complete a Masters of Education through Victoria University of Wellington. As part of this, I wish to undertake a research project looking at the use of e-portfolios and would like to conduct this research at (The School), using your Year 9 Class. My research is supervised by Barbara Craig, Faculty of Education, Victoria University. This research has been assessed and approved by Victoria University College of Education Ethics Committee.

The research would involve a class of students utilising the e-portfolio application MyPortfolio as part of their class work. The research should take around five weeks and will only involve time in English. I am hoping to recruit students for this research during the last week of Term 3 and begin the data 
collection at the beginning of Term 4 . All research data will be securely stored in a locked cabinet and will be destroyed at the end of the project.

As well as forming the basis for my thesis, this research could also provide part of (The School)'s deliverables for the Loop project and could give some useful direction to future ICT developments within the school. The team from the Wellington Loop Project has also offered to support this project and is willing to be involved in setting up and supporting MyPortfolio for use in the school.

I have included copies of information sheets and consent letters for students and parents. If you have any further questions about this project please feel free to contact me by email rochelle.duke@the.school.nz, leave a message at school on 3858514 or contact my supervisor, Barbara Craig at the School of Educational Studies, Victoria University of Wellington, P O Box 600, Wellington, phone 4635404.

Yours sincerely,

Rochelle Duke 


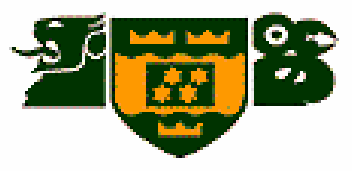

\title{
Consent to participation in research: Class teacher
}

\author{
Title of Project: Using MyPortfolio in a high school setting \\ Researcher: Rochelle Duke, School of Education, Victoria University of \\ Wellington / (The School)
}

I give consent for Rochelle Duke, Masters student at Victoria University of Wellington Education Faculty, to use students in 9.. English, (The School) to participate in her research project.

I understand that I may withdraw myself (or any information I have provided) from this project (before data collection and analysis is complete) without having to give reasons or without penalty of any sort.

Name of teacher

Signed (teacher)

Date 


\section{VICTORIA UNIVERSITY OF WELLINGTON \\ Te Whare Wananga o te Upoko o te Ika a Maui}

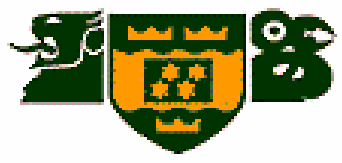

13 Hayward Tce

Waiwhetu

Lower Hutt

rochelle.duke@the.school.nz

Friday, 28 May 2010

Board of Trustees

(The School)

Wellington

Title of Project: Using MyPortfolio in a high school setting

Researcher: Rochelle Duke, School of Education, Victoria University of Wellington / (The School)

\section{Research Information sheet: Board of Trustees}

Dear Board,

As you know, I am current on study leave from (The School) to complete a Masters of Education through Victoria University of Wellington. As part of this, I wish to undertake a research project looking at the use of e-portfolios and would like to conduct this research at (The School). My research is supervised by Barbara Craig, Faculty of Education, Victoria University. This research has been assessed and approved by Victoria University College of Education Ethics Committee.

The research would involve a class of students utilising the e-portfolio application MyPortfolio as part of their class work and I have spoken to (The teacher) who is willing for her Year 9 English class to be involved in this project. The research should take around five weeks and will only involve time in English. I am hoping to recruit students for this research during the last week of Term 3 and begin the data collection at the beginning of Term 4. All research 
data will be securely stored in a locked cabinet and will be destroyed at the end of the project.

As well as forming the basis for my thesis, this research could also provide part of (The School)'s deliverables for the Loop project and could give some useful direction to future ICT developments within the school. The team from the Wellington Loop Project has also offered to support this project and is willing to be involved in setting up and supporting MyPortfolio for use in the school.

I have included copies of information sheets and consent letters for students and parents. If you have any further questions about this project please feel free to contact me by email rochelle.duke@the.school.nz, leave a message at school on 3858514 or contact my supervisor, Barbara Craig at the School of Educational Studies, Victoria University of Wellington, P O Box 600, Wellington, phone 4635404.

Yours sincerely,

Rochelle Duke 


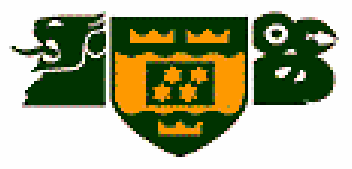

\section{Consent to participation in research: Board of Trustees}

Title of Project: Using MyPortfolio in a high school setting

Researcher: Rochelle Duke, School of Education, Victoria University of Wellington / (The School)

I give consent for Rochelle Duke, Masters student at Victoria University of Wellington Education Faculty, to use students in 9.. English, (The School) to participate in her research project.

I understand that I may withdraw students from this project (before data collection and analysis is complete) without having to give reasons or without penalty of any sort.

Name of Board Chairperson

Signed (Board Chairperson)

Date 